Aus der Abteilung Biochemie II

(Prof. Dr. rer. nat. P. Rehling)

im Zentrum Biochemie und Molekulare Zellbiologie

der Medizinischen Fakultät der Universität Göttingen

\title{
Funktionelle Analyse des murinen 66.3-kDa-Proteins
}

\author{
INAUGURAL - DISSERTATION \\ zur Erlangung des Doktorgrades \\ der Medizinischen Fakultät der \\ Georg-August-Universität zu Göttingen
}

vorgelegt von

Matthias Kettwig

aus

Höxter

Göttingen 2010 
Dekan: Prof. Dr. med. C. Frömmel

I. Berichterstatter: Prof. Dr. rer. nat. T. Lübke

II. Berichterstatter/in: Prof. Dr. Dr. med. R. Steinfeld

III. Berichterstatter/in: -

Tag der mündlichen Prüfung: 29.11.2010 


\section{Inhaltsverzeichnis}

1 EINLEITUNG

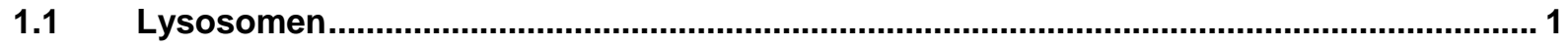

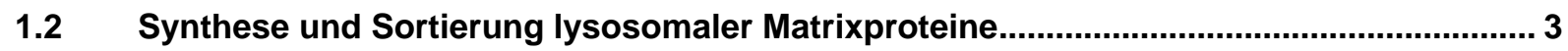

1.2.1 Mannose-6-phosphat-Rezeptor-vermittelte Sortierung................................................. 4

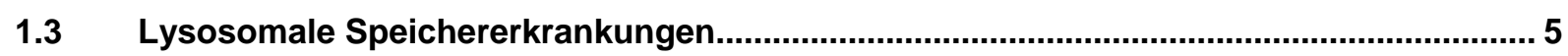

1.3.1 Klinische Aspekte von lysosomalen Speichererkrankungen ......................................... 6

1.3.2 Therapie von lysosomalen Speichererkrankungen ............................................................... 6

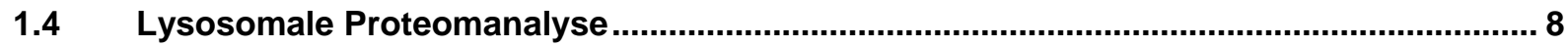

1.4.1 Methode zur Aufreinigung lysosomaler Proteine ............................................................ 8

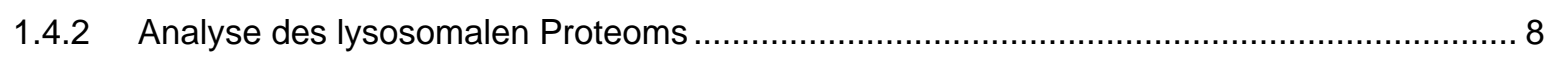

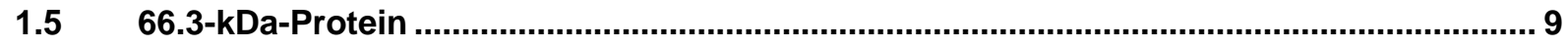

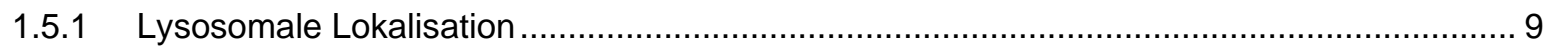

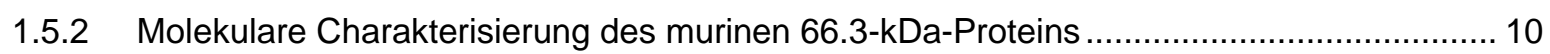

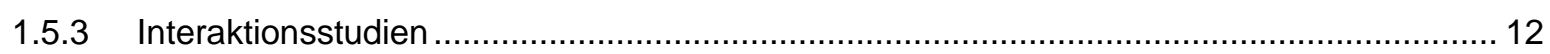

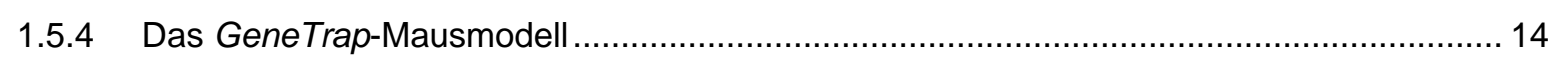

1.6 Cathepsin D als möglicher Interaktionspartner des 66.3-kDa-Proteins .......................... 16

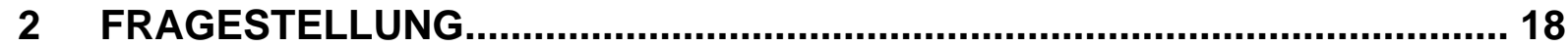

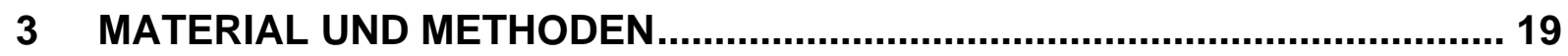

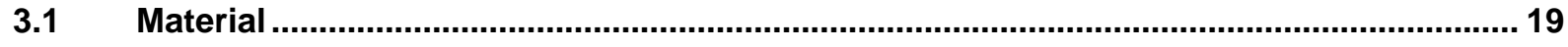

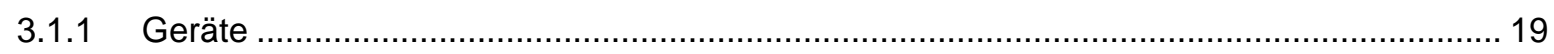

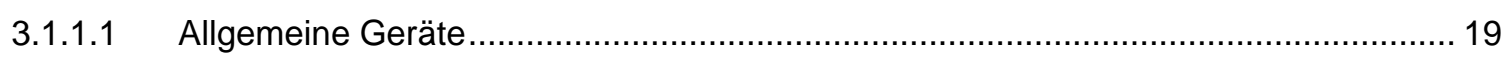

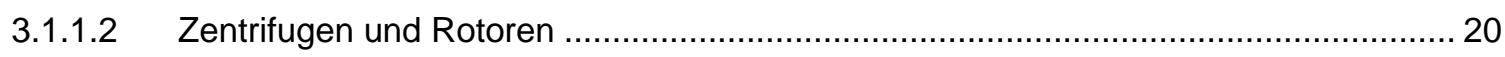

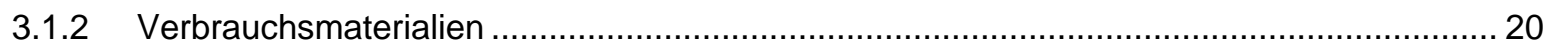

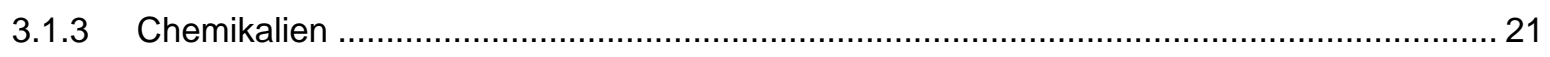

3.1.4 Kits zur Bearbeitung von RNA, DNA und Proteinen .................................................... 24

3.1.5 Enzyme zur Bearbeitung von DNA, RNA und Proteinen .................................................. 24

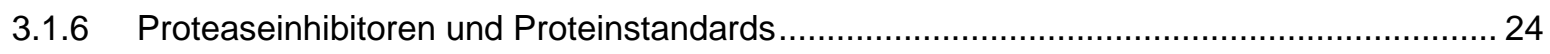

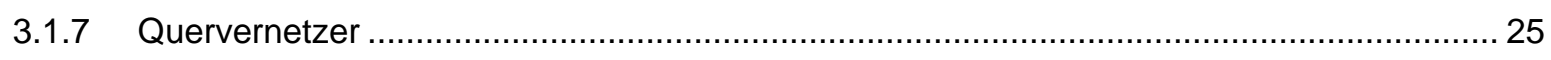

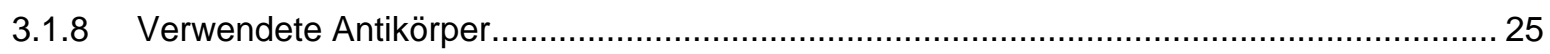

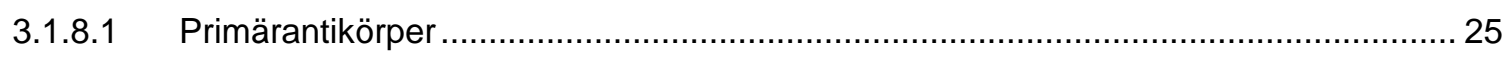

3.1.8.2 Sekundärantikörper für Western-Blot-Analyse ....................................................... 25

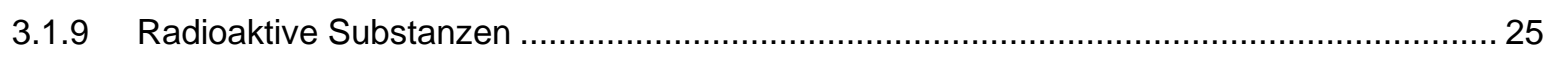

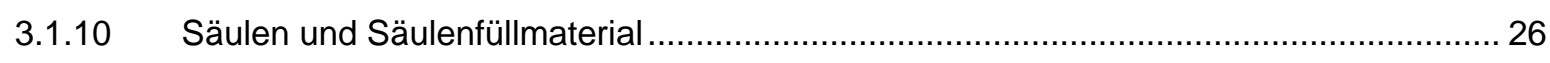

3.1.11 Vektoren, Oligonucleotidprimer und DNA/ RNA-Standards .......................................... 26 


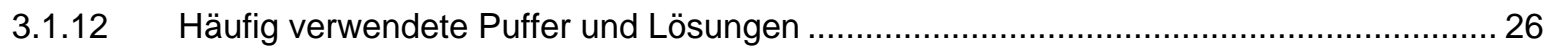

3.1.13 Medien zum Arbeiten mit eukaryontischen Zellkulturen ............................................ 27

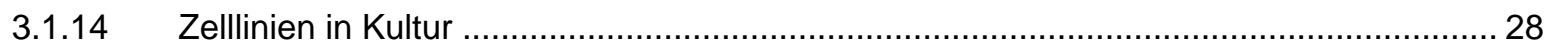

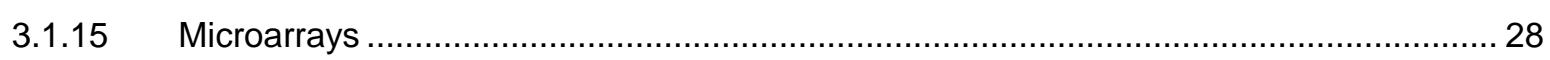

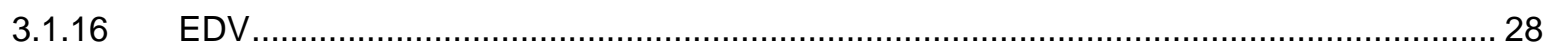

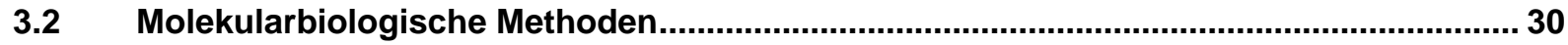

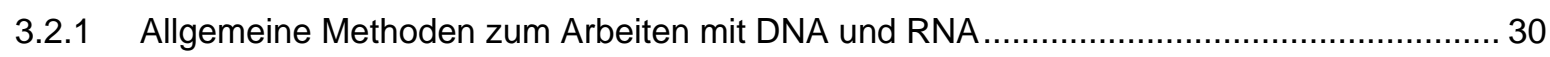

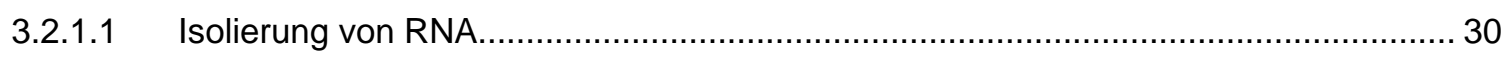

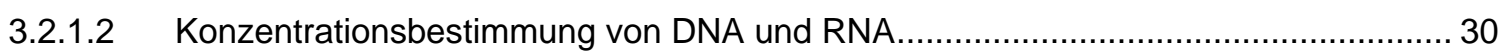

3.2.1.3 DNA-Amplifikation über Polymerase-Ketten-Reaktion............................................... 30

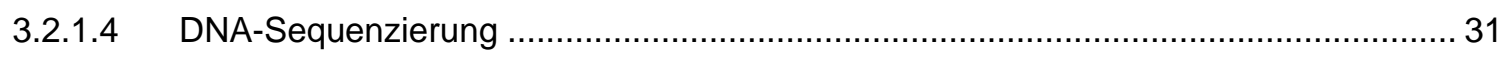

3.2.1.5 Spaltung von DNA mit Restriktionsendonukleasen.................................................... 32

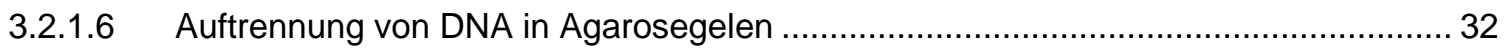

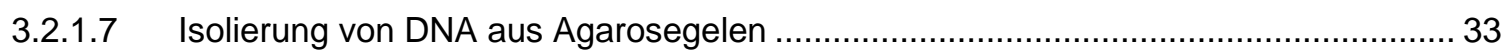

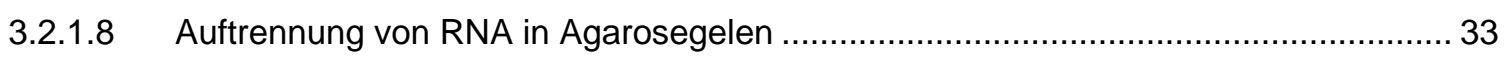

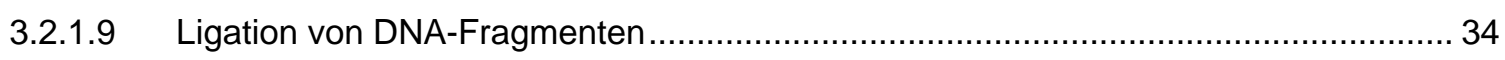

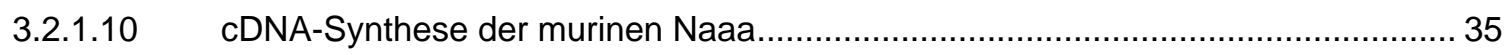

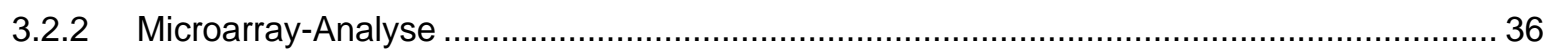

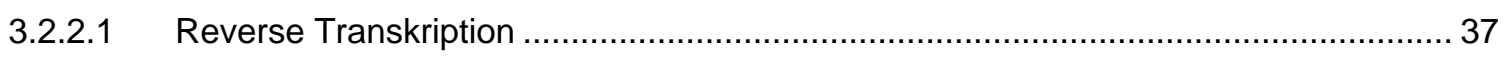

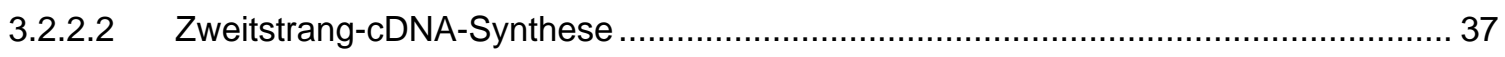

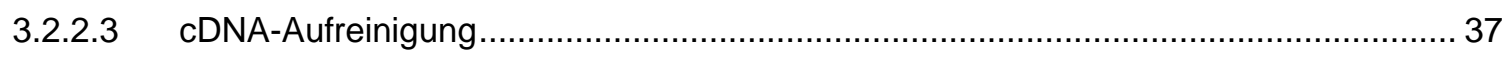

3.2.2.4 In-vitro-Transkription zur Synthese Biotin-markierter aRNA ....................................... 38

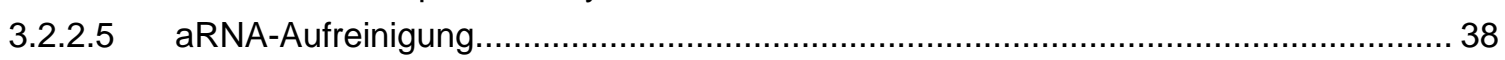

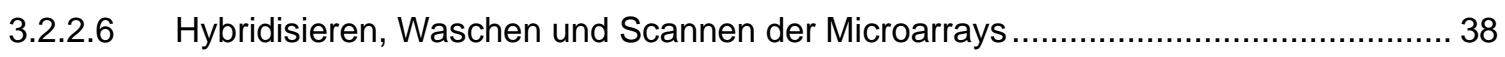

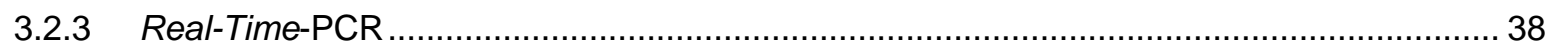

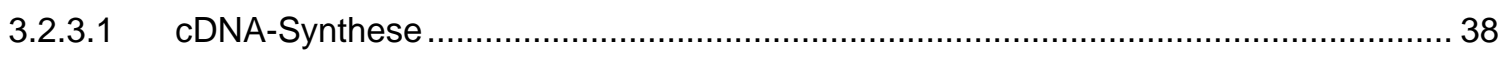

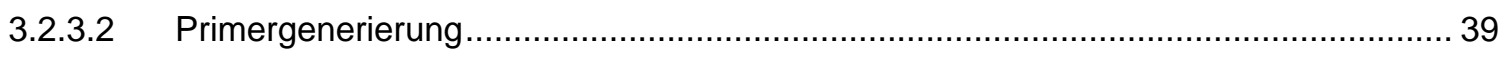

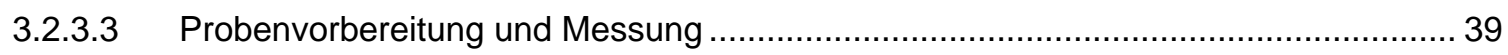

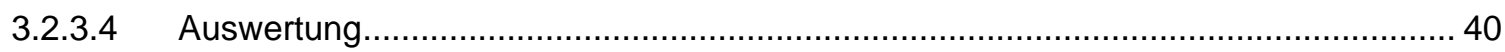

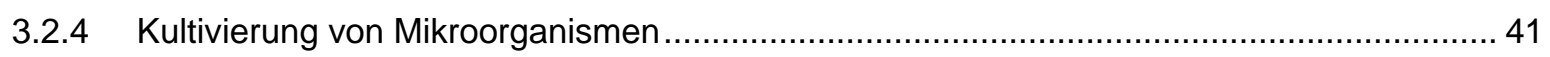

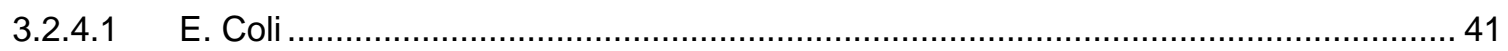

3.2.4.1.1 Medien zum Arbeiten mit Bakterienkulturen ..................................................... 41

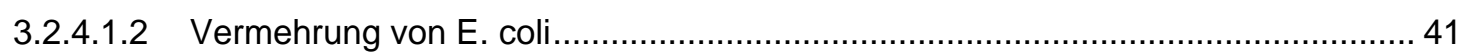

3.2.4.1.3 Präparation chemisch kompetenter E. coli-Zellen ............................................ 42

3.2.4.1.4 Transformation chemisch kompetenter E. coli-Zellen mit Plasmid-DNA ............... 42

3.2.4.1.5 Mini-/Midi-Präparation von Plasmid-DNA ......................................................... 43

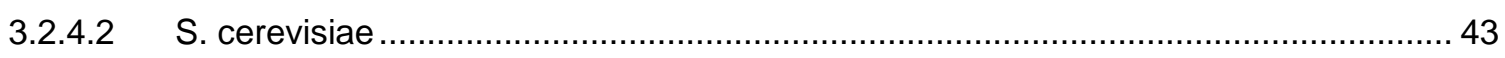

3.2.4.2.1 Medien zum Arbeiten mit S. cerevisiae......................................................... 43

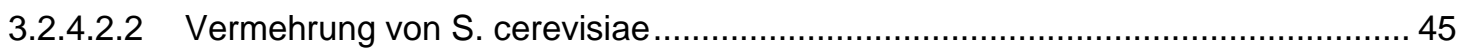

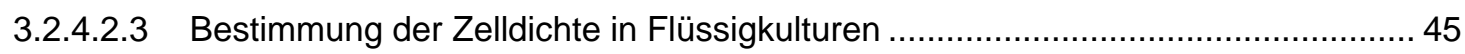

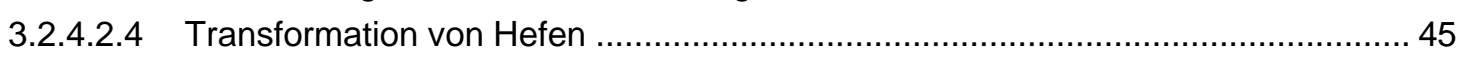

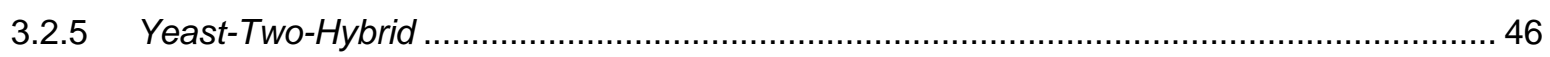

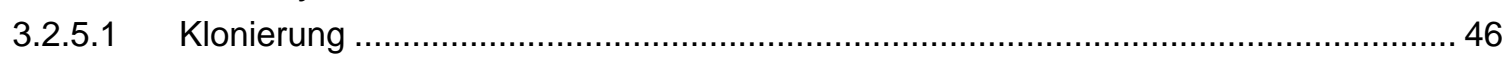

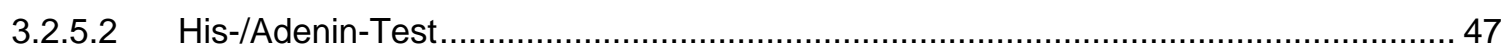

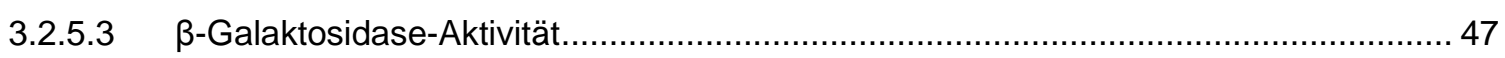


3.3 Zellbiologische Methoden ...........................................................................................49

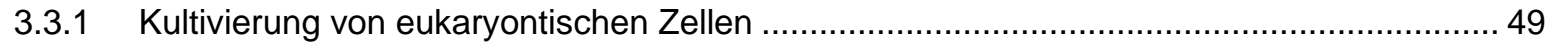

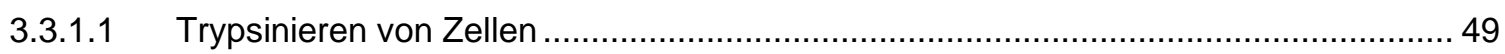

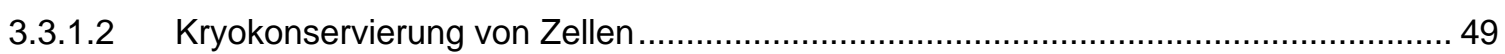

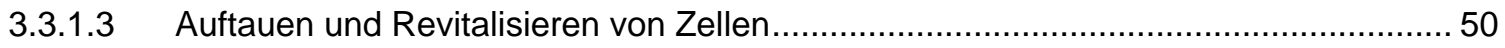

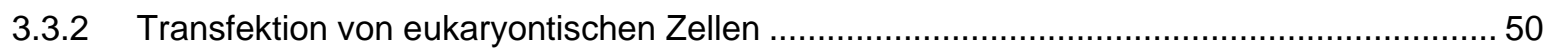

3.3.3 Isolierung von Zellklonen nach stabiler Transfektion ............................................... 50

3.3.4 Ernte von rekombinanten Proteinen aus serumarmem Zellkulturmedium........................5 51

3.3.5 Metabolische Markierung von ethanolaminderivatisierten Lipiden ...............................5 52

Proteinbiochemische Methoden ........................................................................... 52

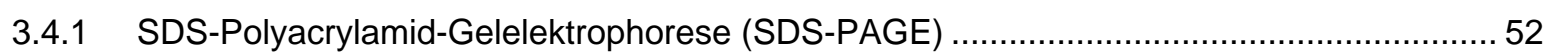

3.4.2 Färbung von Polyacrylamid-Gelen mit kolloidaler Coomassie-Lösung ............................ 54

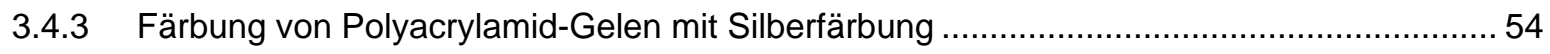

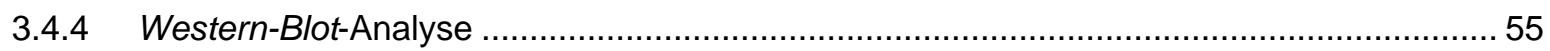

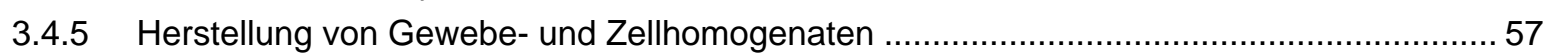

3.4.6 Proteinkonzentrationsbestimmung mittels DC-Protein-Assay ........................................ 58

3.4.7 Anreicherung von Lysosomen Tyloxapol-behandelter Mäuse durch subzelluläre

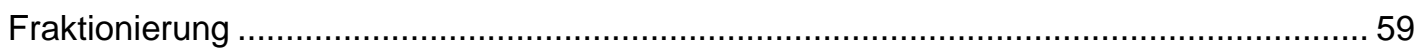

3.4.8 Aufreinigung von überexprimiertem 66.3-kDa-Protein aus Zellkulturüberständen ............6 61

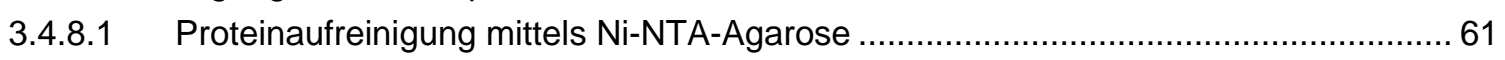

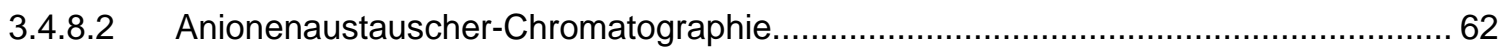

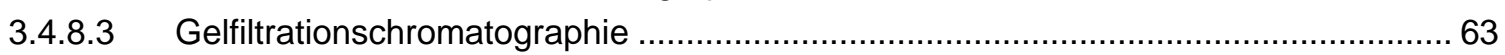

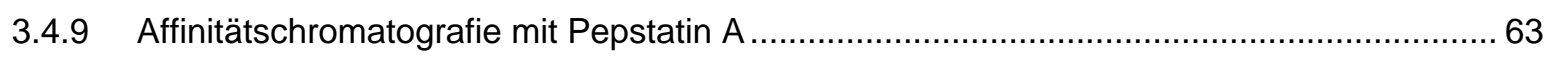

3.4.10 Untersuchung von Protein-Protein-Interakionen mittels Quervernetzern..................... 64

3.4.10.1 In-vivo-Quervernetzung mit photoaktiven Aminosäuren .................................6 64

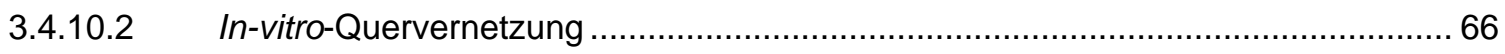

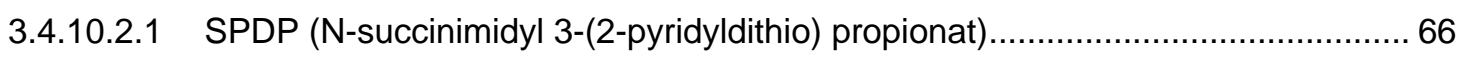

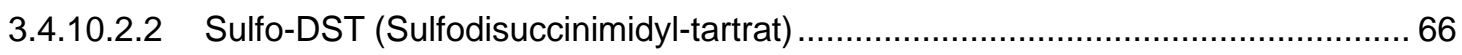

3.4.10.2.3 EDC/ Sulfo-NHS (1-ethyl-3-[3-dimethylaminopropyl]carbodiimid hydrochlorid/

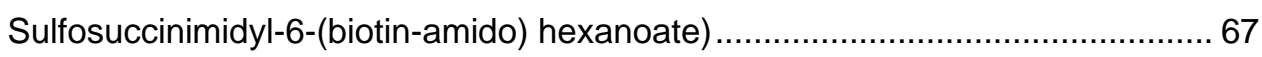

3.4.11 Ko-Immunpräzipitation des 66.3-kDa-Proteins mit Cathepsin D ...............................6. 67

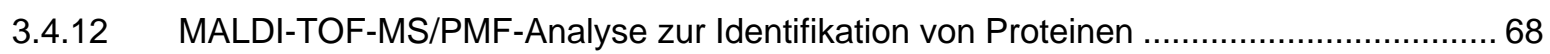

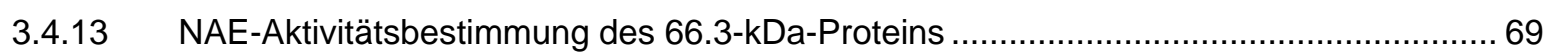

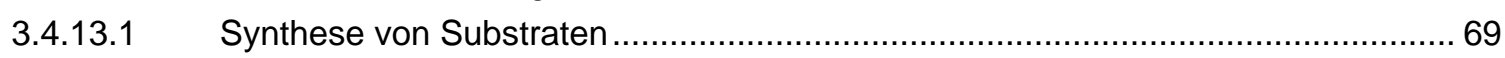

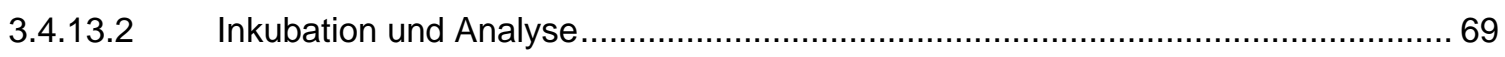

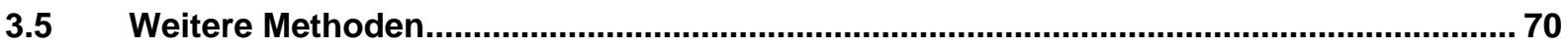

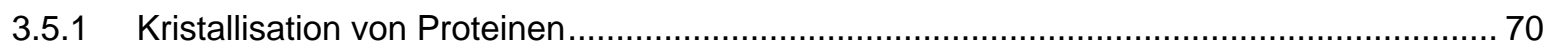

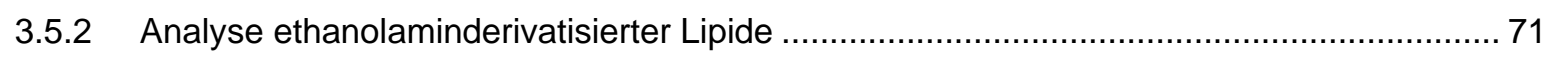

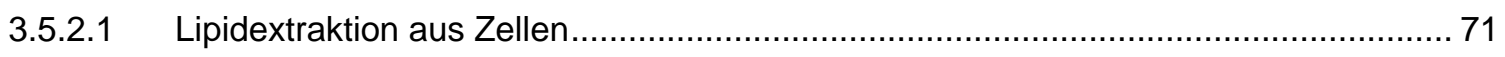

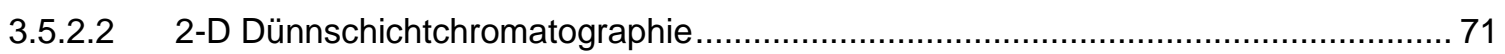


4 ERGEBNISSE.

4.1 Interaktion von 66.3-kDa-Proteinfragmenten mit Cathepsin D im Yeast-Two-Hybrid-

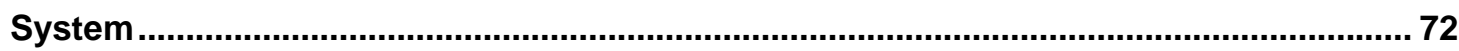

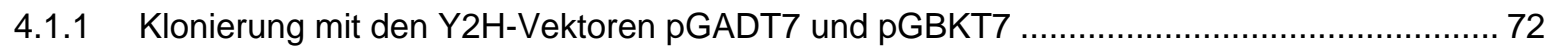

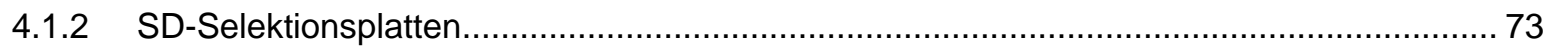

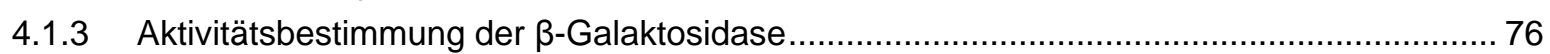

Affinitätschromatographie mit Pepstatin A ............................................................. 78

4.3 Ko-Immunpräzipitation mit Cathepsin D................................................................. 81

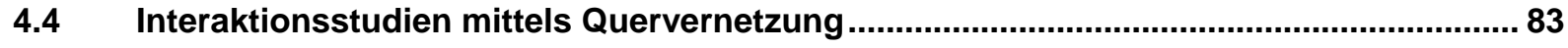

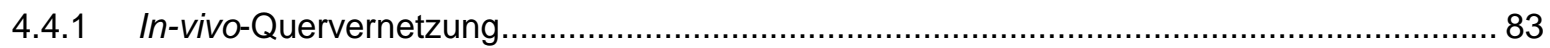

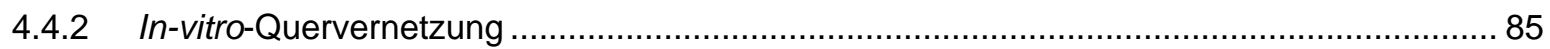

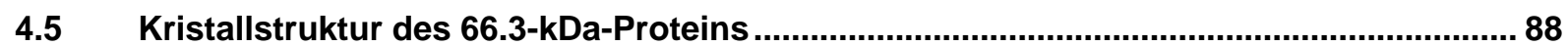

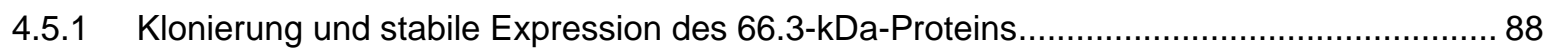

4.5.2 Aufreinigung des 66.3-kDa-Proteins zur Kristallisation........................................ 89

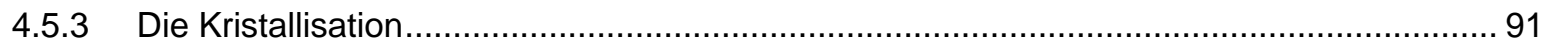

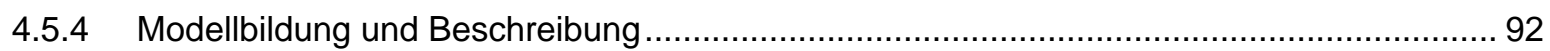

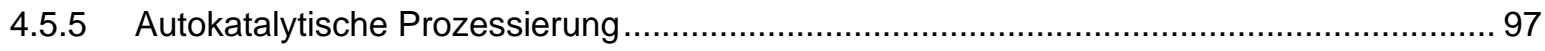

4.5.6 Potentielle Funktion des 66.3-kDa-Proteins durch Strukturvergleich ............................. 99

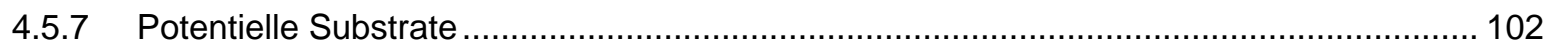

4.6 Funktionelle Analyse des 66.3-kDa-Proteins............................................................... 104

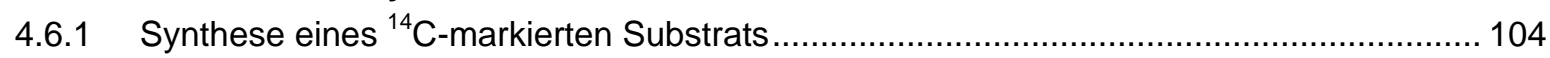

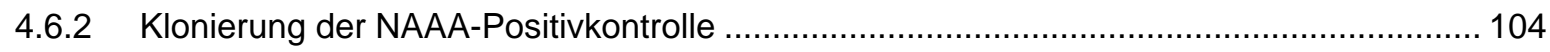

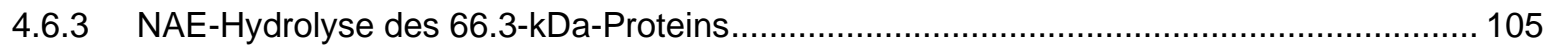

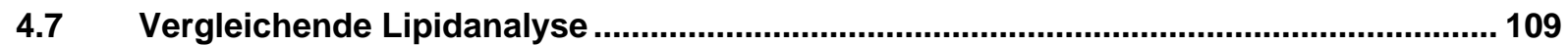

4.8 Massenspektrometrische Untersuchung der verschiedenen Fragmente des 66.3-kDa-

Proteins ........................................................................................................................... 111

4.9 Transkriptomanalyse des 66.3-kDa-Protein-GeneTrap-Mausmodells .......................... 116

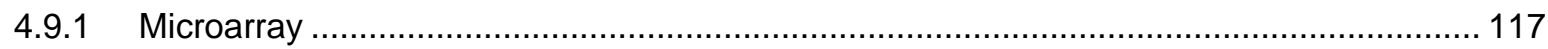

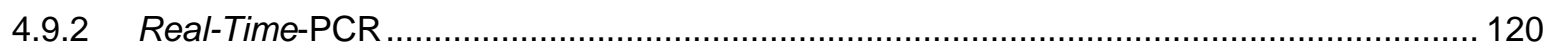

4.9.3 Überprüfung des 66.3-kDa-Transkripts auf Anteile der Neomycinkassette mittels reverser Transkription 


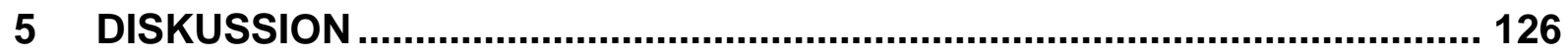

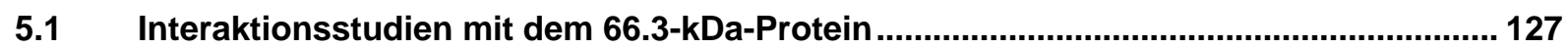

5.1.1 Interaktionstudien von Cathepsin D mit dem 66.3-kDa-Protein............................. 128

5.2 Prozessierung und Dimerisierung des 66.3-kDa-Proteins .......................................... 132

F.3 Funktionelle Analyse des 66.3-kDa-Proteins.......................................................... 135

5.4 Beurteilung des 66.3-kDa-Protein-GeneTrap-Mausmodells.......................................... 140

Ausblick........................................................................................................... 144

6 ZUSAMMENFASSUNG .................................................................. 146

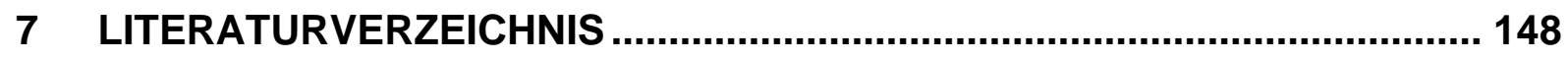

8 ANHANG

8.1 Klonierungen im Y2H-System ........................................................................... 159

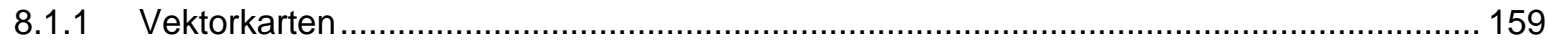

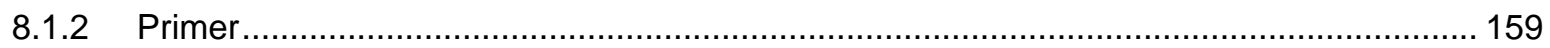

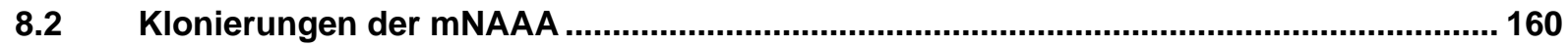

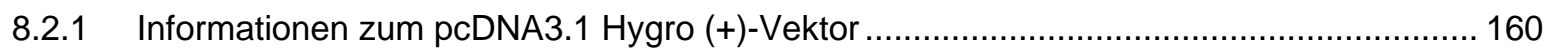

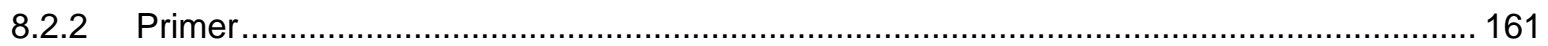

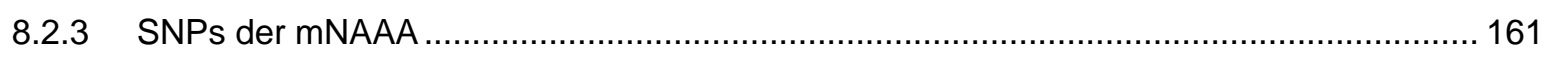

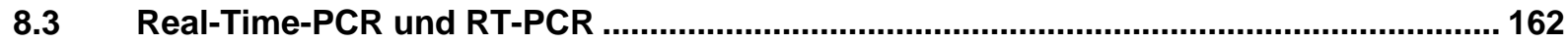

8.3.1 Primer-Sequenzen der Real-Time-PCR ......................................................... 162

8.3.2 Primer für die Überprüfung des 66.3-kDa-Transkripts auf GeneTrap-Kassetten-Anteile .. 162 


\section{Abkürzungsverzeichnis}

66gt

$\AA$

A

Abb.

Ac

AC

AG

APS

AS

bp

BSA

bzw.

${ }^{\circ} \mathrm{C}$

${ }^{14} \mathrm{C}$

C

CA

Cat. D

CBAH

CDNA

$\mathrm{Ci}$

cpm

c-terminal

C-Terminus

CV

$\Delta$

DAG

DALI

dATP

dCTP

DEPC

dFKS
66.3-kDa-Protein-GeneTrap-Mausmodell

Ångström

Ampere

Abbildung

Acetat

Acid Ceramidase

Arbeitsgruppe

Ammoniumperoxodisulfat

Aminosäure

Basenpaare

Rinderserumalbumin

beziehungsweise

Grad Celsius

instabiles Kohlenstoff-Isotop

zenti

Cephalosporin Acylase

Cathepsin D

Conjugated Bile Acid Hydrolase

komplementäre DNA

Curie

Zählimpulse pro Minute (counts per minute)

carboxylterminal

Carboxylterminus

Column Volume

Differenz (Delta)

Diacylglycerin

Internetserver zum Vergleich von 3D-Strukturen

von Proteinen

Desoxyadenosin-5'-Triphosphat

Desoxycytosin-5'-Triphosphat

Diethylpyrocarbonat

dialysiertes, hitzeinaktiviertes FKS 


\begin{tabular}{|c|c|}
\hline dGTP & Desoxyguanin-5'-Triphosphat \\
\hline $\mathrm{dH}_{2} \mathrm{O}$ & destilliertes Wasser \\
\hline DMEM & Dulbecco's Modified Eagle Medium \\
\hline DMSO & Dimethylsulfoxid \\
\hline DNA & Desoxyribonukleinsäure \\
\hline dNTP & die vier Desoxyribonukleosid-5'-Triphosphate \\
\hline DTT & Dithiothreitol \\
\hline dTTP & Desoxythymidin-5'-Triphosphat \\
\hline$\varepsilon$ & Extinktionskoeffizient (Epsilon) \\
\hline E. coli & Escherichia coli \\
\hline EC & Enzymklasse (Enzyme Class) \\
\hline EDC & $\begin{array}{l}\text { 1-ethyl-3-[3-dimethylaminopropyl]carbodiimid- } \\
\text { hydrochlorid }\end{array}$ \\
\hline EDTA & Ethylendiamintetraessigsäure \\
\hline ER & endoplasmatisches Retikulum \\
\hline ERT & $\begin{array}{l}\text { Enzymersatztherapie } \\
\text { (Enzyme Replacement Therapy) }\end{array}$ \\
\hline ES-Zellen & embryonale Stammzellen \\
\hline et al. & und andere (et alii) \\
\hline EtOAc & Ethylacetat \\
\hline ExPASy & Expert Protein Analysis System \\
\hline F2-Fraktion & subzelluläre, Lysosomen-angereicherte Fraktion \\
\hline FFS & freie Fettsäure \\
\hline FGE & Formylglycine-Generating Enzyme \\
\hline FKS & fötales Kälberserum \\
\hline FRET & Fluoreszenz-Resonanzenergietransfer \\
\hline g & Gramm \\
\hline G9 & 66-Antiserum \\
\hline Gal & Galaktose \\
\hline GAPDH & Glycerinaldehyd-3-phosphat-Dehydrogenase \\
\hline ggf. & gegebenenfalls \\
\hline GP & Gesamtprotein \\
\hline GPI-Anker & Gylkosyl-Phosphatidylinositol-Anker \\
\hline $\mathrm{h}$ & Stunde \\
\hline
\end{tabular}


HDAC

HEK293T

HEPES

His-Tag

HPLC

HRP

H. sapiens

HSP70

HT1080

HWZ

IMM

INCL

$\mathrm{IP}_{3}$

JAA

$\mathrm{Kb}$

$\mathrm{kDa}$

KIIS5

Konz.

I

LAMP-1/-2

LB

LDL

LPC

LSD

M

m

$\mathrm{M} 2 \mathrm{H}$

M6P

MALDI-TOF-MS

MEF

MES

MHCII regulatorische Histon-Deacylasen

humane Zellreihe aus embryonalen Nierenzellen

4-(2-Hydroxyethyl)-piperazin-1-Ethansulfonsäure

Polyhistidin-Markierung eines Proteins

High Performance Liquid Chromatography

Horse Radish Peroxidase

Homo sapiens

Heat Shock Protein 70

humane Fibrosarkom-Zellreihe

Halbwertszeit

Immunomix

infantile neuronale Ceroid-Lipofuszinose

Inositol-1,4,5-trisphosphat

Jodacedamin

Kilobasenpaare

Kilodalton

Cathepsin-D-Antiserum

Konzentration

Liter

Iysosomal assoziiertes Membranglykoprotein-1/-2

Lysogeny Broth

Low Density Lipoprotein

Lyso-Phosphatidylcholin

Lysosomale Speichererkrankung

(Lysosomal Storage Disorder)

molar

milli

Mammalian-Two-Hybrid-System

Mannose-6-Phosphat

Matrix-Assisted Laser Desorption Ionization Time-

Offlight Mass Spectrometry

Mouse Embryonic Fibroblasts

2-(N-Morpholino)-Propansulfonsäure

Major Histocompatibility Complex II 
$\min$

M. musculus

mNaaa

MOPS

MPR

MPR 300

MPR 46

mRNA

MW

$\mu$

$\mathrm{n}$

NAAA

NAE

$\mathrm{NCBI}$

Ni-NTA

NP-40

NPT

OD

ONPG

p53

PAGE

PBS

PCR

PDB

PEG

Pfam

PGA

$\mathrm{pH}$

PIMM

PMF

PMSF

PPCA

PPT1
Minuten

Mus musculus

murine N-Acylethanolamine-Hydrolyzing Acid

Amidase

3-(N-Morpholino)-Propansulfonsäure

Mannose-6-Phosphat-Rezeptor

Mannose-6-Phosphat-Rezeptor mit 300 kDa

Mannose-6-Phosphat-Rezeptor mit 46 kDa

messenger RNA

Molekulargewicht (Molecular Weight)

mikro

nano

N-Acylethanolamine-Hydrolyzing Acid Amidase

$\mathrm{N}$-Acylethanolamide

National Center for Biotechnology Information

Nickel-Nitrilotriacetic Acid

Nonidet P-40

Neomycin-Phosphotransferase

optische Dichte

o-Nitrophenyl- $\beta$-D-Galaktopyranosid

Tumorsuppressor-Protein

Polyacrylamid-Gelelektrophorese

Phosphat-gepufferte Kochsalzlösung

Polymerase-Ketten-Reaktion

Proteindatenbank der RSCB

Polyethylenglykol

Datenbank der Proteinfamilien

Penicillin G Acylase

pondus Hydrogenii

Präzipitationsimmunomix

Peptide Mass Fingerprint

Phenylmethylsulfonylfluorid

protective protein/Cathepsin A

Palmitoyl-Protein-Thioetherase1 
PSZT

PVA

PVDF

RAW264.7

RGS-His6

RNA

RNAi

rpm

RT

RT-PCR

RTqPCR

$\rho$

S.

SAD

Scpep1

SDS

sek

SNP

SP

SPDP

Sulfo-DST

Sulfo-NHS

SV40

$\mathrm{t}$

Tab.

TBS

TCA

TE

TEMED

TGN

TRIS

U

ü. N.

UV periphere Stammzelltransplantation

Penicillin-V-Acylase

Polyvinylidenfluorid

Makrophagen-Zelllinie aus der Maus

Arginin-Glycin-Serin-6x-Histidin

Ribonukleinsäure

RNA-interference

Umdrehungen pro Minute (rounds per minute)

Raumtemperatur

Reverse Transkription

quantitative Real-Time-PCR

Dichte (Rho)

siehe

Single-Wavelength Anomalous Diffraction

Serin-Carboxypeptidase 1

Natriumdodecylsulfat

Sekunden

Single-Nukleotid-Polymorphismen

Signalpeptid

N-succinimidyl 3-(2-pyridyldithio) Propionat

Sulfodisuccinimidyl-Tartrat

Sulfosuccinimidyl-6-(biotin-amido) Hexanoat

large-T-Antigen

Zeit

Tabelle

TRIS-gepufferte Kochsalzlösung

Trichloressigsäure

TRIS-EDTA

$\mathrm{N}, \mathrm{N}, \mathrm{N}$ ',N'-Tetramethylethylendiamin

Trans-Golgi-Netzwerk

TRIS-(hydroxymethyl)-Aminomethan

Einheit (Unit)

über Nacht

ultraviolett 


$\begin{array}{ll}\text { V } & \text { Volt } \\ \text { V/cm } & \text { Volt pro Zentimeter } \\ \text { v/v } & \text { Volumen zu Volumen } \\ \text { vgl. } & \text { vergleiche } \\ \text { w/v } & \text { Gewicht zu Volumen } \\ \text { Y2H } & \text { Yeast-Two-Hybrid } \\ \text { YPDA } & \text { Yeast Peptone Dextrose Adenine } \\ \text { z. B. } & \text { zum Beispiel }\end{array}$

Chemische Elemente wurden mit Buchstaben entsprechend dem Periodensystem abgekürzt. Die Aminosäuren wurden entweder im Drei- oder Einbuchstabencode angegeben. Bei einigen Begriffen wurden die englischen Fachtermini verwendet, weil auch in der deutschsprachigen Fachliteratur eine Übersetzung dieser Begriffe unüblich und unzureichend ist. Diese sind im Text kursiv hervorgehoben. 


\section{Abbildungsverzeichnis}

ABB. 1.1: ENTSTEHUNG SEKUNDÄRER LYSOSOMEN AUS EXTRA- UND INTRAZELLULÄREM MATERIAL, MODIFIZIERT NACH VELLODI (2005, S. 415).....

ABB. 1.2: SCHEMATISCHE DARSTELLUNG DES MPR-VERMITTELTEN TRANSPORTS LYSOSOMALER ENZYME.... 4

ABB. 1.3: GeSAmtheit des lysosomalen Proteoms naCh Aufreinigung aUS MPR-DEFIZIENTEN MEFS IM 2D-GEL

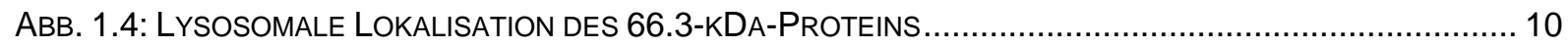

ABB. 1.5: Die Fragmente des 66.3-KDA-PROTEINS Mit GLYKOSYLIERUNGSSTELLEN.............................. 11

ABB. 1.6: UNTERSCHIEDLICHE EXPRESSION DES 66.3-KDA-PROTEINS IN VERSCHIEDENEN GEWEBEN ......... 12

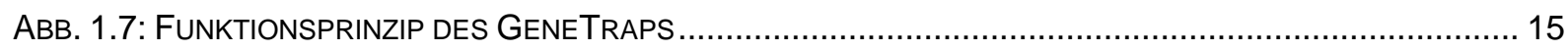

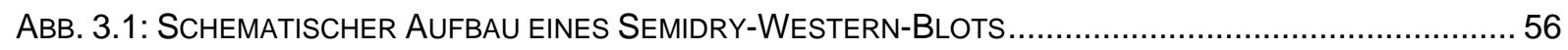

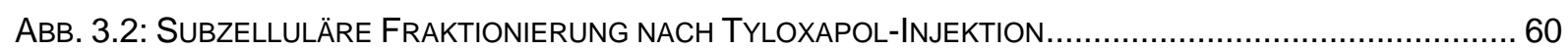

ABB. 3.3: SPEKTRALE EIGENSCHAFTEN DER VERWENDETEN UV-LAMPE INKLUSIVE FILTERSCHEIBE .............. 65

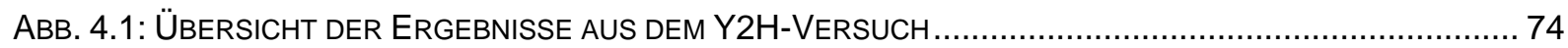

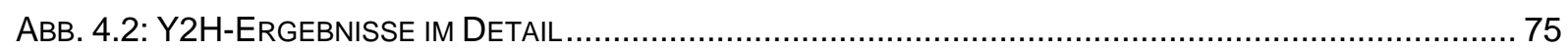

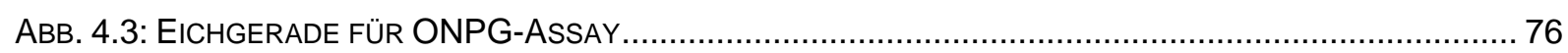

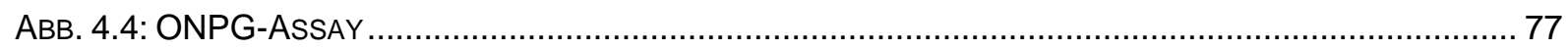

ABb. 4.5: Western-Blot-Analyse der aufgefangenen Fraktionen der Pepstatin-A-

CHROMATOGRAPHIESÄULE NACH BELADUNG MIT LYSOSOMEN-ANGEREICHERTEN FRAKTIONEN ........... 80

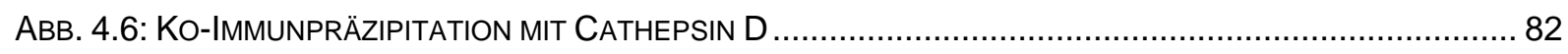

ABB. 4.7: BestimMUng DER HALBWERTSZEIT DER PHOTOAKTIVEN AMINOSÄUREN .................................... 84

ABB. 4.8: 66.3-KDA-PROTEIN ÜBEREXPRIMIERENDE HT1080-ZELLHOMOGENATE NACH IN-VIVO-

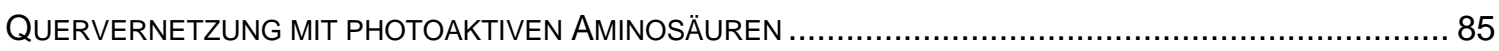

ABB. 4.9: IN-VITRO-QUERVERNETZUNG DES 66.3-KDA-PROTEINS MIT VERSCHIEDENEN QUERVERNETZERN. 87

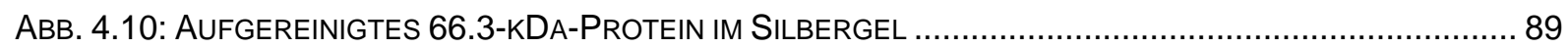

ABB. 4.11: GELFILTRATION DES 66.3-KDA-PROTEINS ALS FINALER AUFREINIGUNGSSCHRITT ..................... 90

ABB. 4.12: SDS-PAGE ANALYSE DER EINGESETZTEN PROTEINLÖSUNGEN NACH GELFILTRATION ............... 91

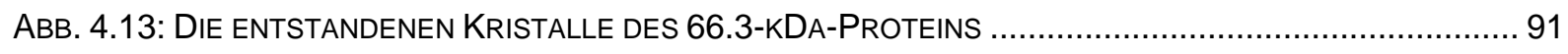

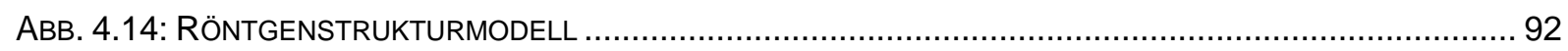

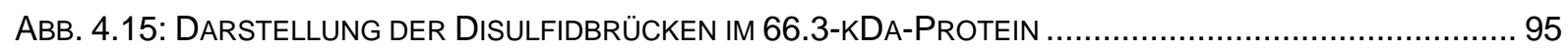

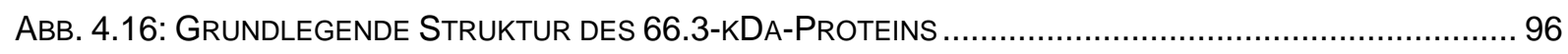

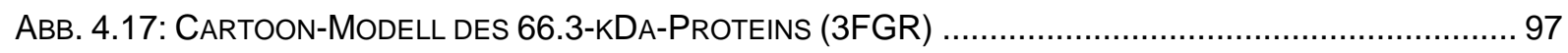

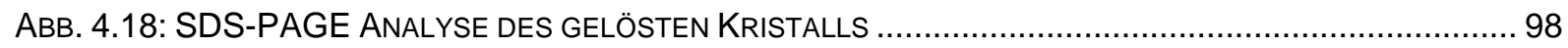

ABB. 4.19: RÄUMLICHE ANORDNUNG DES LINKERS ENTSPRECHEND DEN VERSCHIEDENEN REIFUNGSSTUFEN

.98

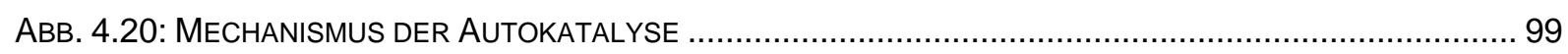

ABB. 4.21: TERTIÄRSTRUKTURVERGLEICH VERSCHIEDENER PROTEINE DER SUPERFAMILIE DER NTN-

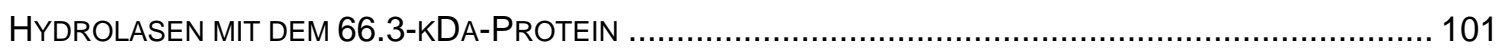

ABB. 4.22: VERGLEICH DES AKTIVEN ZENTRUMS VERSCHIE-DENER NTN-HYDROLASEN ............................. 102

ABB. 4.23: HYDROLYTISCHE AKTIVITÄT FÜR N-PALMITOYLETHANOLAMID IN DOPPELANSÄTZEN .................. 106

ABB. 4.24: HYDROLYTISCHE AKTIVITÄT GEGENÜBER VERSCHIEDENEN N-ACYLETHANOLAMIDEN ................. 108

ABB. 4.25: ZWEIDIMENSIONALE DÜNNSCHICHTCHROMATOGRAPHIE DER EXTRAHIERTEN LIPIDE AUS

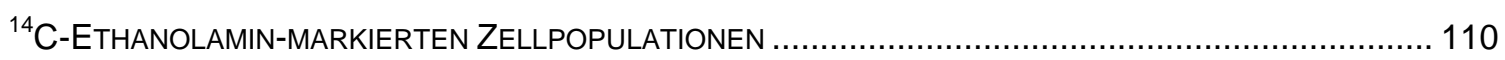

ABB. 4.26: DopPelbande des 66.3-KDA-PROtEINS IM SILBERGEL UND WeSTERN-BLOT ........................ 112

ABB. 4.27: GRAPHISCHE DARSTELLUNG DER MASSENSPEKTROMETRISCH NACHGEWIESENEN PEPTIDE IN DER

DOPPELBANDE 
AвB. 4.28: DARSTELLUNG DES GENETRAPS FÜr DAS 66.3-KDA-PROTEIN IN DER MAUS ...................... 117

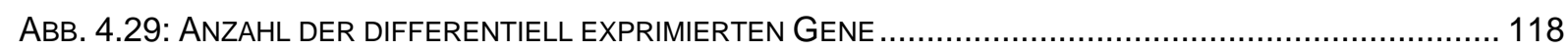

ABB. 4.30: VERTEILUNG DER DIFFERENTIELL EXPRIMIERTEN GENE IM KARYOGRAMM DER MAUS................ 120

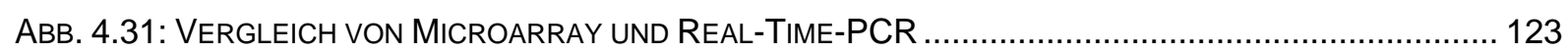

ABB. 4.32: MÖGLICHE TRANSKRIPTE DES 66.3-KDA-PROTEINS IM 66GT-MAUSMODELL ......................... 125

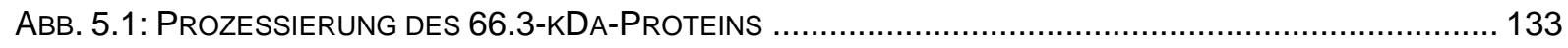

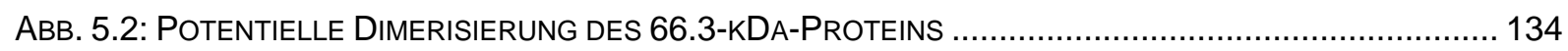

ABB. 5.3: ANGRIFFSPUNKTE DER PHOSPHOLIPASEN ........................................................... 135

ABB. 5.4: MÖGLICHKEITEN DER HYDROPHOBEN POSTTRANSLATIONALEN PROTEINMODIFIKATION ............... 138

ABB. 5.5: ANALYSE EINER SUBZELLULÄREN FRAKTIONIERUNG VON MAUSLEBERHOMOGENAT NACH

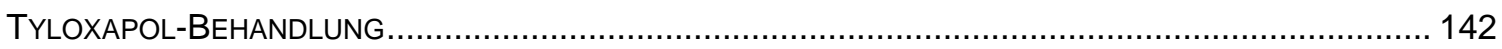

ABB. 8.1: VEKTORKARTEN DER VERWENDETEN VEKTOREN IM MATCHMARKER TWO-HYBRID-SYSTEM ........ 159

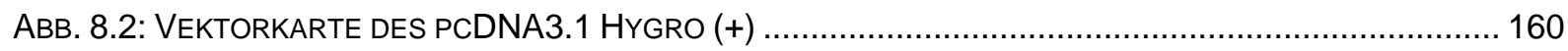

ABB. 8.3: MULTICLONINGSITE (MCS) DES PCDNA3.1 HYGRO (+)-VEKTORS........................................ 160

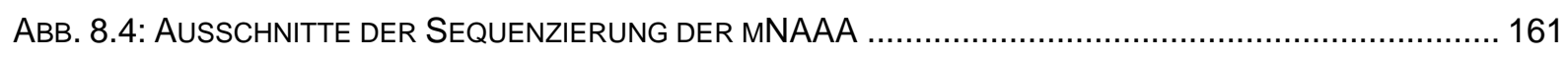

\section{Tabellenverzeichnis}

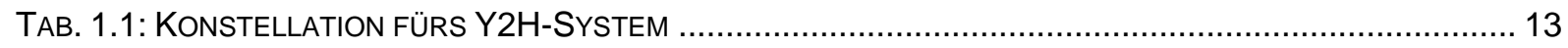

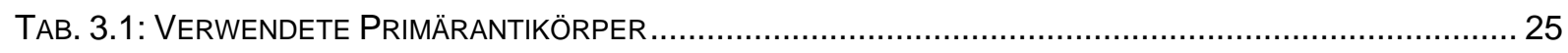

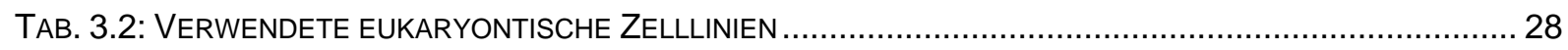

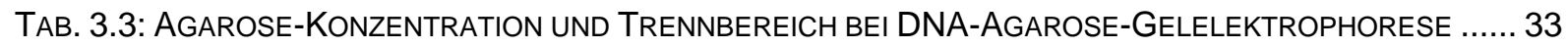

TAB. 3.4: VERWENDETE ANTIBIOTIKA MIT EINGESETZTEN ENDKONZENTRATIONEN .................................4 41

TAB. 3.5: ZUSAMMENSETZUNG VON TRENNGELEN VERSCHIEDENER POLYACRYLAMIDKONZENTRATIONEN UND

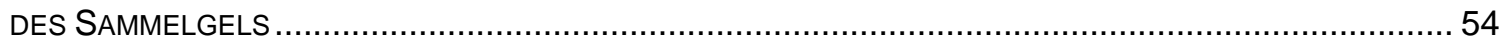

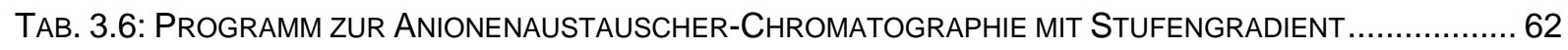

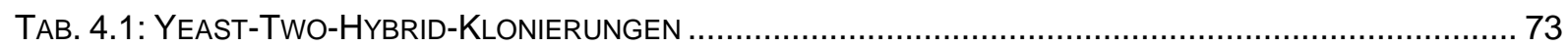

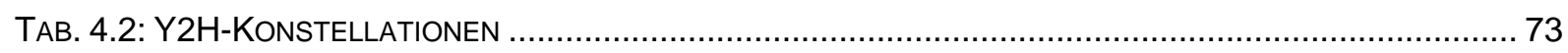

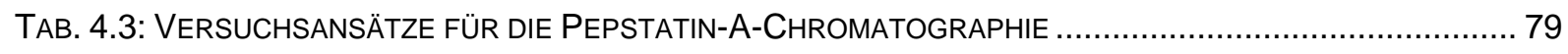

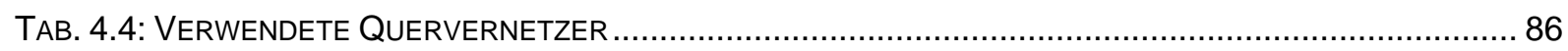

TAB. 4.5: ÜBERSICHT DER VERSCHIEDENEN MODELLE MIT IHREN EIGENSCHAFTEN ................................9.

TAB. 4.6: ERGEBNISLISTE DER STRUKTURDATENBANKABFRAGE MITTELS DALI .................................. 100

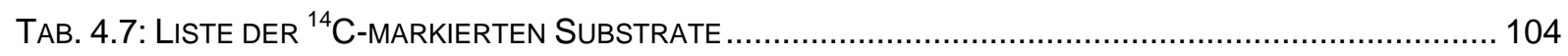

TAB. 4.8: MASSENSPEKTROMETRISCH ERFASSTE, TRYPTISCHE PEPTIDE DES 66.3-KDA-PROTEINS ........... 115

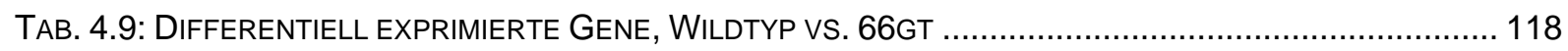

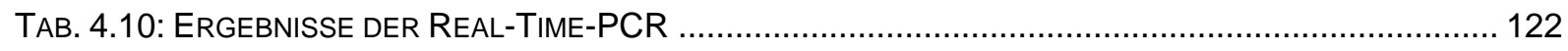

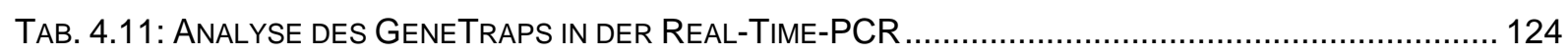

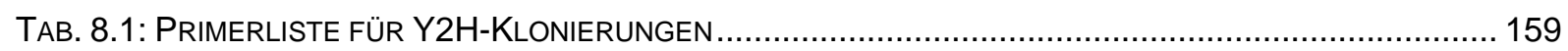

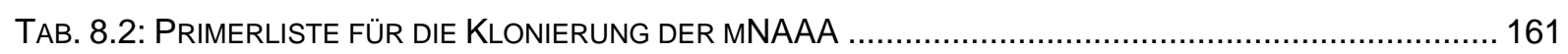

TAB. 8.3: PRIMERLISTE FÜr SEQUENZIERUNGEN DER MNAAA IM PCDNA3.1 HYGRO (+)-VEKTOR ........... 161

TAB. 8.4: PrimerLISTE deR VERWENDETETEN PRIMER FÜR DIE REAL-TIME-PCR ............................... 162

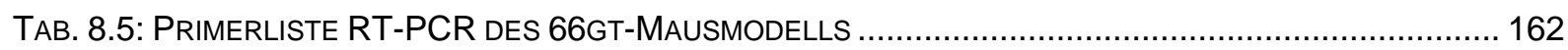





\section{$1 \quad$ Einleitung}

\subsection{Lysosomen}

Das Lysosom als intrazelluläres Kompartiment wurden 1955 von Christian de Duve erstmals beschrieben und zählt zu den mit einer einfachen Membran umschlossenen Organellen (de Duve et al. 1955). Dieses als intrazelluläre Kompartimentierung bezeichnete Prinzip ist ein wesentliches Merkmal eukaryotischer Zellen und dient der Abtrennung unterschiedlicher Funktionsräume. Im Lumen der Lysosomen wird durch eine membrangebundene, ATP-getriebene Protonenpumpe (V-Typ $\mathrm{H}^{+}$-ATPase) und den lysosomalen Chloridkanal CLC7 (Jentsch et al. 2002) ein saurer pH-Wert von 5 aufrecht erhalten (Cuppoletti et al. 1987).

Das Lumen der Lysosomen wird als lysosomale Matrix bezeichnet. Zurzeit sind etwa 60 lysosomale Matrixproteine und rund 25 lysosomale Membranproteine bekannt (Lübke et al. 2009). Die Matrixproteine sind überwiegend saure Hydrolasen wie Proteasen, Nukleasen, Glykosidasen, Lipasen, Phospholipasen, Phosphatasen und Sulfatasen, deren pH-Optimum im sauren Bereich liegt (Ohkuma and Poole 1978) und deren Hauptfunktion in der Zelle die Degradation von Makromolekülen wie Polysacchariden, Proteinen, Nukleinsäuren und Lipiden ist (de Duve 1969).

Die zu degradierenden Makromoleküle gelangen dabei über zwei unterschiedliche Wege in das Lysosom. Zum einen erreichen extrazelluläre Moleküle durch Phagozytose oder rezeptorvermittelte Endozytose das Lysosom (Goldstein et al. 1985), zum anderen erfolgt der Abbau zelleigener, zytosolischer Makromoleküle über zwei Systeme, die ubiquitinvermittelte Proteolyse am Proteasom (Rechsteiner 1991; Hershko and Ciechanover 1992) und die Autophagozytose (vgl. Abb. 1.1). Bei der Autophagozytose wird zytoplasmatisches Material in autophagozytotischen Vakuolen eingeschlossen (Meijer and Codogno 2004). Diese verschmelzen direkt mit den Lysosomen (Lawrence and Brown 1992) oder reifen schrittweise durch Fusion mit endosomalen Vesikeln zu sogenannten Amphisomen heran (Stromhaug and Seglen 1993; Liou et al. 1997). 


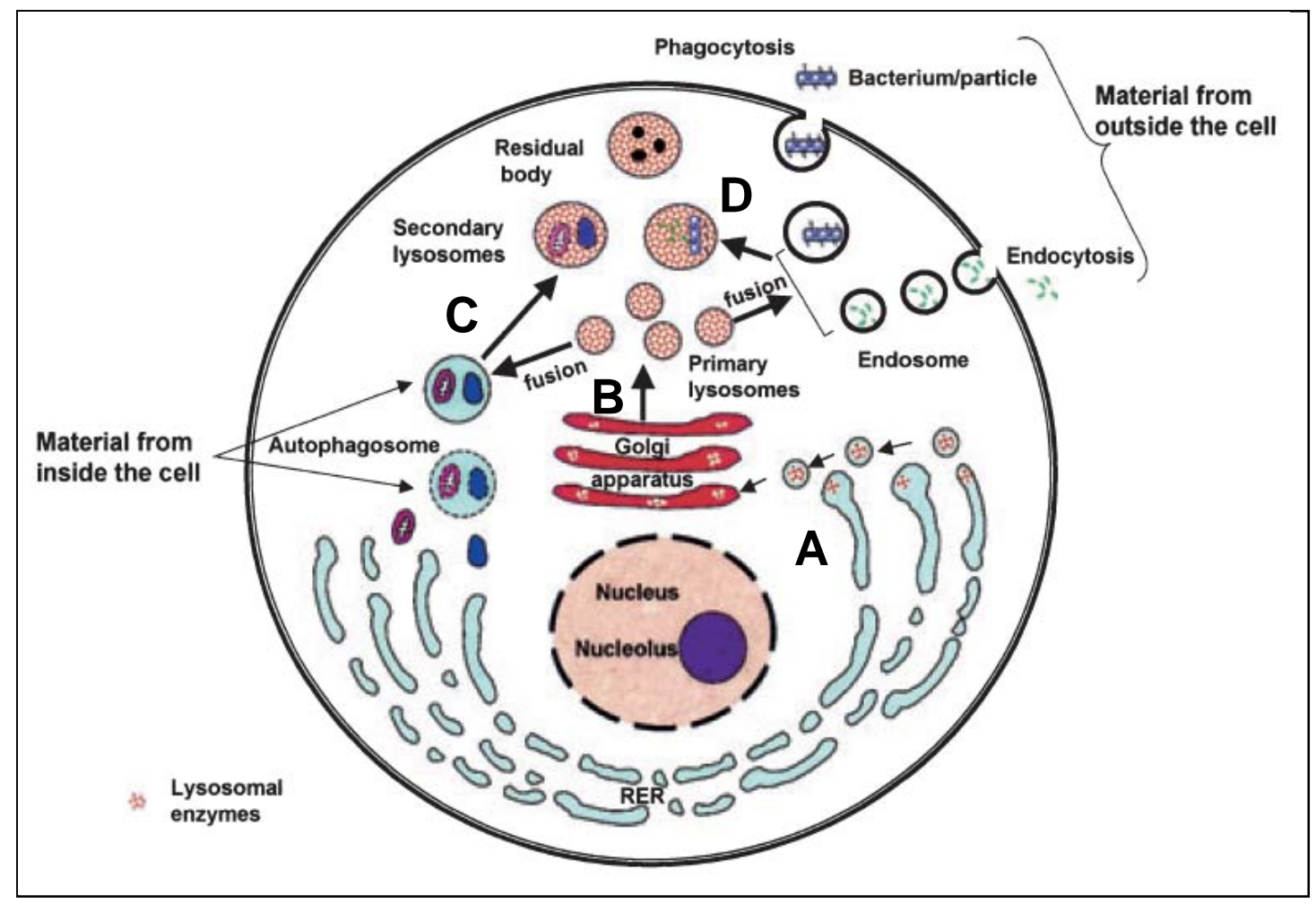

Abb. 1.1: Entstehung sekundärer Lysosomen aus extra- und intrazellulärem Material, modifiziert nach Vellodi (2005, S. 415)

Lysosomale Proteine werden im rauen endoplasmatischen Retikulum synthetisiert und zum GolgiApparat transportiert (A). Sortierung der lysosomalen Proteine und Bildung von Vakuolen bzw. primären Lysosomen (B). Bildung sekundärer Lysosomen durch Fusion mit Autophagosomen (C). Bildung sekundärer Lysosomen durch Fusion mit Endosomen (D).

Neben der katabolen Funktion ist das lysosomale Kompartiment zudem an einer Vielzahl von spezialisierten, zellulären Funktionen beteiligt, wie z. B. an der Antigenpräsentation mittels MHC-II-Komplexen, an der Regulation von Hormonen und Wachstumsfaktoren, sowie am Knochenumbau (Luzio et al. 2007).

Die lysosomale Membran enthält eine große Anzahl vielfach glykolysierter Membranproteine, die das Lysosom vor der Degradation durch die eigenen Hydrolasen schützen und somit für die Integrität der lysosomalen Membran wichtig sind. Andere Membranproteine vermitteln die Interaktion der Lysosomen mit sich und anderen Membransystemen wie Endosomen, Autophagosomen und der Plasmamembran (Fukuda 1991; Peters and von Figura 1994; Hunziker and Geuze 1996). Monomere Abbauprodukte wie Aminosäuren, Fettsäuren, Kohlenhydrate und Nukleoside verlassen das Lysosom durch spezifische Transportkanäle in der Iysosomalen Membran (von Figura and Hasilik 1986; Kornfeld S and Mellman 1989) 
und stehen im Zytosol zum Aufbau neuer Makromoleküle zur Verfügung (Gahl et al. 1982; Rome and Hill 1986).

\subsection{Synthese und Sortierung lysosomaler Matrixproteine}

Lysosomale Matrixproteine werden in der Regel auf Grund einer N-terminalen Signalsequenz, dem so genannten Signalpeptid, am rauen endoplasmatischen Retikulum (ER) synthetisiert und dabei in das Lumen des ER transloziert. Dort erfolgt noch während der Synthese die Abspaltung der Signalsequenz. Hinzu kommt die $\mathrm{N}$-Glykosylierung an einem oder mehreren Asparaginresten (Kornfeld $\mathrm{R}$ and Kornfeld S (1985). Nach dem Transport in den Golgi-Apparat erfahren die Proteine weitere Modifikationen (von Figura and Hasilik 1986). Die wichtigste Modifikation für lysosomale Matrixproteine ist die Mannose-6-Phosphat-Markierung (M6P). Bei dieser für die lysosomalen Matrixproteine spezifischen Modifikation wird im cis-GolgiApparat durch eine Phosphotransferase bzw. Phosphodiesterase ein Mannose-Rest der N-Glykane an Position 6 phosphoryliert (Pohlmann et al. 1982). Diese M6PMarkierung dient als Signal für den Transport in das lysosomale Kompartiment.

Im trans-Golgi-Kompartiment binden die M6P-haltigen Proteine an einen der beiden membranständigen Mannose-6-Phosphat-Rezeptoren (MPR), MPR46 oder MPR300 (Hille-Rehfeld 1995). Mittels Clatrin-coated-Vesikeln werden die M6P-haltigen Proteine zu den Endosomen transportiert (Kornfeld S 1992) und dissoziieren dort pHabhängig vom Rezeptor (Dahms et al. 1989). Die lysosomalen Proteine gelangen über den endosomal-lysosomalen Weg in die Lysosomen, während die M6P-Rezeptoren zurück zum trans-Golgi-Netzwerk (TGN) zirkulieren oder zur Zellmembran gelangen (von Figura and Hasilik 1986) (vgl. Abb. 1.2). Die Vorläuferformen der lysosomalen Proteine werden teilweise endosomal, jedoch zum größeren Teil lysosomal, proteolytisch zu reifen Enzymen prozessiert (Hasilik 1992) und der M6P-Rest dephosphoryliert (Kornfeld S and Mellman 1989; Bresciani and Von Figura 1996). 


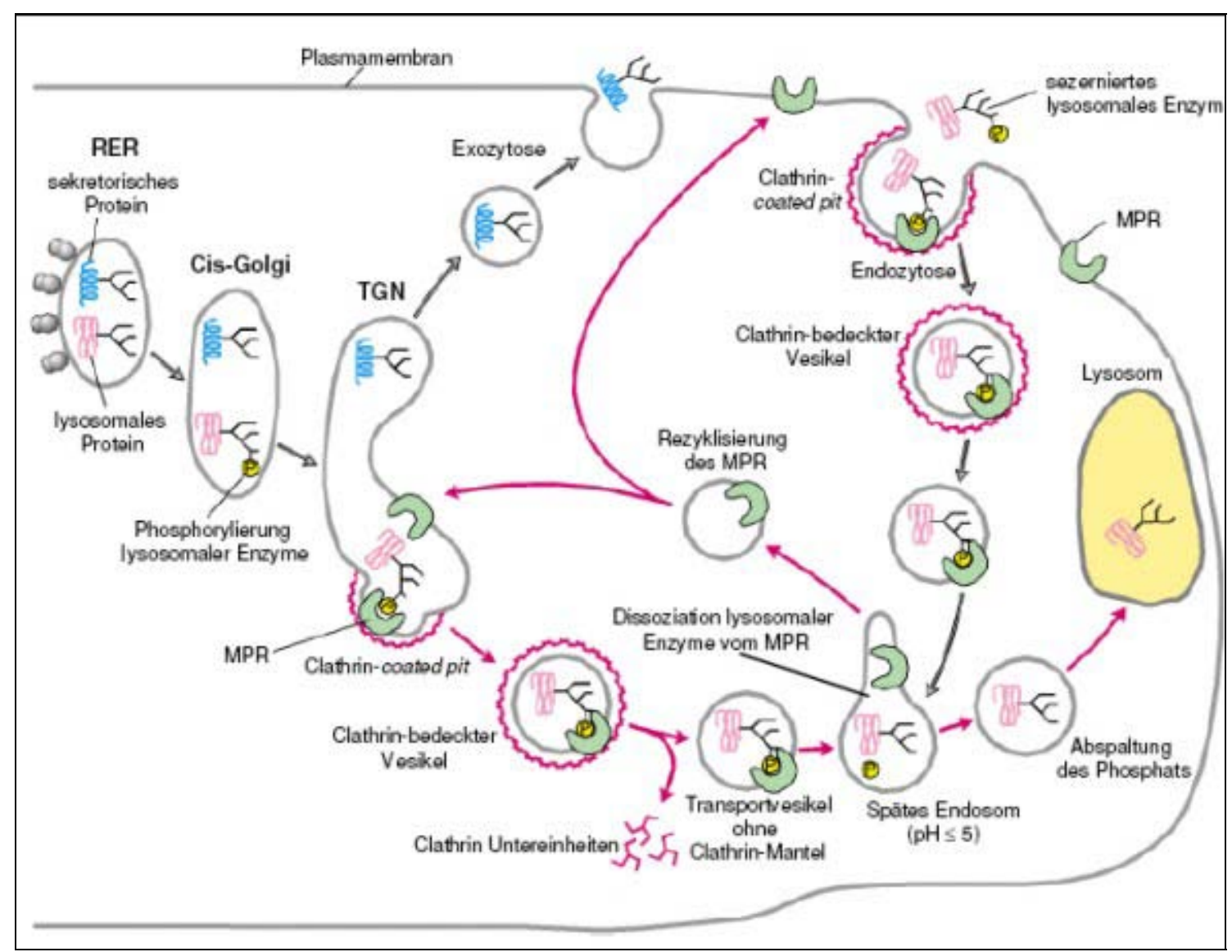

Abb. 1.2: Schematische Darstellung des MPR-vermittelten Transports lysosomaler Enzyme

Lysosomale Enzyme können mehrere Oligosaccharide tragen, die ein- oder zweimal mit M6P substituiert sind. Von den beiden MPRs MPR46 und MPR300 kann nur der MPR300 phosphorylierte Liganden endozytieren. Nach dem Verlust der Clathrin-Hülle verschmelzen die Vesikel mit den frühen Endosomen.

\subsubsection{Mannose-6-phosphat-Rezeptor-vermittelte Sortierung}

Die Mannose-6-Phosphat-Rezeptoren (MPR) sind integrale Membranproteine (Dahms et al. 1987; Dahms et al. 1989), die M6P-haltige Proteine binden und für deren spezifischen Transport in die Lysosomen sorgen. MPRs unterscheiden sich zum einen durch ihre namensgebenden Molekulargewichte von 46- bzw. 300-kDa und zum anderen in ihrer Abhängigkeit kationenabhängig (MPR46) bzw. kationenunabhängig (MPR300) M6P-haltige Proteine zu binden.

Beide Rezeptoren kommen im Golgi-Apparat und den endosomalen Kompartimenten, nicht aber im Lysosom vor. In geringerer Anzahl sind MPRs auch an der Außenseite der Zellmembran lokalisiert, wobei jedoch nur der MPR300 extrazellulär M6P-Liganden zu binden und zu internalisieren vermag (Stein et al. 1987; Byrd and MacDonald 2000). 
Untersuchungen an MPR-doppelt-defizienten Zellen bzw. Tieren haben gezeigt, dass die Aktivität nicht aller lysosomalen Enzyme in gleicher Weise eingeschränkt ist, wie es durch den fehlenden MPR zu erwarten wäre. Dies legt einen vom MPR unabhängigen Transportweg für einige Enzyme nahe. Dieser MPR-unabhängige Transport konnte mittlerweile für die lysosomale $\beta$-Glukocerebrosidase (Reczek et al. 2007), sowie für die beiden lysosomalen Proteasen Cathepsin $D$ und $H$ gezeigt werden (Canuel et al. 2008).

\subsection{Lysosomale Speichererkrankungen}

Die lysosomalen Speichererkrankungen (engl. Lysosomal Storage Disorder = LSD) sind eine Gruppe von über 50 Erkrankungen, die zumeist durch Defekte in lysosomalen Matrixproteinen hervorgerufen werden und durch die konsekutive Akkumulation von nicht abgebauten Substraten in den Lysosomen charakterisiert sind (Gieselmann 1995; Futerman and van Meer 2004; Vellodi 2005). Lysosomale Speichererkrankungen werden zwar hauptsächlich durch den Defekt einzelner lysosomaler Hydrolasen verursacht, jedoch können auch Defekte von Proteinkofaktoren, wie Enzymaktivatoren (z. B. Saposine, sphingolipid activator proteins) oder Proteinstabilisatoren (z. B. PPCA, protective protein/Cathepsin A) sowie Defekte von Transportern (z. B. Sialin (Sialinsäure-Transporter)) und nicht lysosomalen Proteinen, die an der posttranslationalen Modifizierung (z. B. GNPT, $N$-acetylglucosamine 1-phosphotransferase) oder der Aktivierung der neu synthetisierten lysosomalen Proteine (z. B. FGE, Formylglycine-Generating Enzyme) beteiligt sind, zu lysosomalen Erkrankungen führen (Dierks et al. 2009). Die LSDs können demnach anhand des jeweils zugrundeliegenden Defekts entsprechend in fünf Gruppen eingeteilt werden (Greiner-Tollersrud and Berg 2005):
I) Defekte im Glykanabbau
II) Defekte im Lipidabbau
III) Defekte im Proteinabbau
IV) Defekte lysosomaler Transporter
V) Defekte bei der lysosomalen Sortierung.

Auch wenn jede der lysosomalen Speichererkrankungen für sich genommen sehr selten ist, so beträgt die Inzidenz aller LSDs zusammen immerhin 1:8000 (Meikle et al. 1999; Poorthuis et al. 1999). Bis auf wenige Ausnahmen wie z. B. der Morbus 
Fabry, der x-chromosomal vererbt wird, werden alle anderen bekannten LSDs autosomal-rezessiv vererbt (Masson et al. 2004). Die Prävalenz jeder LSD variiert sowohl geographisch, als auch zwischen einzelnen Ethnien erheblich. So treten z. B. der Morbus Gaucher (Horowitz et al. 1998) und der Morbus Tay-Sachs (Myerowitz 1997) bei Ashkenasi-Juden 10 bis 20-mal häufiger auf als in der Durchschnittsbevölkerung.

\subsubsection{Klinische Aspekte von lysosomalen Speichererkrankungen}

Die Akkumulation der nicht abgebauten Makromoleküle führt zur Bildung von großen Speichervakuolen und letztendlich zur Fehlfunktion der betroffenen Zellen und Gewebe (Ballabio and Gieselmann 2009). In Abhängigkeit von der Verteilung und der Menge des gespeicherten Substrats sind meist eine Reihe unterschiedlicher Organe betroffen.

Das klinische Erscheinungsbild der lysosomalen Speichererkrankungen ist auf Grund der unterschiedlichen Ätiologien sehr heterogen und auch der Phänotyp einzelner lysosomaler Speichererkrankungen variiert stark, so dass der Genotyp nur bedingt Aussagen über den Phänotyp zulässt. Der Verlauf ist jedoch stets progredient. Die Symptome einer LSD hängen neben der enzymatischen Restaktivität auch von den betroffenen Gewebe- bzw. Zelltypen ab. Zellen, in denen ein Substrat in hohem Maße umgesetzt wird, bilden eher große Speichervesikel und sind in ihrer Funktion eingeschränkt, wohingegen die Morphologie und Funktion anderer Zellen gänzlich erhalten bleiben kann (Neufeld and Muenzer 2001). Häufig sind besonders die Zellen des Zentralnervensystems von der Speicherung in Vesikeln beeinträchtigt, was den schweren neurologischen Phänotyp der meisten Erkrankungen erklärt. So sind die Leitsymptome vieler lysosomaler Speichererkrankungen mentale Retardierung und Demenz, sowie motorische und sensorische Störungen. Aber auch Funktionsausfälle und Beeinträchtigungen der viszeralen Organe, der Herz- und Skelettmuskeln, sowie der Knochen- und Knorpelgewebe sind je nach Erkrankung möglich (Gieselmann 1995; Futerman and van Meer 2004; Vellodi 2005; Ballabio and Gieselmann 2009).

\subsubsection{Therapie von lysosomalen Speichererkrankungen}

Es existieren verschiedene Ansätze zur Behandlung von LSDs. Den meisten Therapien liegt der Mechanismus der rezeptorvermittelten Endozytose M6P-haltiger 
Proteine zugrunde, so dass verschiedene Zelltypen über eine „Poolsubstitution“ zu behandeln sind. Eine solche „Poolsubstitution“ kann durch die regelmäßige i. v.-Substitution rekombinanter, M6P-haltiger, lysosomaler Enzyme einerseits oder durch das blutbildende System nach einer allogenen Stammzelltransplantation andererseits bewerkstelligt werden. Auf Grund der guten Erfolgsaussichten der Enzymersatztherapie (ERT) nimmt diese eine besondere Stellung in der Therapie der LSDs ein und ist mittlerweile auch mehrfach in klinischer Anwendung. Exemplarisch seien hier nur der Morbus Gaucher (Barton et al. 1991; Weinreb 2008) und der Morbus Fabry (Eng et al. 2001; Mignani and Cagnoli 2004) erwähnt, bei denen die Enzymersatztherpie heute bereits klinischer Standard geworden ist (Schaefer et al. 2009).

Die Enzymersatztherapie wird weiterhin die zentrale Rolle in der Therapie der LSDs einnehmen, da einzig bei diesem Therapiekonzept die Nebenwirkungen der Therapie im Gegensatz zu den anderen unten genannten Therapiemodalitäten in einem angemessenen Verhältnis zum Erfolg stehen. Insbesondere wenn effizientere Wege für die Passage von therapeutisch wirksamen Enzymmengen über die Blut-HirnSchranke beschrieben werden, kann die ERT auch den neurologischen Phänotyp positiv beeinflussen. Um die Blut-Hirn-Schranke als Barriere gänzlich zu umgehen, wird auch die intrathekale Applikation von rekombinantem Enzym bei Mukopolysaccharidosen bereits erprobt (Hemsley and Hopwood 2009). Wie oben bereits erwähnt, besteht auch die Möglichkeit der Behandlung von LSDs durch die allogene Knochenmarkstransplantation oder eine periphere Stammzelltransplantation (PSZT), die allerdings auf Grund der hohen Letalitätsrate der Behandlungsmethoden immer mit größter Fürsorge im Einzelfall abgewogen werden muss und sicherlich nur bei sehr schweren Verläufen Mittel der Wahl sein kann (Wall et al. 1998; Grewal et al. 2004; Greiner-Tollersrud and Berg 2005). Wird die PSZT allerdings durchgeführt, so ist sie in der Lage, auch den neurologischen Phänotyp äußerst günstig zu beeinflussen (Shapiro et al. 1995). Weitere vielversprechende Ansätze sind die Inhibition der Substratbiosynthese (Jeyakumar et al. 1999), die in-vivo-Gentherapie durch adenoviralen Gentransfer (Ohashi et al. 1997; Cheng and Smith 2003) sowie die Optimierung der enzymatischen Restaktivität durch Chaperone (Matsuda et al. 2003; Schiffmann 2010). So konnte jüngst gezeigt werden, dass die Behandlung von Patienten mit Morbus Niemann-Pick Typ A und B mit rekombinantem Heat Shock 
Protein 70 (HSP70), durch dessen stabilisierende Wirkung auf die lysosomale Membran, in der Lage ist, den Phänotyp dieser lysosomalen Speichererkrankung effektiv zu verbessern (Kirkegaard et al. 2010).

\subsection{Lysosomale Proteomanalyse}

Eine lysosomale Proteomanalyse war die Grundlage zur Identifizierung von drei neuen lysosomalen Matrixproteinen (Kollmann et al. 2005), wovon wiederum eines Gegenstand der hier vorliegenden Arbeit ist.

\subsubsection{Methode zur Aufreinigung lysosomaler Proteine}

Um selektiv nur die Proteine des Lysosoms untersuchen zu können, kann man sich die Eigenschaft der MPR-abhängigen Sortierung lysosomaler Proteine zu Nutze machen. Dazu erfolgt die Aufreinigung der lysosomalen Proteine über MPR-affinitätschromatographische Verfahren (Kollmann et al. 2005; Schröder and Hasilik 2006; Sleat et al. 2006).

\subsubsection{Analyse des lysosomalen Proteoms}

Als Proteom wird die Gesamtheit aller zu einem Organismus gehörenden Proteine bezeichnet. Gemäß dieser Definition zählen alle im Lysosom vorhandenen Proteine zum lysosomalen Proteom. Eine vollständige Analyse des lysosomalen Proteoms ist von besonderem Interesse, da eine Fehlfunktion annähernd jedes bis heute bekannten lysosomalen Matrixproteins mit einer lysosomalen Erkrankung einhergeht (Ballabio and Gieselmann 2009).

Der hier vorliegenden Arbeit liegt eine Analyse aller murinen M6P-markierten Proteine zugrunde, die mittels immobilisierter MPRs aufgereinigt wurden. Drei bis dahin unbekannte Proteine konnten dabei identifiziert werden (Kollmann et al. 2005). Bei einem dieser Proteine handelte es sich um das nach seiner molekularen Größe benannte 66.3-kDa-Protein (vgl. Abb. 1.3) (Protein Accession-No. AAH38605). 


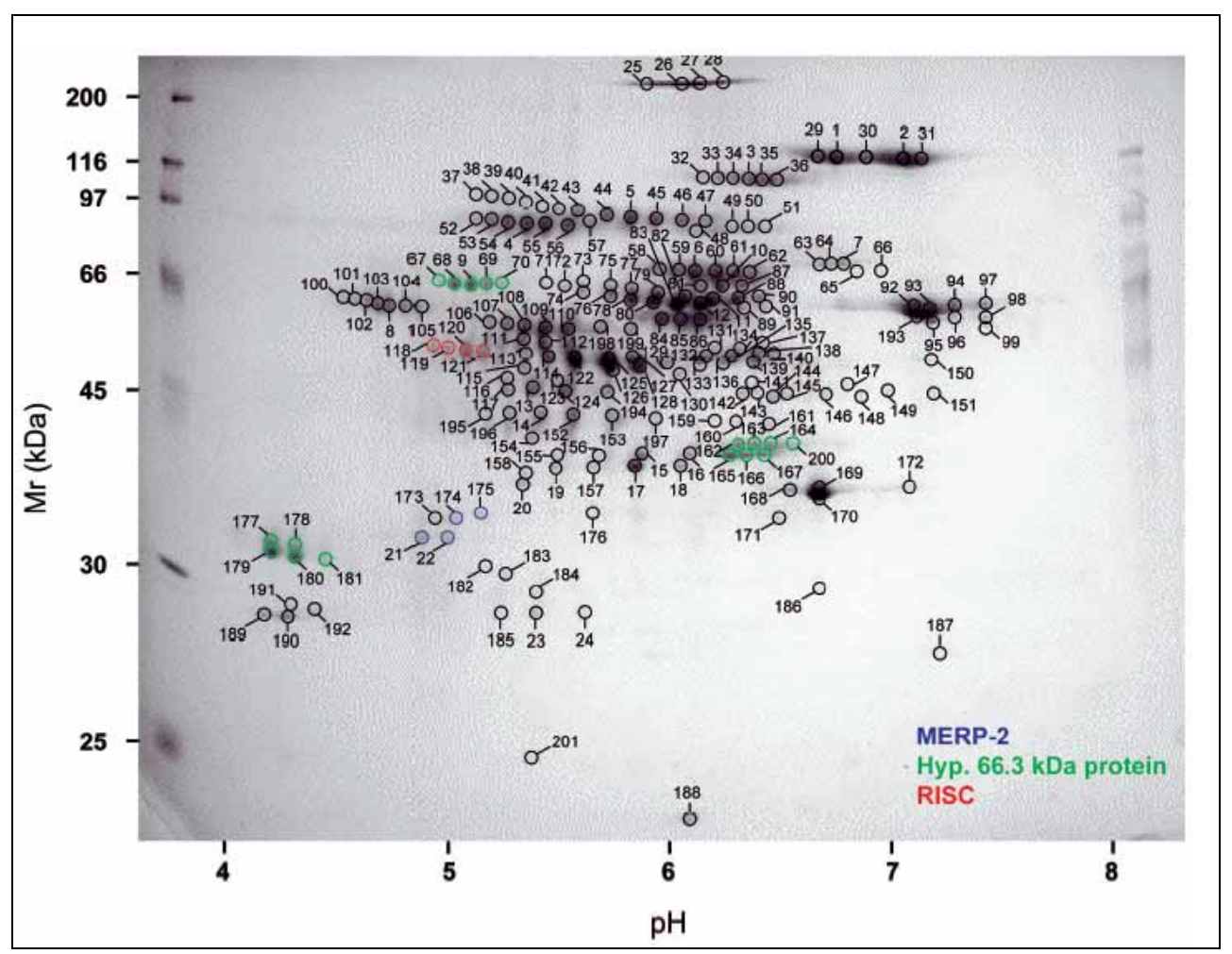

Abb. 1.3: Gesamtheit des lysosomalen Proteoms nach Aufreinigung aus MPR-defizienten MEFs im 2D-Gel

Die Abb. 1.3 zeigt alle von der MPR-Säule eluierten Proteine im 2D-Gel. In der ersten Dimension wurden die Proteine entsprechend ihrem isoelektrischen Punkt fokussiert (pH-Wert) und in der zweiten Dimension der Größe nach aufgetrennt (SDS-PAGE). Alle erkennbaren Spots wurden durchnummeriert und analysiert. Die grünen Kreise zeigen die Proteinspots, die durch eine massenspektrometrische Untersuchung dem 66.3-kDa-Protein zugeordnet werden konnten. Abbildung modifiziert nach Kollmann et. al (2005, S. 3970).

\subsection{3-kDa-Protein}

\subsubsection{Lysosomale Lokalisation}

Ein Nachweis der intralysosomalen Lokalisation des 66.3-kDa-Proteins konnte auf endogenem Proteinlevel mittels indirekter Immunfluoreszenz in mausembryonalen Fibroblasten (MEF) geführt werden (vgl. Abb. 1.4 A). Anhand der subzellulären Fraktionierung Tyloxapol-behandelter Mausleber konnte das 66.3-kDa-Protein mit typischen, lysosomalen Markerproteinen wie LAMP-1 und Cathepsin D kofraktioniert werden (vgl. Abb. 1.4 B) (Deuschl et al. 2006).

In von diesen Ergebnissen unabhängigen Untersuchungen an dem humanen Ortholog des 66.3-kDa-Proteins konnte die lysosomale Lokalisation ebenfalls gezeigt werden (Jensen et al. 2007). 


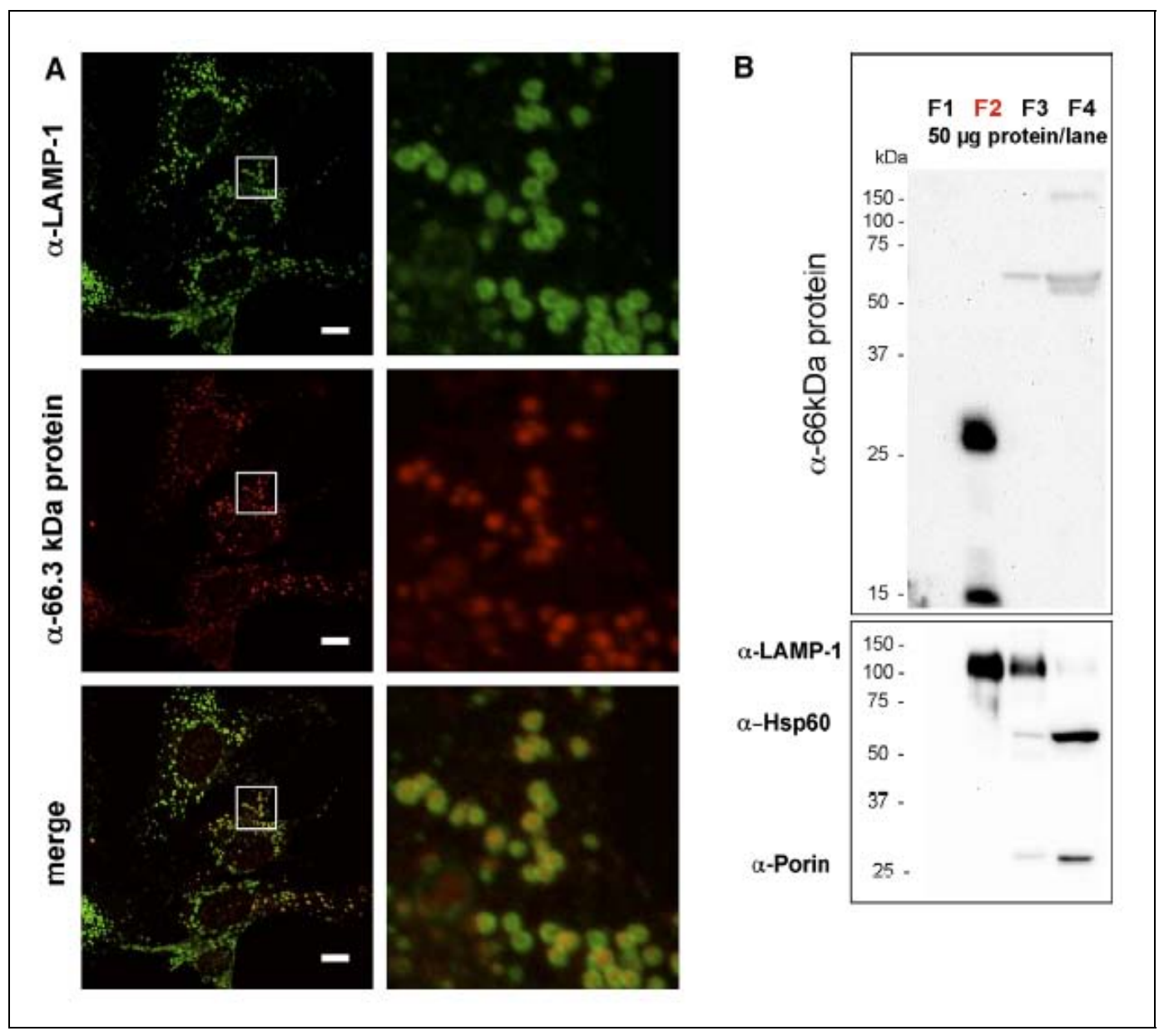

Abb. 1.4: Lysosomale Lokalisation des 66.3-kDa-Proteins

Nachweis der Iysosomalen Lokalisation des 66.3-kDa-Proteins mittels indirekter Immunfluoreszenz. Im merge ist deutlich zu erkennen, dass das 66.3-kDa-Protein (rot) von dem Marker für lysosomale Membranen (LAMP-1, grün) umschlossen wird (A). Subzelluläre Kofraktionierung des 66.3-kDaProteins mit dem lysosomalen Markerprotein LAMP-1 (B). Abbildung aus Deuschl et al. (2006, S. 5750)

\subsubsection{Molekulare Charakterisierung des murinen 66.3-kDa-Proteins}

In Vorarbeiten zur vorliegenden Arbeit sind bereits umfangreiche zellbiologische Charakterisierungen des 66.3-kDa-Proteins durchgeführt worden.

Das murine 66.3-kDa-Protein besteht aus 594 Aminosäuren und besitzt ein N-terminales Signalpeptid aus 46 Aminosäuren. Es besitzt fünf potentielle $\mathrm{N}$-Glykosylierungsstellen mit dem Motiv -N-XS/ T- an den Positionen 93, 115, 236, 441 und 520, die in HT1080-Zellen auch alle genutzt werden (vgl. Abb. 1.5) (Deuschl et al. 2006). 


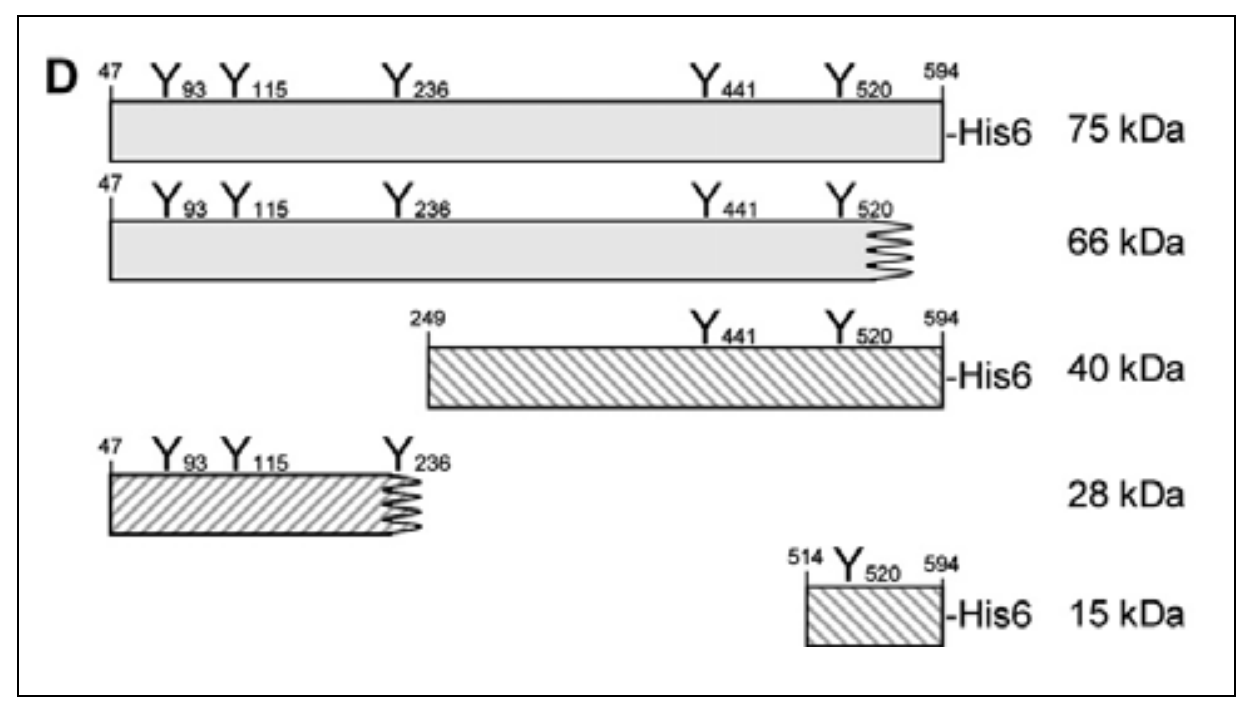

Abb. 1.5: Die Fragmente des 66.3-kDa-Proteins mit Glykosylierungsstellen

Schematische Darstellung der Proform (75 kDa) und der unterschiedlichen Fragmente des 66.3-kDaProteins mit den Positionierungen der N-Glykosylierungen. Soweit bekannt sind die $\mathrm{N}$ - und C-terminalen Aminosäuren der Fragmente angegeben. Abbildung modifiziert nach Deuschl et al. (2006, S. 5749)

Zur Detektion des endogenen 66.3-kDa-Proteins wurde ein polyklonales Antiserum aus Kaninchen hergestellt. Dafür wurde das 66.3-kDa-Protein an ein RGS-His-Tag gekoppelt in HT1080-Zellen stabil überexprimiert, über affinitäts- und ionenchromatografische Aufreinigungsschritte gereinigt und anschließend zur Immunisierung von Kaninchen verwendet. Das so erzeugte 66-Antiserum (G9) wurde in Western-Blot-Analysen und Immunpräzipitationen verwendet. Mit Hilfe des Antiserums konnte gezeigt werden, dass das 66.3-kDa-Protein in stabilüberexprimierenden HT1080-Zellen aus einer Proform von $75 \mathrm{kDa}$ in ein C-terminales 40-kDa-Fragment und ein N-terminales 28-kDa-Fragment prozessiert wird. Durch limitierte Proteolyse erfolgt vom C-terminalen 40-kDa-Fragment die Abtrennung eines C-terminalen 15-kDa-Fragments (vgl. Abb. 1.5). Da das 28-kDaund das 15-kDa-Fragment bei der subzellulären Fraktionierung in der lysosomalen Fraktion nachgewiesen werden konnten, handelt es sich wahrscheinlich um die aktiven, reifen Formen des 66.3-kDa-Proteins (Deuschl et al. 2006).

Zur Analyse der gewebsspezifischen Expression des 66.3-kDa-Protein-Gens wurden Northern- und Western-Blot-Analysen durchgeführt (Deuschl et al. 2006). Für die Charakterisierung der Transkripte wurden drei Transkripte des Gens des 66.3-kDaProteins mit molekularen Größen zwischen $2 \mathrm{~kb}$ und $4 \mathrm{~kb}$ in allen Geweben detektiert. Die Transkriptionshöhe des Gens variierte in den unterschiedlichen 
Geweben stark. Die höchsten Expressionsniveaus wurden im Hoden und in der Lunge detektiert. Bei Western-Blot-Analysen mit dem 66-Antiserum wurden für das 66.3-kDa-Protein in Gewebehomogenaten ebenfalls starke Variationen in der Fragmentgröße und der Signalstärke detektiert. Es wurden spezifische Signale bei $34 \mathrm{kDa}, 50 \mathrm{kDa}$ und $100 \mathrm{kDa}$ in Hirngewebe, bei $24 \mathrm{kDa}$ in Lungengewebe und bei 15 kDa, sowie 28 kDa in Herzgewebe detektiert (vgl. Abb. 1.6) (Deuschl et al. 2006).

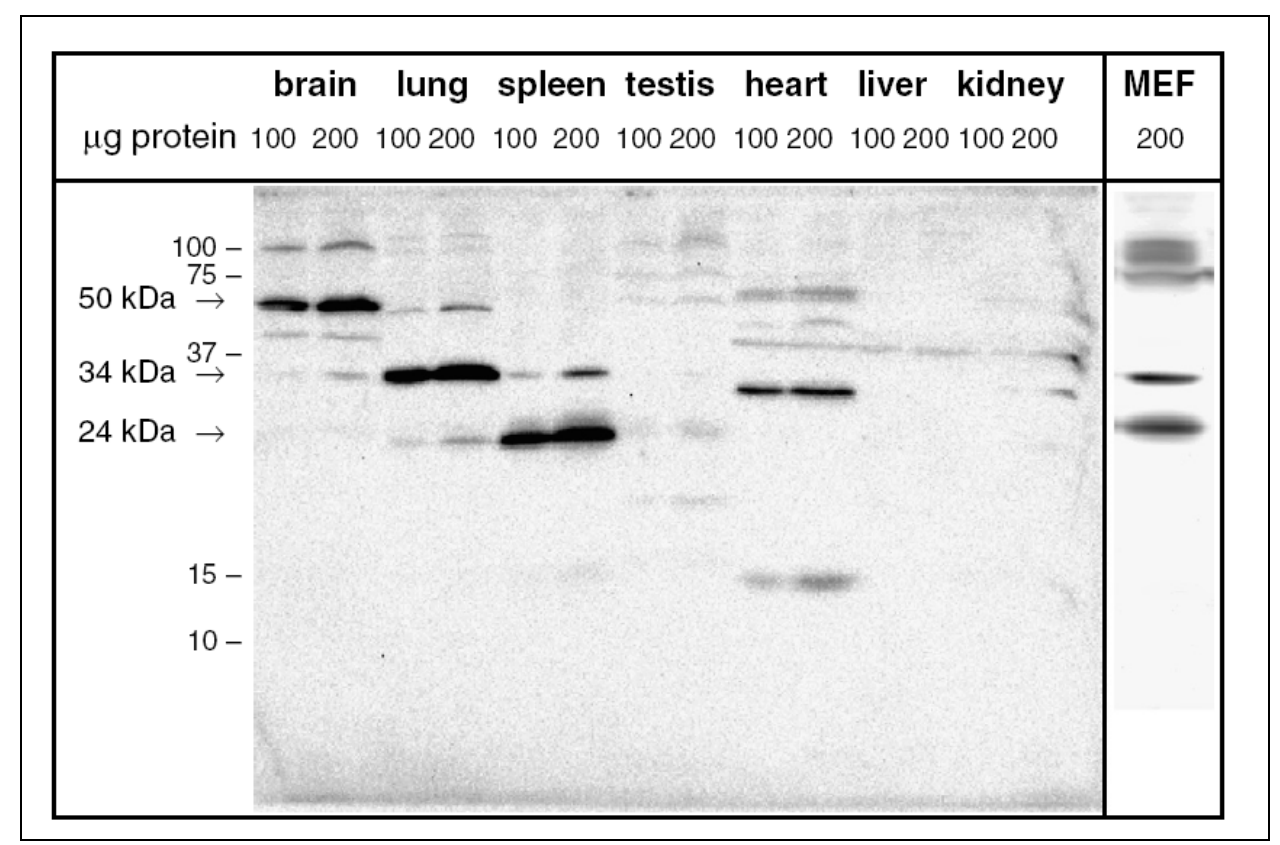

Abb. 1.6: Unterschiedliche Expression des 66.3-kDa-Proteins in verschiedenen Geweben

Die Abb. 1.6 zeigt die Detektion unterschiedlicher 66.3-kDa-Fragmente in unterschiedlichen Gewebetypen. Dazu wurden 100 bzw. $200 \mu g$ Mausgewebe homogenisiert und mit dem 66-Antiserum im Western-Blot analysiert. Abbildung aus Deuschl et al. (2006, S. 5751)

\subsubsection{Interaktionsstudien}

Neben der molekularen Charakterisierung des 66.3-kDa-Proteins wurden in Vorarbeiten zu dieser Arbeit in der Arbeitsgruppe bereits Experimente zur Funktion des 66.3-kDa-Proteins durchgeführt. Dazu zählen unter anderem RNAi-Versuche, die allerdings nicht zu verwendbaren Ergebnissen führten.

Des Weiteren wurde mittels Affinitätschromatographie mit gekoppeltem, rekombinantem 66.3-kDa-Protein versucht, mögliche Interaktionspartner zu identifizieren. Unter den neun identifizierten Interaktionspartnern waren humanes Albumin und Keratin, welche typische Kontaminanten bei massenspektrometrischen Versuchen darstellen, sowie Keratin aus Bos taurus, welches von der Vorreinigung an der BSA-Säule stammen könnte. Drei weitere Proteine waren zytosolisch 
lokalisiert und daher eher unwahrscheinliche Interaktionspartner für das 66.3-kDaProtein. Als einziger möglicher Interaktionspartner wurde bei diesem Versuch die lysosomale Aspartyl-Endopeptidase Cathepsin D identifiziert (Deuschl 2008).

Da eine unspezifische Bindung von Cathepsin D an das 66.3-kDa-Protein oder die Affinitätschromatographiematrix nicht ausgeschlossen werden konnte, sollten alternative Methoden zur Verifizierung der Interaktion zwischen Cathepsin D und dem 66.3-kDa-Protein angewendet werden. Eine daraufhin durchgeführte Interaktionsstudie mit dem Biacore-Analysegerät konnte jedoch keine aussagekräftigen Ergebnisse liefern (Deuschl 2008).

Eine Interaktionsstudie im Yeast-Two-Hybrid-System ( $\mathrm{Y} 2 \mathrm{H})$ konnte eine leichte Interaktion zwischen der Cathepsin-D-full length-Form und dem 15-, respektive dem 28-kDa-Fragment des 66.3-kDa-Proteins zeigen. Die Positivkontrolle mit large-TAntigen (SV40) und p53 war in allen Fällen positiv, die Negativkontrollen der leeren mock-Vektoren miteinander waren negativ. Allerdings fehlen hier die Negativkontrollen der einzelnen Fragmente und Cathepsin D jeweils mit leeren preybzw. bait-Vektoren, um von einer spezifischen Interaktion sprechen zu können (Deuschl 2008). Da auch die Stärke der Interaktion deutlich schwächer ist als die Positivkontrolle mit large-T-Antigen (SV40) und p53, wäre hier eine Quantifizierung nötig, um zuverlässige Aussagen bezüglich einer Interaktion treffen zu können.

Die Ergebnisse einer schwachen Interaktion zwischen Cathepsin D und dem 15-kDabzw. 28-kDa-Fragment beruhten auf folgenden Konstellationen aus prey- und bait-Vektoren:

Tab. 1.1: Konstellation fürs Y2H-System

\begin{tabular}{lll}
\hline prey-Vektor (pGADT7) & bait-Vektor (pGBKT7) & Interaktion \\
\hline mock & mock & - \\
p53 & large-T-Antigen(SV40) & ++ \\
Cathepsin D & Prä-Proform & - \\
Cathepsin D & Proform & - \\
Cathepsin D & 40-kDa-Fragment & - \\
Cathepsin D & 28-kDa-Fragment & + \\
Cathepsin D & 15-kDa-Fragment & + \\
Cathepsin D & Mittelfragment (AS 249-513) & - \\
\hline
\end{tabular}




\subsubsection{Das GeneTrap-Mausmodell}

Zur Untersuchung von Genfunktionen in höheren Eukaryonten werden oftmals Mausmodelle verwendet. Die Vergleichbarkeit und Übertragbarkeit der gewonnenen Ergebnisse auf Grund der ausgeprägten genetischen, aber auch anatomischen und physiologischen Ähnlichkeit zum Menschen macht das Mausmodell zum idealen Versuchssystem. Der für die Praxis relevante Vorteil in der Verwendung von Mausmodellen ist der kurze Lebenszyklus und die hohe Wurfgröße der Tiere. Zudem existieren etablierte Protokolle zur genetischen Manipulation von murinen embryonalen Stammzellen (ES-Zellen), welche die Grundlage für die Mausmodelle darstellen. Die Methode des GeneTraps stellt eine dieser Methoden zur Manipulation des Genoms dar. Hierbei wird eine Selektionskassette zufällig ins Mausgenom eingefügt und mutiert dort ungerichtet einen Genlocus (De-Zolt et al. 2006). Die Zufälligkeit der Insertion stellt den entscheidenden Unterschied zum klassischen knock-out dar, bei dem über homologe Rekombination gezielt bestimmte Gene ausgeschaltet werden (Austin et al. 2004; Skarnes et al. 2004). Die eingefügten Sequenzen sind bei der GeneTrap-Methode retroviralen Ursprungs und besitzen in der Regel keinen Promotor, so dass das getrappte Gen unter der Kontrolle des endogenen Promotors verbleibt. Die Insertionskassette im GeneTrap setzt sich aus einem Splice-Akzeptor-Element im 3'-Bereich, gefolgt von einem Selektionsmarker, bei dem es sich meist um eine Neomycinphosphotransferase-codierende Sequenz handelt, sowie einem Terminator im 5'-Bereich zusammen. Beim Splicen des mutierten Genprodukts entsteht somit ein Fusionstranskript aus der vor der GeneTrap-Insertionsstelle gelegenen RNA des Gens, verknüpft mit den Sequenzen des Selektionsmarkers (vgl. Abb. 1.7). Hinter der GeneTrap-Insertionsstelle gelegene Anteile des Gens werden nicht mehr transkribiert und sind somit deletiert. 


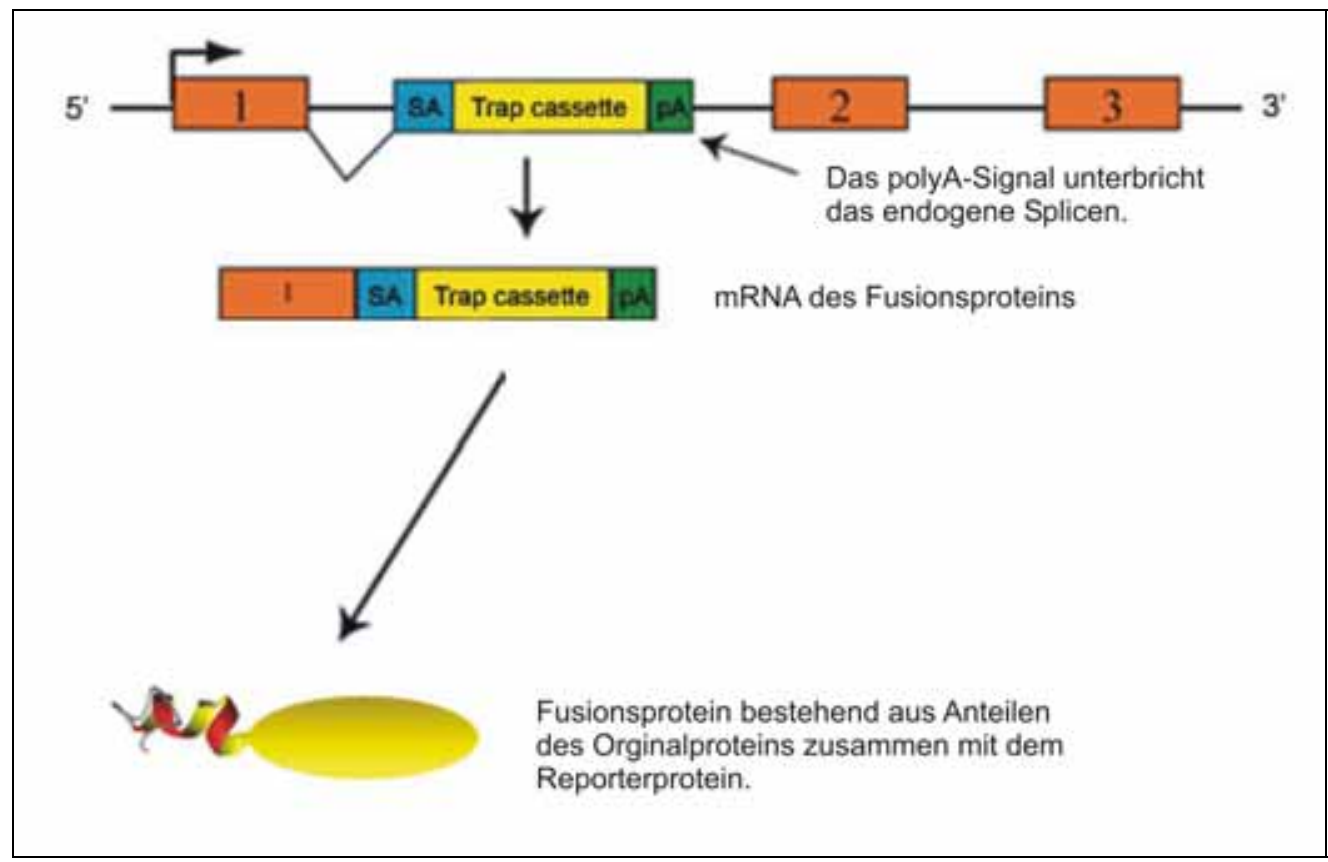

\section{Abb. 1.7: Funktionsprinzip des GeneTraps}

Die Transkription eines getrappten Gens führt auf Grund des polyA-Signals der GeneTrap-Kassette zu einer verkürzten mRNA, die schließlich in ein selektierbares Fusionsprotein übersetzt wird. Dabei enthält das Fusionsprotein die N-terminalen Anteile des Originalproteins gekoppelt an das Selektionsprotein, in diesem Fall eine Neomycin-Phosphotransferase. Abbildung modifiziert nach International Gene Trap Consortium (http://www.genetrap.org/tutorials/overview.html; Stand: Januar 2010)

Die GeneTrap-Vektorsequenz wird über retroviralen Transfer ins Genom totipotenter ES-Zellen von Mäusen mit weißer Fellfarbe integriert. Die genetisch veränderten ESZellen werden in Blastozysten von Spendermäusen mit schwarzer Fellfarbe injiziert und in den Uterus scheinträchtiger Weibchen implantiert. Nachkommen der injizierten Zellen können auf Grund der Totipotenz der embryonalen Stammzellen zur Ausbildung aller Gewebe beitragen. Die erzeugten chimären Mäuse können anhand des Chimärismus ihrer Fellfarbe als transgen identifiziert werden. Bei einer Verpaarung der chimären Mäuse mit schwarzen Mäusen weist die Vererbung der Agouti-Fellfarbe eine Keimbahnbeteiligung der injizierten ES-Zellen nach. Die Beteiligung an der Keimbahn wiederum gewährleistet eine Vererbung der genetischen Modifikation an nachfolgende Generationen und macht die Zucht einer neuen Maus-Linie möglich.

Im Gegensatz zu einem klassischen knock-out ist durch das Vorhandensein eines GeneTraps auf Grund der noch immer translatierten Proteinanteile eine Inaktivierung des betreffenden Gens nicht garantiert und muss daher für jedes GeneTrapMausmodell im Einzelnen überprüft werden. 


\subsection{Cathepsin D als möglicher Interaktionspartner des 66.3-kDa- Proteins}

Das lysosomale Protein Cathepsin D als wichtiger Vertreter der lysosomalen Aspartyl-Endopeptidasen hatte sich in Vorarbeiten zu dieser Arbeit als möglicher Interaktionpartner erwiesen und soll deshalb hier etwas genauer beschrieben werden.

Cathepsin D ist ein in der lysosomalen Matrix lokalisiertes Protein, welches die hydrolytische Spaltung von Peptidbindungen katalysiert. Cathepsin D ist eine Endopeptidase und gehört auf Grund der zwei katalytisch aktiven Aspartatreste im aktiven Zentrum zu den Aspartylproteasen. Das aktive Zentrum von Cathepsin D besitzt eine hohe Affinität $\mathrm{zu}$ hydrophoben Aminosäuren. Das pH-Optimum von Cathepsin D liegt bei 3,5 (Bond and Butler 1987). Das N-acylierte Pentapeptid Pepstatin A bindet mit hoher Affinität im aktiven Zentrum von Cathepsin D und inhibiert dessen Funktion (Morishima et al. 1970; Knight and Barrett 1976). Procathepsin D (53 kDa) wird lysosomal sowohl durch Cysteinpeptidasen als auch autoproteolytisch über eine Zwischenstufe (47 kDa) zu nicht-kovalent verknüpftem, enzymatisch aktivem Cathepsin D (31 kDa und 15 kDa) aktiviert (Gieselmann et al. 1983). Neben seiner Funktion als Endopeptidase beim allgemeinen lysosomalen Proteinabbau spielt Cathepsin D eine wichtige Rolle bei der Apoptose.

Auf der einen Seite ist Cathepsin D ein Mediator der durch TNF- $\alpha$, FAS/APO1 und Interferon $y$ induzierten Apoptose und kann bei entsprechender Überexpression in HeLa-Zellen zum früheren Zelltod führen (Deiss et al. 1996). Auf der anderen Seite aber führt die Defizienz von Cathepsin D in Photorezeptorzellen von Cathepsin-Dknock-out-Mäusen zur frühzeitigen Apoptose (Koike et al. 2003). Zudem wurde Cathepsin D hinsichtlich seiner Rolle bei der Proliferation (Glondu et al. 2002), Angiogenese (Berchem et al. 2002) und Metastasierung (Garcia et al. 1990) des Mammakarzinoms eingehend untersucht.

Cathepsin-D-knock-out-Mäuse entwickeln sich bis zur zweiten Lebenswoche normal. Nach 14 Tagen entsteht eine Mukoseatrophie des lleums, die sich zu einer fulminanten, nekrotisierenden Enterokolitis mit vermehrten Thromboembolien entwickelt. Zudem kommt es zu einem nekrotisierenden Abbau von Milz und Thymus 
und einem Verlust von T- und B-Zellen in lymphatischem Gewebe. Die Mäuse sterben mit 26 \pm 1 Tagen an den genannten Pathologien. Cathepsin D scheint damit eine wichtige Rolle bei der Umwandlung der neonatalen zur adulten Schleimhaut zu spielen. Die proteolytische Aktivität von Fibroblasten Cathepsin-D-defizienter Mäuse war nicht eingeschränkt, was darauf schließen lässt, dass die Endopeptidaseaktivität von Cathepsin D von anderen Proteinen übernommen werden kann (Saftig et al. 1995).

Da die Möglichkeit bestand, dass Cathepsin D als Aspartyl-Endopeptidase eine Rolle bei der Prozessierung des 66.3-kDa-Proteins spielt, wurden Prozessierungsversuche mit aufgereinigtem 66.3-kDa-Protein und aktiviertem Cathepsin D durchgeführt. Eine Cathepsin-D-abhängige Prozessierung des 66.3-kDa-Proteins ließ sich dabei allerdings nicht darstellen (Deuschl 2008). 


\section{$2 \quad$ Fragestellung}

In Vorarbeiten zur hier vorliegenden Arbeit wurde eine lysosomale Proteomanalyse durchgeführt, bei der drei potentiell neue lysosomale Proteine beschrieben werden konnten (Kollmann et al. 2005). Eines dieser erstmals beschrieben Proteine war die murine Form des lysosomalen 66.3-kDa-Proteins. Im Anschluss an die Identifizierung des 66.3-kDa-Proteins konnten im Rahmen seiner molekularen Charakterisierung neben dem Prozessierungs- und Glykosylierungsmuster, sowie der lysosomalen Lokalisation, bereits erste Hinweise auf eine Interaktion des 66.3-kDa-Proteins mit der lysosomalen Protease Cathepsin D gefunden werden (Deuschl et al. 2006).

Im ersten Teil dieser Arbeit sollte die bereits vermutete Interaktion des 66.3-kDaProteins mit Cathepsin D genau untersucht werden. Dazu sollten Interaktionsstudien im $\mathrm{Y} 2 \mathrm{H}$-System vervollständigt und weitere Methoden zur Verifizierung dieser Interaktion durchgeführt werden.

Den zweiten Teil der Arbeit sollte die Kristallisation des aufgereinigten, rekombinanten 66.3-kDa-Proteins bilden. Durch die sich anschließende, ausführliche Beschreibung der Kristallstruktur des 66.3-kDa-Proteins und den Vergleich der dreidimensionalen Struktur mit anderen, bereits bekannten Proteinen sollte eine mögliche physiologische Funktion des 66.3-kDa-Proteins abgeleitet und in biochemischen Analysen nachgewiesen werden.

Im dritten und letzten Teil sollte anhand einer Transkriptomanalyse ein 66.3-kDaGeneTrap-Mausmodell charakterisiert und eine mögliche Beeinflussung des Genoms bzw. Proteoms durch den GeneTrap bzw. durch die fehlende enzymatische Funktion des 66.3-kDa-Proteins dargestellt werden. 


\section{Material und Methoden}

\subsection{Material}

\subsubsection{Geräte}

\subsubsection{Allgemeine Geräte}

ABI Prism 7900HT (Real-Time-Cycler)

Acrylamidgel-Elektrophoresekammer

Agarosegel-Elektrophoresekammer

Analysewaage Modell 1602 MP

Autoklav Modell Tecnoclav 50

Biocad-Vision ${ }^{\circledR}$ Workstation HPLC System

Bio-Photometer

Branson Sonifier 450

CCD-Kamera LAS-1000

Digitales $\mathrm{pH}$-Meter

Drehrad für Eppendorfgefäße

Eismaschine Modell Scotsman MF 30

Filterscheibe (B270)

Flüssigkeitsszintillationszähler 1900TR

Geltrockner Modell Gel Air Dryer

GeneChip Hybridizatio Oven 640

GeneChip Scanner 3000

Heizblock HTM 130

Inkubationsschüttler Modell G25

Mastercycler Gradient

Phegasus Semi-Dry Western-Blot-Kammer

Phosphoimager PMI
Applied Biosystems, Framingham, USA

Werkstatt des Instituts

Werkstatt des Instituts

Sartorius, Göttingen

Tecnomara AG, Zürich, Schweiz

Applied Biosystems,

Eppendorf, Hamburg

Heinemann, Schwäbisch Gmünd

Fujifilm, Tokyo, Japan

Schütt, Göttingen

Eigenbau, Werkstatt des Instituts

Frimont, Mailand, Italien

MPI für Experimentelle Medizin,

Göttingen

Packard, Perkin Elmer, Überlingen

Framingham, USA

Biorad, München

Affymetrix, Santa Clara, USA

Affymetrix, Santa Clara, USA

HLC, Bovenden

New Brunswick Scientific, Edison, USA

Eppendorf, Hamburg

Phase, Lübeck

Biorad, München 
Pipetman Mikroliterpipetten 20, 200, $1000 \mu \mathrm{l}$

Reflex III-Flugzeit Massenspektrometer

SMART ${ }^{\text {TM }}$ HPLC System

Spectrophotometer Cary 50 Bio

Spectrophotometer NanoVue

Tecan Microplate Reader Model Spectra II

Teflon-Homogenisator

Typhoon 9400 Scanner

UV-Handlampe (312 nm, $254 \mathrm{~nm}$ )

UV-Lampe (Ultratech 400)

UV-Transilluminator Modell ETX $20 \mathrm{M}$

Vakuumkonzentrator

Modell Speed Vac SVC100H

\subsubsection{Zentrifugen und Rotoren}

Kühlzentrifuge 5804R mit Rotor A-4-44

Labofuge GL

Tischkühlzentrifuge Mikro 200R

Tisch-Ultrazentrifuge Modell TL-100

mit Rotor TLA-45

Tischzentrifuge 5415D

Ultrazentrifuge Modell Optima L90K mit

Rotoren Ti 75 und SW 40

\subsubsection{Verbrauchsmaterialien}

Dialyseschlauch Type 8, cut-off: 12-16 kDa, Biomol, Hamburg Porengröße 25A

Einfrierröhrchen

Einmalkanülen,-spritzen

Einmalpipetten 5, 10, $20 \mathrm{ml}$

Gewebekulturflaschen, -schalen

Glaswaren für Labor

384-Lochplatten

5-ml-Mobitec-Säule
Gilson, Middleton, USA

Brunker Daltonik, Bremen

Pharmacia, Uppsala, Schweden

Varian, Darmstadt

GE Healthcare, München

Tecan, SLT, Crailsheim

Braun, Melsungen

GE Healthcare, München

Bachofer, Reutlingen

MPI für Experimentelle Medizin,

Göttingen

LTF Labortechnik, Wasserburg

Bachofer, Reutlingen

Eppendorf, Hamburg

Heraeus Spatech, Osterode

Hettich Zentrifugen, Tuttlingen

Beckmann Coulter, Krefeld

Eppendorf, Hamburg

Beckmann Coulter, Krefeld
Nunc, Wiesbaden

Braun, Melsungen

Sarstedt, Nümbrecht

Greiner, Nürtingen

Schott, Mainz

Gilson, Middleton, USA

Eppendorf, Hamburg 
Pasteurpipetten

Plastikreaktionsgefäße

Polyvinylidenfluorid (PVDF) -

Transfermembran

Spritzenaufsatzfilter $0,2 \mu \mathrm{m}$ und $0,45 \mu \mathrm{m}$

Ultrazentrifugenröhrchen Ti75

UVetten $^{\circledR}$

Whatman-Filterpapier

Zellschaber

ZipTipC18 Pipettenspitzen

\subsubsection{Chemikalien}

Acetat

Acetonitril

Acrylamid/Bisacrylamid-Lösung

(Rotiphorese $^{\circledR}$-Gel 30)

Adeninhemisulfat

Agar

Agarose

Albumin (BSA, bovine serum albumin)

Ameisensäure

$\varepsilon$-Aminocapronsäure

Ammoniumacetat

Ammoniumhydroxid

Ammoniumperoxodisulfat (APS)

Ammoniumsulfat

Ampicillin

$\beta$-Mercaptoethanol

Bromphenolblau

Chloramphenicol

Coomassie Brilliant Blue G250

Diethylpyrocarbonat (DEPC)

Diethylether
Schütt, Göttingen

Sarstedt, Nümbrecht

Whatman, Göttingen

Fujifilm, Düsseldorf

Heinemann, Duderstadt

Beckmann Coulter, Krefeld

Eppendorf, Hamburg

Whatman, Göttingen

Sarstedt, Nümbrecht

Millipore, Schwalbach

Roth, Karlsruhe

Sigma, Deisenhofen

Roth, Karlsruhe

Sigma, Deisenhofen

Roth, Karlsruhe

Roth, Karlsruhe

Serva, Heidelberg

Merck, Darmstadt

Roth, Karlsruhe

Merck, Darmstadt

Roth, Karlsruhe

Merck, Darmstadt

Merck, Darmstadt

Serva, Heidelberg

Merck, Darmstadt

Merck, Darmstadt

Sigma, Deisenhofen

Merck, Darmstadt

Roth, Karlsruhe

Sigma, Deisenhofen 
2,5-Dihydroxybenzoesäure (DHB)

Dimethylsulfoxid (DMSO)

Dinatriumhydrogenphosphat

Dinatriummethylendiaminotetraacetat (EDTA)

Dithiothreitol (DTT)

Essigsäure

Ethanol

Ethidiumbromid (1\% (w/v) Lösung)

Ethylacetat

Formaldehydlösung (37\%)

Formamid

Glucose

Glutaraldehyd (25\% (v/v) in $\left.\mathrm{dH}_{2} \mathrm{O}\right)$

Glycerin

Glycin

Harnstoff

Hefeextrakt

Hering-Sperma-DNA

4-(2-Hydroxyethyl)-piperazin-1-

ethansulfonsäure (HEPES)

Imidazol

Iodacetamid

Isopropanol

Kaliumchlorid

Lithiumacetat

Magermilchpulver

Magnesiumchlorid

Magnesiumsulfat $\left(\mathrm{MgSO}_{4}\right)$

Methanol

Natriumacetat

Natriumazid

Natriumcarbonat

Natriumchlorid

Natriumcitrat
Sigma, Deisenhofen

Merck, Darmstadt

Roth, Karlsruhe

Roth, Karlsruhe

Roth, Karlsruhe

Roth, Karlsruhe

Roth, Karlsruhe

Roth, Karlsruhe

Roth, Karlsruhe

Merck, Darmstadt

Merck, Darmstadt

Roth, Karlsruhe

Serva, Heidelberg

Roth, Karlsruhe

Roth, Karlsruhe

Serva, Heidelberg

Roth, Karlsruhe

Sigma, Deisenhofen

Serva, Heidelberg

Merck, Darmstadt

Sigma, Deisenhofen

Roth, Karlsruhe

Roth, Karlsruhe

Sigma, Deisenhofen

Töpfer, Dietmannsried

Merck, Darmstadt

Merck, Darmstadt

Roth, Karlsruhe

Merck, Darmstadt

Merck, Darmstadt

Merck, Darmstadt

Roth, Karlsruhe

Merck, Darmstadt 
Natriumdesoxycholat

Natriumdihydrogenphosphat

Natriumdodecylsulfat (SDS)

Natriumhydroxid

Natriumthiosulfatpentahydrat

Natriumphosphat

2-(N-Morpholino)-Propansulfonsäure (MES)

3-(N-Morpholino)-Propansulfonsäure (MOPS)

NNN'N'-Tetramethylethylendiamin (TEMED)

Nonidet P-40 (NP-40)

o-Nitrophenyl- $\beta$-D-galaktopyranosid (ONPG)

Pepton

Percoll ${ }^{\mathrm{TM}}$

Phenolrot

Phenylalanin

Phosphorsäure (ortho-)

Polyethylenglykol 7500 (PEG)

Protaminsulfat

Protein-A-Sepharose

Protein-G-Sepharose

Saccharose (Sucrose)

Salzsäure (37\%)

Silbernitrat

Stickstoff

Sorbitol

SYBR-green ${ }^{\circledR}$

Trichlormethan (Chloroform)

Trifluoressigsäure (TFA)

Tris-(hydroxymethyl)-aminomethan (TRIS)

Triton X-100

Tween 20

Tyloxapol (Triton WR-1339)

Tyrosin

Wasser, reinst
Serva, Heidelberg

Merck, Darmstadt

Roth, Karlsruhe

Roth, Karlsruhe

Merck, Darmstadt

Merck, Darmstadt

Serva, Heidelberg

Serva, Heidelberg

Serva, Heidelberg

Sigma, Deisenhofen

Sigma, Deisenhofen

Roth, Karlsruhe

GE Healthcare, München

Merck, Darmstadt

Roth, Karlsruhe

Sigma, Deisenhofen

Serva, Heidelberg

GE Healthcare, München

GE Healthcare, München

Roth, Karlsruhe

Roth, Karlsruhe

Roth, Karlsruhe

Messer Griesheim, Siegen

Merck, Darmstadt

BioRad, München

Roth, Karlsruhe

Merck, Darmstadt

Roth, Karlsruhe

Serva, Heidelberg

Roth, Karlsruhe

Sigma, Deisenhofen

Baker, Deventer, Niederlande 
Yeast- $\mathrm{N}_{2}$-Base

Roth, Karlsruhe

\subsubsection{Kits zur Bearbeitung von RNA, DNA und Proteinen}

BigDye ${ }^{\circledR}$ Terminator v3.1 Cycle

Sequencing Kit

BioRad DC Protein Assay

iScript ${ }^{\mathrm{TM}}$ CDNA Synthesis Kit

FideliTaq ${ }^{\mathrm{TM}}$ DNA Polymerase

MessageAmp ${ }^{\mathrm{TM}}$ II-Biotin enhanced Kit

Omniscript ${ }^{\circledR}$ Reverse Transcriptase Kit

Plasmid Midi Kit

Plasmid Mini Kit

QIAquick ${ }^{\circledR}$ Gel Extraction Kit

RNeasy ${ }^{\circledR}$ Midi Kit

Supersignal West Pico Chemiluminescent -

Substrate

Taq DNA-Polymerase Kit
Applied Biosystems, Foster City, USA

BioRad, Hercules, Kalifornien

BioRad, Hercules, Kalifornien

USB, Staufen

Ambion, Austin, USA

Qiagen, Hilden

Qiagen, Hilden

Qiagen, Hilden

Qiagen, Hilden

Qiagen, Hilden

Pierce, Rockford, USA

Roche Applied Science, Indian., USA

\subsubsection{Enzyme zur Bearbeitung von DNA, RNA und Proteinen}

Platinum ${ }^{\circledR}$ Pfx-DNA-Polymerase

Restriktionsendonukleasen

Trypsin, modifiziert aus Rinderpankreas

T4-DNA-Ligase

USB-Taq DNA-Polymerase
Invitrogen, Karlsruhe

NEB, Frankfurt am Main

Serva, Heidelberg

NEB, Frankfurt am Main

Affymetrix, Santa Clara, USA

\subsubsection{Proteaseinhibitoren und Proteinstandards}

Dinatriummethylendiaminotetraacetat (EDTA) Roth, Karlsruhe

lodacetamid (IAA)

Sigma, Deisenhofen

Pepstatin A

Biomol GmbH, Hamburg

Phenylmethylsulfonylfluorid (PMSF)

Roth, Karlsruhe

Precision Plus Protein All Blue Standard

BioRad, München

Proteaseinhibitorenmix

Sigma, Deisenhofen 


\subsubsection{Quervernetzer}

Alle Quervernetzer wurden von Pierce Biotechnology, Rockford, USA bezogen.

EDC (1-ethyl-3-[3-dimethylaminopropyl]carbodiimid hydrochlorid)

SPDP (N-succinimidyl 3-(2-pyridyldithio) propionat)

Sulfo-DST (Sulfodisuccinimidyl-tartrat)

Sulfo-NHS (Sulfosuccinimidyl-6-(biotin-amido) hexanoate)

\subsubsection{Verwendete Antikörper}

\subsubsection{Primärantikörper}

Tab. 3.1: Verwendete Primärantikörper

\begin{tabular}{|c|c|c|c|c|}
\hline Name & $\begin{array}{l}\text { Antigen, } \\
\text { (H.-Name) } \\
\text { Ag-Spezies }\end{array}$ & $\begin{array}{l}\text { immun. } \\
\text { Spezies }\end{array}$ & Anwendung* & Referenz \\
\hline$\alpha$-Scpep1-D2 & Scpep1, murin & $\begin{array}{l}\text { Kaninchen, } \\
\text { polyklonal }\end{array}$ & WB 1:1000 & $\begin{array}{l}\text { Eigene Produktion } \\
\text { (Kollmann et al. 2009) }\end{array}$ \\
\hline$\alpha-H i s$ & RGS-His6-Epitop & $\begin{array}{l}\text { Maus, } \\
\text { monoklonal }\end{array}$ & WB 1:3000 & $\begin{array}{l}\text { Qiagen, Hilden, } \\
\text { (Preusser-Kunze et al. } \\
\text { 2005) }\end{array}$ \\
\hline 66-Antiserum & $\begin{array}{l}\text { 66.3-kDa-Protein, } \\
\text { murin }\end{array}$ & $\begin{array}{l}\text { Kaninchen, } \\
\text { polyklonal }\end{array}$ & WB 1:1000 & $\begin{array}{l}\text { Eigene Produktion } \\
\text { (Deuschl et al. 2006) }\end{array}$ \\
\hline$\alpha$-CatD & $\begin{array}{l}\text { CatD (KIIS5), } \\
\text { murin }\end{array}$ & $\begin{array}{l}\text { Kaninchen, } \\
\text { polyklonal }\end{array}$ & $\begin{array}{l}\text { WB 1:1000 } \\
\text { IP 1:100 }\end{array}$ & $\begin{array}{l}\text { Produktion Institut } \\
\text { (Braulke et al. 1987) }\end{array}$ \\
\hline
\end{tabular}

*= WB=Western-Blot; IP =Immunpräzipitation

\subsubsection{Sekundärantikörper für Western-Blot-Analyse}

Sekundärantikörper für die Analyse im Western-Blot wurden routinemäßig in einer Verdünnung von 1:5000 eingesetzt.

Ziege anti Kaninchen, HRP konjugiert

Ziege anti Maus, HRP konjugiert

\subsubsection{Radioaktive Substanzen}

$\left[{ }^{14} \mathrm{C}\right]$-Arachidonsäure

$\left[{ }^{14} \mathrm{C}\right]$-Ethanolamin $100 \mu \mathrm{Ci} / \mathrm{ml}$

$\left[{ }^{14} \mathrm{C}\right]$-Laurinsäure
Dianova, Hamburg

Dianova, Hamburg
Nu-Chek-Prep Inc., Elysian,

Minnesota, USA

Hartmann Analytic GmbH,

Braunschweig

GE Healthcare, München 
$\left[{ }^{14} \mathrm{C}\right]$-Myristinsäure

$\left[{ }^{14} \mathrm{C}\right]$-Ölsäure

$\left[{ }^{14} \mathrm{C}\right]$-Palmitinsäure

$\left[{ }^{14} \mathrm{C}\right]$-Stearinsäure
Moravek Biochemicals, Brea, Carlifornien, USA

GE Healthcare, München

PerkinElmer, Waltham, Massachusetts, USA

GE Healthcare, München

\subsubsection{Säulen und Säulenfüllmaterial}

Ni-NTA-Agarose

Pepstatin-A-Agarose

Poros $20 \mathrm{HQ} / \mathrm{M}$ Anionenaustauscher

Superdex 200 HR 10/30
Qiagen, Hilden

Pierce, Rockford, USA

Applied Biosystems, Foster City, USA

GE Healthcare, Chalfont St. Giles, Großbritannien

\subsubsection{Vektoren, Oligonucleotidprimer und DNA/ RNA-Standards}

pcDNA3.1/Hygro (+)

pGADT7

pGBKT7

pGEM-T easy
Invitrogen, Karlsruhe

Clontech, Palo Alto, Kalifornien, USA

Clontech, Palo Alto, Kalifornien, USA

Promega, Madison, Wisconsin, USA

Primer wurden von der Firmen IBA (Göttingen) und Metabion (Göttingen) mit folgenden Spezifikationen bezogen: 0,02 $\mu \mathrm{mol} ; 100 \mathrm{pmol} / \mu \mathrm{l}$; entsalzt.

0,5-10-kb-RNA-Ladder

Tracklt 1kb Plus DNA Ladder
Invitrogen, Karlsruhe

Invitrogen, Karlsruhe

\subsubsection{Häufig verwendete Puffer und Lösungen}

$10 \times$ PBS:

$80 \mathrm{~g} \mathrm{NaCl}$

$2 \mathrm{~g} \mathrm{KCl}$

$14,4 \mathrm{~g} \mathrm{Na}_{2} \mathrm{HPO}_{4}$

$2,4 \mathrm{~g} \mathrm{KH}_{2} \mathrm{PO}_{4}$

mit $\mathrm{dH}_{2} \mathrm{O}$ auf $1 \mathrm{I}$ auffüllen, pH 6,8, autoklavieren 
$10 \times$ TBS

$10 \times$ TE-Puffer:
$100 \mathrm{mM}$ TRIS/HCl pH 7,4

\section{$1,5 \mathrm{M} \mathrm{NaCl}$}

$100 \mathrm{mM}$ TRIS/HCl pH 7,6

10 mM EDTA

\subsubsection{Medien zum Arbeiten mit eukaryontischen Zellkulturen}

PBS (für Zellkultur)

Dulbecco's Modified Eagle Medium (DMEM)

DMEM (ohne AS Leucin und Methionin)

L-Photo-Leucin

L-Photo-Methionin

Fötales Kälberserum (FKS)

MEM Non-Essential Amino Acids

(10 mM Solution, $100 \times$, liquid)

L-Glutamin (200 mM) (100 × Stocklösung)

Penicillin/Streptomycin (100 × Stocklösung)

Hygromycin B

0,05 \% (w/v) Trypsin-EDTA-Lösung

FuGENE $^{\text {TM }}$ Transfektionsreagenz
$40 \mathrm{~g} \mathrm{NaCl}, 1 \mathrm{~g} \mathrm{KCl}, 7,2 \mathrm{Na}_{2} \mathrm{HPO}_{4}$

$2 \mathrm{H}_{2} \mathrm{O}, 1 \mathrm{~g} \mathrm{K \textrm {K } _ { 2 }} \mathrm{PO}_{4}, 0,1 \mathrm{~g}$ Phenolrot

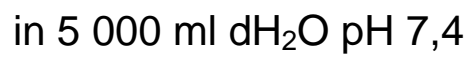

Gibco Invitrogen, Karlsruhe

Pierce, Rockford, USA

Pierce Biotechnology, Rockford, USA

Pierce Biotechnology, Rockford, USA

PAN, Aidenbach

Gibco Invitrogen, Karlsruhe

Gibco Invitrogen, Karlsruhe

Gibco Invitrogen, Karlsruhe

Calbiochem, Frankfurt

Gibco Invitrogen, Karlsruhe

Roche Applied Science, USA 


\subsubsection{Zelllinien in Kultur}

Tab. 3.2: Verwendete eukaryontische Zelllinien

\begin{tabular}{|c|c|c|}
\hline Zelllinie & Beschreibung & Referenz \\
\hline HT1080 & Humane Fibrosarkom-Zelllinie & $\begin{array}{l}\text { Erworben bei Stratagene, } \\
\text { La Jolla, USA, (Roeser et } \\
\text { al. 2006) }\end{array}$ \\
\hline НT1080-66 & 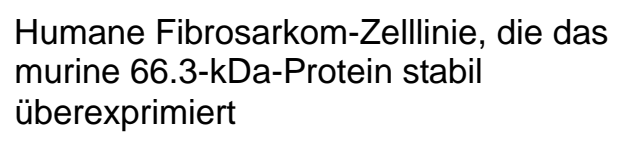 & Eigene Produktion \\
\hline HT1080-66-Cat. D & $\begin{array}{l}\text { Humane Fibrosarkom-Zelllinie, die } \\
\text { sowohl das murine 66.3-kDa-Protein } \\
\text { als auch das murine Cathepsin D stabil } \\
\text { überexprimiert }\end{array}$ & Eigene Produktion \\
\hline HeLa & $\begin{array}{l}\text { Humane epitheloid cervix carcinoma } \\
\text { Zelllinie }\end{array}$ & $\begin{array}{l}\text { European Collection of } \\
\text { Cell Cultures (ECACC) }\end{array}$ \\
\hline HEK 293T & $\begin{array}{l}\text { Human embryonic kidney 293-Zellen, } \\
\text { die das large T-Antigen (SV40) stabil } \\
\text { exprimieren }\end{array}$ & (Graham et al. 1977) \\
\hline MEF-66gt & $\begin{array}{l}\text { Primäre embryonale Mausfibroblasten } \\
\text { des } 66 \text { gt-Mausmodells }\end{array}$ & $\begin{array}{l}\text { Eigene Präparation, aus } \\
66 g t-\text { Embryonen Tag 12,5 } \\
\text { post conceptionem }\end{array}$ \\
\hline RST 426 +/+ MEF & $\begin{array}{l}\text { Primäre embryonale Mausfibroblasten, } \\
\text { Kontrolle zu Scpep1-GeneTrap }\end{array}$ & $\begin{array}{l}\text { Eigene Präparation, aus } \\
\text { RST426 Embryonen Tag } \\
12,5 \text { post conceptionem }\end{array}$ \\
\hline RST 426 -/- MEF & $\begin{array}{l}\text { Primäre embryonale Mausfibroblasten, } \\
\text { Scpep1-GeneTrap }\end{array}$ & $\begin{array}{l}\text { Eigene Präparation, aus } \\
\text { RST426 Embryonen Tag } \\
\text { 12,5 post conceptionem }\end{array}$ \\
\hline
\end{tabular}

\subsubsection{Microarrays}

Whole Mouse Genome Microarray G4122F

Agilent Technologies, Santa Clara, USA

\subsubsection{EDV}

\section{Software:}

Adobe Acrobat Professional 9.3.0

AIDA Image analysing software

Corel Draw - Graphic Suite 11.0

EndNote X2.0.1

FinchTV 1.4

GraphPad Prism 4.00

Image Reader LAS
Adobe, San Jose, USA

Fujifilm, Düsseldorf

Corel Corporation, Ottawa, Kanada

Thomson Reuters, Carlsbad, USA

Geospiza, Seattle, USA

GraphPad Software, La Jolla, USA

Fujifilm, Düsseldorf 
Image J $1.42 q$

Microsoft Office Standard Edition 2003

Mozilla Firefox 3.6

Sequence Detection System 2.2.1

Vektor NTI Suite 10.3.0

Windows XP Home

\section{Hardware:}

Drucker HP LaserJet 1020

Laptop (A9Rp) Intel Celeron M
NIH, Washington, USA

Microsoft, Redmond, USA

Mozilla Foundation,

Mountain View, USA

Applied Biosystems, Forster City, Kalifornien, USA

Invitrogen, Karlsruhe

Microsoft, Redmond, USA

Hewlett\&Packard, Palo Alto, USA

ASUSTeK Computer, Taiwan

\section{Online-Programme/Datenbanken:}

BayGenomics

Blast

DALI-Server

ELM

Ensembl

EXPASY

MASCOT Search

MEROPS

NCBI Datenbanken

PFAM

Primer3

SwissModel http://www.genetrap.org/

http://www.ncbi.nlm.nih.gov/blast/Blast.cgi

http://ekhidna.biocenter.helsinki.fi/dali_server/

http://elm.eu.org/links.html

http://www.ensembl.org

http://www.expasy.ch/

http://www.matrixscience.com/search_form_select.html http://merops.sanger.ac.uk/

http://www.ncbi.nlm.nih.gov/

http://www.sanger.ac.uk/Software/Pfam/

http://frodo.wi.mit.edu/

http://swissmodel.expasy.org/ 


\subsection{Molekularbiologische Methoden}

\subsubsection{Allgemeine Methoden zum Arbeiten mit DNA und RNA}

Die folgenden Methoden und Vorschriften wurden, soweit nicht anders angegeben, dem Laborhandbuch Molecular Cloning (Sambrook et al. 1989) entnommen.

\subsubsection{Isolierung von RNA}

Zur Isolierung von RNA aus Mausgewebe wurde das RNeasy ${ }^{\circledR}$ Midi Kit (Qiagen, Hilden) verwendet. Die Präparation erfolgte nach dem Herstellerprotokoll (RNeasy ${ }^{\circledR}$ Handbook, 2001). Zur RNA-Präparation wurde jeweils 200 mg frisch entnommenes Mauslebergewebe eingesetzt.

\subsubsection{Konzentrationsbestimmung von DNA und RNA}

Zur Konzentrationsbestimmung von DNA und RNA in wässriger Lösung erfolgte eine photometrische Messung der Absorption bei $260 \mathrm{~nm}$ gegen $\mathrm{dH}_{2} \mathrm{O}$. Eine $\mathrm{OD}_{260 \mathrm{~nm}}$ von 1 entspricht einer DNA-Konzentration von $50 \mu \mathrm{g} / \mathrm{ml}$ oder einer RNA-Konzentration von $40 \mu \mathrm{g} / \mathrm{ml}$. Die Messung wurde am Bio-Photometer (Eppendorf, Hamburg) in einer Eppendorf UVette ${ }^{\circledR}$ durchgeführt.

\subsubsection{DNA-Amplifikation über Polymerase-Ketten-Reaktion}

Die Polymerase-Ketten-Reaktion (PCR) ist eine Methode zur Amplifikation von definierten DNA-Bereichen. In einem zyklischen Prozess aus Denaturierung des DNA-Doppelstrangs, Anlagerung von spezifischen Oligonukleotid-Primern (Annealing) und Synthese des komplementären DNA-Strangs mittels DNAPolymerase (Elongation) wird ein spezifischer DNA-Abschnitt exponentiell vermehrt. Dabei wird die Synthesereaktion durch Auswahl und Konzentration der Primer, die Qualität des Templates, die Pufferbedingungen, sowie die Zeiten und Temperaturen der einzelnen Zyklusschritte beeinflusst. Als DNA-Template für die PCR dienten Plasmid-DNA und cDNA nach reverser Transkription von RNA. Zur Klonierung von Vektoren wurde die Platinum ${ }^{\circledR}$ Pfx-DNA-Polymerase (Invitrogen, Karlsruhe) verwendet. Zur analytischen PCR und zur Subklonierung wurde die USB-TaqDNA-Polymerase (Affymetrix, Santa Clara, USA), sowie die mitgelieferten Puffer und dNTPs verwendet. 
PCR-Ansatz:

100 - 250 ng DNA-Template

$5 \mu \mathrm{l} 10 \times$ PCR Reaktionspuffer

$1 \mu \mathrm{d}$ dNTP - Mix (10 mM)

$2 \mu \mathrm{l} 10$ MM Primer (3'-terminal)

$2 \mu \mathrm{l} 10 \mu \mathrm{M}$ Primer (5'-terminal)

0,5-1 $\mu \mathrm{l}$ Taq DNA-Polymerase (5 U/ $\mu \mathrm{l})$

mit $\mathrm{dH}_{2} \mathrm{O}$ auf $50 \mu$ auffüllen.

PCR-Reaktionsprotokoll:

\begin{tabular}{cc}
2 min & $95^{\circ} \mathrm{C}$ \\
\hline $30 \times \quad 30$ sek & $95^{\circ} \mathrm{C}$ \\
60 sek & $55^{\circ} \mathrm{C}$ \\
$1-3 \min$ & $72^{\circ} \mathrm{C}$ \\
\hline $10 \min$ & $72^{\circ} \mathrm{C}$
\end{tabular}

\subsubsection{DNA-Sequenzierung}

Zur Sequenzierung von DNA-Abschnitten wurde das BigDye ${ }^{\circledR}$ Terminator v3.1 Cycle Sequencing Kit (Applied Biosystems, Foster City, USA) verwendet. Der Sequenzierungspremix enthält alle Komponenten für eine fluoreszenzbasierte Sequenzierungsreaktion. Die Reaktion erfolgte in einem $10 \mu \mathrm{l}$ Ansatz.

Sequenzierungsansatz:

200 - 400 ng Template (dsDNA)

$1 \mu$ Sequenzierungspremix

1,5 $\mu$ l Sequenzierungspuffer

$1 \mu \mathrm{l} 10 \mu \mathrm{M}$ Sequenzierungsprimer

mit $\mathrm{dH}_{2} \mathrm{O}$ auf $10 \mu$ auffüllen.

Sequenzierungsprotokoll:

$$
\begin{array}{r}
25 \times \quad 10 \text { sek } 96^{\circ} \mathrm{C} \\
15 \text { sek } 55^{\circ} \mathrm{C} \\
4 \min \quad 60^{\circ} \mathrm{C} .
\end{array}
$$

Die Sequenzierungsreaktion wurde anschließend aufgereinigt. Dazu wurden dem Ansatz $1 \mu \mathrm{l} 125$ mM EDTA und $1 \mu \mathrm{l} 3 \mathrm{M}$ Natriumacetat zugesetzt. Die DNA wurde mit $50 \mu 100 \%$ Ethanol gefällt und nach 5 min für 15 min bei 14000 rpm pelletiert. Der Überstand wurde abgenommen. Das Pellet wurde mit $70 \mu \mathrm{l} 70 \%$-igem Ethanol 
gewaschen. Nach 5 min Zentrifugation bei $14000 \mathrm{rpm}$ wurde der Überstand abgenommen, das Pellet wurde bei $37^{\circ} \mathrm{C}$ vollständig getrocknet und in $15 \mu \mathrm{l}$ Formamid aufgenommen. Die elektrophoretische Analyse des Sequenzierungsansatz erfolgte als Service in der Abteilung Entwicklungsbiochemie am ABI PRISM ${ }^{\circledast} 3100$ Genetic Analyzer.

\subsubsection{Spaltung von DNA mit Restriktionsendonukleasen}

Restriktionsendonukleasen erkennen ihre Schnittstellen an spezifischen Basensequenzen und spalten die DNA nach einem ebenso spezifischen Mechanismus. Die Aktivität von Restriktionsendonukleasen wird in Units (U) angegeben. Eine Unit entspricht der Menge an Restriktionsenzym, die benötigt wird, um $1 \mu \mathrm{g}$ DNA in einer Stunde vollständig zu schneiden. Zur Spaltung von DNA wurden Restriktionsenzyme der Firma New English Biolabs (NEB, Frankfurt am Main) verwendet. Das NEB Restriktionspuffer-System besteht aus enzymspezifischen Puffern, sowie aus vier NEB Basispuffern. Für einen Restriktionsverdau von Plasmid-DNA wurden $1 \mu \mathrm{g}$ DNA eingesetzt.

Restriktionsansatz:

$1 \mu \mathrm{g}$ Plasmid-DNA

$2 \mu$ empfohlener NEB $10 \times$ Puffer

$2 \cup$ Restriktionsendonuklease

auf $20 \mu \mathrm{l}$ mit $\mathrm{dH}_{2} \mathrm{O}$ auffüllen.

Der Ansatz wurde für $2 \mathrm{~h}$ oder über Nacht bei $37^{\circ} \mathrm{C}$ inkubiert. Anschließend wurden die DNA-Fragmente durch Auftrennung im Agarosegel analysiert.

\subsubsection{Auftrennung von DNA in Agarosegelen}

$50 \times$ TAE-Puffer:

2 M TRIS/Essigsäure $\mathrm{pH} 8,0$ 100 mM EDTA

Proben-Ladepuffer: $0,25 \%$ (w/v) Bromphenolblau $40 \%(w / v)$ Sucrose in $1 \times$ TAE

Zur Analyse und Isolierung von DNA-Fragmenten unterschiedlicher Größe erfolgte ihre Auftrennung durch Agarosegel-Elektrophorese, wobei die Agarose- 
Konzentration der Gele je nach gewünschtem Trennbereich variiert wurde (vgl. Tab. 3.3). Entsprechend der Größe der zu trennenden DNA-Fragmente wurde Agarose in $350 \mathrm{ml} 1 \times$ TAE-Puffer eingewogen und in der Mikrowelle aufgekocht. Nach Erkalten der Agarose-Lösung auf maximal $60{ }^{\circ} \mathrm{C}$ wurden $0,5 \mu \mathrm{g} / \mathrm{ml}$ Ethidiumbromid zugesetzt. Die Lösung wurde in eine Gelform gegossen und bei RT weiter abgekühlt. Die horizontale Elektrophoresekammer wurde mit TAE-Puffer gefüllt und das erstarrte Gel wurde in die Kammer überführt. Die DNA-Proben wurden mit 10-20\% Probenpuffer versetzt und in die Geltaschen pipettiert. Die Elektrophorese erfolgte mit einer Spannung von 3-4 V/cm. Das Ethidiumbromid interkaliert während der Elektrophorese in das DNA-Molekül. Die aufgetrennten DNA-Fragmente werden unter UV-Licht als Banden sichtbar. Auf dem UV-Transilluminator wurde das Gel analysiert und zur Dokumentation mit einem Video-System (Biometra) aufgenommen.

Tab. 3.3: Agarose-Konzentration und Trennbereich bei DNA-Agarose-Gelelektrophorese

\begin{tabular}{cc}
\hline Agarose-Konz. (\% w/v) & Trennbereich $(\mathbf{k b})$ \\
\hline 0,6 & $20-1$ \\
0,9 & $7-0,5$ \\
1,2 & $6-0,4$ \\
1,5 & $4-0,2$ \\
2,0 & $3-0,1$ \\
\hline
\end{tabular}

\subsubsection{Isolierung von DNA aus Agarosegelen}

Zur Isolierung von DNA-Fragmenten aus Agarosegelen wurde das QIAquick $^{\circledR}$ Gel Extraction Kit (Qiagen, Hilden) verwendet. Die DNA-Bande wurde unter UV-Licht (UV-Handlampe) mit einem Skalpell ausgeschnitten und gewogen. Anschließend erfolgte die DNA-Isolierung nach dem Herstellerprotokoll (QIAquick ${ }^{\circledR}$ Spin Handbook, 2006).

3.2.1.8 Auftrennung von RNA in Agarosegelen

DEPC-Wasser:

$0,1 \%$ DEPC (Diethylpyrocarbonat)

in $\mathrm{dH}_{2} \mathrm{O}$, über Nacht rühren, autoklavieren.

$10 \times$ MOPS-Laufpuffer:

$200 \mathrm{mM}$ MOPS

$50 \mathrm{mM}$ Natriumacetat 
10 mM EDTA

einstellen von $\mathrm{pH}$ 7,0 mit $\mathrm{NaOH}$.

$5 \times$ RNA Ladepuffer:

$16 \mu$ l gesättigte Bromphenolblaulösung in $\mathrm{dH}_{2} \mathrm{O}$

$80 \mu \mathrm{l} 800 \mathrm{mM}$ EDTA

$720 \mu \mathrm{l} 37 \%$ Formaldehyd

$2 \mathrm{ml}$ Glycerin

$3084 \mu$ Formamid

$4 \mathrm{ml} 10 \times$ MOPS-Laufpuffer

mit DEPC-Wasser auf $10 \mathrm{ml}$ auffüllen.

RNA-Gel:

9 Teile DEPC-Wasser

1 Teil $10 \times$ MOPS-Laufpuffer

$2 \%$ Agarose

aufkochen, auf $65^{\circ} \mathrm{C}$ abkühlen lassen

1,6 \% (v/v) einer 37\%-igen Formaldehyd-

Lösung

$1 \mu \mathrm{g} / \mathrm{ml}$ Ethidiumbromid.

Zur qualitativen Analyse von extrahierter RNA erfolgte eine Auftrennung der RNA durch Formaldehyd-Agarosegel-Elektrophorese. Alle verwendeten Materialien wurden vor Verwendung mindestens $30 \mathrm{~min}$ in $1 \mathrm{M} \mathrm{NaOH}$ eingelegt und anschließend mit $\mathrm{dH}_{2} \mathrm{O}$ gespült. Die RNA wurde mit Ladepuffer versetzt und bei $65^{\circ} \mathrm{C} 5 \mathrm{~min}$ erhitzt. Die Proben wurden auf das Formaldehyd-Agarosegel aufgetragen und bei $40 \mathrm{~mA} 6-7 \mathrm{~h}$ aufgetrennt. Die aufgetrennte RNA wird unter UV-Licht sichtbar. Auf dem UV-Transilluminator wurde das Gel analysiert und zur Dokumentation mit einem Video-System (Biometra) aufgenommen.

\subsubsection{Ligation von DNA-Fragmenten}

Das Enzym Ligase katalysiert die Verknüpfung freier 3'-Hydroxy- und 5'-PhosphatEnden von Nukleinsäuren zu Phosphodiesterbindungen. Durch die Ligation können DNA-Fragmente in Vektoren integriert werden. Mit Restriktionsendonukleasen wurden der Klonierungsvektor und die zu integrierende cDNA gespalten. Die DNAFragmente wurden im Agarosegel aufgetrennt und aus dem Gel isoliert. 
Anschließend konnten die kohäsiven Enden von Vektor-DNA und cDNA durch Ligation verknüpft werden.

Es wurden 100 ng Vektor und ein 2- bis 3-molarer Überschuss an cDNA eingesetzt. Zur Ligation wurde die T4-DNA-Ligase (NEB, Frankfurt/Main) verwendet. Die Ligation erfolgte über Nacht bei $16^{\circ} \mathrm{C}$.

Ligationsansatz:

$$
\begin{aligned}
& 100 \text { ng Vektor-DNA } \\
& \text { x } \mu \text { l DNA-Fragment (3-5 molarer Überschuss) } \\
& 1 \mu \mathrm{l} 10 \times \text { T4-Ligase-Puffer } \\
& 1 \mu \mathrm{l} \text { T4-DNA-Ligase (400 NEB-Einheiten/ } \mu \mathrm{l}) \\
& \text { auf } 10 \mu \mathrm{l} \text { mit } \mathrm{dH}_{2} \mathrm{O} \text { auffüllen. }
\end{aligned}
$$

\subsubsection{0 cDNA-Synthese der murinen Naaa}

Die RT-PCR ist eine Methode zur Synthese von cDNA aus RNA. In einer zweistufigen Reaktion erfolgt zunächst die reverse Transkription mittels einer RNAspezifischen, Primer-abhängigen DNA-Polymerase (Reverse Transkriptase) und anschließend die Amplifikation der generierten cDNA mittels PCR. Zur Isolierung der cDNA der murinen Naaa wurde das Omniscript ${ }^{\circledR}$ Reverse Transkriptase Kit (Qiagen, Hilden) verwendet. Die Reaktion erfolgte im $20 \mu \mathrm{l}$-Ansatz. Es wurde jeweils $1 \mu \mathrm{g}$ Maus-RNA aus Hirn, Leber, Niere und Herz eingesetzt. Reverse Transkriptase, Puffer, dNTP-Mix und RNase-freies Wasser waren im Kit enthalten. Zur spezifischen RT-Reaktion wurden Primer eingesetzt, die die zu amplifizierende cDNA 3'-terminal flankierten.

RT-Reaktion:

$1 \mu \mathrm{g}$ RNA

$2 \mu \mathrm{l} 10 \times$ RT-Puffer

$2 \mu \mathrm{dNTP}$ Mix (5 mM)

$2 \mu \mathrm{l} 10$ HM Primer (3'-terminal)

$1 \mu \mathrm{l} \mathrm{Omniscript}{ }^{\circledR}$ Reverse Transkriptase (4 U)

mit RNase-freiem Wasser auf $20 \mu$ auffüllen.

Der Ansatz wurde 90 min bei $37^{\circ} \mathrm{C}$ inkubiert und dann 5 min bei $93{ }^{\circ} \mathrm{C}$ aufgekocht, um die Reverse Transkriptase zu inaktivieren. $3 \mu$ des RT-Ansatzes wurde als 
Template zur anschließenden PCR eingesetzt. Zur Amplifikation der cDNA des RT-Ansatzes erfolgte eine PCR mit der Platinum ${ }^{\circledR}$ Pfx-DNA-Polymerase (Invitrogen, Karlsruhe). Diese DNA-Polymerase besitzt eine proofreading 3'-5'-ExonukleaseAktivität und bietet somit eine hohe Synthesegenauigkeit. Die Pfx-Polymerase liegt in einer inaktivierten form vor und muss durch einen initialen $94^{\circ} \mathrm{C}$ Denaturierungsschritt aktiviert werden. Die PCR-Reaktion erfolgte im $50 \mu$-Ansatz. Als Template dienten $3 \mu$ der RT-Reaktion.

PCR-Ansatz:

$3 \mu \mathrm{R}$ R-Reaktionsprodukt

$5 \mu \mathrm{l} 10 \times$ Pfx-Amplifikationspuffer

$5 \mu \mathrm{l} 10 \times$ Enhancer Solution

$1,5 \mu \mathrm{l}$ dNTP Mix (10 mM)

$1 \mu \mathrm{l} 50 \mathrm{mM} \mathrm{MgSO}_{4}$

$2 \mu \mathrm{l} 10 \mu \mathrm{M}$ Primer (3'-terminal)

$2 \mu \mathrm{l} 10 \mu \mathrm{M}$ Primer (5'-terminal)

0,6 $\mu \mathrm{l} \mathrm{Pfx-DNA-Polymerase} \mathrm{(1,5} \mathrm{U)}$

mit $\mathrm{dH}_{2} \mathrm{O}$ auf $50 \mu \mathrm{l}$ auffüllen.

PCR-Reaktionsprotokoll:

\begin{tabular}{cl}
2 min & $95^{\circ} \mathrm{C}$ \\
\hline $35 \times \quad 20$ sek & $95^{\circ} \mathrm{C}$ \\
30 sek & $55^{\circ} \mathrm{C}$ \\
180 sek & $68^{\circ} \mathrm{C}$ \\
\hline 10 min & $68^{\circ} \mathrm{C}$
\end{tabular}

Um die Spezifität der PCR zu erhöhen erfolgte eine zweite, nested PCR auf das erste PCR-Produkt, nach dem gleichen Protokoll. $3 \mu \mathrm{l}$ des PCR-Produkt 1 wurden als Template eingesetzt und es wurden Primer genutzt, die die zu amplifizierende cDNA etwa 20 bp vom 5'- und 3'-Terminus des PCR-Produkt binden. Die PCR-Produkte 1 und 2 wurden anschließend im Agarosegel analysiert.

\subsubsection{Microarray-Analyse}

Die folgenden Arbeitsanweisungen sind dem Standard Operation Procedure (SOP) des Transkriptomanalyselabor der Universität Göttingen entnommen (Stand 06. April 2008), http://www.microarrays.med.uni-goettingen.de/. 
Für die Markierung der RNA für die Microarray-Analyse wurde das MessageAmp ${ }^{\mathrm{TM}}$ II-Biotin enhanced Kit der Firma Ambion (Austin, USA) verwendet. RNA wird dabei durch reverse Transkription in cDNA umgeschrieben und anschließend durch eine DNA-Polymerase und RNase $\mathrm{H}$ zu doppelsträngiger cDNA (dsDNA) synthetisiert. Schließlich wird durch in-vitro-Transkription unter Verwendung Biotin-konjugierter Nukleotide mit der dsDNA als Matrize zu Biotin-markierter aRNA amplifiziert.

\subsubsection{Reverse Transkription}

1000 ng Gesamt-RNA und 1 l T7 Oligo(dT) wurden in einem Gesamtvolumen von $12 \mu \mathrm{l}$ bei $70{ }^{\circ} \mathrm{C}$ für 10 min denaturiert.

Mastermix RT-Reaktion:

$$
\begin{aligned}
& 2 \mu \mathrm{l} 10 \times \text { First Strand Buffer } \\
& 4 \mu \mathrm{l} \text { dNTP Mix } \\
& 1 \mu \mathrm{l} \text { RNase Inhibitor } \\
& 1 \mu \mathrm{l} \text { ArrayScript Reverse Transkriptase. }
\end{aligned}
$$

$8 \mu \mathrm{l}$ des Mastermix wurden zu den denaturierten RNA-Proben gegeben und für 120 min bei $42^{\circ} \mathrm{C}$ inkubiert.

\subsubsection{Zweitstrang-cDNA-Synthese}

Zweitstrang-Synthese Mastermix: $\quad 63 \mu$ l Nuklease-freies Wasser

$$
\begin{aligned}
& 10 \mu \mathrm{l} 10 \times \text { Second Strand Buffer } \\
& 4 \mu \mathrm{l} \text { dNTP Mix } \\
& 2 \mu \mathrm{l} \text { DNA-Polymerase } \\
& 1 \mu \mathrm{l} \text { RNase H. }
\end{aligned}
$$

Je $80 \mu \mathrm{l}$ des Zweitstrang-Synthese-Mastermix wurden zu $12 \mu \mathrm{l}$ cDNA gegeben und bei $16{ }^{\circ} \mathrm{C}$ für 120 min inkubiert.

\subsubsection{3 cDNA-Aufreinigung}

$250 \mu \mathrm{l}$ cDNA-Bindepuffer wurden zu den $92 \mu \mathrm{l}$ Zweitstrang-cDNA gegeben und der Ansatz auf cDNA-Filtersäulen gegeben und anschließend 1 min bei 10000 rpm zentrifugiert. Nach dem Waschen mit $500 \mu \mathrm{l}$ Waschpuffer wurde die cDNA mit zweimal $12 \mu \mathrm{l} 50^{\circ} \mathrm{C}$ warmem $\mathrm{dH}_{2} \mathrm{O}$ eluiert. 


\subsubsection{In-vitro-Transkription zur Synthese Biotin-markierter aRNA}

Markierungs-Mastermix:

$12 \mu$ Biotin-NTP Mix

$4 \mu \mathrm{IT7} 10 \times$ Reaction Buffer

$4 \mu \mathrm{lT7}$ Enzyme Mix.

$20 \mu \mathrm{l}$ der aufgereinigten cDNA wurden mit $20 \mu \mathrm{l}$ des Biotin-Markierungs-Mastermix gemischt und bei $37^{\circ} \mathrm{C}$ für $14 \mathrm{~h}$ inkubiert um Biotin-markierte Nukleotide in den neusynthetisierten aRNA-Strang einzubauen. Die Reaktion wurde mit $60 \mu \mathrm{l}$ nukleasefreiem $\mathrm{dH}_{2} \mathrm{O}$ gestoppt.

\subsubsection{5 aRNA-Aufreinigung}

$100 \mu \mathrm{l}$ Biotin-markierter aRNA wurden mit $350 \mu \mathrm{l}$ aRNA-Binding-Puffer gemischt, anschließend $100 \mu \mathrm{l} 100 \%$ Ethanol hinzugefügt und der Ansatz sofort danach auf aRNA-Filter-Säulen gegeben und bei 10000 rpm zentrifugiert. Die Säulen wurden mit $650 \mu \mathrm{l}$ Wasch-Puffer gewaschen und die aRNA schließlich durch Zentrifugation für 1 min bei $10000 \mathrm{rpm}$ mit $100 \mu \mathrm{l} 50{ }^{\circ} \mathrm{C}$ warmen $\mathrm{dH}_{2} \mathrm{O}$ eluiert.

\subsubsection{Hybridisieren, Waschen und Scannen der Microarrays}

Die Hybridisierung und das Waschen der Microarrays wurde nach Angaben des Herstellers durchgeführt.

\subsubsection{Real-Time-PCR}

Die genauste Methode um Transkriptmengen in mehreren Proben quantitativ miteinander zu vergleichen ist die Real-Time-PCR. Hierbei wird ein interkalierendes Fluorophor (SYBR-green ${ }^{\circledR}$ ) verwendet um die Menge an DNA in einer Probe darzustellen. Die relative Zunahme der Fluoreszenz wird während der PCR nach jedem Amplifikationszyklus durch einen Laser in Echtzeit bestimmt. Aus der Anzahl von Zyklen, die für das Erreichen eines bestimmten Fluoreszenz-Schwellenwerts benötigt werden, lässt sich so quantitativ auf die relative Menge des eingesetzten Transkripts schließen.

\subsubsection{1 cDNA-Synthese}

Für den Microarray wurde die RNA von jeweils fünf 66gt-Mäusen mit der von Kontrolltieren verglichen. Die RNA wurde aus frischer Mausleber isoliert (vgl. 3.2.1.1). Die Integrität der RNA wurde vor der Reversen Transkription durch 
Auftrennung im Agarosegel überprüft (vgl. 3.2.1.8). Die Reverse Transkription wurde mittels iScript ${ }^{\mathrm{TM}}$ cDNA-Synthesis-Kit (BioRad, Hercules, Kalifornien) durchgeführt. Die Reaktion erfolgte in $20 \mu \mathrm{l}$-Ansätzen. Es wurde $1 \mu \mathrm{g}$ Maus-RNA aus Lebergewebe eingesetzt. Reverse Transkriptase, Puffer, dNTP-Mix und RNase-freies Wasser waren im Kit enthalten. Um möglichst die gesamte RNA in cDNA umzuschreiben wurden die im Kit enthaltenen Oligo (dT) und random-hexamer Primer verwendet.

RT-Reaktion:

$1 \mu \mathrm{g}$ RNA

$4 \mu \mathrm{l} 5 \times$ RT-Mix

$1 \mu$ iScript Reverse Transkriptase

mit RNase-freiem Wasser auf $20 \mu$ l auffüllen.

Der Ansatz wurde für 5 min bei $25^{\circ} \mathrm{C}$ vorinkubiert, 30 min bei $42{ }^{\circ} \mathrm{C}$ inkubiert und dann 5 min bei $85^{\circ} \mathrm{C}$ gekocht, um die Reverse Transkriptase zu inaktivieren.

\subsubsection{Primergenerierung}

Die Auswahl der Primer für die Real-Time-PCR erfolgte mit Hilfe des OnlineProgramms Primer3. Mittels Primer3 wurden so hochspezifische Primer generiert, die ein Fragment von 100-150 Basenpaaren amplifizieren. Die Primer wurden vor der Verwendung in der Real-Time-PCR in einem Testlauf mit gemischter cDNA auf ihre Spezifität hin überprüft.

\subsubsection{Probenvorbereitung und Messung}

Die Real-Time-PCR wurde am ABI Prism 7900HT der Firma Applied Biosystems in 384-Lochplatten durchgeführt. Alle Messungen erfolgten in technischen Triplikaten. Es wurden $2 \mu \mathrm{l}$ der zuvor 1:5 verdünnten cDNA-Synthese pro Ansatz eingesetzt.

Reaktionsansatz:

$2 \mu \mathrm{l}$ cDNA (1:5 verd.)

$1 \mu \mathrm{l}$ Primer for (10 pmol/ $\mu \mathrm{l})$

$1 \mu \mathrm{l}$ Primer rev $(10 \mathrm{pmol} / \mu \mathrm{l})$

$5 \mu$ S SYBR-green ${ }^{\circledR}$-Mix $(2 x)$

$1 \mu \mathrm{dH} \mathrm{d}_{2} \mathrm{O}$. 
Die Reaktionsansätze wurden in 384-Lochplatten pipettiert. Anschließend wurde die 384-Lochplatte mit einer Folie luftdicht verschlossen, kurz zentrifugiert und im RealTime-Cycler ABI Prism 7900HT der Firma Applied Biosystems gemessen.

Real-Time-PCR Protokoll:

\begin{tabular}{ccc} 
& $10 \mathrm{~min}$ & $95^{\circ} \mathrm{C}$ \\
\hline $40 \mathrm{x}$ & 15 sek & $95^{\circ} \mathrm{C}$ \\
60 sek & $60^{\circ} \mathrm{C}$ \\
\hline 15 sek & $95^{\circ} \mathrm{C}$ \\
15 sek & $60^{\circ} \mathrm{C}$ \\
15 sek & $95^{\circ} \mathrm{C}$
\end{tabular}

\subsubsection{Auswertung}

$\mathrm{Da}$ in der vorliegenden Arbeit nur relative Mengen von Transkripten von verschiedenen Tieren verglichen werden sollten, wurde eine relative Quantifizierung nach Pfaffl (Pfaffl 2001) durchgeführt. Hierbei wird die Anzahl an Zyklen, die für das Erreichen einer bestimmten Fluoreszenz-Schwelle (threshold cycle, CT) bei dem zu untersuchenden Transkript (gene of interest, GOI) nötig sind, auf die Anzahl von Zyklen normalisiert, die notwendig sind, um die bestimmte Fluoreszenz-Schwelle eines internen Referenz-Standard-Transkripts (housekeeping-Gen) zu erreichen. Ein housekeeping-Gen muss bestimmten Anforderungen genügen, um als solches fungieren zu können. Es sollte in allen Proben gleich exprimiert und nicht durch die experimentellen Bedingungen in seiner Expression beeinflusst werden. Als ReferenzStandard-Transkript wurde in diesem Fall Glycerinaldehyd-3-PhosphatDehydrogenase (GAPDH) gewählt.

Die differentielle Expression wurde wie folgt berechnet:

$$
\mathrm{CTGOI}-\mathrm{CTGAPDH}=\Delta \mathrm{CT}
$$

Anschließend wurde die Differenz aus beiden $\Delta \mathrm{CT}$-Werten der zu vergleichenden Tiere gebildet:

$$
\Delta \mathrm{CT}_{\text {Tier1 }}-\Delta \mathrm{CT}_{\mathrm{Tier} 2}=\Delta \Delta \mathrm{CT}
$$


$\Delta \Delta \mathrm{CT}$ gibt schließlich die differentielle Expression zwischen Tier1 und Tier2 an. Zum besseren Verständnis wurde die Expression von Transkripten in Wildtyp-Tieren auf 1 normalisiert und der Expressionsunterschied gegenüber der 66gt-Maus als x-faches angegeben.

\subsubsection{Kultivierung von Mikroorganismen}

3.2.4.1 E. Coli

3.2.4.1.1 Medien zum Arbeiten mit Bakterienkulturen

$10 \mathrm{~g}$ Pepton

(engl. lysogeny broth) $\quad 5 \mathrm{~g} \mathrm{Hefeextrakt}$

$10 \mathrm{~g} \mathrm{NaCl}$

mit $\mathrm{dH}_{2} \mathrm{O}$ auf $1 \mathrm{I}$ auffüllen,

$\mathrm{pH}$ 7,0 mit $\mathrm{NaOH}$ einstellen

$20 \mathrm{~min}$ bei $121^{\circ} \mathrm{C}$ autoklavieren.

LB-Agarplatten:

7,5 g Agar

in 1 I LB-Medium

nach dem Autoklavieren auf $60^{\circ} \mathrm{C}$ abkühlen lassen, ggf. Antibiotikum zusetzen und je $30 \mathrm{ml}$ in 10-cmPlatten gießen. Nach dem Erkalten bei $4^{\circ} \mathrm{C}$ lagern.

Tab. 3.4: Verwendete Antibiotika mit eingesetzten Endkonzentrationen

\begin{tabular}{lll}
\hline Antibiotikum & Stocklösung & Endkonzentration \\
\hline Ampicillin & $25 \mathrm{mg} / \mathrm{ml} \mathrm{in} \mathrm{dH}_{2} \mathrm{O}$ & $100 \mu \mathrm{g} / \mathrm{ml}$ \\
Chloramphenicol & $30 \mathrm{mg} / \mathrm{ml} \mathrm{in} \mathrm{Ethanol}$ & $30 \mu \mathrm{g} / \mathrm{ml}$ \\
\hline
\end{tabular}

3.2.4.1.2 Vermehrung von E. coli

Zur Amplifikation von Plasmid-DNA wurde der Bakterienstamm

$\underline{\mathrm{DH} 5 \alpha}(\mathrm{F}-$, recA1, endA1, hsdR17(rk-, mk+), supE44, $\lambda$-, thi-1, gyrA96, relA1) oder

XL1-BLUE (endA1, gyrA96, hsdR17 (rk- mk-), lac, recA1, relA1, supE44, thi-1, F' [proAB, laclqZM15, TN10(Tetr)]) verwendet. 
E. coli-Zellen wurden auf LB-Platten oder LB-Ampicillin-Platten bei $37^{\circ} \mathrm{C}$ im Brutschrank vermehrt. Flüssigkulturen von E. coli wurden in LB-Medium oder LB-Ampicillin-Medium bei $37^{\circ} \mathrm{C}$ in Reagenzgläsern $(2-3 \mathrm{ml})$ oder in Erlenmeyerkolben (50-500 ml) auf einer Schüttelplattform bei 250 rpm kultiviert.

\subsection{Präparation chemisch kompetenter E. coli-Zellen}

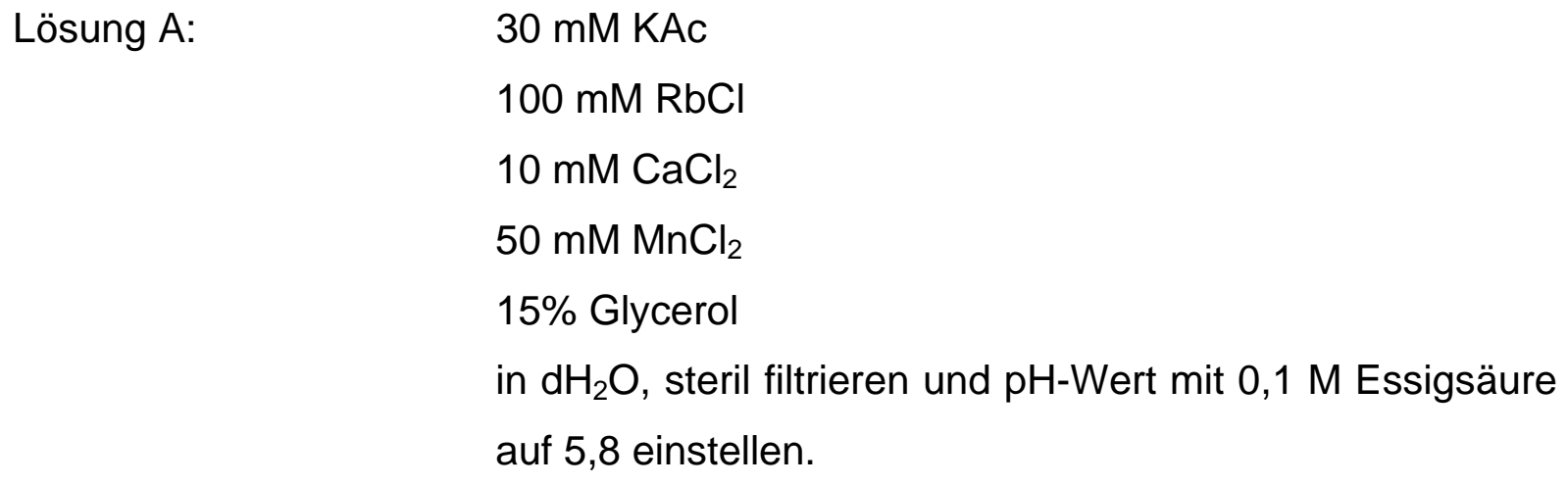

Lösung B: $\quad 10 \mathrm{mM}$ MOPS

$$
\begin{aligned}
& 10 \mathrm{mM} \mathrm{RbCl} \\
& 75 \mathrm{mM} \mathrm{CaCl}_{2} \\
& 15 \% \text { Glycerol }
\end{aligned}
$$

in $\mathrm{dH}_{2} \mathrm{O}$, steril filtrieren und $\mathrm{pH}-$ Wert mit $1 \mathrm{M}$ Natronlauge auf 6,5 einstellen.

$1 \mathrm{ml}$ einer Übernachtkultur einer DH5 $\alpha$ E. coli-Bakterienkultur wurden in $99 \mathrm{ml}$ Medium A bei $37^{\circ} \mathrm{C}$ im Schüttelinkubator inkubiert, bis eine Dichte von OD 0,4 bis 0,6 erreicht war. Die Bakterienkultur wurde $15 \mathrm{~min}$ auf Eis abgekühlt und anschließend bei $3500 \mathrm{rpm} 10 \mathrm{~min}$ in der Kühlzentrifuge bei $4{ }^{\circ} \mathrm{C}$ pelletiert. Das Bakterienpellet wurde vorsichtig mit $30 \mathrm{ml}$ kalter Lösung A resuspendiert. Die Kultur wurde für 15 min auf Eis inkubiert und anschließend erneut bei $3000 \mathrm{rpm} 15 \mathrm{~min}$ in der Kühlzentrifuge bei $4{ }^{\circ} \mathrm{C}$ pelletiert. Das Pellet wurde in $5 \mathrm{ml}$ der Lösung $\mathrm{B}$ resuspendiert und für 10 min auf Eis inkubiert. Die Bakteriensuspension wurde dann in $200 \mu \mathrm{l}$ Volumina aliquotiert, in flüssigem Stickstoff eingefroren und bei $-80^{\circ} \mathrm{C}$ gelagert.

3.2.4.1.4 Transformation chemisch kompetenter E. coli-Zellen mit Plasmid-DNA Ein $200 \mu \mathrm{l}$ Aliquot chemisch kompetenter DH5 $\alpha$ wurde auf Eis aufgetaut. 1 ng ligierte Plasmid-DNA wurde mit der Bakteriensuspension vorsichtig vermischt. Nach 45 min 
Inkubation auf Eis erfolgte ein Hitzeschock für 2 min bei $42^{\circ} \mathrm{C}$. Dann folgte eine weitere 10-minütige Inkubation auf Eis. Der Bakteriensuspension wurde anschließend 0,5 ml LB-Medium zugesetzt und wurde $1 \mathrm{~h}$ bei $37^{\circ} \mathrm{C}$ auf dem Drehrad inkubiert. Danach wurden $100 \mu \mathrm{l}$ der transformierten Bakterien auf eine LBAgarplatte mit Antibiotikum (vgl. Tab. 3.4) (entsprechend der Antibiotikumresistenz des Klonierungsvektors) ausgestrichen. Die Platten wurden über Nacht bei $37^{\circ} \mathrm{C}$ im Brutschrank inkubiert. Am nächsten Morgen wurden einige der gewachsenen

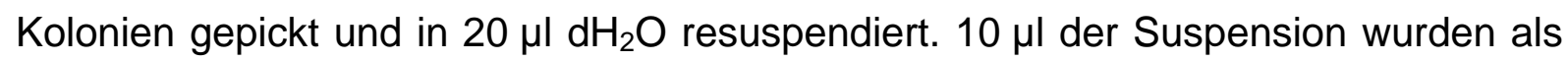
Template zur PCR eingesetzt, um die erfolgreiche Insertion in den ligierten Vektor zu überprüfen. Mit dem Rest der Suspension wurden $5 \mathrm{ml}$ Flüssigkultur (LBMedium + Antibiotikum) angeimpft. Am folgenden Tag konnten $2 \mathrm{ml}$ der Flüssigkultur zur Plasmid-Präparation (vgl. 3.2.4.1.5) eingesetzt werden. $700 \mu \mathrm{l}$ Flüssigkultur wurden mit $300 \mu \mathrm{l}$ sterilem Glycerin versetzt. Die Glycerinkultur wurde bei $-80^{\circ} \mathrm{C}$ gelagert und zum Animpfen neuer Kulturen verwendet.

\subsection{Mini-/Midi-Präparation von Plasmid-DNA}

Zur Isolierung von Plasmid-DNA aus $2 \mathrm{ml}$ Bakterienkultur transformierten E. coli wurde das QIAprep ${ }^{\circledR}$ Spin Miniprep Kit (Qiagen, Hilden) verwendet. Die PlasmidIsolierung erfolgte nach dem Herstellerprotokoll (QIAprep ${ }^{\circledR}$ Miniprep Handbook, 2006). Zur Isolierung von Plasmid-DNA aus $100 \mathrm{ml}$ Kultur transformierten E. coli wurde das QIAGEN $^{\circledR}$ Plasmid Midi Kit (Qiagen, Hilden) verwendet. Die PlasmidIsolierung erfolgte ebenfalls nach dem Herstellerprotokoll (QIAGEN ${ }^{\circledR}$ Plasmid Purification Handbook, 2006).

\subsubsection{S. cerevisiae}

Im Rahmen der Y2H-Versuche wurde der Hefestamm AH109 (Mata, trp1-901, leu2-3,

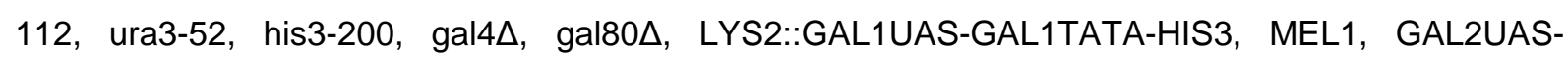
GAL2TATA-ADE2, URA3::MEL1UAS-MEL1TATA-lacZ) der Firma CLONTECH ${ }^{\circledR}$ verwendet.

\subsection{Medien zum Arbeiten mit S. cerevisiae}

50x-Aminosäure-Cocktail:

(-His/ -Trp/ -Leu/ -Ade)
300 mg L-Lysin- $\mathrm{HCl}, 200$ mg Uracil, 1500 mg

L-Valin, $300 \mathrm{mg}$ L-Isoleucin, $200 \mathrm{mg}$ L- Arginin-HCl, 200 mg L-Methionin, $300 \mathrm{mg}$ L-Tyrosin, $500 \mathrm{mg}$ L-Phenylalanin, $1000 \mathrm{mg}$ L-Glutamat, $3750 \mathrm{mg}$ L-Serin und 
$2000 \mathrm{mg}$ L-Threonin

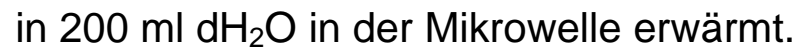

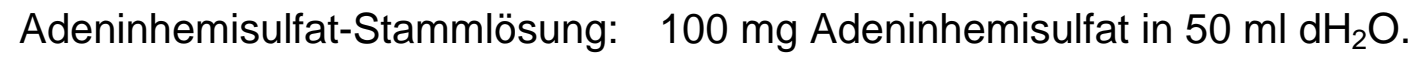

Histidin-Stammlösung:

Glukose-Stammlösung:

LiAc-Sorbitollösung:

40\% PEG-LiAc-Lösung:

65\% Gycerol/MgSO 4 -Lösung:

YPDA-Medium:

SD-Medien:
$100 \mathrm{mg}$ Histidin in $50 \mathrm{ml} \mathrm{dH_{2 }} \mathrm{O}$.

$20 \%$ (w/v) Glucose in 1 I d $\mathrm{H}_{2} \mathrm{O}$ gelöst und sterilfiltriert.

$100 \mathrm{mM}$ Lithiumacetat, $10 \mathrm{mM}$ TRIS/Acetat und $1 \mathrm{mM}$ EDTA sterilfitrieren oder autoklavieren und danach $1 \mathrm{M}$ Sorbitol hinzufügen.

100 mM Lithiumacetat, $10 \mathrm{mM}$ TRIS/Acetat und $1 \mathrm{mM}$ EDTA sterilfitrieren oder autoklavieren und danach $50 \mathrm{ml}$ mit $20 \mathrm{~g} \mathrm{(w/v)} \mathrm{Polyethylenglycol}$ versetzen und zur Lösung in der Mikrowelle aufgekochen.

$65 \%$ (v/v) Glycerol, $100 \mathrm{mM} \mathrm{MgSO}_{4}$ und $25 \mathrm{mM}$ TRIS/HCl pH 8,0.

$20 \mathrm{~g}$ Pepton, $10 \mathrm{~g}$ Hefeextrakt und $15 \mathrm{ml}$ 0,2 \%ige Adeninhemisulfat-Stammlösung $\mathrm{pH}$ 6,5 mit $\mathrm{dH}_{2} \mathrm{O}$ auf $900 \mathrm{ml}$ aufgefüllt und autoklaviert. Nach Abkühlung auf ca. $55^{\circ} \mathrm{C}$ wurden $100 \mathrm{ml}$ sterile, 20 \%ige Glukose-Stammlösung zugesetzt.

3,35 g Yeast-N2-Base, 10 ml 50̣x Aminosäure-Cocktail und 5 ml der jeweiligen Aminosäure-Stammlösung bzw. Adenin (für Platten $10 \mathrm{~g}$ Agar zugeben) mit $\mathrm{dH}_{2} \mathrm{O}$ auf $450 \mathrm{ml}$ aufgefüllt und autoklaviert, nach 
Abkühlung auf ca. $55^{\circ} \mathrm{C}$ wurden $50 \mathrm{ml}$ GlukoseStammlösung zugeben.

\subsection{Vermehrung von S. cerevisiae}

Hefevorkulturen wurden aus Glycerolstocks (Hefe in YPDA-Medium mit 50 \% [v/v] Glycerol) auf YPD-Agarplatten angeimpft. Das Wachstum von Hefezellen auf Festmedium erfolgte bei $30^{\circ} \mathrm{C}$ im Brutschrank. Anzuchten in Flüssigmedium (YPDA) wurden bei $30^{\circ} \mathrm{C}$ in Reagenzgläsern oder Erlenmeyerkolben bei $220 \mathrm{rpm}$ im Brutraum geschüttelt. Eine frische Übernachtkultur wurde in der Regel 1:20 in YPDMedium auf eine $\mathrm{OD}_{600}$ 0,3-0,4 verdünnt und bis zum Erreichen der logarithmischen Phase $\left(\mathrm{OD}_{600}\right.$ von ca. 1,0) inkubiert.

\subsection{Bestimmung der Zelldichte in Flüssigkulturen}

Die Zelldichte von Flüssigkulturen wurde durch photometrische Messungen bei einer Wellenlänge von $600 \mathrm{~nm}$ bestimmt. Als Nullwert diente das Medium, in dem die Zellen angezogen wurden. Dabei entspricht eine optischen Dichte von $\mathrm{OD}_{600}=1,0$ etwa $2 \times 107$ Hefezellen/ml.

\subsection{Transformation von Hefen}

Die Transformation von Hefen mit Plasmid-DNA wurde nach der LithiumacetatMethode durchgeführt. Eine etwa eine Woche alte AH109 Hefekolonie wurde in $5 \mathrm{ml}$ YPDA-Medium aufgenommen und ü. N. bei $30^{\circ} \mathrm{C}$ und $220 \mathrm{rpm}$ inkubiert. $100 \mathrm{ml}$ YPDA wurden mit der Vorkultur versetzt (1:20), dies entspricht etwa einer OD $_{600}$ von 0,1 bis 0,3 . Die Inkubation für $3 \mathrm{~h}$ bei $30^{\circ} \mathrm{C}$ und $220 \mathrm{rpm}$ führte zu einer $\mathrm{OD}_{600}$ von 0,5-0,7. Die Zellen wurden für 5 min bei RT und 2000 rpm zentrifugiert, zwei Mal mit

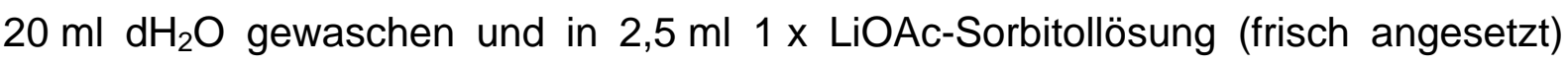
aufgenommen. Anschließend wurden die Hefen für 3 min bei RT und 2000 rpm pelletieren und in $500 \mu \mathrm{l}$ LiOAc-Sorbitollösung aufgenommen und für $15 \mathrm{~min}$ bei $30{ }^{\circ} \mathrm{C}$ inkubiert, aber nicht geschüttelt. Die Hering-Sperma-DNA (10 mg/ml, Sigma) wurde für 10 min auf $95^{\circ} \mathrm{C}$ erhitzt und sofort auf Eis gestellt.

In einen Transformationsansatz wurden 0,1 $\mu \mathrm{g}$ bait-DNA, 0,1 $\mu \mathrm{g}$ prey-DNA, $50 \mu \mathrm{g}$ Hering-Sperma-DNA und $50 \mu \mathrm{l}$ Zellsuspension sorgfältig vermischt, bevor $300 \mu \mathrm{l}$ einer 50 \%igen PEG/Lithiumacetat/TE-Lösung zum Ansatz hinzugegeben wurden. Es folgte eine Inkubation für $30 \mathrm{~min}$ bei $30^{\circ} \mathrm{C}$. Anschließend wurde der Ansatz für 15 min bei $42^{\circ} \mathrm{C}$ einem Hitzeschock unterzogen und für 2 min auf Eis abgekühlt. Es 
folgte eine 2-minütige Zentrifugation bei RT und $2000 \mathrm{rpm}$, der Überstand wurde verworfen und die Zellen in $200 \mu \mathrm{dH}_{2} \mathrm{O}$ aufgenommen, auf Selektionsplatten (SDPlatten) (-Leu/ -Trp) ausplattiert und für 2-4 Tage bei $30^{\circ} \mathrm{C}$ inkubiert.

\subsubsection{Yeast-Two-Hybrid}

Für die Yeast-Two-Hybrid-Versuche wurde das Matchmaker-GAL4-Two-HybridSystem 3 der Firma Clontech ${ }^{\circledR}$ in Verbindung mit dem Hefestamm AH109 verwendet. Der Hefestamm AH109 besitzt drei Reportergene (His3, Ade2, lacZ), deren Transkription von verschiedenen GAL4-UAS (Upstream Activating Sequences) und TATA-Boxes kontrolliert wird. Das grundlegene Prinzip des Y2H-Systems beruht darauf, dass für einen funktionsfähigen Transkriptionsfaktor GAL4 der Hefe S. cerevisiae sich die GAL4-DNA-Bindungsdomäne und die GAL4Aktivierungsdomäne räumlich nahe kommen müssen. Im Matchmaker-GAL4-TwoHybrid-System-3 kodiert der pGBKT7-Vektor die DNA-Bindungsdomäne und der pGADT7-Vektor die Aktivierungsdomäne. In den Vektoren lassen sich Zielproteine als Fusionsproteine (bait- und prey- Protein) mit der jeweiligen GAL4-Domäne in S. cerevisiae exprimieren. Interagieren die Zielproteine miteinander, so führt die sterische Annäherung der GAL4-DNA-Bindungs- und Aktivierungsdomäne zu einem funktionellen Transkriptionsfaktor und somit zur Expression der entsprechenden Reportergene. Dabei lässt das Wachstum auf Mangelmedium Rückschlüsse auf die Intensität der Proteininteraktion zu. So wachsen Hefen bei schwacher Interaktion lediglich auf His-Mangelmedium und bei starker Proteininteraktion auf His-/AdeMangelmedium, da das Reportergen für His näher am Transkriptionsursprung liegt als Adenin.

Dem Hefestamm fehlen außerdem die Gene für die Synthese von Trp und Leu. Diese Gene sind in den beiden Vektoren pGADT7 und pGADT7 (vgl. Kap. 8.1.1) enthalten. Dies ermöglicht die gezielte Selektion von doppelt-transformierten Hefezellen auf Selektionsnährböden.

\subsubsection{Klonierung}

Über Add-on-PCRs mit dem pcDNA3.1 Hygro (+)-66.3-kDa-Protein-Plasmid als Vorlage (vgl. Kap. 8.2.1), wurden verschiedene Fragmente des 66.3-kDa-Proteins unter Einführung der benötigten Schnittstellen amplifiziert; mit den Primern $A$ und $E$ (für Vektoren und Primer vgl. Kap. 8.1.2) die Prä-Proform (AS Met1 - Asp594), mit den Primern B und E die Proform (AS Leu47 - Asp594 ), mit den Primern B und G 
das 28-kDa-Fragment (AS Leu47 - Ser248), mit den Primern C und E das 40-kDaFragment (AS Cys249 - Asp594), mit den Primern D und E das 15-kDa-Fragment (AS Ser514 - Asp594) und mit den Primern C und F ein Mittelfragment (AS Cys249 Arg513). Die Fragmente wurden am 5'-Ende über EcoR1 und am 3'-Ende über BamH1 als Fusionsprotein mit der Gal-Domäne in den pGBKT7- und pGADT7Vektor kloniert. Die Cathepsin-D-cDNA wurde ebenfalls gerichtet in den pcDNA3.1Hygro-Vektor kloniert. Aus diesem Konstrukt wurden über Add-on-PCR mit den Primern $\mathrm{H}$ und $\mathrm{J}$ die Full-length-Form von Cathepsin $\mathrm{D}$ mit den Schnittstellen Nde1 und Sal1 amplifiziert und in den pGBKT7- und pGADT7-Vektor kloniert.

\subsubsection{His-/Adenin-Test}

In $5 \mathrm{ml} \mathrm{SD-T/-L-Medium} \mathrm{wurde} \mathrm{eine} \mathrm{Vorkultur} \mathrm{ü.} \mathrm{N.} \mathrm{bei} 30^{\circ} \mathrm{C}$ und $220 \mathrm{rpm}$ mit den zu untersuchenden Klonen angelegt. Am nächsten Tag wurde mit der Vorkultur $5 \mathrm{ml}$ SD-Trp/-Leu-Medium angeimpft und bis zu einer OD600 von $0,6-0,7$ bei $30{ }^{\circ} \mathrm{C}$ und $220 \mathrm{rpm}$ inkubiert. Es wurde mit $\mathrm{dH}_{2} \mathrm{O}$ eine Verdünnungsreihe hergestellt. Anschließend wurden auf SD-Trp/-Leu-, SD-His/-Trp/-Leu- und SD-Adenin/-His/-Trp/Leu-Platten je $5 \mu$ der Verdünnungen mit einer $\mathrm{OD}_{600}$ von 0,05 und 0,01 von jeweils 3 Klonen eines Transfektionsansatzes ausplattiert. Die Platten wurden für 1-3 Tage bei $30^{\circ} \mathrm{C}$ inkubiert und das Wachstum mit der Digitalkamera dokumentiert.

\subsubsection{3 $\quad \beta$-Galaktosidase-Aktivität}

TRIS-Puffer:

$40 \mathrm{mM}$ TRIS/HCl pH 6,8.

Permeabilisierer-Lösung: Harnstoff $8 \mathrm{M}$

SDS $5 \% \mathrm{w} / \mathrm{V}$

$40 \mathrm{mM}$ TRIS/HCl pH 6,8

EDTA 0,1 mM

Bromphenol-Blau 0,4 mg/ml.

Z-Puffer:

$$
\begin{aligned}
& \mathrm{Na}_{2} \mathrm{HPO}_{4} * 7 \mathrm{H}_{2} \mathrm{O} 16,1 \mathrm{~g} / \mathrm{L} \\
& \mathrm{NaH}_{2} \mathrm{PO}_{4} * \mathrm{H}_{2} \mathrm{O} 5,5 \mathrm{~g} / \mathrm{L} \\
& \mathrm{KCl} \mathrm{0,75} \mathrm{g} / \mathrm{L} \\
& \mathrm{MgSO}_{4} * 7 \mathrm{H}_{2} \mathrm{O} 0,246 \mathrm{~g} / \mathrm{L} \\
& \mathrm{pH} 7,0 .
\end{aligned}
$$


ONPG-Stammlösung:

$4 \mathrm{mg} / \mathrm{ml}$ o-Nitrophenyl- $\beta$-D-galaktopyranosid

in Z-Puffer.

Natriumcarbonat-Lösung: $\quad 1 \mathrm{M} \mathrm{Na}_{2} \mathrm{CO}_{3}$.

Der Versuch wurde nach einer modifizierten Version nach Gaxiola et al. (1992) durchgeführt. Dabei wird das Hilfssubstrat o-Nitrophenyl- $\beta$-D-galaktopyranosid (ONPG) durch das Enzym $\beta$-Galaktosidase hydrolysiert, wobei o-Nitrophenol freigesetzt wird. o-Nitrophenol liegt im Alkalischen als gelbes Phenolat vor und kann photometrische bei $420 \mathrm{~nm}$ bestimmt werden (Ausubel et al. 1997; Zhang T et al. 2004).

Zur Bestimmung der $\beta$-Galaktosidase-Aktivität der einzelnen Hefeklone wurden $2 \mathrm{ml}$ SD -T/-L Medium mit den Klonen auf den SD-Platten (-Leu/-Trp) inokuliert und ü. N. bei $30^{\circ} \mathrm{C}$ und $220 \mathrm{rpm}$ inkubiert. Am Folgetag wurde die $\mathrm{OD}_{600}$ bestimmt und mit SD -T/-L Medium auf 0,5 eingestellt. Danach folgte eine Inkubation bei $30^{\circ} \mathrm{C}$ und $220 \mathrm{rpm}$ bis zu einer $\mathrm{OD}_{600}$ von etwa 1,0. $1 \mathrm{ml}$ dieser Kultur wurde abgenommen und durch zentrifugieren bei $13200 \mathrm{rpm}$ für 2 min pelletiert. Die Hefezellen wurden in $100 \mu \mathrm{l}$ TRIS-Puffer aufgenommen und mit $6 \mu \mathrm{l}$ Permeabilisierer-Lösung versetzt. Nach 3-minütigem Vortexen folgt eine Inkubation für $10 \mathrm{~min}$ bei RT. Zur Volumenexpandierung wurden $100 \mu \mathrm{l}$ Z-Puffer hinzugegeben. Die $200 \mu \mathrm{l}$ Zellextrakte wurden mit weiteren $500 \mu \mathrm{l}$ Z-Puffer versetzt und $15 \mathrm{~min}$ bei $37^{\circ} \mathrm{C}$ äquilibriert. Anschließend erfolgte die Zugabe von $200 \mu \mathrm{l}$ ONPG-Stammlösung. Die so gestartete Reaktion wurde für 120 bis $180 \mathrm{~min}$ bei $37^{\circ} \mathrm{C}$ aufrechterhalten und dann mit $500 \mu \mathrm{l}$ Natriumcarbonat-Lösung gestoppt. Der Reaktionsansatz wurde für $7 \mathrm{~min}$ bei $2800 \mathrm{rpm}$ zentrifugiert und der Überstand photometrisch bei $420 \mathrm{~nm}$ gegen den Pufferleerwert bestimmt. Die Enzymaktivität wurde nach der unten stehenden Formel in Miller Units (MU) berechnet.

MU: $\left(O D_{420} \times 1000\right) /\left(O D_{600} \times \vee \times t\right)$

$\mathrm{OD}_{420}$ : Extinktion des ONPG bei $\lambda=420 \mathrm{~nm}$

$\mathrm{OD}_{600}$ : Extinktion der Zellsuspension im SD-Medium bei $\lambda=600 \mathrm{~nm}$

V: Probenvolumen (ml)

t: Reaktionszeit (min) 


\subsection{Zellbiologische Methoden}

\subsubsection{Kultivierung von eukaryontischen Zellen}

Die Zellen wurden in wassergesättigter Atmosphäre unter $5 \% \mathrm{CO}_{2}$ bei $37^{\circ} \mathrm{C}$ kultiviert. Medien und Lösungen wurden auf $37^{\circ} \mathrm{C}$ vorgewärmt. Im Allgemeinen erfolgte die Kultivierung der Zellen mit dem folgenden Medium:

Normalmedium:

\section{DMEM}

$10 \%$ dialysiertes FKS

$1 \%(v / v)$ Penicillin/Streptomycin (100 × Stocklösung)

$1 \%(v / v)$ Glutamin $(200$ mM, $100 \times$ Stocklösung).

Hygromycin-Stocklösung: 394 mg/ml Hygromycin B.

Medien für stabil transfizierte Zellen mit pcDNA3.1-Hygro (+) enthielten zusätzlich $0,5 \mathrm{mg} / \mathrm{ml}$ Hygromycin B.

\subsubsection{Trypsinieren von Zellen}

Die Trypsinierung und Passage der Zellen erfolgte im Allgemeinen nach Erreichen der Konfluenz des Zellrasens. Das Medium wurde abgesaugt. Die Zellen wurden einmal mit PBS gewaschen. Nach dem Absaugen des PBS wurden die Zellen etwa $5 \mathrm{~min}$ mit 0,05\% (w/v) Trypsin-EDTA-Lösung (Gibco, Invitrogen, Karlsruhe) bei $37^{\circ} \mathrm{C}$ bis zum Abrunden der Zellen inkubiert. Die Trypsinierung wurde durch Zugabe von Normalmedium gestoppt. Die Zellen wurden durch mehrfaches Aufsaugen mit der Pipette vereinzelt und dann in der gewünschten Dichte ausgesät. Um die Zellen zur weiteren Verarbeitung zu pelletieren, wurden sie in der Labofuge 5 min bei 1000 rpm zentrifugiert. Das Zellpellet wurde mit PBS gewaschen und erneut abzentrifugiert. Die Zellpellets wurden bei Bedarf bei $-20^{\circ} \mathrm{C}$ gelagert.

\subsubsection{Kryokonservierung von Zellen}

Einfriermedium: $\quad 10 \%$ DMSO in Normalmedium.

Die Zellen wurden trypsiniert, in Normalmedium aufgenommen und in der Labofuge (1 000 rpm, 5 min) pelletiert. Nach Absaugen des Überstandes wurden die Zellen in $1 \mathrm{ml}$ kaltem Einfriermedium aufgenommen und in Kryoröhrchen überführt. Die Zellen 
wurden zunächst bei $-80^{\circ} \mathrm{C}$ eingefroren und nach $24 \mathrm{~h}$ in flüssigen Stickstoff überführt.

\subsubsection{Auftauen und Revitalisieren von Zellen}

Die Kryoröhrchen wurden aus dem Stickstoff genommen. Die Zellsuspension wurde bei $37^{\circ} \mathrm{C}$ aufgetaut und direkt nach dem Auftauen in $5 \mathrm{ml} 4{ }^{\circ} \mathrm{C}$ kaltem Normalmedium aufgenommen. Die Zellen wurden in der Labofuge (1 $000 \mathrm{rpm}, 5 \mathrm{~min}$ ) pelletiert. Der Überstand wurde abgesaugt. Die Zellen wurden in $10 \mathrm{ml}$ warmen Normalmedium resuspendiert und in eine Zellkulturflasche überführt. Nach $24 \mathrm{~h}$ wurde das Medium gewechselt. Falls erforderlich, wurde dem Medium Selektionsantibiotikum zugesetzt.

\subsubsection{Transfektion von eukaryontischen Zellen}

Zur Transfektion von adhärenten Zellen in Zellkultur wurde das FuGENE ${ }^{\text {TM }}$ Transfektionsreagenz verwendet. Die Transfektion wurde auf 6-cm-Zellkulturschalen nach Angaben des Herstellers durchgeführt (FuGENE $^{\text {TM }}$ Transfektionsreagenz Handbuch 2007, Roche Applied Science, Indianapolis, USA). Die Zellen wurden $24 \mathrm{~h}$ vor der Transfektion mit $70 \%$ Konfluenz ausgesät. Für die Transfektion wurden $6 \mu \mathrm{l}$ FuGENE $^{\text {TM }}$ Transfektionsreagenz mit $200 \mu$ serumfreiem DMEM vorsichtig vermischt. Der Ansatz wurde $5 \mathrm{~min}$ bei RT inkubiert. Dann wurden dem Transfektionsansatz $2-4 \mu \mathrm{g}$ der zu transfizierenden Plasmid-DNA $(0,2-2 \mu \mathrm{g} / \mathrm{\mu l})$ zugefügt. Der komplette Ansatz wurde für 20-30 min bei RT inkubiert und anschließend tröpfchenweise in das Zellkulturmedium gegeben. Für die Transfektion in kleineren Zellkulturschalen wurde die Menge des Transfektionsansatzes angepasst.

\subsubsection{Isolierung von Zellklonen nach stabiler Transfektion}

Zur Herstellung stabil transfizierter Zellklone wurden die HT1080-Zellen mit dem FuGENE $^{\text {TM }}$ Transfektionsreagenz transfiziert. Zur Selektion von transfizierten Zellen wurde das Medium $48 \mathrm{~h}$ nach der Transfektion gewechselt. Die Zellen wurden mit Normalmedium mit $150 \mathrm{U} / \mathrm{ml}$ Hygromycin inkubiert. Als Sterbekontrolle wurden zusätzlich nicht transfizierte Zellen unter den gleichen Selektionsbedingungen kultiviert. Die Konzentration an Hygromycin B wurde alle $48 \mathrm{~h}$ bis zu einer Konzentration von $500 \mathrm{U} / \mathrm{ml}$ Normalmedium erhöht. Als auf der Kontrollplatte alle Zellen tot waren, wurden die selektionierten Zellen trypsiniert und in 
unterschiedlichen Zelldichten auf 14-cm-Zellkulturschale mit Selektionsmedium ausplattiert. Auf den 14-cm-Schalen wuchsen innerhalb von 14 Tagen Zellklone heran. Zellklone, die sich durch starkes Wachstum im Selektionsmedium auszeichneten und sich gut von anderen Zellen abgrenzten, wurden von der Schale mit einer Pipettenspitze gelöst und in eine 96-well-Schale pipettiert, in der $50 \mu \mathrm{l}$ Trypsinlösung vorgelegt wurden. Nach 10 min wurden die Zellen auf 24-well-Schalen überführt. Die Zellen eines Zellklons wurden vermehrt und kryokonserviert. Durch Western-Blot-Analyse wurde die Menge des sezernierten Proteins im Zellkulturmedium des Zellklons bestimmt. Dafür wurden die Zellen für $48 \mathrm{~h}$ mit DMEM/ 0,05 \% FKS inkubiert, der Zellüberstand wurde abgenommen, $50 \mu \mathrm{l}$ des Überstands wurde in Laemmli-Auftragspuffer aufgenommen und auf ein SDS-PAGE Gel aufgetragen.

\subsubsection{Ernte von rekombinanten Proteinen aus serumarmem Zellkulturmedium}

Erntemedium: DMEM

$0,05 \%$ dialysiertes FKS

$1 \%(v / v)$ Penicillin/Streptomycin (100 $\times$ Stocklösung)

$1 \%(v / v)$ Glutamin $(200$ mM, $100 \times$ Stocklösung).

Stabil transfizierte Zellen, die lysosomale Matrixproteine exprimieren, sezernieren auf Grund der hohen Expressionsrate große Mengen des Proteins in das Zellkulturmedium. Zur Ernte des Proteins aus dem Zellkulturmedium wurden die stabil transfizierten Zellen auf $14-\mathrm{cm}$-Zellkulturschalen ausplattiert. Der konfluente Zellrasen wurde zweimal mit PBS gespült und anschließend mit $20 \mathrm{ml}$ Erntemedium inkubiert. Nach $48 \mathrm{~h}$ wurde der Überstand von den Zellen abgesaugt und bei $9000 \mathrm{~g}$ zentrifugiert, um abgestorbene Zellen zu entfernen. Anschließend wurde das im Medium enthaltene Protein durch Zugabe von $0,5 \mathrm{~g} / \mathrm{ml}$ Ammoniumsulfat gefällt. Das gefällte Protein wurde bei $4{ }^{\circ} \mathrm{C}$ in der Ammoniumsulfat-Lösung gelagert. Die Zellen wurden noch zwei weitere Male für $48 \mathrm{~h}$ mit Erntemedium inkubiert und dann verworfen. 


\subsubsection{Metabolische Markierung von ethanolaminderivatisierten Lipiden}

Markiermedium:

DMEM

$+2,5 \%$ dialysiertes FKS

$+\left[{ }^{14} \mathrm{C}\right]$-Ethanolamin $2,5 \mu \mathrm{Ci} / \mathrm{ml}$.

Lysepuffer

$$
\begin{aligned}
& 1 \times \text { TBS } \\
& 0,1 \% \text { TX-100 } \\
& 1 \mathrm{mM} \text { EDTA } \\
& 1 \mathrm{mM} \text { PMSF } \\
& 5 \mathrm{mM} \text { JAA. }
\end{aligned}
$$

Am Vortag der metabolischen Markierung wurden HT1080-66-Zellen und MEF-66gt-Zellen in $6 \mathrm{~cm}$ großen Zellkulturschalen ausplattiert. Am Folgetag waren die Zellen zu 80 \% konfluent. Die Zellen wurden vor der metabolischen Markierung zweimalig mit PBS gewaschen. Danach erfolgte die 20-stündige Inkubation der Zellen mit $3 \mathrm{ml}$ Markiermedium, bei der die Inkorporation des radioaktiven Ethanolamin in die verschiedenen Ethanolaminderivate stattfand. Nach Abschluss der metabolischen Markierung wurden die Zellen zuerst zweimalig mit Normalmedium und anschließend zweimalig mit PBS gewaschen (Hansen HS et al. 1995). Im Anschluss wurden die Zellen in der Zellkulturschale mit einem Zellschaber vom Untergrund gelöst und in $500 \mu \mathrm{l}$ eiskaltem PBS aufgenommen. Die Zellensuspension wurde nachfolgend zur Lipidextraktion verwendet.

\subsection{Proteinbiochemische Methoden}

\subsubsection{SDS-Polyacrylamid-Gelelektrophorese (SDS-PAGE)}

Anodenpuffer:

Kathodenpuffer:
$50 \mathrm{mM}$ TRIS/HCl pH 8,6

$384 \mathrm{mM}$ Glycin

in $\mathrm{dH}_{2} \mathrm{O}$.

$0,1 \%$ SDS

0,001 \% Bromphenolblau

in Anodenpuffer. 
3x Laemmli-Auftragspuffer:

Trenngelpuffer:

Sammelgelpuffer:

Acrylamidlösung:

Ammoniumperoxodisulfat (APS):
$150 \mathrm{mM}$ TRIS/HCl pH 6,8

$6 \%$ SDS

$30 \%$ Glycerin

0,3\% Bromphenolblau

$3 \% \beta$-Mercaptoethanol (frisch zusetzen).

1,5 M TRIS/HCl pH 8,8

$0,4 \%$ SDS.

0,5 M TRIS/HCl pH 6,8

$0,4 \%$ SDS.

$30 \%$ Acrylamid/ 0,8\% Bisacrylamid in $\mathrm{dH}_{2} \mathrm{O}$ (Rotiphorese ${ }^{\circledR}$ Gel 30, Roth).

$10 \%$ Ammoniumperoxodisulfat in $\mathrm{dH}_{2} \mathrm{O}$.

Die elektrophoretische Trennung von Proteinen erfolgte mittels diskontinuierlicher SDS-Polyacrylamid-Gelelektrophorese (Laemmli 1970). Das Polyacrylamidgel wurde zwischen zwei Glasplatten ( $16 \times 18 \mathrm{~cm}$, Abstandshalter 1,5 mm dick) gegossen. Es bestand aus einem Trenngel, das je nach gewünschtem Auftrennungsbereich der Proteine zwischen $10 \%$ und $15 \%$ Acrylamid enthielt und einem $4 \%$-igen Sammelgel. Die Komponenten des Trenngels wurden entsprechend Tab. 3.5 gemischt, bis $4 \mathrm{~cm}$ unter den Rand zwischen die Glasplatten eingegossen und mit Isopropanol überschichtet um Blasenbildung zu vermeiden. Nach etwa $30 \mathrm{~min}$ war das Gel polymerisiert. Das Isopropanol wurde abgegossen, die Trenngeloberfläche wurde mehrfach mit $\mathrm{dH}_{2} \mathrm{O}$ gespült und anschließend das Sammelgel auf das Trenngel gegossen und ein Probenkamm eingesetzt. Nach 30 min war das Gel auspolymerisiert und konnte zur Elektrophorese verwendet werden. Das Gel wurde in die Elektrophoresekammer eingesetzt. Die Kammern wurden mit Anoden- und Kathodenpuffer gefüllt. Die Proteinproben wurden mit $3 \times$ Laemmli-Auftragspuffer versetzt und $5 \mathrm{~min}$ bei $96^{\circ} \mathrm{C}$ denaturiert. Die Elektrophorese erfolgte für $2 \mathrm{~h}$ bei $20 \mathrm{~mA}$ und weiteren $2 \mathrm{~h}$ bei $40 \mathrm{~mA}$. 
Tab. 3.5: Zusammensetzung von Trenngelen verschiedener Polyacrylamidkonzentrationen und des Sammelgels

\begin{tabular}{lcccc}
\hline & $\begin{array}{c}\text { Trenngel 10\% } \\
(\mathbf{3 0} \mathbf{~} \mathbf{l})\end{array}$ & $\begin{array}{c}\text { Trenngel 13\% } \\
\mathbf{( 3 0} \mathbf{~} \mathbf{l})\end{array}$ & $\begin{array}{c}\text { Trenngel 15\% } \\
\mathbf{( 3 0} \mathbf{~} \mathbf{l})\end{array}$ & $\begin{array}{c}\text { Sammelgel 4\% } \\
\mathbf{( 1 0} \mathbf{~} \mathbf{~} \mathbf{)}\end{array}$ \\
\hline Acrylamidlösung $(\mathrm{ml})$ & 9,8 & 12,7 & 14,7 & 1,3 \\
Trenngelpuffer $(\mathrm{ml})$ & 7,5 & 7,5 & 7,5 & --- \\
Sammelpuffer $(\mathrm{ml})$ & --- & --- & --- & 2,5 \\
$10 \%$ APS in $\mathrm{dH}_{2} \mathrm{O}(\mu \mathrm{l})$ & 250 & 250 & 250 & 100 \\
TEMED $(\mu \mathrm{l})$ & 25 & 25 & 25 & 10 \\
$\mathrm{dH}_{2} \mathrm{O}(\mathrm{ml})$ & 12,6 & 9,6 & 7,7 & 6,1 \\
\hline
\end{tabular}

\subsubsection{Färbung von Polyacrylamid-Gelen mit kolloidaler Coomassie-Lösung}

Fixierlösung:

$40 \%$ Ethanol

$10 \%$ Essigsäure.

Coomassie-Stocklösung: $\quad$ 0,1 \% Coomassie Brilliant Blue G250

$2 \%$ (w/v) Phosphorsäure

$10 \%$ Ammoniumsulfat.

Coomassie-Gebrauchslösung: $\quad 80$ \% Coomassie-Stocklösung

$20 \%$ Methanol.

Entfärbelösung:

$1 \%$ Essigsäure.

Das Polyacrylamidgel wurde nach der Elektrophorese für $1 \mathrm{~h}$ bei RT mit der Fixierlösung inkubiert. Dann wurde das Gel zweimal für 10 min mit $\mathrm{dH}_{2} \mathrm{O}$ gewaschen. Die Coomassie-Gebrauchslösung wurde vor der Verwendung frisch angesetzt (Neuhoff et al. 1988). Das Gel wurde mindestens $16 \mathrm{~h}$ gefärbt. Dann wurde es mit der Entfärbelösung bis zur gewünschten Farbintensität entfärbt. Zur Digitalisierung wurde das Gel in Folie eingehüllt eingescannt und im Geltrockner getrocknet.

\subsubsection{Färbung von Polyacrylamid-Gelen mit Silberfärbung}

Fixierlösung l: $\quad 30 \%$ Ethanol

$10 \%$ Essigsäure. 
Fixierlösung II:

Silber-Färbelösung:

Entwicklerlösung:

Glycinlösung:
2,5\% Natriumcarbonat

0,01 \% Formaldehyd.

0,5 M Natriumacetat

$30 \%$ Ethanol

0,5\% Glutaraldehyd

$0,2 \%$ Natriumthiosulfat-Pentahydrat.

0,1\% Silbernitrat

$0,02 \%$ Formaldehyd.

0,05 M Glycin.

Die Silberfärbung erfolgte nach der Methode von Heukeshoven (Heukeshoven and Dernick 1988). Das Polyacrylamidgel wurde nach der Elektrophorese $1,5 \mathrm{~h}$ bei RT in Fixierungslösung I inkubiert. Dann erfolgte eine weitere Fixierung in Fixierlösung II für $2 \mathrm{~h}$ bei RT. Anschließend wurde das Gel dreimal für je 20 min mit $\mathrm{dH}_{2} \mathrm{O}$ gespült und dann für $1 \mathrm{~h}$ mit der Silber-Färbelösung inkubiert. Es folgte die Entwicklung des Gels. Dazu wurde das Gel für $1 \mathrm{~min}$ in $\mathrm{dH}_{2} \mathrm{O}$ und 1 min mit der Entwicklerlösung gespült. Anschließend wurde das Gel mit Entwicklerlösung inkubiert bis die Proteinbanden gut sichtbar waren. Die Entwicklerlösung wurde abgegossen und die Reaktion wurde durch die Inkubation des Gels in Glycinlösung gestoppt. Nach 10 min konnte das Gel mit Wasser gespült werden. Zur Digitalisierung wurde das Gel eingescannt und im Geltrockner getrocknet.

\subsubsection{Western-Blot-Analyse}

Kathodenpuffer:

$40 \mathrm{mM} \varepsilon$-Aminocapronsäure

$20 \mathrm{mM}$ TRIS/HCl pH 9,0

$20 \%$ Methanol.

Anodenpuffer:

75 mM TRIS/HCl pH 7,4

$20 \%$ Methanol. 
Zur Immundetektion von Proteinen wurden die Proben nach ihrer Auftrennung im Polyacrylamidgel durch das Semidry-Western-Blot-Verfahren auf eine PVDF-Membran transferiert. Anschließend erfolgte die Immundetektion mittels Chemilumineszenz-Nachweis von HRP-konjugierten Sekundärantikörpern. Nach Beendigung der Polyacrylamid-Gelelektrophorese wurde das Polyacrylamidgel aus der Elektrophoresekammer genommen. Das Sammelgel wurde entfernt und das Trenngel wurde zum Äquilibrieren $10 \mathrm{~min}$ in Semidry-Kathodenpuffer inkubiert. Die PVDF-Membran wurde durch kurzes Schwenken in Methanol aktiviert und ebenfalls in Kathodenpuffer äquilibriert. Dann wurde der Blot in der Phegasus Blotkammer (Phase, Lübeck) aufgebaut. Der Aufbau ist in Abb. 3.1 schematisch dargestellt. Auf die untere Elektrodenplatte (Kathode) wurden drei in Kathodenpuffer getränkte Whatman-Filterpapiere gestapelt. Dann wurden das Gel, die Membran, drei in Anodenpuffer getränkte Whatman-Filterpapiere und anschließend die Anodenplatte aufgelegt. Der Elektrotransfer erfolgte bei einer Stromstärke von $1 \mathrm{~mA} / \mathrm{cm}^{2}$ für $70 \mathrm{~min}$.

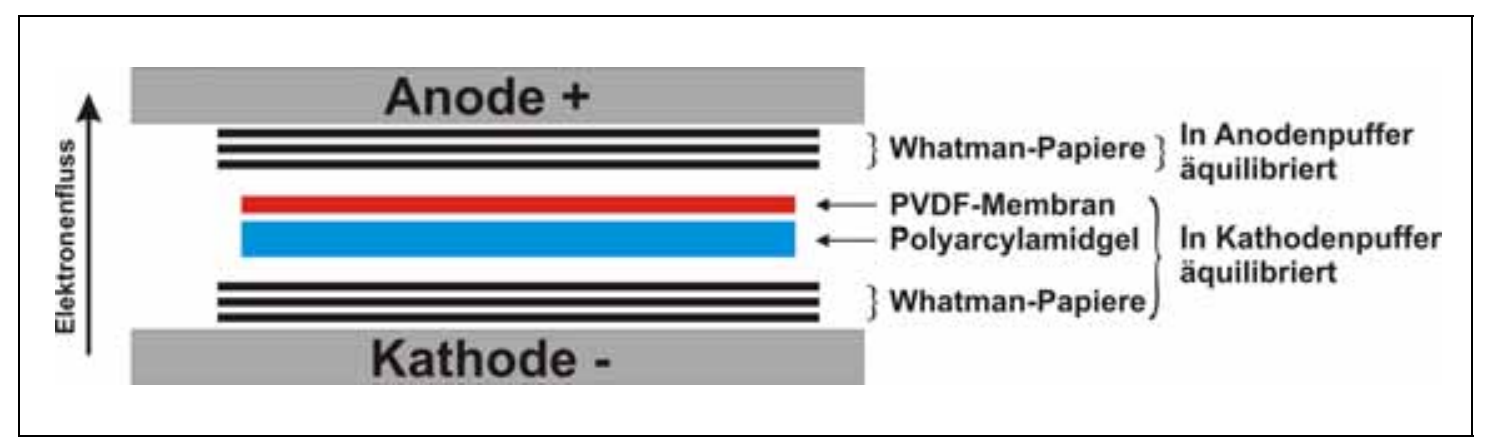

Abb. 3.1: Schematischer Aufbau eines Semidry-Western-Blots

PBST:

$1 \times$ PBS

$0,1 \%$ Tween-20.

Blotto:

$1 \times$ PBS

$0,1 \%$ Tween-20

$5 \%$ Magermilchpulver.

Nach Beendigung des Elektrotransfers wurde der Blot abgebaut und die PVDF-Membran wurde unter kontinuierlicher Bewegung auf einer Wippe inkubiert. Zunächst wurde die Membran, zum Blocken von Antigenbindungsstellen, $1 \mathrm{~h}$ in Blotto inkubiert. Dann folgte eine Inkubation mit Primärantikörper verdünnt in Blotto 
über Nacht bei $4^{\circ} \mathrm{C}$. Anschließend wurde die Membran 5 × 10 min mit PBST gespült. Es folgte eine 1-stündige Inkubation mit HRP-konjugiertem (horseradish peroxidase) Sekundärantikörper und ein weiterer Waschschritt mit $5 \times 10$ min PBST. Die verwendeten Primärantikörper und ihre Verdünnung sind in Tab. 3.1 angegeben.

Die Detektion der Proteine erfolgt mit Hilfe des Supersignal West Pico Chemiluminescent Detection Kits (Pierce, Rockford, USA). Die beiden Lösungen des Kits wurden 1:1 gemischt, auf der Membran verteilt, 5 min inkubiert und anschließend in eine Folie eingeschlagen. Die Detektion der Chemilumineszenz erfolgte durch die CCD-Kamera LAS-1000 (Fujifilm, Tokyo, Japan), wobei die Expositionszeit je nach Signalstärke variiert wurde. Durch „Strippen“ der PVDFMembran können die gebundenen Antikörperkomplexe von der Membran entfernt werden, ohne die Qualität und die Quantität der geblotteten Proteine zu verändern, so dass der Blot anschließend für die Immundetektion eines weiteren Proteins eingesetzt werden kann. Zum Strippen wurde die Membran $2 \times 5$ min mit $\mathrm{dH}_{2} \mathrm{O}$ gewaschen, dann $2 \times 5$ min mit $0,2 \mathrm{M} \mathrm{NaOH}$ inkubiert und anschließend nochmals $2 \times 5$ min mit $\mathrm{dH}_{2} \mathrm{O}$ gewaschen. Nach dieser Behandlung konnte die Membran beginnend mit der Blockierung mit Blotto zur weiteren Immundetektion eingesetzt werden.

\subsubsection{Herstellung von Gewebe- und Zellhomogenaten}

Lysepuffer: $1 \times 1$ TBS

$$
\begin{aligned}
& 1 \text { mM PMSF } \\
& 1 \text { mM EDTA } \\
& 5 \text { mM JAA } \\
& 0,1 \% \text { Triton } X-100 .
\end{aligned}
$$

Proteaseinhibitoren:

$$
\begin{aligned}
& 200 \mathrm{mM} \text { PMSF in DMSO }\left(-20^{\circ} \mathrm{C}\right) \\
& 500 \mathrm{mM} \text { JAA in } \mathrm{dH}_{2} \mathrm{O}\left(-20^{\circ} \mathrm{C}\right) \\
& 200 \mathrm{mM} \text { EDTA in } \mathrm{dH}_{2} \mathrm{O} .
\end{aligned}
$$

Zur Herstellung von Gewebehomogenaten wurde die Maus mit Genickbruch getötet, die Organe wurden entnommen und auf Eis gelagert. Die Organe wurden gewogen, mit neun Volumen Lysepuffer versetzt, mit einer scharfen Schere grob zerkleinert 
und anschließend mit 20 Hüben im Teflon-Homogenisator (Braun, Melsungen) homogenisiert. Das Lysat wurde $3 \times 20$ sek sonifiziert und bei $4{ }^{\circ} \mathrm{C}$ und $13000 \mathrm{rpm}$ abzentrifugiert. Der Überstand wurde in ein neues Gefäß überführt und die Proteinkonzentration wurde mittels DC-Protein-Assay (Biorad, Hercules, Kalifornien) bestimmt.

Zur Herstellung von Homogenaten aus Zellen wurden die Zellen in der Labofuge (1 $000 \mathrm{rpm}, 5 \mathrm{~min}$ ) pelletiert. Das Pellet wurde mit PBS gewaschen und in $500 \mu \mathrm{l}$ Lysepuffer resuspendiert. Anschließend wurden die Zellen $3 \times 20$ sek sonifiziert und bei $4{ }^{\circ} \mathrm{C}$ und $13000 \mathrm{rpm}$ abzentrifugiert. Bei Verwendung der Homogenate zur Western-Blot-Analyse wurde dem Lysepuffer zusätzlich 1 \% NP-40 zugesetzt.

\subsubsection{Proteinkonzentrationsbestimmung mittels DC-Protein-Assay}

Reagenz A:

Reagenz B:

Reagenz S:

Reagenz A': alkalische Kupfertartrat-Lösung. verdünntes Folin-Reagenz. keine Angaben vom Hersteller.

$1 \mathrm{ml}$ Reagenz A.

$20 \mu \mathrm{l}$ Reagenz S.

Der DC-Protein-Assay (BioRad) ist eine colorimetrische Methode zur Bestimmung von Proteinkonzentrationen, basierend auf der Methode nach Lowry (Lowry et al. 1951; Peterson 1979). Er toleriert die Anwesenheit von Detergenzien wie Triton X-100 und Tween-20 bis zu einer Konzentration von $1 \%$. In eine Mikrotiterplatte wurde eine Protein-Eichreihe mit $0-20 \mu \mathrm{g} / 100 \mu \mathrm{l}$ BSA in Doppelwerten pipettiert. Jeweils $10 \mu \mathrm{l}$ einer Verdünnung der Proteinprobe wurden zur Proteinbestimmung eingesetzt und mit $\mathrm{dH}_{2} \mathrm{O}$ auf $100 \mu \mathrm{l}$ aufgefüllt. Anschließend wurde zu jeder Probe $25 \mu \mathrm{l}$ des Reagenz A' und dann $200 \mu$ l des Reagenz B pipettiert. Nach 15 min Inkubation wurde die Extinktion der Proben bei $630 \mathrm{~nm}$ im Microplate Reader Model Spectra II (Tecan, SLT, Crailsheim) bestimmt. Mit Hilfe der Eichgeraden wurde die Proteinkonzentration der Proben bestimmt. 


\subsubsection{Anreicherung von Lysosomen Tyloxapol-behandelter Mäuse durch subzelluläre Fraktionierung}

Intravenös injiziertes Tyloxapol inhibiert im Plasma der Mäuse die Lipoprotein-Lipase (Hayashi et al. 1981). Der dadurch bedingte Anstieg des LDL-Spiegels im Plasma führt zu einer verstärkten Expression des LDL-Rezeptors und konsekutiv zur vermehrten Aufnahme von LDL in die Hepatozyten. Das LDL wird zum Abbau durch saure Hydrolasen in die Lysosomen transportiert und verringert somit deren Dichte (Hayashi et al. 1982).

Erst jetzt lassen sich Lysosomen aus Tyloxapol-behandelter Mausleber durch differentielle Zentrifugation und anschließende Ultrazentrifugation im diskontinuierlichen Sucrosegradienten effizient von anderen Zellorganellen, speziell den Mitochondrien, trennen (Wattiaux et al. 1963; Leighton et al. 1968).

Zur Isolierung der Tyloxapol-gefüllten Lysosomen wurde 4 Mäusen $5 \mu \mathrm{l} / \mathrm{g}$ Körpergewicht einer $17 \%$-igen (v/v)-Tyloxapol-Lösung (Triton WR-1339)/ 0,9 \% NaCl intraperitoneal injiziert. 4 Tage nach der Injektion wurden die Mäuse narkotisiert, durch Dekaptieren getötet und ausgeblutet. 2,2 g Leber wurde mit $5 \mathrm{ml}$ eiskalter 0,25 M Sucrose-Lösung versetzt und im Teflonpotter homogenisiert. Das Homogenat wurde anschließend mit Sucrose-Lösung auf $12 \mathrm{ml}$ aufgefüllt, gemischt und $10 \mathrm{~min}$ bei $4{ }^{\circ} \mathrm{C}$ mit $2300 \mathrm{rpm}$ in der Kühlzentrifuge 5804R (Eppendorf) zentrifugiert. Der Überstand (E1) wurde abgenommen, das Pellet wurde erneut in $5 \mathrm{ml}$ SucroseLösung homogenisiert, auf $12 \mathrm{ml}$ aufgefüllt und abzentrifugiert. Das Pellet enthält die nukleäre Fraktion N. Die postnukleären Überstände wurden vereinigt und auf $22 \mathrm{ml}$ aufgefüllt. Je $10 \mathrm{ml}$ wurden auf zwei Ti75-Zentrifugen-Röhrchen aufgetragen und für 3 min bei $4^{\circ} \mathrm{C}$ mit $13000 \mathrm{rpm}$ in der Ultrazentrifuge im Rotor Ti75 zentrifugiert. Der Überstand wurde abgenommen. Die Pellets wurden in $10 \mathrm{ml}$ Sucrose-Lösung vereinigt und erneut für 3 min bei $4{ }^{\circ} \mathrm{C}$ mit $13000 \mathrm{rpm}$ zentrifugiert. Das Pellet enthält die mitochondriale Fraktion $(\mathrm{M})$. Die beiden Überstände wurden vereinigt und anschließend auf die Ti75-Röhrchen verteilt. Es folgte eine 7-minütige Zentrifugation bei $4{ }^{\circ} \mathrm{C}$ mit $25000 \mathrm{rpm}$ im Rotor Ti75. Der Überstand wurde quantitativ abgenommen. Die Pellets wurden mit $10 \mathrm{ml}$ Sucrose-Lösung resuspendiert, vereint und erneut abzentrifugiert. Das Pellet enthält die light mitochondrial Fraktion (L). Der Überstand wurde im Rotor Ti75 bei 35000 rpm für 40 min zentrifugiert. Das Pellet wurde resuspendiert und erneut zentrifugiert. Das Pellet enthält mikrosomalen 
(Fraktion P) und der Überstand die zytosolischen Bestandteile (Fraktion S). Das Pellet $L$ wurden in 1,21 $\rho$ Sucrose-Lösung resuspendiert, in einem Glaspotter vereinigt und homogenisiert. Anschließend wurde ein Sucrose-Dichte-Gradient geschichtet. Dazu wurde die L-Fraktion in ein SW40-Röhrchen gegeben und mit $3 \mathrm{ml}$ 1,15 $\rho$ Sucrose, mit $3 \mathrm{ml}$ 1,14 $\rho$ Sucrose und $2 \mathrm{ml}$ 1,06 $\rho$ Sucrose überschichtet. Der Gradient wurde für 150 min bei $4^{\circ} \mathrm{C}$ mit $25000 \mathrm{rpm}$ in der Ultrazentrifuge (Rotor SW40) zentrifugiert, wobei langsam beschleunigt und abgebremst wurde. Der Gradient besitzt nach der Zentrifugation drei Interphasen. Die Schicht über der Interphase 1 wurde als Fraktion F1 abgenommen. Die Interphase 1 (F2) enthält die Tyloxapol-gefülten Lysosomen. Die Interphase 2 wird als F3 abgenommen und die Interphase 3, sowie das Pellet ergeben die Fraktion F4 (vgl. Abb. 3.2). Zur Analyse der subzellulären Fraktionierung wurden jeweils $250 \mu \mathrm{g}$ der Fraktionen $\mathrm{N}$ bis $\mathrm{S}$ und $50 \mu \mathrm{g}$ der Fraktionen F1 bis F4 zur Western-Blot-Analyse eingesetzt.

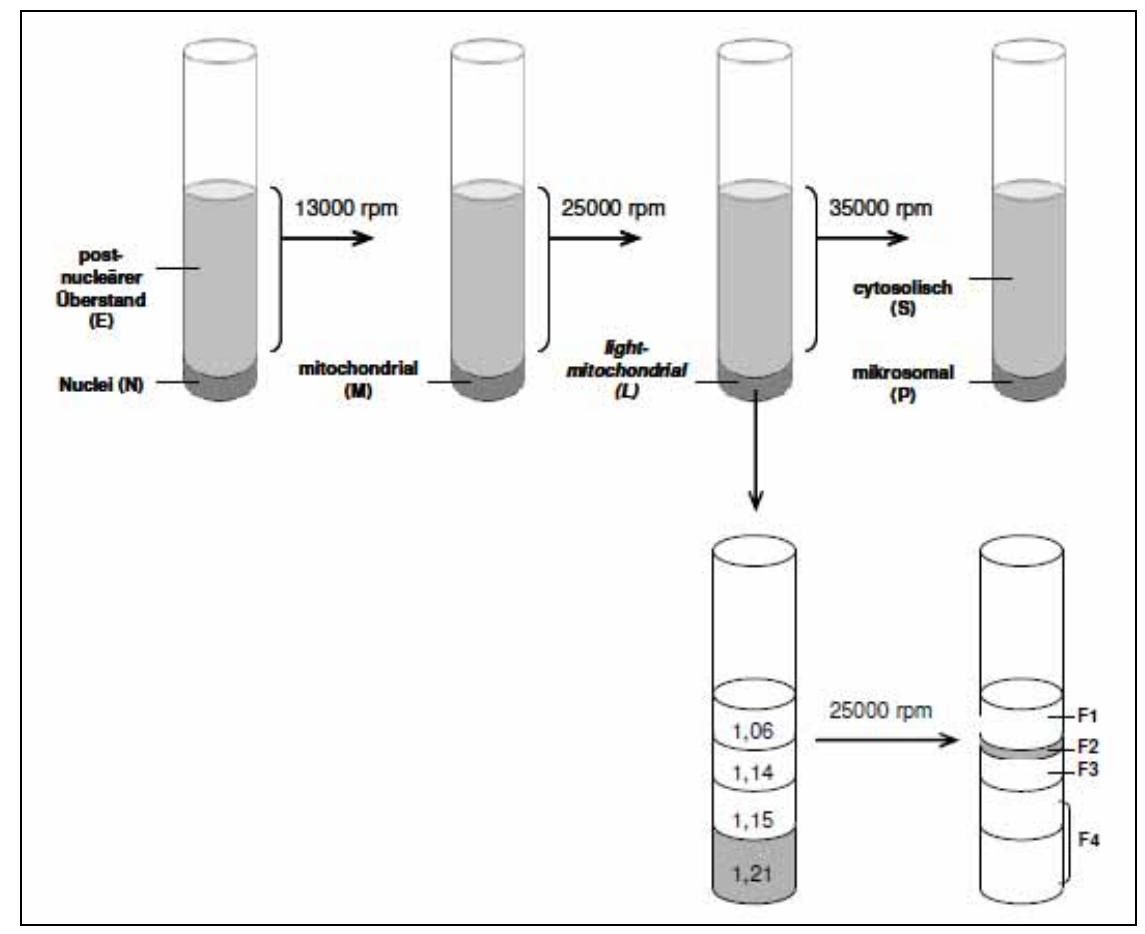

Abb. 3.2: Subzelluläre Fraktionierung nach Tyloxapol-Injektion

Für detailierte Erläuterungen zur Abbildung siehe Text. 


\subsubsection{Aufreinigung von überexprimiertem 66.3-kDa-Protein aus Zellkulturüberständen}

Zur Aufreinigung des rekombinanten 66.3-kDa-Proteins wurden Zellkulturüberstände von HT1080-66-Zellen gesammelt (vgl. 3.3.4). Das Protein im Medium wurde mit Ammoniumsulfat gefällt und bei $4{ }^{\circ} \mathrm{C}$ gelagert. Anschließend wurde das Protein über ein zweistufiges Aufreinigungsprotokoll isoliert. Im ersten Schritt erfolgte eine partielle Aufreinigung mittels Ni-NTA-Agarose. Im Anschluss daran wurde das Protein über Anionenaustauscher-Chromatographie von verbliebenen Proteinkontaminationen befreit.

\subsubsection{Proteinaufreinigung mittels Ni-NTA-Agarose}

Waschpuffer:

$$
\begin{aligned}
& 50 \mathrm{mM} \mathrm{NaH}_{2} \mathrm{PO}_{4} \\
& 300 \mathrm{mM} \mathrm{NaCl} \\
& 0-20 \mathrm{mM} \text { Imidazol } \\
& \mathrm{pH} \text { mit NaOH auf pH 8,0 einstellen. }
\end{aligned}
$$

Elutionspuffer: $\quad \begin{aligned} & 50 \mathrm{mM} \mathrm{NaH}_{2} \mathrm{PO}_{4} \\ & 300 \mathrm{mM} \mathrm{NaCl} \\ & 100-250 \mathrm{mM} \text { Imidazol } \\ & \\ & \mathrm{pH} \text { mit NaOH auf pH 8,0 einstellen. }\end{aligned}$

Zur partiellen Aufreinigung von RGS-His6-markiertem Protein wurde die Ni-NTA-Agarose von Qiagen (The QIAexpressionist Handbook, 2003, Qiagen, Hilden) verwendet. Für einen Proteinaufreinigungsansatz wurde das gefällte Protein aus 5 Litern Zellkulturüberständen von HT1080-66-Zellen eingesetzt. Das gefällte Protein wurde in der Kühlzentrifuge im JA-10 Rotor bei 10000 rpm pelletiert. Das Proteinpellet wurde in $50 \mathrm{ml}$ PBS gelöst und gegen $3 \times 5$ Liter PBS über Nacht dialysiert. Anschließend wurden durch $30 \mathrm{~min}$ Zentrifugation bei $4500 \mathrm{~g}$ in der Eppendorf Kühlzentrifuge nicht gelöste Anteile aus dem Dialysat entfernt. Der Überstand wurde in ein neues Gefäß überführt. Es wurden 4 ml Ni-NTA-Suspension (50\%ige Suspension von Ni-NTA-Agarose in $30 \%$ igem Ethanol) zugesetzt und über Nacht bei $4{ }^{\circ} \mathrm{C}$ auf dem Drehrad inkubiert. Die Ni-NTA-Agarose wurden bei $4500 \mathrm{~g}$ pelletiert und in $50 \mathrm{ml}$ Waschpuffer ohne Imidazol resuspendiert. Zentrifugation und Resuspension wurden noch zweimal wiederholt. Dann wurde die Resuspension auf 
eine 5-ml-Mobitec-Säule aufgetragen. Die Ni-NTA-Agarose wurde auf der Säule mit Waschpuffer mit steigender Imidazolkonzentration gespült. Zuerst wurde die Agarose mit $150 \mathrm{ml}$ Waschpuffer mit $5 \mathrm{mM}$ Imidazol gewaschen. Es folgten Waschschritte mit $50 \mathrm{ml}$ Waschpuffer mit $10 \mathrm{mM}$ Imidazol, mit $50 \mathrm{ml}$ Waschpuffer mit $15 \mathrm{mM}$ Imidazol und mit $10 \mathrm{ml}$ Waschpuffer mit 20 mM Imidazol. Dann wurde das Protein mit $7 \times 1 \mathrm{ml}$ Elutionspuffer mit 100 mM Imidazol von der Säule eluiert. Die Elutionsfraktionen wurden gepoolt und zum Umpuffern über Nacht gegen $10 \mathrm{mM}$ TRIS/HCl pH 8,0 dialysiert. Zur Analyse der Aufreinigung wurden jeweils 0,1\% der Aufreinigungsfraktionen im Western-Blot und im Polyacrylamidgel durch Silberfärbung analysiert.

\subsubsection{Anionenaustauscher-Chromatographie}

Die Anionenaustauscher-Chromatographie erfolgte an der Vision HPLC Anlage (Applied Biosystems, Darmstadt). Es wurde eine Chromatographiesäule mit Poros 20 $\mathrm{HQ} / \mathrm{M}$ Anionenaustauscher-Matrix verwendet. Die Säule wurde mit $10 \mathrm{mM} T \mathrm{TIS} / \mathrm{HCl}$ $\mathrm{pH}$ 8,0 äquilibriert. Ein $4 \mathrm{ml}$ Aliquot der Proteinprobe wurde auf die Säule aufgetragen und durch einen Stufengradienten von 0 bis $1 \mathrm{M} \mathrm{NaCl}$ aufgetrennt. Das aufgetrennte Protein wurde in $2,5 \mathrm{ml}$ Fraktionen gesammelt. Zur Analyse der Aufreinigung wurden $0,5 \%$ der Fraktionen durch Western-Blot und SDS-PAGE, sowie Silberfärbung auf Menge und Reinheit des Proteins überprüft. Die Fraktionen, die das aufgereinigte Protein enthielten, wurden im Vakuumkonzentrator ankonzentriert, anschließend gegen PBS dialysiert und bei $-20^{\circ} \mathrm{C}$ gelagert.

Tab. 3.6: Programm zur Anionenaustauscher-Chromatographie mit Stufengradient

\begin{tabular}{lccc}
\hline Programmschritt & Säulenvolumen & Puffer $\boldsymbol{A}$ & Puffer B \\
\hline Injektion der Probe & $4 \mathrm{ml}$ & $100 \%$ & $0 \%$ \\
Konstanter Fluss & 2 & $100 \%$ & $0 \%$ \\
Linearer Gradient & 5 & $85 \%$ & $15 \%$ \\
Konstanter Fluss & 3 & $85 \%$ & $15 \%$ \\
Linearer Gradient & 5 & $70 \%$ & $30 \%$ \\
Konstanter Fluss & 3 & $70 \%$ & $30 \%$ \\
Linearer Gradient & 5 & $50 \%$ & $50 \%$ \\
Konstanter Fluss & 3 & $50 \%$ & $50 \%$ \\
Linearer Gradient & 5 & $0 \%$ & $100 \%$ \\
Konstanter Fluss & 4 & $0 \%$ & $100 \%$ \\
\hline
\end{tabular}


Die Anionenaustauscher-Chromatographie erfolgte an der Vision HPLC Anlage über eine 1,7 ml-Säule mit Poros HQ Matrix äquilibriert in $10 \mathrm{mM} \mathrm{TRIS/HCl} \mathrm{pH} \mathrm{8,0.} \mathrm{Bei}$ einer konstanten Flußrate von $5 \mathrm{ml} / \mathrm{min}$ verlief ein Stufengradient von $0 \mathrm{M} \mathrm{NaCl}$ (Puffer A) zu $1 \mathrm{M} \mathrm{NaCl}$ (Puffer B) in 10 mM TRIS/HCl pH 8,0.

\title{
3.4.8.3 Gelfiltrationschromatographie
}

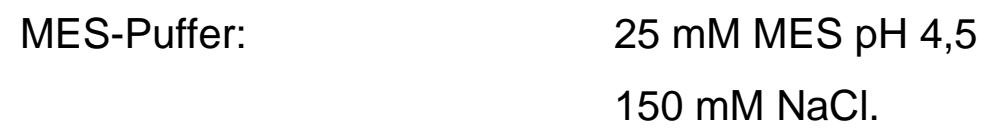

Gelfiltrationsexperimente wurden mit dem SMART ${ }^{\mathrm{TM}}$ System (Pharmacia, Uppsala, Schweden) mit der Gelfiltrationssäule Superdex 200 HR 10/300 (GE Healthcare,) durchgeführt. Die Gelfiltrationssäule wurde zunächst mit $\mathrm{dH}_{2} \mathrm{O}$ gespült und anschließend mit MES-Puffer äquilibriert. Eine $50 \mu \mathrm{l}$ Proteinprobe, äquilibriert in MES-Puffer, wurde in eine Auftragsschleife injiziert. Anschließend erfolgte ein Gelfiltrationslauf mit einer Flussrate von $40 \mu \mathrm{l} / \mathrm{min}$, wobei die Probe automatisch auf die Säule aufgetragen wurde. Die Elution der Säule wurde in $20 \mu$ Aliquots fraktioniert und im Western-Blot analysiert. Als Größenstandard wurde anschließend ein Gemisch aus verschiedenen Standardproteinen unter gleichen Chromatographieund Pufferbedingungen über die Säule aufgetrennt. Nach Verwendung der Säulen wurden diese mit $\mathrm{dH}_{2} \mathrm{O}$ gespült und anschließend in $20 \%$ Ethanol abgestellt.

\subsubsection{Affinitätschromatografie mit Pepstatin A}

Probenpuffer:

25 mM MES

$150 \mathrm{mM} \mathrm{NaCl}$

$\mathrm{pH}$ mit $\mathrm{HCl}$ auf 4,5 eingestellt.

Waschpuffer:

25 mM MES

$250 \mathrm{mM} \mathrm{NaCl}$

$\mathrm{pH}$ mit $\mathrm{HCl}$ auf 4,5 eingestellt.

Elutionpuffer:

\author{
$10 \mathrm{mM}$ TRIS/HCl \\ $400 \mathrm{mM} \mathrm{NaCl}$ \\ $\mathrm{pH}$ mit $\mathrm{HCl}$ auf 8,3 eingestellt.
}


Zur Durchführung der Affinitätschromatographie mit Pepstatin A wurde die PepstatinA-Agarose von Pierce (Rockford, USA) verwendet. Es wurden 0,5 ml Pepstatin-ASuspension (50 \%ige Suspension von Pepstatin-A-Agarose in 30 \%igem Ethanol) in Probenpuffer äquilibriert $(C V=250 \mu l)$ und mit $200 \mu \mathrm{g}$ F2-Fraktionen in $1,5 \mathrm{ml}$ Probenpuffer für $3 \mathrm{~h}$ bei $4{ }^{\circ} \mathrm{C}$ auf dem Drehrad inkubiert. Alternativ zu Lysosomenangereicherten Fraktionen (F2) wurde aufgereinigtes rekombinantes, murines 66.3kDa-Protein (eigenen Produktion, vgl. Kap. 3.4.8), aufgereinigte, rekombinante, murine Scpep1 (eigene Produktion) und rekombinantes, murines, Cathepsin D (R\&D Systems, Minneapolis, USA) verwendet. Nach der Inkubation wurde der Ansatz auf eine $5 \mathrm{ml}$-Mobitec-Säule aufgetragen. Alle weiteren Wasch- und Elutionsschritte erfolgten mit vorgekühlten Puffern im Kühlraum bei $4{ }^{\circ} \mathrm{C}$, um die katalytische Aktivität der Hydrolasen im Ansatz möglichst gering zu halten. Nachdem das geladene Volumen als Durchfluss die Säule verlassen hatte, wurde die Säule mit $5 \times 500 \mu l$ Probenpuffer gespült. Anschließend erfolgte die Spülung mit $5 \times 500 \mu \mathrm{l}$ Waschpuffer, gefolgt von der Elution in $5 \times 250 \mu$ Elutionspuffer. Jede Fraktion wurde zur späteren Analyse in $1,5 \mathrm{ml}$ Eppendorfgefäßen aufgefangen. Nach Abschluss der Elution wurde die Säule zuerst mit $\mathrm{dH}_{2} \mathrm{O}$ gewaschen und anschließend in $\mathrm{dH}_{2} \mathrm{O}$ mit $20 \%$ Ethanol abgestellt und im Kühlraum gelagert. Zur Analyse der einzelnen Fraktionen wurden jeweils $5 \%$ der ersten und letzten Waschfraktion, sowie alle Elutionsfraktionen zusammen mit dem aufgetragenen Proteingemisch und der Durchflussfraktion im Western-Blot mit verschiedenen Antikörpern analysiert.

\subsubsection{Untersuchung von Protein-Protein-Interakionen mittels Quervernetzern}

\subsubsection{In-vivo-Quervernetzung mit photoaktiven Aminosäuren}

Markierungsmedium:

DMEM-LM (ohne die AS Leucin und Methionin)

$5 \%$ dialysiertes FKS

$+4 \mathrm{mM}=28,6 \mathrm{mg} / 50 \mathrm{ml}$

$+2 \mathrm{mM}=15,7 \mathrm{mg} / 50 \mathrm{ml}$.

Lysepuffer:

$10 \mathrm{ml}$ TBS

5 mM JAA

1 mM PMSF

1 mM EDTA. 
Das in-vivo-Quervernetzen wurde nach der Methode von Suchanek durchgeführt (Suchanek et al. 2005). Die dazu benötigten photoaktiven Aminosäuren L-PhotoLeucin und L-Photo-Methionin wurden von Thermo Scientific ${ }^{\circledR}$ (Pierce Biotechnology, Rockford, USA) bezogen.

Zum in-vivo-Quervernetzen wurden HT1080-66-Cat. D-Zellen sowie MEFs am Vortag des Versuchs auf 3-cm-Zellkulturschalen ausplattiert und über Nacht zu etwa $80 \%$ Konfluenz kultiviert. Die Zellen wurden zweimal mit PBS gewaschen und mit Markierungsmedium über Nacht inkubiert. Am Folgetag wurden die Zellen zweimal mit PBS gewaschen und mit ca. $500 \mu$ l Lysepuffer überschichtet. Zur Aktivierung der photoaktiven Aminosäuren wurden die Zellen im Abstand von $15 \mathrm{~cm}$ zur Lampe für 8,5 Minuten (5 x HWZ) mit UV-Licht bestrahlt (vgl. Kap. 4.4.1). Um die Zellen bei der Bestrahlung vor Schäden durch hochenergetisches UV-Licht zu schützen, wurden die Zellen auf Eis gekühlt und in den Strahlengang eine Filterscheibe installiert (vgl. Abb. 3.3). Nach der Bestrahlung wurden die Zellen mit dem Zellschaber geerntet und bei $500 \mathrm{~g}$ für $5 \mathrm{~min}$ abzentrifugiert. Der Überstand wurde verworfen und das Zellpellet wurde in $100 \mu \mathrm{l}$ Lysepuffer aufgenommen. Anschließend wurden die Zellen 6 × 20 sek sonifiziert. Nach der Homogenisierung wurden die Zellmembranen und die DNA durch Zentrifugation für $30 \mathrm{~min}$ bei 14000 rpm in der Kühlzentrifuge entfernt. Von dem Überstand wurde eine Proteinbestimmung durchgeführt und $250 \mu \mathrm{g}$ Gesamtprotein im Western-Blot analysiert.

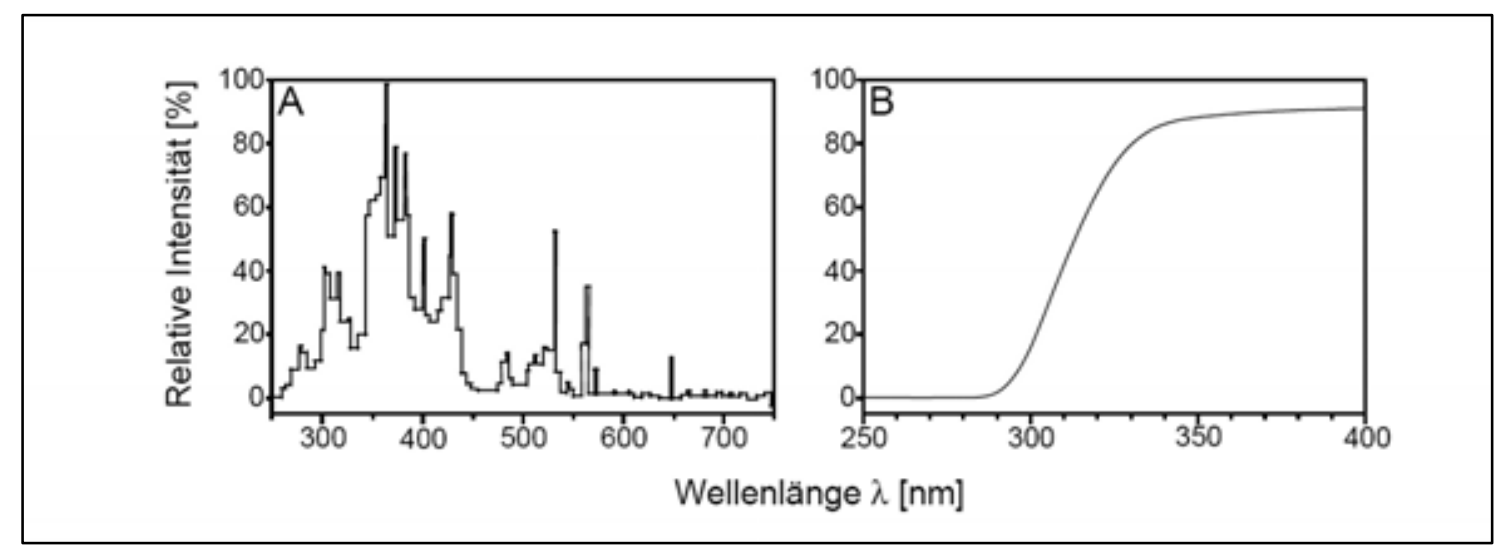

Abb. 3.3: Spektrale Eigenschaften der verwendeten UV-Lampe inklusive Filterscheibe

Abb. 3.3 (A) zeigt das Emissionsspektrum der verwendeten UV-Lampe (Ultratech 400). Dieses erstreckt sich in etwa von 250 bis $450 \mathrm{~nm}$, mit einem Maximum bei ca. $370 \mathrm{~nm}$. In (B) ist das Transmissionspektrum der schützenden Filterscheibe (B270) gezeigt, welches das auf den Zellen ankommende Licht auf Wellenlängen über $300 \mathrm{~nm}$ beschränkt. 


\subsubsection{In-vitro-Quervernetzung}

Zur in-vitro-Quervernetzung wurden $2 \mu \mathrm{g}$ aufgereinigtes rekombinantes 66.3-kDaProtein (eigene Produktion, vgl. Kap. 3.4.8) mit verschiedenen Quervernetzern inkubiert. Alle Pufferangaben und die eingesetzten Konzentrationen der Quervernetzer sowie die Inkubationszeiten wurden den Begleitinstruktionen der jeweiligen Quervernetzer entnommen (Pierce Biotechnology, Rockford, USA, www.piercenet.com).

Nach der Inkubation wurden alle Ansätze vollständig zur Analyse der Quervernetzung im Western-Blot eingesetzt.

\subsection{SPDP (N-succinimidyl 3-(2-pyridyldithio) propionat)}

PBS-EDTA-Puffer:

$$
\begin{aligned}
& 1 \times \text { PBS } \\
& 1 \text { mM EDTA } \\
& 0,02 \% \text { Natrium-Azid } \\
& \text { pH-Wert auf } 7,5 \text { eingestellt. }
\end{aligned}
$$

TRIS-Quenching-Puffer:

$$
\begin{aligned}
& 1 \mathrm{M} \text { TRIS/HCl } \\
& 10 \mathrm{mM} \text { Cystein } \\
& \text { pH-Wert auf 8,0 eingestellt. }
\end{aligned}
$$

Für die Quervernetzung mit SPDP wurde eine finale Konzentration von 0,5 mM SPDP im PBS-EDTA-Puffer eingesetzt und der Ansatz für 60 min bei RT inkubiert. Nach Ablauf der Inkubationszeit wurde dem Ansatz $10 \mu \mathrm{l}$ TRIS-Quenching-Puffer zugesetzt, um die verbliebenen freien Reaktionsstellen des Quervernetzter abzusättigen.

\subsection{Sulfo-DST (Sulfodisuccinimidyl-tartrat)}

Natrium-Phosphat-Puffer:

TRIS- Puffer:

\author{
$200 \mathrm{mM} \mathrm{NaH}_{2} \mathrm{PO}_{4}$ \\ $150 \mathrm{mM} \mathrm{NaCl}$ \\ pH-Wert auf 7,2 eingestellt. \\ $50 \mathrm{mM}$ TRIS/HCl \\ $\mathrm{pH}$-Wert auf 8,0 eingestellt.
}


Die Quervernetzung mit Sulfo-DST erfolgte mit Sulfo-DST in einer finalen Konzentration von 0,5 mM im TRIS- und Glycin-freien Natrium-Phosphat-Puffer. Der Ansatz wurde für 30 min bei RT inkubiert und nach Ablauf der Inkubationszeit dem Ansatz $10 \mu$ l TRIS-Puffer zum Besetzen der verbliebenen freien Reaktionsstellen des Quervernetzter zugesetzt.

\subsection{EDC/ Sulfo-NHS (1-ethyl-3-[3-dimethylaminopropyl]carbodiimid} hydrochlorid/ Sulfosuccinimidyl-6-(biotin-amido) hexanoate)

MES-Puffer: 100 mM MES $500 \mathrm{mM} \mathrm{NaCl}$ pH-Wert eingestellt auf 6,0.

Die Quervernetzung mit EDC/Sulfo-NHS erfolge in einem zwei-stufigen Prozess. Dazu wurde EDC in einer finalen Konzentration von 0,2 mM im MES-Puffer eingesetzt und der Ansatz für $15 \mathrm{~min}$ bei RT inkubiert. Nach Ablauf der Inkubationszeit wurde dem Ansatz $20 \mathrm{mM}$ ß-Mercaptoethanol zugesetzt, um die verbliebenen freien Reaktionsstellen des Quervernetzter zu besetzten. Anschließend wurde Sulfo-NHS in einer finalen Konzentration von 0,5 mM dem Ansatz beigefügt und PBS zum Umpuffern hinzugefügt. Der Ansatz wurde für 60 min bei RT inkubiert. Nach Ablauf der Inkubationszeit wurde dem Ansatz 10 mM Hydroxylamine zugesetzt, um die nicht-reagierten Quervernetzter zu hydrolysieren.

\subsubsection{Ko-Immunpräzipitation des 66.3-kDa-Proteins mit Cathepsin D} MES-Puffer: 25 mM MES $150 \mathrm{mM} \mathrm{NaCl}$ $\mathrm{pH}-$ Wert auf 4,5 eingestellt.

Für die Ko-Immunpräzipitation des 66.3-kDa-Proteins mit dem Cathepsin D wurden HT1080-66-Cat. D-Zellen homogenisiert und das Homogenat nachfolgend zweimal sonifiziert und $30 \mathrm{~min}$ bei $100000 \mathrm{~g}$ und $4^{\circ} \mathrm{C}$ abzentrifugiert. Das Homogenat wurde über Nacht mit Präimmunserum und Protein-G-Sepharose bei $4{ }^{\circ} \mathrm{C}$ inkubiert und am nächsten Tag erneut für 30 min bei $100000 \mathrm{~g}$ zentrifugieren (Pre-Cleaning). In jedem Ansatz der Ko-Immunpräzipitation wurde eine bestimme Menge Homogenat mit 6-fachen Volumen MES-Puffer verwendet. Jeder Ansatz enthielt weiterhin $10 \mu \mathrm{l}$ Protein-G-Sepharose (GE Healthcare, München), $10 \%$ BSA und 0,1\% SDS. Den 
Proben wurden 2,5 $\mu \mathrm{l}$ Cathepsin-D-Antiserum (KIIS5) hinzugegeben, während die Kontrolle 2,5 $\mu \mathrm{l}$ Präimmunserum enthielt. Es erfolgte eine 2-stündige Inkubation bei $4{ }^{\circ} \mathrm{C}$ auf dem Drehrad. Anschließend wurden die Ansätze achtmal mit MES-Puffer + $1 \%$ BSA gewaschen und in SDS-Probenpuffer aufgenommen (Masters 2004). Die Ansätze wurden mit dem 66-Antiserum im Western-Blot analysiert.

\subsubsection{MALDI-TOF-MS/PMF-Analyse zur Identifikation von Proteinen}

Proteine aus Gelen wurden über eine peptide mass fingerprinting-Analyse massenspektrometrisch identifiziert. Dazu wurden die Proteine mit der Protease Trypsin im Gel verdaut und die Massen der proteolytischen Peptide über Matrix Assisted Laser Desorption / Ionisation - Time Of Flight (MALDI-TOF) analysiert. Jedes Protein zeigt dabei ein charakteristisches Peptid-Muster verschiedener Massen, die mit einer Datenbank (Mascot, Matrix Science, Boston, USA) abgeglichen werden können. Aus dem Coomassie-gefärbten Gel wurden Stücke ausgestanzt und für $15 \mathrm{~min}$ bei $37^{\circ} \mathrm{C}$ in $100 \mu \mathrm{l}$ Waschlösung I, anschließend zweimal 30 min in Waschlösung II gewaschen und schließlich für 10 min in $100 \mu$ Acetonitril inkubiert. Danach wurde das Gelstück für etwa 5 min luftgetrocknet und die Proteine reduktiv in $10 \mu \mathrm{LTT}$-Lösung für $1 \mathrm{~h}$ bei $56^{\circ} \mathrm{C}$ carbamidomethyliert. Die Probe wurde auf Eis abgekühlt und der Überstand abgenommen. Das Gelstück wurde dann für $30 \mathrm{~min}$ bei RT in $10 \mu \mathrm{l}$ lodacetamid inkubiert, um die Proteine zu alkylieren. Anschließend wurde der Überstand abgenommen und noch vorhandenes, überschüssiges lodacetamid durch Inkubation bei $37^{\circ} \mathrm{C}$ für $10 \mathrm{~min}$ in $10 \mu \mathrm{DTT}$ Lösung abgefangen. Das Gelstück wurde erneut für 30 min bei $37^{\circ} \mathrm{C}$ in $100 \mu \mathrm{l}$ Waschlösung II, danach in $100 \mu \mathrm{l}$ Acetonitril inkubiert und getrocknet. Das Gelstück wurde in $6 \mu$ l einer $20 \mathrm{ng}$ Trypsin/ $\mu \mathrm{l}$ Waschlösung I auf Eis inkubiert, bis sich die Lösung vollständig in das Gelstück gesogen hatte. Dann wurde das Gelstück mit weiterer Waschlösung I bedeckt und ü. N. bei $37^{\circ} \mathrm{C}$ inkubiert. Der Überstand wurde am Folgetag abgenommen und die Peptide mit $20 \mu \mathrm{l} 1 \%$ Trifluoressigsäure (TFA) bei $37^{\circ} \mathrm{C}$ für $30 \mathrm{~min}$ aus dem Gel extrahiert. Die Lösung wurde im Vakuumkonzentrator eingeengt und nach Lyophilisierung in $10 \mu \mathrm{l} \mathrm{0,1 \%} \mathrm{TFA}$ aufgenommen. $0,5 \mu \mathrm{l}$ der Peptid-Lösung wurden mit 0,5 $\mu \mathrm{l}$ 2,5-Dihydroxybenzoesäure (DHB)-Matrix gemischt und auf das MALDI-target aufgetragen. Die Massen wurden nach Ko-Kristallisierung mit einem Reflex III (Bruker Daltonics) Massenspektrometer bestimmt und gegen den Mascot-Algorithmus mit der NCBI 
Proteindatenbank verglichen (Perkins et al. 1999). Auf Grund von Verunreinigungen durch die DHB-Matrix konnten Massen unter 500 Da nicht mehr detektiert werden.

\subsubsection{NAE-Aktivitätsbestimmung des 66.3-kDa-Proteins}

\subsubsection{Synthese von Substraten}

Als Substrate für die Überprüfung der hydrolytischen Aktivität des 66.3-kDa-Proteins wurden sowohl unterschiedliche ${ }^{14} \mathrm{C}$-markierte Fettsäuren mit Ethanolamin amidiert, als auch ${ }^{14} \mathrm{C}$-markiertes Ethanolamin mit freien Fettsäuren amidiert. Dabei erfolgte die Synthese der benötigten Substrate durch die Inkubation der Fettsäure mit dem Ethanolamin in Anwesenheit von 1-Ethyl-3-(3-dimethylaminopropyl)carbodiimid (EDC). Das EDC ist eine häufig in der Synthesechemie eingesetzte, reaktive organische Verbindung aus der Gruppe der Carbodiimide. Für die Synthese wurde sowohl das 1-Ethyl-3-(3-dimethylaminopropyl)carbodiimid-Hydrochlorid (EDC/HCl), als auch die entsprechenden freien Fettsäuren und das Ethanolamin in je $10 \mathrm{ml}$ trockenem Dichlormethan gelöst. Anschließend wurden $200 \mu \mathrm{l}$ des ${ }^{14} \mathrm{C}$-markierten Ethanolamins unter Stickstoff abgedampft und jeweils $100 \mu \mathrm{l}$ der freien Fettsäure und nicht radioaktiv markiertes Ethanolamin hinzugegeben. Der gesamte Syntheseansatz wurde mit Argon überschichtet und für $10 \mathrm{~min}$ im Eiswasser inkubiert. Nachfolgend wurde dem Ansatz $\mathrm{EDC} / \mathrm{HCl}$ hinzugegeben und erneut mit Argon überschichtet. Die Synthese erfolgte dann für 3,5 bis $4 \mathrm{~h}$ unter Rühren im Eiswasser. Nach abgeschlossener Synthese wurde der Ansatz wie folgt aufgearbeitet. Der Gesamtansatz wurde unter Stickstoff eingedampft und in $1 \mathrm{ml}$ Ethylacetat (EtOAc) aufgenommen. Nach Zugabe von $200 \mu \mathrm{d}_{2} \mathrm{O}$ wurde der Ansatz ausgeschüttelt und das $\mathrm{dH}_{2} \mathrm{O}$ anschließend wieder abgesaugt. Das gleiche Procedere wurde mit $200 \mu \mathrm{l}$

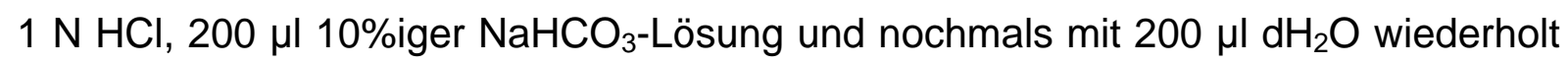
(Ueda et al. 1995).

\subsubsection{Inkubation und Analyse}

Probenpuffer:

100 mM Natrium-Citrat

$150 \mathrm{mM} \mathrm{NaCl}$

$3 \mathrm{mM}$ DTT

$0,1 \%$ Nonidet P40

$0,05 \%$ BSA

$\mathrm{pH}$-Wert auf 4,5 eingestellt. 
Subtrat (10x):

$20 \mu \mathrm{M}\left[{ }^{14} \mathrm{C}\right]$-markiertes N-Acylethanolamin

$+180 \mu \mathrm{M}$ nicht markiertes N-Acylethanolamin

in DMSO [2 mM].

HT1080-Zellen und HEK293T-Zellen, die entweder das 66.3-kDa-Protein oder die murine Naaa transient überexprimieren, sowie nur mit dem pcDNA3.1-Hygro (+)Vektor transfizierte HT1080-Zellen als Kontrolle, wurden $48 \mathrm{~h}$ nach der Transfektion homogenisiert und 20 bis $50 \mu \mathrm{g}$ der Zellhomogenate für die Aktivitätsbestimmung eingesetzt. Zusätzlich wurde $1 \mu \mathrm{g}$ aufgereinigtes rekombinantes 66.3-kDa-Protein in zwei verschiedenen Konzentrationen (3 bzw. $10 \mu \mathrm{g} / \mu \mathrm{l}$ ) auf seine Aktivität hin überprüft. Das eingesetzte Protein und die Zellhomogenate wurden für $30 \mathrm{~min}$ bei $37^{\circ} \mathrm{C}$ im Probenpuffer mit $200 \mu \mathrm{M}$ verschiedenen Substraten inkubiert (vgl. Tab. 4.7). Die Analyse der hydrolytischen Aktivität erfolgte mittels Dünnschichtchromatographie. Dazu wurde die Reaktion durch die Zugabe eines Diethylether-Methanol-Citrat-Gemisches (30:4:1 v/v) gestoppt. Die obere wässrige Phase wurde von der unteren organischen Phase quantitativ getrennt und die organische Phase jeder Probe auf eine $10 \mathrm{~cm}$ hohe DünnschichtchromatograpiePlatte aufgebracht. Anschließend erfolgte die Auftrennung mit dem Laufmittel aus Chloroform-Methanol-28\% Ammoniumhydroxid (40:10:1 v/v) für 25 min bei $4{ }^{\circ} \mathrm{C}$. Die Verteilung der radioaktiv markierten Fettsäure auf der Dünnschichtchromatographieplatte wurde mittels Bioimager visualisiert (Tsuboi et al. 2005).

\subsection{Weitere Methoden}

\subsubsection{Kristallisation von Proteinen}

Die Kristallisation des 66.3-kDa-Proteins wurde in der Abteilung Molekulare Strukturbiologie von Dr. Kristina Lakomek durchgeführt. Für die detaillierte Beschreibung der Kristallisation vgl. Lakomek 2009. Hier sollen der Vollständigkeit halber nur die wichtigsten Abläufe der Kristallisation, wie sie für das 66.3-kDa-Protein durchgeführt wurde, dargestellt werden.

Zur Kristallisation des 66.3-kDa-Proteins wurden 1,6 $\mu \mathrm{l}$ einer Proteinkonzentration von $23 \mathrm{mg} / \mathrm{ml}$, die sowohl die 66-kDa-Proform, als auch die beiden 40- und 28-kDa- 
Fragmente nach der Methode des „sitzenden Tropfens" bei $0{ }^{\circ} \mathrm{C}$ inkubiert. Die verwendete Reservoirlösung enthielt $12 \%$ (w/v) PEG 4000, $200 \mathrm{mM}$ Ammoniumacetat und $100 \mathrm{mM}$ Natriumacetat. Der pH-Wert wurde dabei mit 5,0 auf lysosomale Verhältnisse eingestellt. Nach wenigen Tagen bildeten sich Kristalle. Für die Röntgenstrukturanalyse wurden die Kristalle in eine Kryoprotektionslösung überführt, mit Xenon begast und anschließend direkt in flüssigen Stickstoff eingefroren und am BESSY Beamline BL14.2 mit dem SX165 Detektor analysiert (Lakomek et al. 2009a).

\subsubsection{Analyse ethanolaminderivatisierter Lipide}

\subsubsection{Lipidextraktion aus Zellen}

Zur $0,5 \mathrm{ml}$ Zellsuspension mit metabolisch markierten Ethanolderivaten (vgl. 3.3.5) wurde $1 \mathrm{ml}$ Chloroform/Methanol (2:1 v/v) hinzugegeben und der Ansatz anschließend ausgeschüttelt. Der Ansatz wurde stehen gelassen bis sich deutlich zwei Phasen voneinander getrennt hatten. Die obere, wässrige Phase wurde verworfen und die untere Chloroform-Phase, in der sich die extrahierten Lipide befinden, wurde im Stickstoffstrom bei $37^{\circ} \mathrm{C}$ eingedampft (Roldan and Harrison 1989; Signorell et al. 2008) und für die Dünnschichtchromatographie verwendet.

\subsubsection{2-D Dünnschichtchromatographie}

Für die Dünnschichtchromatographie wurden die getrockneten Lipidextrakte in $200 \mu \mathrm{l}$ Chloroform:Methanol (2:1 v/v) aufgenommen und die darin enthaltene Radioaktivität bestimmt. 100000 dpm der HT1080-66-Zell-Extrakte und 400000 dpm der MEF66gt-Zell-Extrakte wurden auf eine Dünnschichtchromatographieplatte aufgebracht. Die Dünnschichtchromatographie wurde nachfolgend in zwei Dimensionen durchgeführt. Dabei diente als Laufmittel für die 1. Dimension ein Gemisch aus Chloroform:Methanol:25 \%Ammoniak:Wasser (90:74:12:8 v/v). Für die 2. Dimension wurde anschließend ein Gemisch aus Chloroform:Methanol:Ameisensäure:Wasser (40:15:15:12:8 v/v) verwendet (Bütikofer et al. 1989; Signorell et al. 2008). Die Detektion der Verteilung der radioaktiven Ethanolaminderivate auf der Dünnschichtchromatographieplatte erfolgte mittels Exposition gegenüber einer Phospho-Imaging-Plate. 


\section{Ergebnisse}

\subsection{Interaktion von 66.3-kDa-Proteinfragmenten mit Cathepsin D im Yeast-Two-Hybrid-System}

Vorarbeiten der Arbeitsgruppe wiesen auf eine Interaktion zwischen dem 66.3-kDa-

Protein und der lysosomalen Aspartylprotease Cathepsin D hin. Mittels Affinitätschromatographie konnten erste Hinweise auf die Interaktion der beiden Proteine gefunden werden (Deuschl 2008). Um diese zu validieren, sollte die Interaktion im Yeast-Two-Hybrid-System (Y2H-System) überprüft werden.

\subsubsection{Klonierung mit den Y2H-Vektoren pGADT7 und pGBKT7}

Aus vorangegangenen Arbeiten mit dem 66.3-kDa-Protein im $\mathrm{Y} 2 \mathrm{H}$-System war bekannt, dass das 28- sowie das 15-kDa-Fragment des 66.3-kDa-Proteins eine leichte Interaktion mit dem Cathepsin D zeigte. Um diese Hinweise auf eine Interaktion besser beurteilen zu können, wurden umfangreiche Kontrollen im YeastTwo-Hybrid-System durchgeführt.

Für diese Versuche wurde das Matchmaker GAL4 Two-Hybrid-System 3 der Firma Clontech ${ }^{\circledR}$ mit den Vektoren pGBKT7 als sogenannter bait-Vektor (Köder) und pGADT7 als sogenannter prey-Vektor (Beute) verwendet (vgl. Kap. 8.1.1). Es wurden verschiedene Inserts durch Add-on-PCR mit Primern, welche Schnittstellen für die Restriktionsendonukleasen EcoR1 und BamH1 trugen gerichtet in den pGADT7 und/oder in den pGBKT7 kloniert (vgl. Kap. 3.2.5.1 und Kap. 8.1.2 sowie Tab. 4.1). Das pcDNA3.1-66.3-kDa-Protein-Plasmid diente dabei als Template für die Amplifikation. Anschließend wurden die Konstrukte durch Sequenzierung hinsichtlich ihrer Vollständigkeit und Integrität analysiert. 
Tab. 4.1: Yeast-Two-Hybrid-Klonierungen

\begin{tabular}{ll}
\hline pGADT7 (prey) & pGBKT7 (bait) \\
\hline Cathepsin D - full length & Cathepsin D - full length \\
75-kDa-Proform & 75-kDa-Proform \\
40-kDa-Fragment & 40-kDa-Fragment \\
28-kDa-Fragment & 28-kDa-Fragment \\
15-kDa-Fragment & 15-kDa-Fragment \\
Leervektor & Leervektor \\
SV40 (large T-Antigen) & p53 \\
\hline
\end{tabular}

\subsubsection{SD-Selektionsplatten}

Um die Interaktion zu analysieren, wurde der Hefestamm AH109 mit den prey- und bait-Vektoren in den folgenden Konstellationen (vgl. Tab. 4.2) kotransfiziert und das Wachstum auf sogenannten Mangelnährböden analysiert.

Tab. 4.2: Y2H-Konstellationen

\begin{tabular}{lll}
\hline Nr. & pGADT7 (prey) & pGBKT7 (bait) \\
\hline+ & SV 40 (large T-Antigen) & p53 \\
1 & Cathepsin-D-full length & 15-kDa-Fragment \\
2 & 15-kDa-Fragment & Cathepsin-D-full length \\
3 & Cathepsin-D-full length & 28-kDa-Fragment \\
4 & 28-kDa-Fragment & Cathepsin-D-full length \\
5 & Cathepsin-D-full length & 40-kDa-Fragment \\
6 & 40-kDa-Fragment & Cathepsin-D-full length \\
7 & Cathepsin-D-full length & 66.3-kDa-Protein-full length \\
8 & 66-3-kDa-Protein-full length & Cathepsin-D-full length \\
9 & Cathepsin-D-full length & Leervektor \\
10 & Leervektor & Cathepsin-D-full length \\
11 & Leervektor & 28-kDa-Fragment \\
12 & 28-kDa-Fragment & Leervektor \\
13 & Leervektor & 15-kDa-Fragment \\
14 & 15-kDa-Fragment & Leervektor \\
- & Leervektor & p53 \\
\hline
\end{tabular}


Dabei diente ein Wachstum der Hefen auf Selektionsnährböden ohne die Aminosäuren Leucin und Tryptophan als Kontrolle der Doppeltransfektion. Wuchsen die Hefen auch auf Nährböden, denen zusätzlich die Aminosäure Histidin fehlte, zeigte dies eine schwache Interaktion der getesteten Proteine an. Ein Wachstum der Hefen auf Nährböden, denen zusätzlich zu den Aminosäuren Leucin, Tryptophan und Histidin die Purinbase Adenin fehlte, wies letztendlich auf eine starke Interaktion der Partner hin (vgl. Abb. 4.1), da nur bei einer stabilen Interaktion der beiden Proteine die jeweiligen Transkriptionsfaktoren ausreichend lange in räumlicher Nähe sind, um auch das Ablesen der Information für die Synthese der Purin-Base Adenin zu gewährleisten. Diese dem Hefestamm AH109 fehlenden Aminosäuren bzw. die Purin-Base Adenin werden in diesem Zusammenhang als auxotrophe Marker bezeichnet.

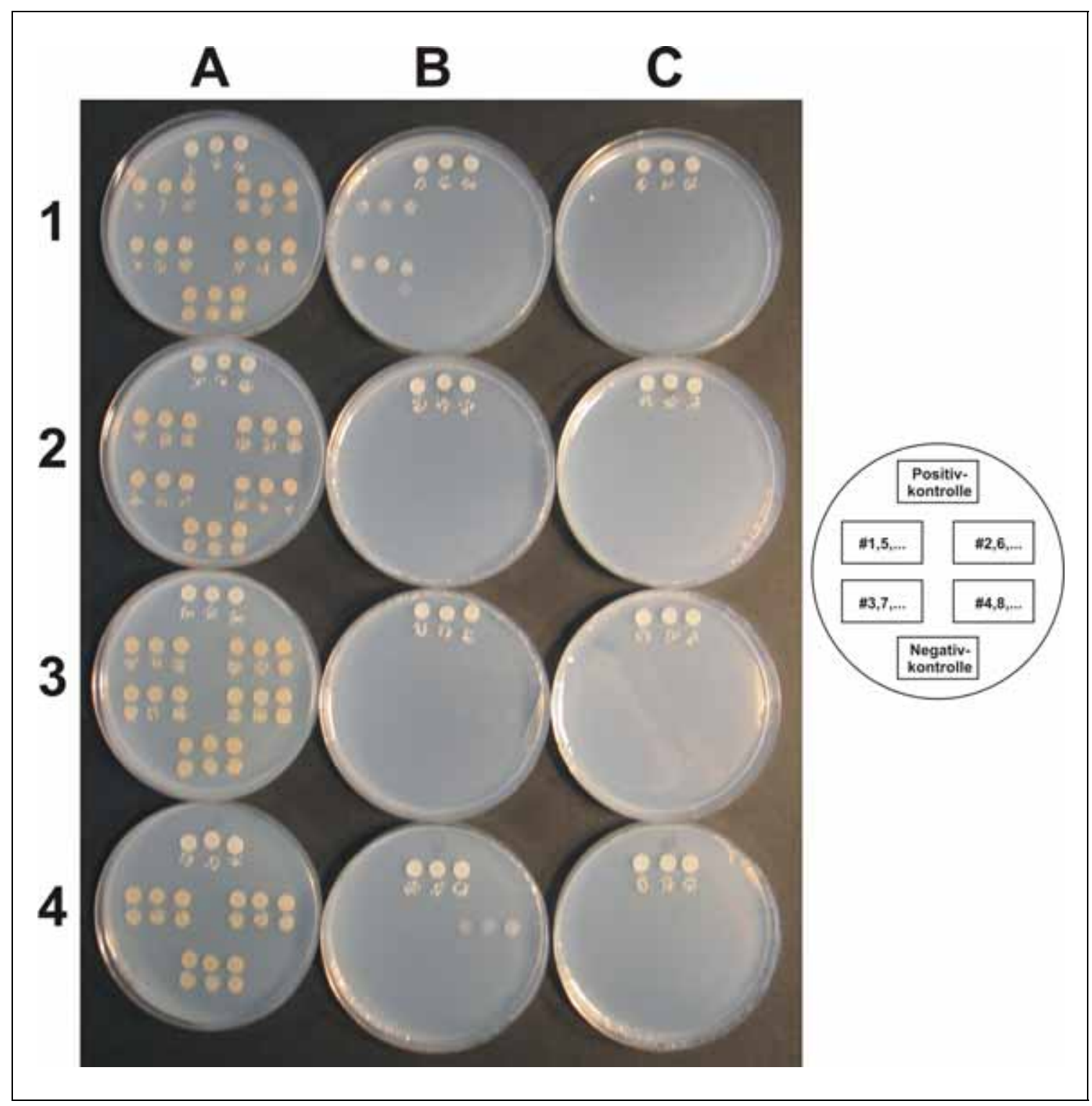

Abb. 4.1: Übersicht der Ergebnisse aus dem Y2H-Versuch 
Abb. 4.1 zeigt die gesamten Ergebnisse des $\mathrm{Y} 2 \mathrm{H}$-Versuchs. Alle Klone wurden in Triplikaten und in zwei verschiedenen Konzentrationen ausplattiert. Auf jeder Platte befindet sich oben die Positivkontrolle aus SV40 mit p53, unten eine Negativkontrolle mit leerem prey-Vektor mit p53, dazwischen jeweils vier bzw. zwei verschiedene Klone (vgl. Musterplatte rechts). Links sind die Klone auf dem SD-Medium -Leu/-Trp als Kotransfektionskontrolle dargestellt (A). Rechts davon die Klone auf SD-Medium -Leu/Trp/-His als Indikator einer leichten Interaktion (B). Auf der rechten Seite die Klone auf SD-Medium -Leu/-Trp/-His/-Ade als Hinweis einer starken Interaktion (C). Wie in Spalte A zu erkennen ist, wurden alle Klone suffizient kotransfiziert und ermöglichen den Hefen damit ein Wachstum auf diesem Mangelnährboden (-Leu/-Trp). Die Hefen der Positivkontrolle wachsen auf jeder Platte und zeigen damit die Funktionalität des Y2H-Systems an. Das auf den Platten B1 und B4 zu erkennende Wachstum weiterer Klone, als Hinweis auf eine leichte bis mittlere Interaktion, ist in Abb. 4.2 detailliert dargestellt.

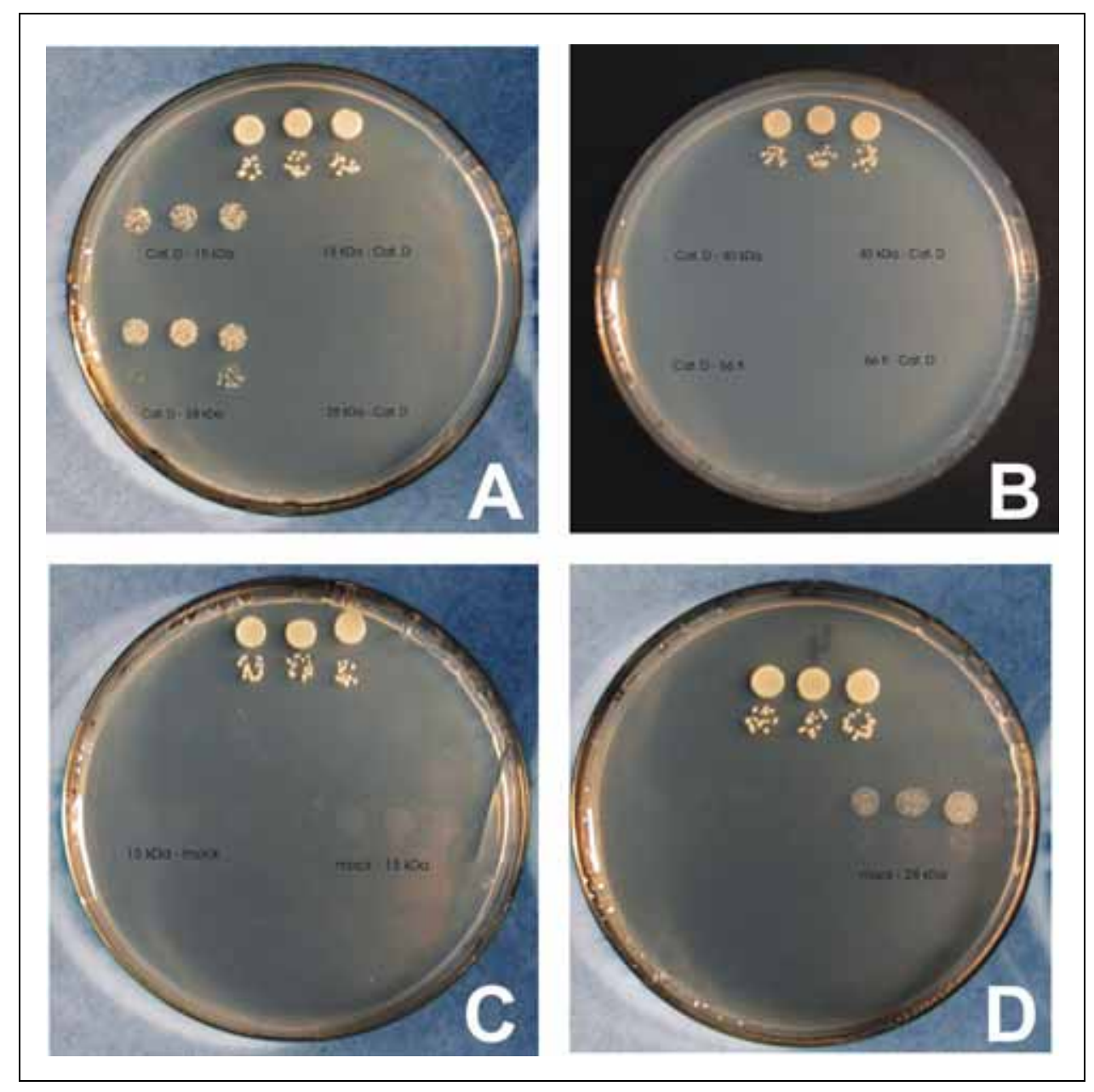

\section{Abb. 4.2: Y2H-Ergebnisse im Detail}

Das Wachstum aller Klone auf dem SD-Medium -Leu/-Trp/-His ist hier im Detail dargestellt. Oben auf jeder Platte ist die Positivkontrolle aus SV40 mit p53. Cathepsin D mit dem 15- bzw. 28-kDa-Fragment zeigt ein deutliches Wachstum, zum Teil auch in der geringeren ausplattierten Konzentration, wohingegen das Wachstum der umgekehrten Orientierung kaum zu erkennen ist (A). Das 40-kDaFragment sowie die 66-full-length-Form zeigen kein Wachstum (B). Das 15-kDa-Fragment (C), als auch das 28-kDa-Fragment (D) mit dem leeren prey-Vektor zeigen dem gegenüber ein deutliches Wachstum.

Bei den getesteten Konstellationen zeigte sich, wie es in Vorarbeiten bereits beschrieben wurde (Deuschl 2008), eine schwache Interaktion zwischen dem Cathepsin D im bait-Vektor einerseits und dem 28- bzw. dem 15-kDa-Fragment im prey-Vektor andererseits. Die Positivkontrolle mit SV40 und p53 zeigte 
erwartungsgemäß eine starke Interaktion, während sich bei den Kontrollen aus dem 28- bzw. 15-kDa-Fragment mit dem leeren prey-Vektor keine Interaktion darstellen ließ. Allerdings zeigten die Versuchsanordnungen in umgekehrter Orientierung, in denen die Inserts aus prey- und bait-Vektoren getauscht wurden, davon abweichende Ergebnisse. So ließ sich hier zwischen den 66.3-kDa-ProteinFragmenten im bait-Vektor und dem Cathepsin D im prey-Vektor keine Interaktion darstellen, wohingegen die Negativkontrollen aus leeren bait-Vektoren mit dem 28bzw. dem 15-kDa-Fragment im prey-Vektor gleichsam eine schwache Interaktion aufwies (vgl. Abb. 4.1 und Abb. 4.2).

\subsubsection{Aktivitätsbestimmung der $\beta$-Galaktosidase}

Um eine quantitative Aussage über die Interaktionsstärke der einzelnen Ansätze zu erzielen und somit mehr über die Qualität der Interaktion der Fragmente des 66-kDaProteins und Cathepsin D sagen zu können, wurde ein quantitativer $\beta$-GalaktosidaseAssay (ONPG-Assay) durchgeführt. Hierbei machte die enzymatische Umsetzung des o-Nitrophenyl- $\beta$-D-Galaktopyranosid (ONPG) als Indikator eine Quantifizierung der Interaktion möglich (vgl. Kap. 3.2.5.3). Dabei war die Umsetzung des Substrates direkt proportional zur in den getesteten Hefen durch die Interaktion der Partner induzierten und somit neu gebildeten $\beta$-Galaktosidase (vgl. Abb. 4.3). Es wurden die Umsatzraten der verschiedenen Konstellationen analysiert und mit jener der Positivkontrolle aus p53 mit dem large-T-Antigen (SV40) verglichen, um einen relativen Wert für jede Konstellation zu erhalten (vgl. Abb. 4.4).

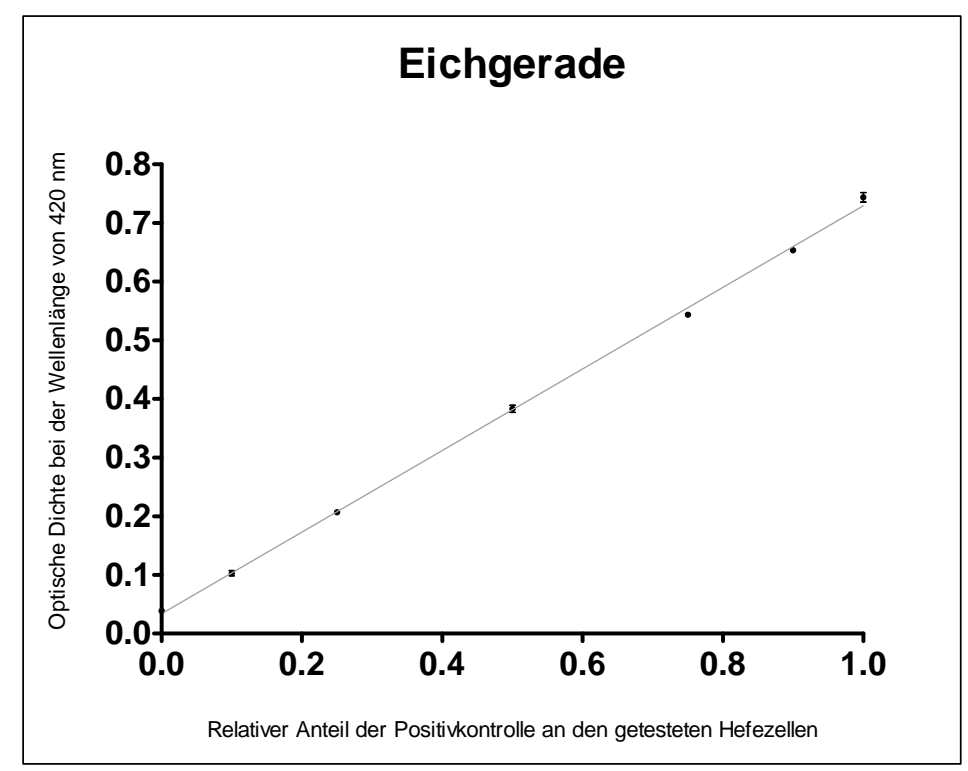

\section{Abb. 4.3: Eichgerade für ONPG- Assay}

Es wurden sechs Ansätze mit jeweils unterschiedlichen Anteilen an p53SV40 doppelttransfizierten Hefezellen (Positivkontrolle) mit nicht transfizierten Hefezellen gemischt und drei Stunden mit ONPG inkubiert. Dabei besteht eine verlässliche Korrelation zwischen dem Anteil der $\beta$-Galaktosidaseproduzierenden Hefezellen und der Umsetzung des Substrates ONPG, wie die in Abb. 4.3 dargestellte Eichgerade zeigt (Bestimmtheitsgrad $R^{2}=0.9988$ ). 
Hierbei zeigte sich, dass die Stärke der Interaktion zwischen dem Cathepsin D und dem 28-kDa-Fragment einerseits und zwischen Cathepsin D und dem leeren bait-Vektor andererseits in etwa vergleichbar war (vgl. Abb. 4.4). Dieses Ergebnis bestätigte das Wachstumsverhalten der Klone auf den Selektionsmedien in vollem Umfang. Daher ist im $\mathrm{Y} 2 \mathrm{H}$ von einer unspezifischen Interaktion zwischen dem 28bzw. dem 15-kDa-Fragment und dem bait-Vektor pGADT7 auszugehen, so dass die Ergebnisse der $\mathrm{Y} 2 \mathrm{H}$-Versuche insgesamt keine Bestätigung der Interaktion von Cathepsin D mit dem neu gefundenen lysosomalen Matrixprotein 66.3-kDa-Protein leisten konnten.

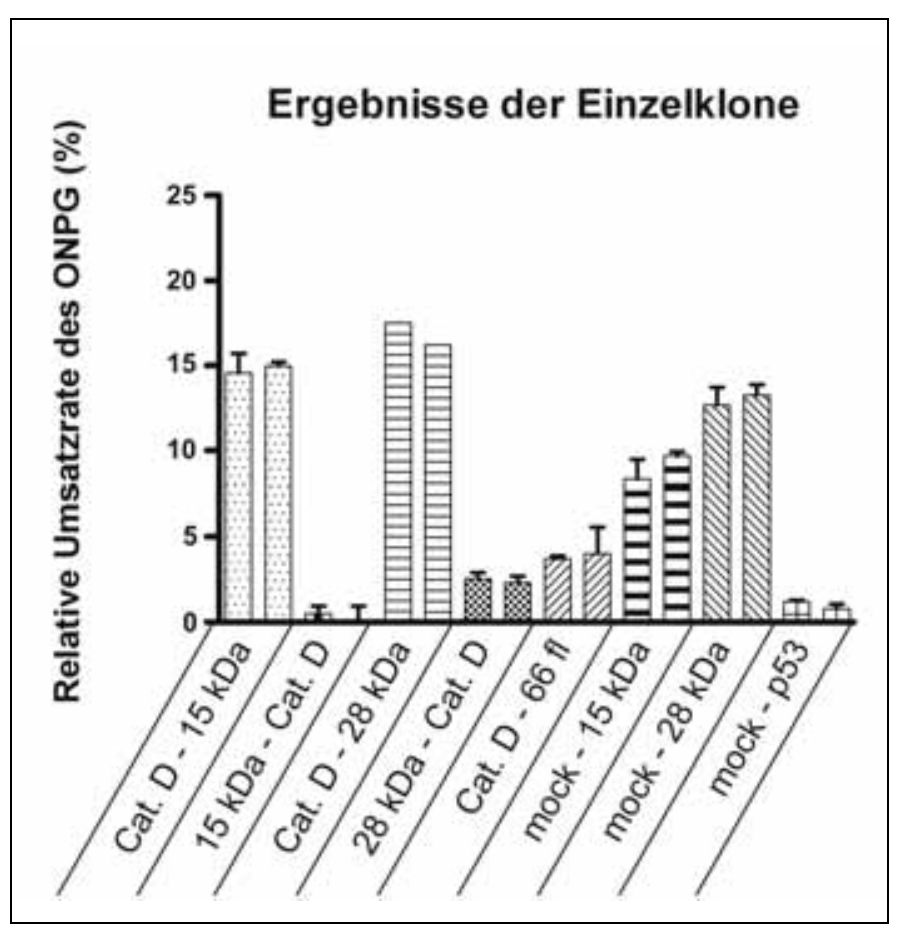

\section{Abb. 4.4: ONPG-Assay}

Abb. 4.4 zeigt die relative Umsatzrate des ONPG der einzelnen Klone im Verhältnis zur Umsatzrate der Positivkontrolle. Die Untersuchungen wurden für jede Konstellation mit zwei verschiedenen Klonen in Doppelwerten durchgeführt, daher ergeben sich jeweils zwei Säulen für jeden Ansatz. 


\subsection{Affinitätschromatographie mit Pepstatin A}

Die Y2H-Ergebnisse konnten die Interaktion zwischen Cathepsin D und dem 66.3kDa-Protein nicht bestätigen. Kritisch ist dabei der neutrale pH-Wert im Zellkern der Hefen, bei dem die Interaktion im $\mathrm{Y} 2 \mathrm{H}$ stattfinden müsste, der für die Interaktionen lysosomaler Proteine unphysiologisch ist. Daher sollte mittels einer alternativen Methode die Interaktion von Cathepsin D und dem 66.3-kDa-Protein im sauren Millieu bestätigt werden.

Im folgenden Versuchsansatz sollte Cathepsin D im Komplex mit seinen möglichen Interaktionspartnern präzipitiert werden. Dafür wurde Pepstatin A als artifizielles Substrat und hochaffiner Inhibitor des Cathepsin D auf einer Chromatographiesäule immobilisiert. Anschließend wurde die Chromatographiesäule mit Pepstatin-Agekoppelter Matrix mit einer Lysosomen-angereicherten, subzellulären Fraktion, in der die Lysosomen etwa 50-fach angereichert sind, beladen. Dabei sollten PepstatinA-bindende Proteine aus der Lysosomen-angereicherten Fraktion, wie Cathepsin D, als auch Proteine, die mit Proteinen wie Cathepsin D interagieren, auf der Chromatographiesäule verbleiben, während alle anderen unspezifisch gebundenen Proteine in den Waschfraktionen zu finden sein sollten.

Die Pepstatin-A-Chromatographie-Säule wurde mit Puffern im sauren $\mathrm{pH}$-Bereich mit steigender Salzkonzentration gewaschen. Für die Elution des Cathepsin $D$ vom Pepstatin A inklusive möglicher Interaktionspartner wurde ein Puffer mit leicht alkalischem pH-Wert gewählt, um die $\mathrm{pH}$-abhängige Interaktion von Cathepsin $\mathrm{D}$ und Pepstation A aufzuheben. Die unterschiedlichen Wasch- und Elutionsfraktionen wurden aufgefangen und im Western-Blot analysiert.

In einem ersten Versuchsansatz wurde die Pepstatin-A-Chromatographie-Säule ausschließlich mit der subzellulären, Lysosomen-angereicherten Fraktion („F2“Fraktion) beladen. Dabei konnte eine effiziente Bindung des Cathepsin $D$ an das Pepstatin $\mathrm{A}$, sowie dessen $\mathrm{pH}$-abhängige Elution beobachtet werden (vgl. Abb. 4.5 A). Eine Bindung des endogenen 66.3-kDa-Proteins an die Chromatographie-Säule konnte nicht nachgewiesen werden, so dass das gesamte 66.3-kDa-Protein in der 
Durchbruch-Fraktion zu detektieren war (Ergebnisse wurden aus Gründen der Übersichlichtkeit nicht dargestellt).

Cathepsin D macht schätzungsweise ca. $10 \%$ des gesamten lysosomalen Matrixproteins in der Leber aus, während für das 66.3-kDa-Protein von einer geringeren Expressionshöhe ausgegangen werden muss. Um die Bedingungen für eine Interaktion zwischen dem Cathepsin D und dem 66.3-kDa-Protein stöchiometrisch zu optimieren, wurde einem zweiten Versuchsansatz aufgereinigtes rekombinantes 66.3-kDa-Protein zugemischt. Ein weiterer Vorteil gegenüber dem vorherigen Versuchsansatz war, dass nun alle Formen des 66.3-kDa-Proteins, von der 75-kDa-Proform bis zum prozessierten 40- bzw. 28-kDa-Fragment, im Versuchsansatz enthalten waren, so dass auch eine Interaktion mit der unprozessierten Vorläuferform darstellbar wäre. Im Versuchsansatz 2 wurde ein Pepstatin A von einem anderen Hersteller verwendet, dadurch ergab sich eine weniger effiziente Bindung des Cathepsin D an das Pepstatin A als im Versuchsansatz 1 (vgl. Abb. 4.5).

\section{Tab. 4.3: Versuchsansätze für die Pepstatin-A-Chromatographie}

Die Tab. 4.3 zeigt die zwei verschiedenen Versuchsansätze für die Chromatographie mit Pepstatin A mit besonderem Augenmerk auf das geladene Protein.

\begin{tabular}{ll}
\hline Ansatz & Säulenbeladung \\
\hline 1 & endogenes Cathepsin D und 66.3-kDa-Protein („F2“-Fraktion) \\
\hline 2 & $\begin{array}{l}\text { endogenes Cathepsin D und 66.3-kDa-Protein („F2“-Fraktion) } \\
+ \\
\text { + aufgereinigtes rekombinantes 66.3-kDa-Protein } \\
+ \text { aufgereinigtes rekombinantes Scpep1-Protein }\end{array}$ \\
\hline
\end{tabular}



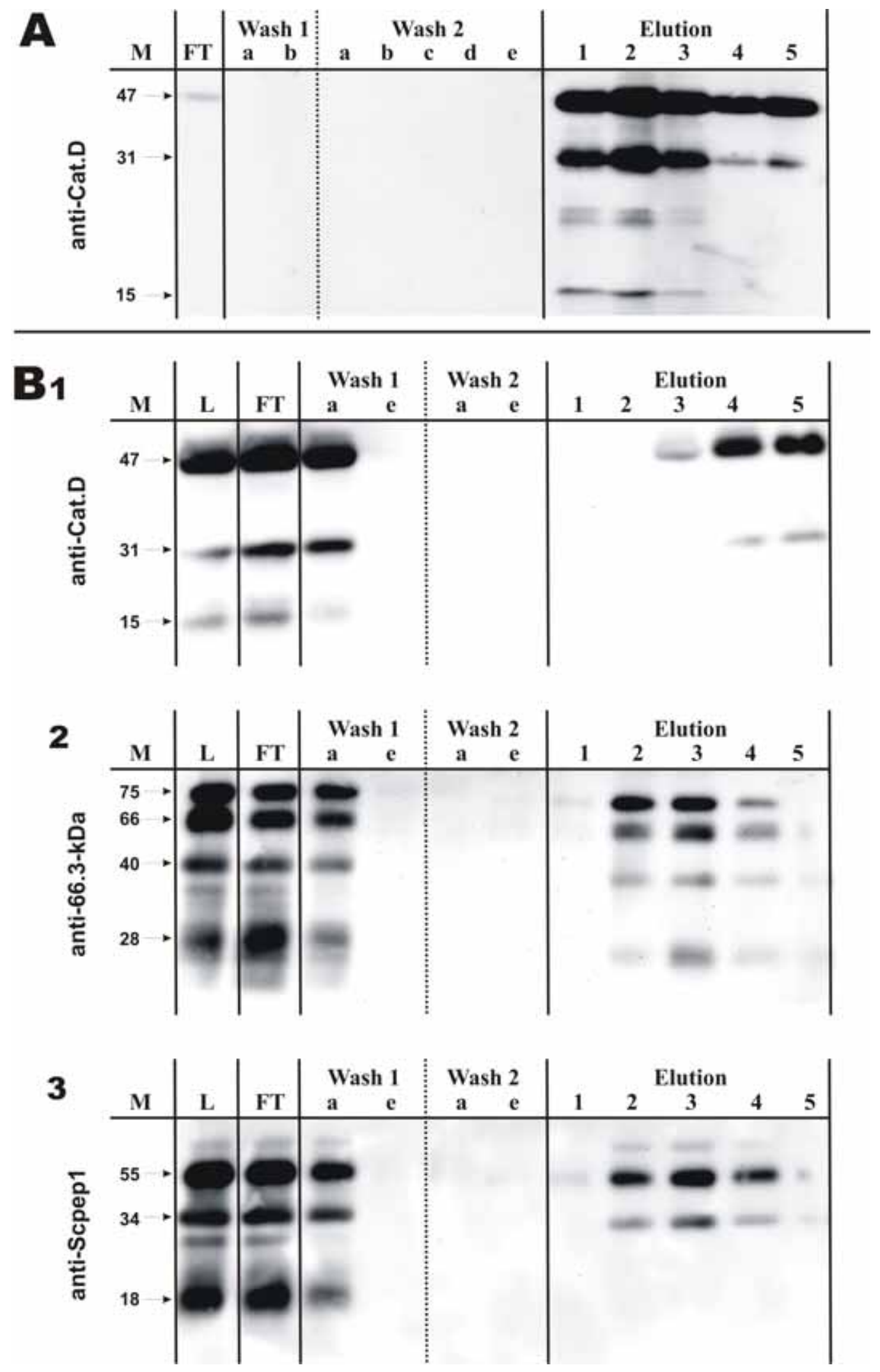

Abb. 4.5: Western-Blot-Analyse der aufgefangenen Fraktionen der Pepstatin-AChromatographiesäule nach Beladung mit Lysosomen-angereicherten Fraktionen

Erläuterungen siehe nächste Seite 
A: $200 \mu \mathrm{g}$ „F2“-Fraktion wurden mit der Pepstatin-A-Matrix für drei Stunden bei $4{ }^{\circ} \mathrm{C}$ inkubiert und anschließend der flow through (=Durchbruch, FT) aufgefangen. Im Folgenden wurde mit MES-Puffern (pH 4,5; 150 bzw. $250 \mathrm{mM} \mathrm{NaCl}$ ) mit 2 × 2,5 ml (Wash 1) bzw. $5 \times 2,5 \mathrm{ml}$ (Wash 2) gewaschen und die Fraktionen wurden aufgefangen. Die Säule wurde mit $5 \times 2,5 \mathrm{ml}$ TRIS/HCl-Puffer, $400 \mathrm{mM} \mathrm{NaCl}, \mathrm{pH}$ 8,3 eluiert und die Fraktionen wurden entsprechend aufgefangen (E1-5). Alle Fraktionen wurden über Nacht TCA-gefällt, vollständig auf ein Polyacrylamidgel geladen und anschließend auf eine PVDFMembran übertragen. Der Western-Blot wurde mit anti-Cathepsin-D-Antikörper entwickelt. Links sind die entsprechend zu erkennenden Fragmente des Cathepsin D mit Pfeilen markiert.

B: $200 \mu \mathrm{g}$ „F2“-Fraktion mit jeweils $10 \mu \mathrm{g}$ aufgereinigtem rekombinantem 66.3-kDa-Protein und Scpep1 wurden mit der Pepstatin-A-Matrix für drei Stunden bei $4{ }^{\circ} \mathrm{C}$ inkubiert $(\mathrm{L})$ und anschließend der flow through (=Durchbruch, FT) aufgefangen. Im Folgenden wurde mit MES-Puffern (pH 4,5; 150 bzw. $250 \mathrm{mM} \mathrm{NaCl}$ ) mit jeweils $5 \times 0,5 \mathrm{ml}$ gewaschen und die Fraktionen wurden aufgefangen. Aufgetragen wurden jeweils die erste und letzte Fraktion der beiden Waschschritte (W1a, e; W2a, e). Die Säule wurde mit $5 \times 250 \mu \mathrm{IRIS} / \mathrm{HCl}$-Puffer, $400 \mathrm{mM} \mathrm{NaCl}, \mathrm{pH} 8,3$ eluiert und die Fraktionen wurden entsprechend aufgefangen (E1-5). 5\% jeder Fraktion wurden auf ein Polyacrylamidgel geladen und anschließend auf eine PVDF-Membran übertragen. (B1) wurde mit anti-Cathepsin-DAntikörper entwickelt, (B2) mit 66-Antiserum und (B3) mit anti-Scpep1-Antikörper. Links sind die verschiedenen Fragmente eines jeden Proteins mit Pfeilen markiert.

Im Versuchsansatz 2 ließ sich eine pH-abhängige Ko-Elution des 66.3-kDa-Proteins mit dem Cathepsin D darstellen (vgl. Abb. 4.5 B1, B2). Dabei fällt auf, dass überwiegend die unprozessierten Formen des aufgereinigten, rekombinanten 66.3kDa-Proteins, wie die 75-Proform respektive die 66-kDa-Form, in den Elutionsfraktionen zu detektieren waren, während die prozessierten endogenen Fragmente des 66.3-kDa-Proteins überwiegend im Durchbruch (flow through, FT) zur Darstellung kamen. Selbiges ließ sich auch für das Cathepsin D beobachten. Das 66.3-kDa-Protein eluierte bereits eine Fraktion vor dem Cathepsin D, welches sich mit einer schwächeren Bindung zwischen dem 66.3-kDa-Protein und dem Cathepsin D im Vergleich zu Cathepsin D mit dem Inhibitor Pepstatin A erklären ließe.

Als Kontrolle, ob es sich bei der dargestellten Ko-Elution des Cathepsin D mit dem 66.3-kDa-Protein um eine spezifische Interaktion handelt, wurde mit der Scpep1 ein weiteres lysosomales Matrixprotein dem Versuchsansatz in aufgereinigter, rekombinanter Form zugesetzt und anschließend im Western-Blot analysiert (vgl. Abb. 4.5 B3). Dabei ist zu erkennen, dass die Scpep1 in identischer Weise wie das 66.3-kDa-Protein mit dem Cathepsin D koeluiert.

\subsection{Ko-Immunpräzipitation mit Cathepsin D}

Da auch die Scpep1 als Kontrollprotein in ähnlicher Weise wie das 66.3-kDa-Protein mit dem Cathepsin D von der Pepstatin-A-Chromatographiesäule koeluierte, konnte 
nicht sicher davon ausgegangen werden, dass es sich bei der gezeigten Ko-Elution um eine spezifische Interaktion des 66.3-kDa-Proteins mit dem Cathepsin D handelt. Daher wurde im folgenden Versuchsansatz ein Cathepsin-D-Antiserum (KIIS5) (vgl. 3.1.8.1) zur spezifischen Ko-Immunpräzipitation des 66.3-kDa-Proteins verwendet. Dazu wurden HT1080-Zellen, in denen sowohl das Cathepsin D als auch das 66.3kDa-Protein stabil überexprimiert werden, homogenisiert und Cathepsin D wurde mit dem KIIS5-Antiserum mittels Protein-G-Sepharose aus dem HT1080-ZellHomogenat in MES-Puffer bei einem für lysosomale Bedingungen physiologischen $\mathrm{pH}$-Wert von 4,5 immunpräzipitiert. Die Präzipitate wurden gewaschen und im Western-Blot mit dem 66-Antiserum bezüglich einer Ko-Immunpräzipitation des 66.3kDa-Proteins mit dem Cathepsin D analysiert. Als Negativkontrolle wurde der Versuch mit Prä-Immunserum aus Kaninchen durchgeführt.

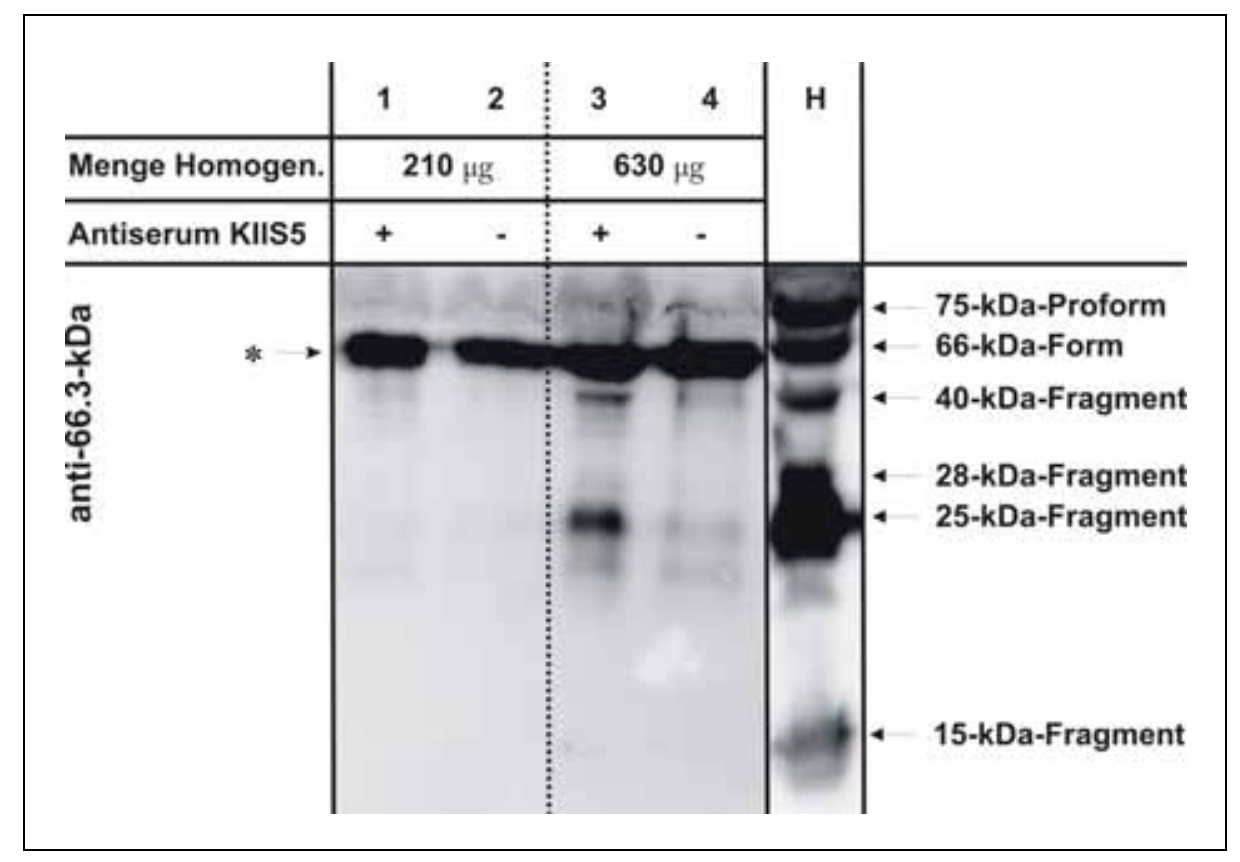

\section{Abb. 4.6: Ko-Immunpräzipitation mit Cathepsin D}

Abb. 4.6 zeigt die Ergebnisse der Ko-Immunpräzipitation. Detektiert wurden die verschiedenen Formen des 66.3-kDa-Proteins mit dem 66-Antiserum nach Präzipitation des Cathepsin D aus HT1080-Zell-Lysaten. In Spalte 1 und 2 sind $25 \mu$ Zellhomogenat eingesetzt worden, in Spalte 3 und $475 \mu \mathrm{l}$. Zum Ausschluss von unspezifischen Präzipitaten in den Proben wurde jeder Ansatz mit spezifischen Antikörper KIIS5 (+) und mit Prä-Immunserum aus Kaninchen (-) durchgeführt. In Spalte $\mathrm{H}$ wurden $50 \mu \mathrm{g}$ HT1080-Zellhomogenat aufgetragen. Dabei waren alle Formen des 66.3-kDaProteins zu detektieren. In Spalte 3 waren spezifische Banden des 40-kDa-Fragments und des 25kDa-Fragments zu detektieren, was eine Ko-Immunpräzipitation dieser beiden Formen des 66.3-kDaProteins anzeigt. In der dazugehörigen Kontrolle mit Prä-Immunserum waren diese Banden des 66.3kDa-Proteins in wesentlich geringerer Intensität zu detektieren. Bei den mit ${ }^{*}$ ) markierten Banden bei ca. $50 \mathrm{kDa}$, die sich in allen Immunpräzipitationsansätzen darstellen, handelt es sich um die schweren Ketten aus dem verwendeten Cathepsin-D-Antiserum (KIIS5) bzw. Prä-Immunserum. 
Bei der Ko-Immunpräzipitation mit dem Cathepsin-D-Antiserum konnte sowohl das 40-kDa-Fragment als auch das 25-kDa-Fragment des 66.3-kDa-Proteins mit dem Cathepsin D präzipitiert werden. In der Negativkontrolle mit Prä-Immunserum konnten die entsprechenden Fragmente des 66.3-kDa-Proteins mit sehr viel geringerer Intensität detektiert werden (vgl. Abb. 4.5). Diese Ergebnisse sprechen für eine spezifische Interaktion des 40-kDa-Fragments sowie des 25-kDa-Fragmentes mit dem Cathepsin D. Die in allen Ansätzen zu detektierende Bande bei etwa 50 kDa wird von den schweren Ketten der bei der Ko-Immunpräzipitation verwendeten Antikörper im Cathepsin-D-Antiserum (KIIS5) als auch im Prä-Immunserum aus Kaninchen hervorgerufen.

\subsection{Interaktionsstudien mittels Quervernetzung}

\subsubsection{In-vivo-Quervernetzung}

Eine weitere Möglichkeit die Interaktion zwischen Proteinen darzustellen ist die chemisch kovalente Verknüpfung in räumlicher Nähe zueinander liegender Moleküle mittels chemischer Agenzien (Quervernetzer). Hierbei werden Proteine über sogenannte Quervernetzer kovalent miteinander verknüpft, so dass anschließend die Analyse der neu gebildeten Komplexe mit verschiedenen Verfahren möglich ist. Eine besonders physiologische Variante, bei der die Interaktionspartner in der lebenden Zelle ohne Anwesenheit von chemischen Agenzien verlinkt werden können, ist das in-vivo-Quervernetzen mit photoaktiven Aminosäuren (Suchanek et al. 2005). Diese Methode erfordert allerdings eine große räumliche Nähe der entsprechenden Aminosäuren der potentiellen Interaktionspartner. Zusätzlich müssen die photoaktiven Aminosäuren, die während der metabolischen Markierung in das Molekül eingebracht werden, auch an der Interaktion der Proteine teilnehmen bzw. in der räumlichen Nähe zum Interaktionsmotiv liegen. Das 66.3-kDa-Protein enthält eine Reihe von Leucin- (74x) und Methioninseitengruppen (16x), die für diese Art des Quervernetzens benötigt werden.

Für das Quervernetzen mit photoaktiven Aminosäuren wurden HT1080 Zellen, die das 66.3-kDa-Protein stabil überexprimieren, für 24 Stunden mit Zellkulturmedium inkubiert, welches statt der proteinogenen Aminosäuren Leucin und Methionin, Photo-Leucin und Photo-Methionin enthielt. Dieser als metabolische Markierung 
bezeichnete Vorgang der Inkoorperation der photoaktiven Aminosäuren in neusynthetisierte Proteine erfolgte über Nacht. Um die photoaktiven Aminosäuren in einen reaktiven Zustand zu überführen, musste ihnen Energie zugeführt werden. Dazu wurden die Zellkulturschalen auf Eis mit UV-Licht mit einem Emissionsspektrum zwischen 280 und $450 \mathrm{~nm}$ bestrahlt. Zum Schutz der Zellen vor zu hochenergetischer Strahlung wurde zwischen UV-Lampe und Zellkulturschale eine Filterscheibe installiert, die auf Grund ihres Transmissionsspektrums das Licht der Wellenlängen unter $300 \mathrm{~nm}$ nicht hindurch ließ. (Die UV-Lampe mit zugehöriger Filterscheibe in der entsprechenden Apparatur wurde freundlicherweise von Dr. Olaf Jahn am Max Planck Institut für Experimentelle Medizin zur Verfügung gestellt.)

Zur Ermittlung der genauen Bestrahlungsdauer im Experiment wurden die photoaktiven Aminosäuren zuvor in PBS gelöst und in einem Vorversuch mit dem beschriebenen Versuchsaufbau bestrahlt. Die Reaktion der photoaktiven Aminosäuren wurde anhand der Abnahme der Absorption von Licht der Wellenlänge $345 \mathrm{~nm}$ gemessen. Nach diesem Vorgehen wurde eine Halbwertszeit der photoaktiven Aminosäuren von 1,5 Minuten ermittelt (vgl. Abb. 4.7). Laut Herstellerangaben soll die Bestrahlung der Zellen nach der metabolischen Markierung mit fünf Halbwertszeiten (HWZ) erfolgen. Da die UV-Lampe nach dem Anschalten einige Zeit benötigte, um das Licht mit einem konstanten Energieniveau zu emittieren, wurde grundsätzlich mit einer Minute Vorlaufzeit gearbeitet. Deshalb ergab sich die Bestrahlungsdauer aus der fünffachen HWZ (7,5 min) plus 1 min Vorlauf, also 8,5 min Bestrahlung jeder Probe im Experiment.

\section{Abb. 4.7: Bestimmung der Halbwertszeit der photoaktiven Aminosäuren}

Für die Ermittlung der Halbwertszeit wurden photoaktive Aminosäuren (1 $\mathrm{mg} / \mathrm{ml})$ in PBS gelöst und im Abstand von $15 \mathrm{~cm}$ zur Lichtquelle bestrahlt, während die Absorption bei $345 \mathrm{~nm}$ in regelmäßigen Abständen bestimmt wurde. Dabei ergab sich eine Halbwertszeit der photoaktiven Aminosäuren von 1,562 min mit einer Genauigkeit von $\mathrm{R}^{2}=0,9996$.

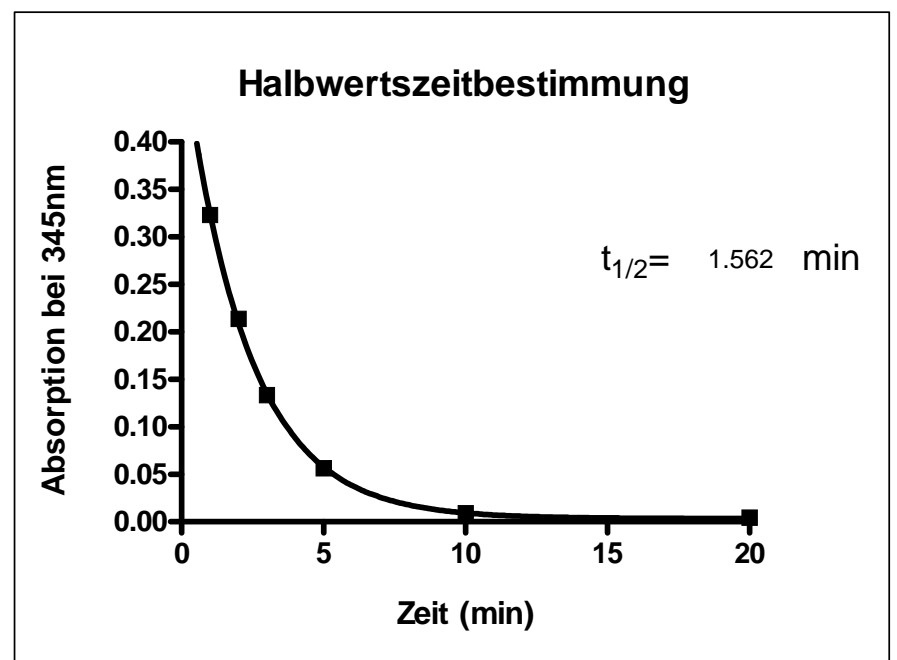


Nach der 8,5-minütigen Bestrahlung wurden die Zellen homogenisiert, im Polyacrylamidgel ihrer Größe nach aufgetrennt und auf eine PVDF-Membran übertragen. Der Western-Blot wurde mit dem 66-Antiserum (G9) analysiert (vgl. Abb. 4.8).

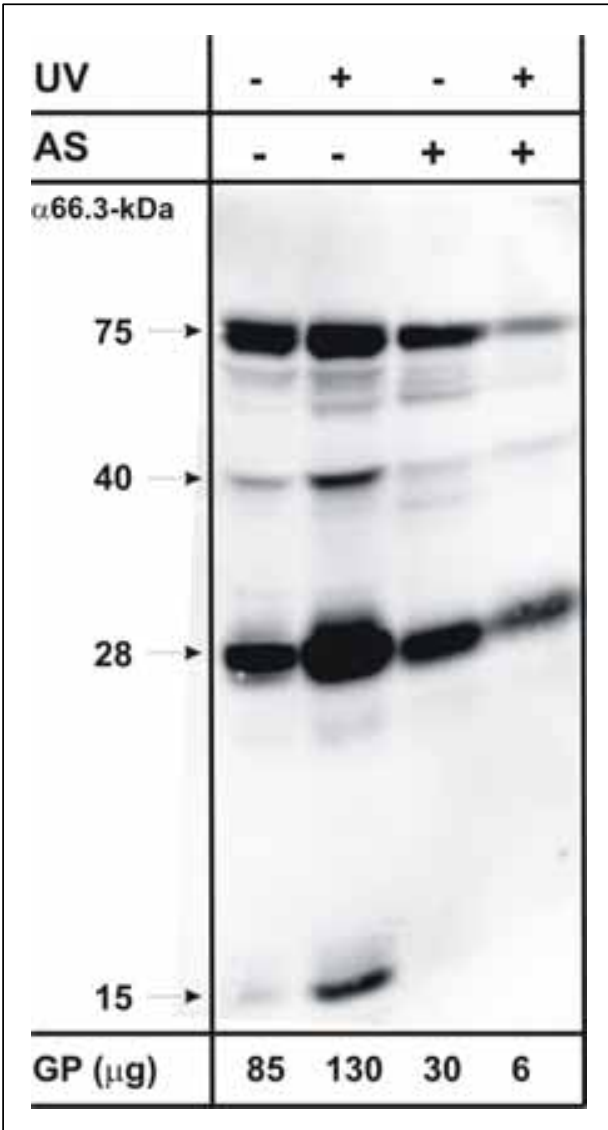

Abb. 4.8: 66.3-kDa-Protein überexprimierende HT1080Zellhomogenate nach in-vivo-Quervernetzung mit photoaktiven Aminosäuren

Der in Abb. 4.8 dargestellte Western-Blot zeigt die HT108066.3-kDa-Zell-Homogenate nach der in-vivoQuervernetzung mit photoaktiven Aminosäuren. Die Fragmente des 66.3-kDa-Proteins wurden mit dem 66Antiserum (G9) detektiert. Als Negativkontrollen wurden Zellhomogenate von HT1080-66.3-kDa-Zellen, die weder bestrahlt (UV) noch metabolisch markiert (AS) wurden, sowie Zellen, die entweder nur bestrahlt oder nur metabolisch markiert wurden, denen, die metabolisch markiert und bestrahlt wurden, gegenübergestellt. Dabei fallen die quantitativen Unterschiede des aufgetragenen Gesamtproteins (GP) auf. Signifikante Unterschiede in den Bandenmustern sind allerdings nicht zu erkennen.

Wie in Abb. 4.8 dargestellt, zeigten sich deutliche, quantitative Unterschiede zwischen den einzelnen Versuchsansätzen. Diese resultieren aus der unterschiedlichen Menge an geladenem Protein, da die Proteinausbeute im Homogenat nach mehrminütiger Inkubation der Zellen in PBS mit anschließender Zentrifugation bei einigen Ansätzen nur sehr schwach war. Signifikante Unterschiede in den Proteinbanden des 66.3-kDa-Proteins, sowie hochmolekulare Proteinkomplexe nach dem Quervernetzen mit den photoaktiven Aminosäuren lassen sich jedoch nicht erkennen, so dass auf weitere Versuche verzichtet wurde.

\subsubsection{In-vitro-Quervernetzung}

Das in-vitro-Quervernetzen bietet die Möglichkeit des Interaktionsnachweises verschiedener Proteine, bzw. einzelner Proteinuntereinheiten miteinander. Hierbei 
wurden allerdings keine photoaktiven Aminosäuren verwendet, sondern verschiedene klassische heterobifunktionale Quervernetzer.

Anders als bei der in-vivo-Quervernetzung, bei der eine Quervernetzung mit allen potentiellen Interaktionspartnern möglich gewesen wäre, sollte in diesem Versuchansatz die Komplexbildung des 66.3-kDa-Proteins in Form von Di- bzw. Oligomerisierung der einzelnen Fragmente des 66.3-kDa-Proteins untereinander überprüft werden. Dazu wurde aufgereinigtes rekombinantes 66.3-kDa-Protein mit verschiedenen Quervernetzern inkubiert (vgl. Tab. 4.4) und anschließend im Western-Blot mit dem 66-Antiserum (G9) analysiert.

\section{Tab. 4.4: Verwendete Quervernetzer}

Die Tab. 4.4 listet alle im Versuchsansatz verwendeten Quervernetzer auf. Dabei sind deren Eigenschaften bezüglich der Länge des Spacerarms und das Reaktions-pH-Optimum angegeben.

\begin{tabular}{lll}
\hline Abk. & Name & Eigenschaften \\
\hline SPDP & N-succinimidyl 3-(2-pyridyldithio) propionat & Spacer: 6,8 \\
& & pH-Optimum: 7-8 \\
Sulfo-DST & Sulfodisuccinimidyl-tartrat & Spacer: 6,4 $\AA$ \\
& & pH-Optimum: 7-9 \\
EDCl & 1-ethyl-3-[3-dimethylaminopropyl]carbodiimid hydrochlorid & Spacer: 22,4 \\
Sulfo-NHS & Sulfosuccinimidyl-6-(biotin-amido) hexanoate & pH-Optimum: \\
& & $4,5-7,2$ \\
\hline
\end{tabular}

Nach der Inkubation des aufgereinigten rekombinanten 66.3-kDa-Proteins mit den Quervernetzern Sulfo-DST und EDC/Sulfo-NHS konnten keine Unterschiede zum Ausgangsmaterial festgestellt werden. Allerdings zeigte sich nach der Inkubation mit dem SPDP eine neue Bande, die bei etwa 140-160 kDa mit dem 66-Antiserum (G9) detektiert werden konnte, während die anderen Banden des 66.3-kDa-Proteins deutlich an Intensität gegenüber dem Ausgangsprotein abgenommen hatten. Dies legt eine Beteiligung der 66-, 40-, 28-kDa-Formen an der Komplexbildung des 66.3kDa-Proteins nahe, während die 75-kDa-Proform nicht an der Komplexbildung beteiligt zu sein scheint. Auch eine hier erstmals in der Deutlichkeit zu erkennende 25-kDa-Form des 66.3-kDa-Proteins scheint an der Komplexbildung beteiligt zu sein. Auf die genauere Bedeutung dieser 25-kDa-Form wird später ausführlich 
eingegangen (vgl. Kap. 4.8). Auf Grund des Molekulargewichts von etwa 140 kDa könnte es sich bei den gebildeten Komplexen am ehesten um eine Homodimerisierung von zwei 66.3-kDa-Proteinen bzw. den jeweiligen Fragmenten handeln. Eine weitere deutlich schwächere Bande mit noch höherem Molekulargewicht lässt sich ebenfalls nach der Inkubation mit SPDP erkennen (vgl. Abb. 4.9).

\section{Abb. 4.9: In-vitro-Quervernetzung des 66.3-kDa-} Proteins mit verschiedenen Quervernetzern

Abb. 4.9 zeigt den Western-Blot der verschiedenen Ansätze des 66.3-kDa-Proteins, welche mit den Quervernetzern der Tab. 4.4 inkubiert wurden. Dabei ist in der ersten Reihe die gleiche Menge an unbehandeltem 66.3-kDa-Protein aufgetragen. Nach Inkubation mit Sulfo-DST und EDC/Sulfo-NHS finden sich keine signifikanten Unterschiede zum Ausgangsmaterial. Nach der Inkubation mit SPDP finden sich zwei weitere Banden, die sich mit dem 66-Antiserum (G9) darstellen lassen (rote Pfeile). Diese haben ein ungefähres Molekulargewicht von 140 bzw. 250-300 kDa. Ebenfalls gut zu erkennen ist eine Abnahme der Intensität der anderen Banden des 66.3-kDa-Proteins, mit Ausnahme der 75-kDaProform.

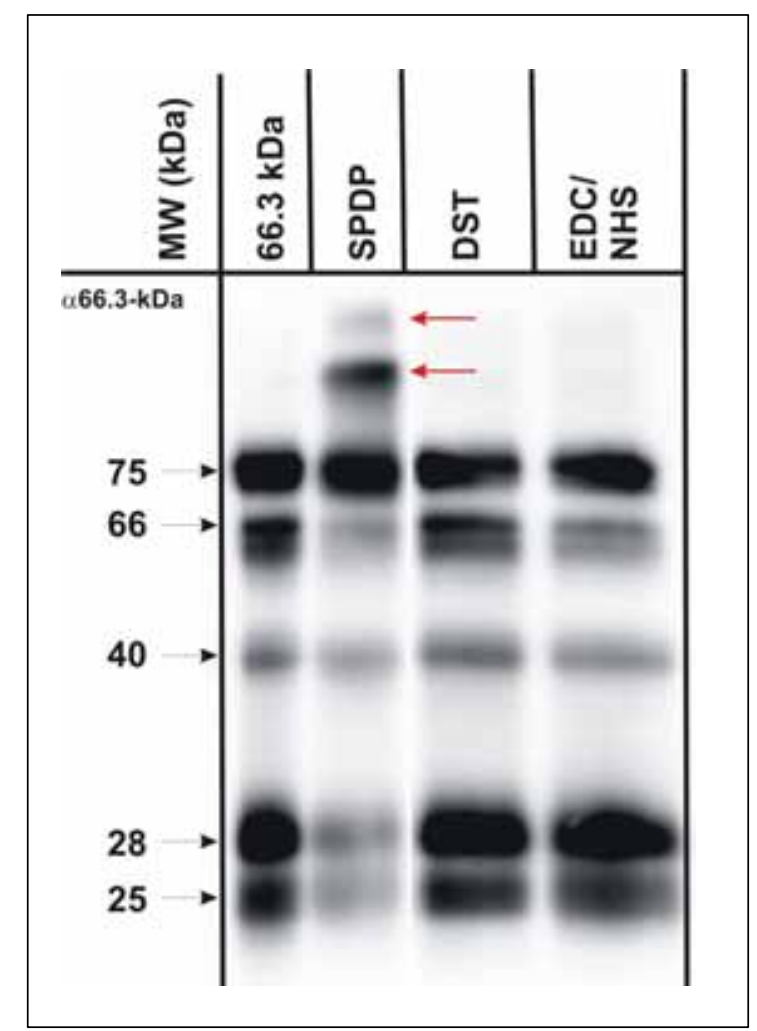




\subsection{Kristallstruktur des 66.3-kDa-Proteins}

Die im Folgenden dargestellten Ergebnisse wurden in enger Kooperation mit der Abteilung Molekulare Strukturbiologie von Herrn Prof. Ficner ermittelt. Dabei verteilten sich die Arbeitsschritte wie nachfolgend beschrieben. Die Expression und Aufreinigung des 66.3-kDa-Proteins mit den beiden Chromatographieschritten wurde in der Abteilung Biochemie II, AG Lübke durchgeführt. Die darauf folgende präparative Gelfiltration, sowie alle Arbeiten zur Kristallisation und Modellgenerierung wurden ausschließlich von der Abteilung Strukturbiologie durchgeführt. Eine im Anschluss an die Kristallisation durchgeführte analytische Gelfiltration wurde wiederum in der Abteilung Biochemie II durchgeführt. Die sich anschließenden Überlegungen zur möglichen Funktion und zu potentiellen Substraten des 66.3-kDaProteins waren Gegenstand gemeinsamer Diskussionen.

Teile der daraus entstandenen Ergebnisse wurden bereits gemeinsam publiziert:

Lakomek K, Dickmanns A, Kettwig M, Urlaub H, Ficner R, Lübke T (2009a): Initial insight into the function of the lysosomal $66.3 \mathrm{kDa}$ protein from mouse by means of X-ray crystallography. BMC Struct Biol $\underline{9}, 56$.

Lakomek K, Dickmanns A, Mueller U, Kollmann K, Deuschl F, Berndt A, Lübke T, Ficner R (2009b): De novo sulfur SAD phasing of the lysosomal $66.3 \mathrm{kDa}$ protein from mouse. Acta Crystallogr D Biol Crystallogr $\underline{65}$, 220-228.

\subsubsection{Klonierung und stabile Expression des 66.3-kDa-Proteins}

Die Klonierung und stabile Expression des 66.3-kDa-Proteins wurde in Vorarbeiten der AG Lübke nach folgendem Vorgehen durchgeführt. Mittels Reverser Transkription und Polymerase-Kettenreaktion wurde cDNA aus Gesamt-MausleberRNA amplifiziert. Anschließend wurde die cDNA des 66.3-kDa-Proteins am CTerminus mit einem His-Tag versehen und so modifiziert in den eukaryontischen Expressionsvektor pcDNA3.1-Hygro (+) kloniert. Nach der Transfektion von HT1080Zellen mit dem pcDNA3.1-Hygro (+)-Vektor, welcher die cDNA des 66.3-kDaProteins trug, wurden mittels Hygromycin B-Selektion stabil transfizierte Einzelklone mit möglichst hoher Expressionsrate ausgewählt und expandiert (Deuschl et al. 2006). 


\subsubsection{Aufreinigung des 66.3-kDa-Proteins zur Kristallisation}

Zur Kristallisation von Proteinen werden extrem reine und hochkonzentrierte Proteinlösungen benötigt. Diese Tatsache stellt besondere Anforderungen an die Aufreinigung des zu kristallisierenden Proteins.

Im Fall des 66.3-kDa-Proteins wurde das Protein aus dem Zellkulturüberstand einer überexprimierenden Fibrosarkomzelllinie (HT1080 vgl. Tab. 3.2) aufgereinigt. Insgesamt wurden ca. 50 Liter Zellkulturmedium geerntet und das darin enthaltene Protein quantitativ mittels Ammoniumsulfat gefällt, um es anschließend über zwei nacheinander geschaltete Chromatographieschritte aufzureinigen. Dabei diente das C-terminale His-Tag zur Aufreinigung über Ni-NTA, an die sich eine Ionenaustauschersäule anschließt. Das so aufgereinigte rekombinante 66.3-kDaProtein enthält sowohl die Vorläuferform mit einem Molekulargewicht von $75 \mathrm{kDa}$, als auch die beiden Fragmente mit 40 bzw. 28 kDa, da diese während der Aufreinigung nicht voneinander getrennt werden konnten (vgl. Abb. 4.10). Da die mit dieser Lösung entstandenen Kristalle nur bedingt zur Kristallanalyse verwendet werden konnten (vgl. Kap. 4.5.3), erfolgte ein finaler Aufreinigungsschritt mittels Gelfiltration, welcher die nötige Reinheit des aufgereinigten rekombinanten 66.3-kDa-Proteins gewährleistete (vgl. Abb. 4.12).

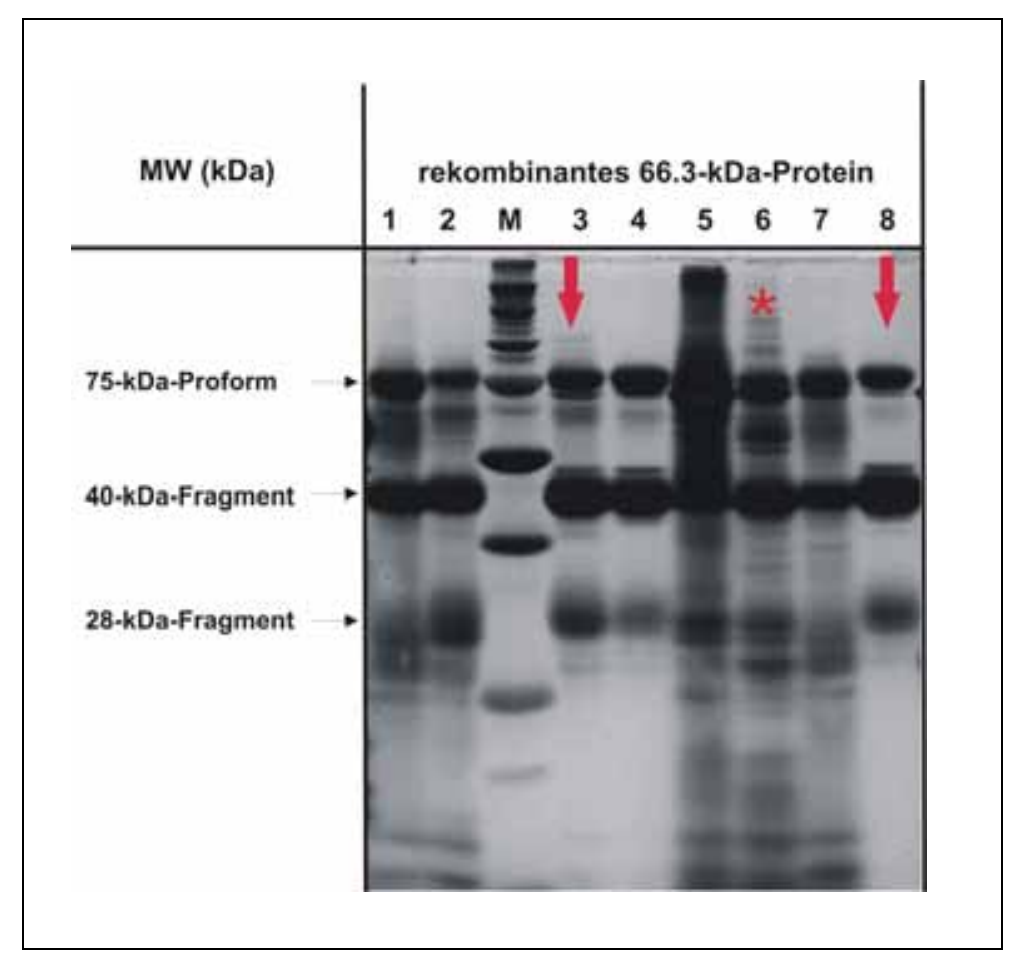

Abb. 4.10: Aufgereinigtes 66.3-kDa-Protein im Silbergel 
Die Abb. 4.10 zeigt das Ergebnis der Aufreinigung des rekombinanten 66.3-kDa-Proteins nach den beiden affinitätschromatographischen Schritten im Silbergel. Dazu wurden $4 \mu \mathrm{g}$ unterschiedlicher Aufreinigungen im Silbergel analysiert. Dabei ist die mit rotem Sternchen gekennzeichnete Aufreinigung in HEPES-Puffer, während alle anderen in TRIS-Puffer vorliegen. Die mit roten Pfeilen markierten Präparationen drei und acht wurden auf Grund ihrer Reinheit für die Kristallisation verwendet. Zwischen Spalte zwei und drei ist ein Größenstandard aufgetragen.

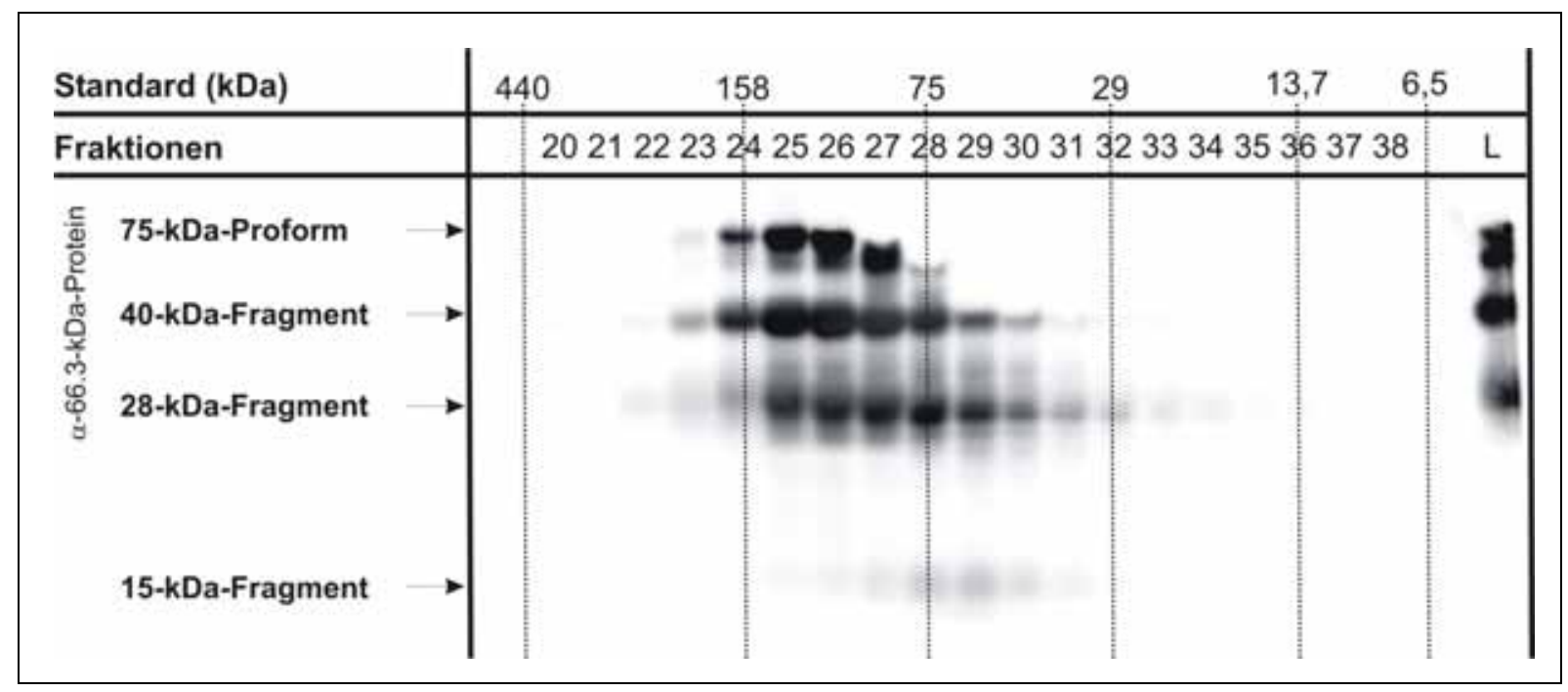

\section{Abb. 4.11: Gelfiltration des 66.3-kDa-Proteins als finaler Aufreinigungsschritt}

Die Abb. 4.11 zeigt die Gelfiltration des aufgereinigten rekombinanten 66.3-kDa-Proteins. Bei der Gelfiltration wanderten die Proteine anhand ihrer Größe unterschiedlich schnell durch die Gelmatrix und eluierten somit in unterschiedlichen Fraktionen entsprechend ihres Molekulargewichts. Die Elutionsfraktionen 20 bis 38 der Gelfiltration, sowie eine Ladekontrolle (L) wurden im Polyacrylamidgel aufgetrennt, auf eine PVDF-Membran übertragen und mit dem 66-Antiserum (G9) detektiert. Zur Größenbestimmung wurde parallel die Gelfiltration einiger Standardproteine unter gleichen Bedingungen durchgeführt. Das Elutionsverhalten der Standardproteine ist oberhalb der Fraktionen dargestellt und mit gepunkteten Linien zur besseren Orientierung angedeutet. Die Standardproteine sind im einzelnen Ferritin (440 kDa), Aldolase (158 kDa), Conalbumin (75 kDa), Carboanhydrase (29 kDa), sowie Ribonuclease (13,7 kDa) und Aprotinin (6,5 kDa).

Bei der Gelfiltration des 66.3-kDa-Proteins fiel auf, dass die einzelnen Fragmente nicht in den Fraktionen entsprechend ihres jeweiligen Molekulargewichts eluierten, sondern dass alle Fragmente des 66.3-kDa-Proteins gemeinsam bei deutlich höherem Molekulargewicht eluierten. Legte man das Maximum der Elution etwa zwischen Fraktion 25 und 26, so ergab sich durch Interpolation des Größenstandards, dass das meiste Protein bei etwa 120 - 140 kDa eluierte (vgl. Abb. 4.11). Da die einzelnen Fragmente des 66.3-kDa-Proteins nicht entsprechend ihres Molekulargewichts eluierten, ist von einer stabilen Komplexbildung der Untereinheiten auszugehen. Analog zu dem Ergebnis des in-vitroQuervernetzungsversuches mit SPDP (vgl. Kap 4.4.2) bestätigte sich hier eine Interaktion der einzelnen Fragmente zu einem größeren Proteinkomplex mit einem Molekulargewicht von ca. 120 - 140 kDa. 


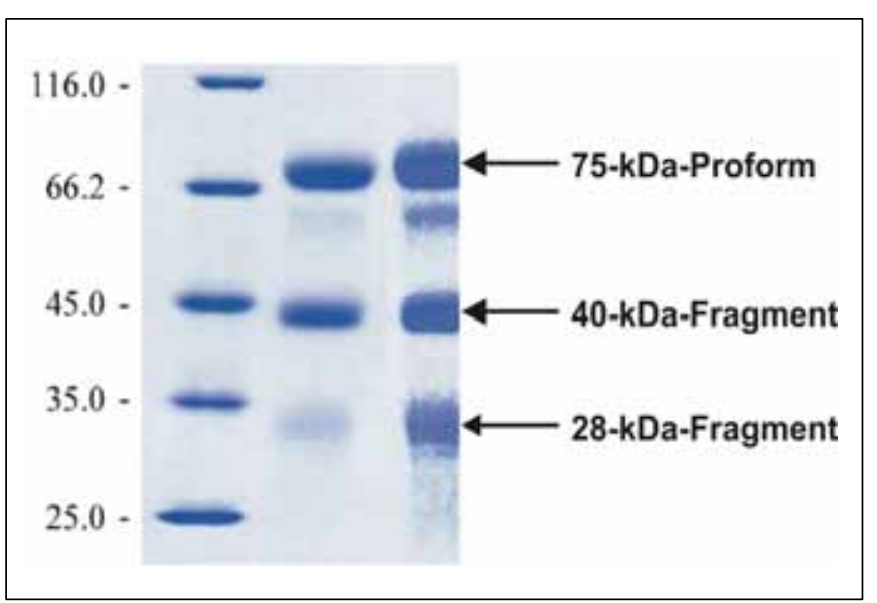

Abb. 4.12: SDS-PAGE Analyse der eingesetzten Proteinlösungen nach Gelfiltration

Darstellung der Proteinlösungen des 66.3kDa-Proteins nach SDS-PAGE und anschließender Coomassie Blue-Färbung. Links ist ein Größenstandard aufgetragen. In der Mitte und rechts sind die eingesetzten Proteinlösungen für die Kristallisation dargestellt. $\mathrm{Zu}$ sehen sind jeweils die Proform mit $75 \mathrm{kDa}$, sowie die Fragmente mit 40 bzw. $28 \mathrm{kDa}$. Abbildung modifiziert nach Lakomek et al. (2009b, S. 223).

\subsubsection{Die Kristallisation}

Die mehrtägige Inkubation (3-7 Tage) des aufgereinigten rekombinanten 66.3-kDaProteins führte zu ineinander verwachsenen Kristallen (vgl. Abb. 4.13 A). Da diese Kristalle für die Analyse im Röntgenstrahl nicht geeignet waren, wurden durch die Variation des Puffersystems die benötigten Einkristalle gezüchtet, aus denen letztendlich Modelle generiert werden konnten (vgl. Abb. 4.13 B). Ein finaler Aufreinigungsschritt mittels Gelfiltration erbrachte jedoch die besten Bedingungen für größere und stabilere, zwar ineinander verwachsene Kristalle (vgl. Abb. 4.13 C), aus denen jedoch die zur Strukturanalyse benötigten Einkristalle abgetrennt werden konnten.

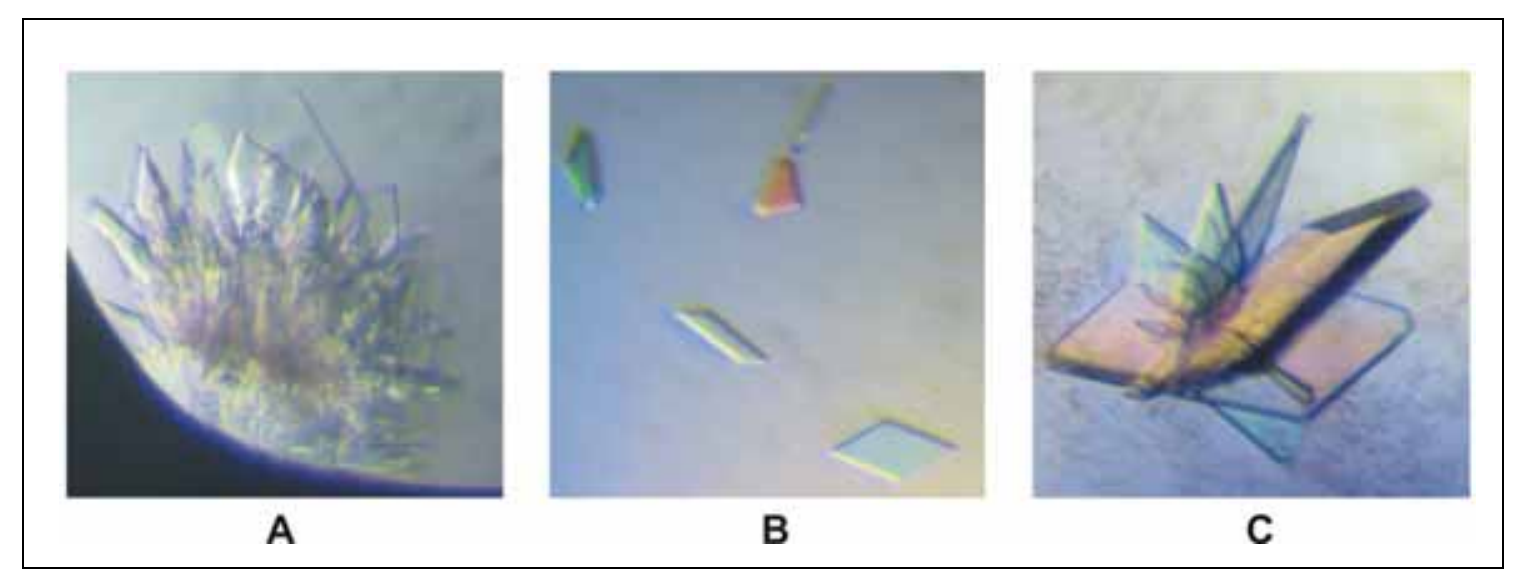

Abb. 4.13: Die entstandenen Kristalle des 66.3-kDa-Proteins

Die Abb. 4.13 zeigt die unterschiedlichen entstandenen Kristalle bei verschiedenen Versuchsbedingungen. Ineinander wachsende Kristalle (A). Einkristalle nach Pufferwechsel (B). Größere, miteinander verwachsene, jedoch trennbare Einkristalle (C). Abbildung aus Lakomek et al. (2009b, S. 223). 


\subsubsection{Modellbildung und Beschreibung}

Zur Ermittlung der dreidimensionalen Struktur wurden verschiedene Datensätze verschiedener Kristalle des 66.3-kDa-Proteins gesammelt und ausgewertet. Das erste Modell konnte mit den Daten eines Schwefel-SAD-Experiments (S-SAD) bei einer Wellenlänge von $1,700 \AA$ errechnet werden und lieferte mit einer maximalen Auflösung von 2,40 $\AA$ ein gutes Röntgenkristallstrukturergebnis (Modell $3 F B X$ ) (Lakomek et al. 2009a).

Es soll hier kurz auf die Struktur des 66.3-kDa-Proteins eingegangen werden, da die anschließend durchgeführten funktionellen Analysen auf dieser Struktur aufbauen. Die ausführliche Beschreibung der Kristallisation mit anschließender Strukurbildung ist Gegenstand der Dissertation von Frau Dr. rer. nat. Kristina Lakomek (Lakomek 2009).

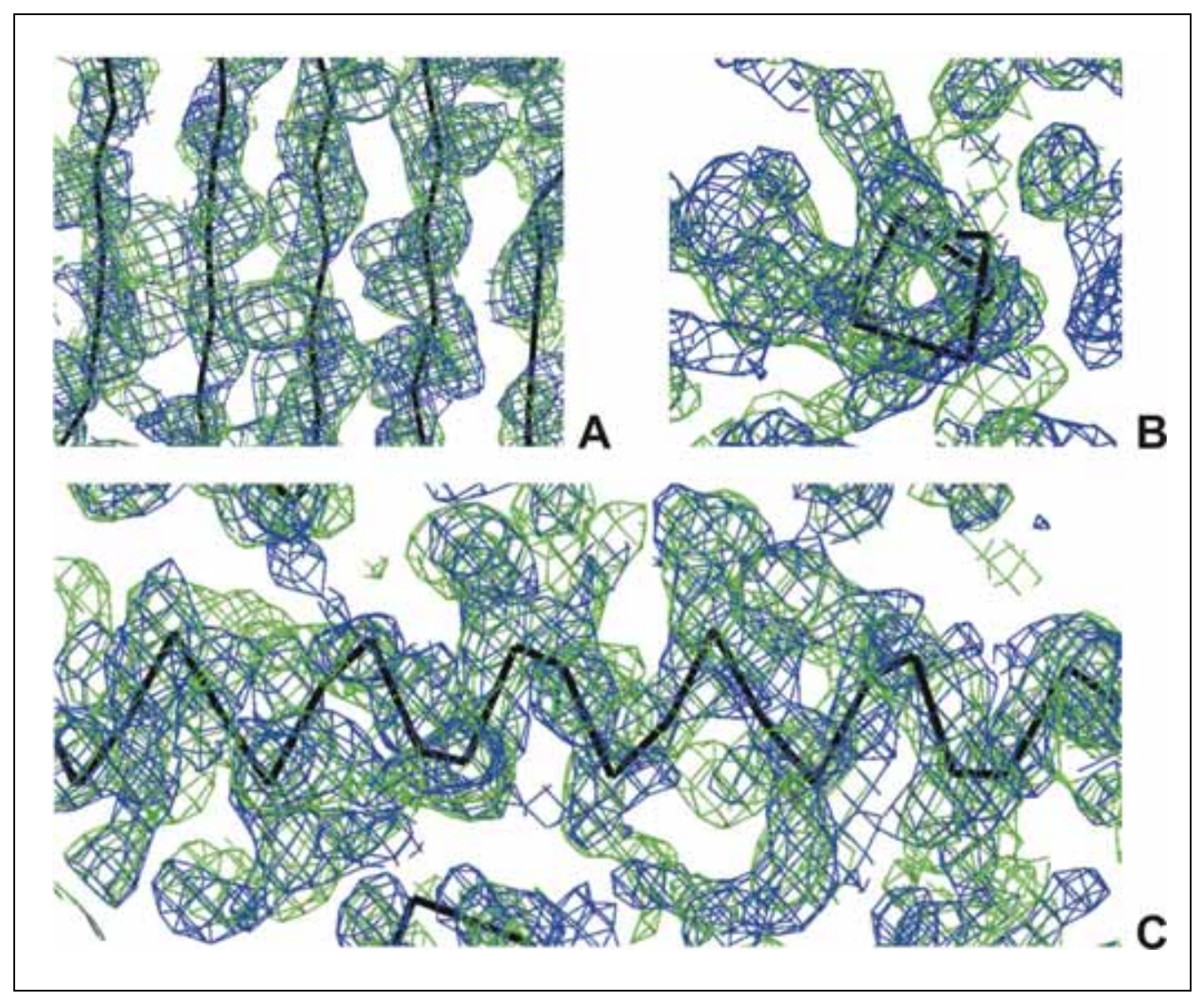

\section{Abb. 4.14: Röntgenstrukturmodell}

Abb. 4.14 zeigt in $(A)$ wie mehrere, nebeneinander angeordnete $\beta$-Faltblattstränge ein $\beta$-Faltblatt bilden. (B) und (C) zeigen eine $\alpha$-Helixstruktur von oben bzw. von der Seite betrachtet. Dabei sind die unterschiedlichen Aminosäureseitenketten gut zu erkennen. Abbildung modifiziert nach Lakomek et al. (2009b, S. 226). 
Die aus dieser Elektronendichtekarte gewonnene Struktur des Kristalls enthielt 520 der 594 Aminosäuren des 66.3-kDa-Proteins (AS 63-238 und AS 249-592). Dabei waren $\beta$-Faltblatt- und $\alpha$-Helixstrukturen der Aminosäurekette klar zu erkennen (vgl. Abb. 4.14). Zusätzlich zeigten sich an den fünf Asparaginseitengruppen der Aminosäuren 93, 115, 236, 441 und 520 des 66.3-kDa-Proteins verschiedene N-Acetylglukosamin-Motive (vgl. Abb. 4.17). Zusätzlich enthielt der Kristall ein vom Protein oktaedrisch gebundenes Natrium-Ion (vgl. Abb. 4.20), 294 Wassermoleküle und einzelne weitere Moleküle aus den Medien für die Aufreinigung und Kristallisation, wie z. B. ein Xenon-Atom in einer hydrophoben Tasche des Proteins.

Auf Grund der Elektronendichte war davon auszugehen, dass das Cystein an Position 249 in den prozessierten Formen des 66.3-kDa-Proteins in ca. 50\% der Fälle als oxidiertes Cystein vorlag, also als Cysteinsulfonsäure. Ob dies in vivo ebenfalls der Fall ist, bleibt offen.

Im Verlauf konnten drei weitere Datensätze gesammelt werden (Lakomek et al. 2009b), von denen einer eine noch bessere Auflösung mit 1,8 $\AA$ bot und vier weitere Aminosäuren des 66.3-kDa-Proteins beinhaltete (Modell 3FGR). Die anderen beiden Datensätze waren deshalb interessant, weil das Modell 3FGW eine weniger prozessierte Form des 66.3-kDa-Proteins darstellte, während das Modell 3FGT eine weitere, zu dem Modell 3FGR verschiedene, prozessierte Form des gleichen Proteins darstellte (vgl. Kap. 4.5.5). Somit war davon auszugehen, dass es sich um unterschiedliche Intermediate des 66.3-kDa-Proteins handelte, die während dessen langsamer autokatalytischer Prozessierung entstanden waren. 
Tab. 4.5: Übersicht der verschiedenen Modelle mit ihren Eigenschaften

Die Tabelle Tab. 4.5 zeigt eine Übersicht der verschiedenen Datensätze und die daraus abgeleiteten Modelle des 66.3-kDa-Proteins mit den jeweiligen Kristallisationsbedingungen und Besonderheiten des Modells. Die enthaltenen Aminosäuren sind je nach Zugehörigkeit zum N-terminalen bzw. C-terminalen Fragment des 66.3-kDa-Proteins nach Subunit A bzw. B aufgeteilt. Tabelle modifiziert nach Lakomek et al. 2009a S. 4).

\begin{tabular}{lcccc}
\hline Modell Name: & 3FBX & 3FGR & 3FGW & 3FGT \\
\hline $\begin{array}{l}\text { Gelfiltration } \\
\text { Kristallisations- } \\
\text { bedingungen }\end{array}$ & Xenonbegasung & Xenonbegasung & Kaliumiodid & nativ \\
Methode & S-SAD & Molekularer & Molekularer & Molekularer \\
Auflösung $(\AA)$ & 2,4 & Ersatz & Ersatz & Ersatz \\
AS gesamt & 520 AS & 524 AS & AS29 AS & 524 AS \\
& A: $63-238$ & A: $63-238$ & A: $61-239$ & A: $60-238$ \\
& B: $249-592$ & $245-248$ & $245-594$ & B: 249-592 \\
& & B: $249-592$ & & prozessiert \\
\hline
\end{tabular}

Die Informationen aus dem Kristall, die mittels SAD-Phasierung mit einer Auflösung von 2,4 $\AA$ ermittelt wurden, dienten als Suchmodell für bereits aufgelistete Modelle. Die gewonnenen dreidimensionalen Strukturen aus den Modellen 3FBX und 3FGR stellen das grundlegende Modell des 66.3-kDa-Proteins dar (vgl. Abb. 4.17). Die weiteren Beschreibungen des 66.3-kDa-Proteins beziehen sich deshalb auf die Modelle 3FBX und 3FGR (vgl. Tab. 4.5).

Der Kristall enthält das 40- und 28-kDa-Fragment in äquimolaren Mengen, was die Komplexbildung von einem 40-kDa-Molekül mit einem 28-kDa-Molekül zu einem funktionalen Gesamtprotein belegt. Die dreidimensionale Verbindung der beiden Fragmente wird durch 37 Wasserstoffbrückenbindungen und zwei Salzbrücken stabilisiert (Lakomek et al. 2009a). Als weiteren Beleg für die Komplexbildung der beiden Fragmente können die Ergebnisse der Gelfiltration ebenso wie die chromatographische Aufreinigung an der Anionenaustauschersäule angesehen werden, denn hier eluierten die beiden Fragmente in der gleichen Fraktion wie die unprozessierte Proform des 66.3-kDa-Proteins.

Es konnten zwei Disulfidbrücken zwischen den Cysteinseitengruppen 147 und 157, bzw. 497 und 500 dargestellt werden. Diese Disulfidbrücken verbinden somit nicht 
die Untereinheiten des 66.3-kDa-Proteins miteinander, sondern sind intramolekular gelegen (vgl. Abb. 4.15).

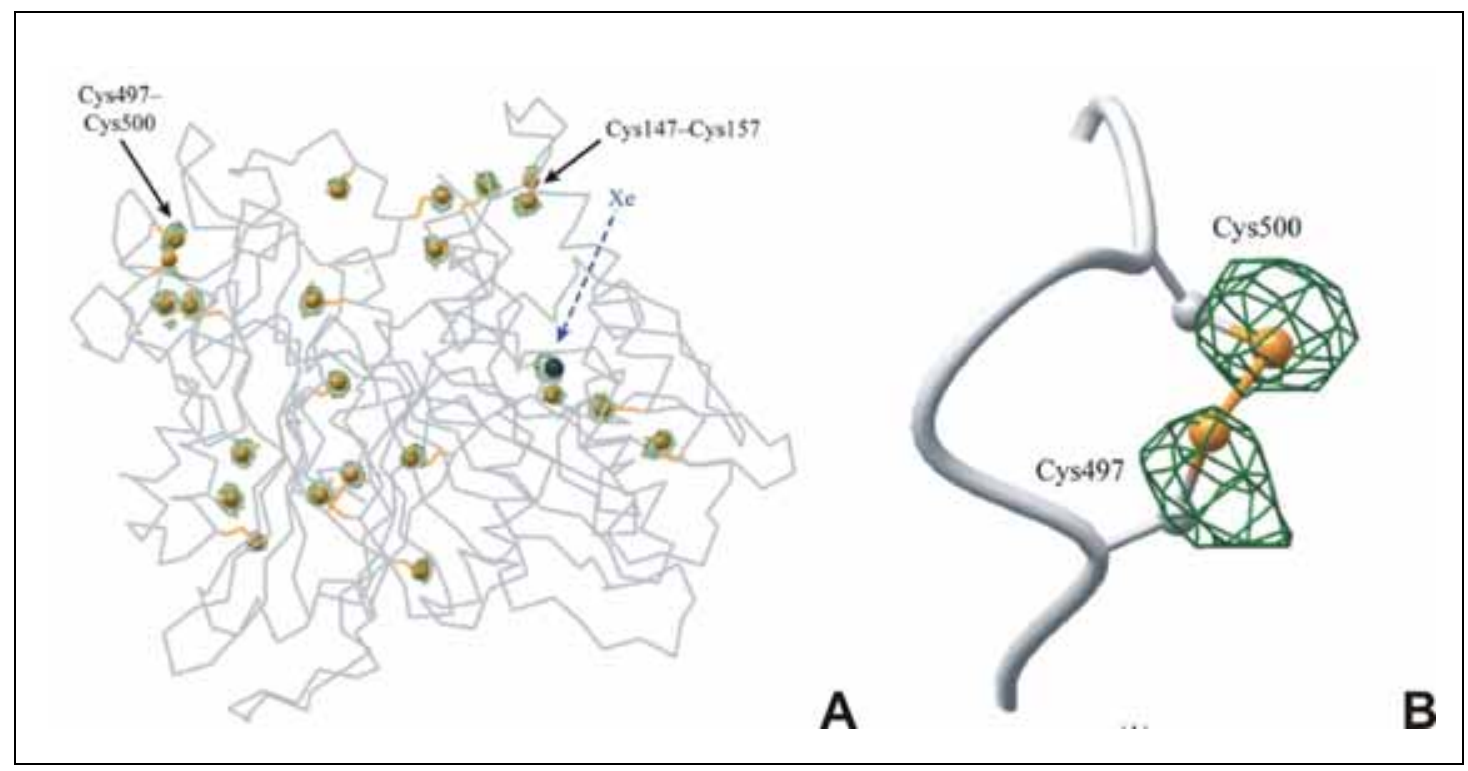

Abb. 4.15: Darstellung der Disulfidbrücken im 66.3-kDa-Protein

In (A) ist die Struktur des 66.3-kDa-Proteins in grau als Strichmodell dargestellt, alle Cystein- und Methioninseitenketten sind in gelb dargestellt. Als runde, gelbe Struktur sind alle Schwefelatome hervorgehoben, die mit schwarzen Pfeilen gekennzeichneten Stellen sind die Disulfidbrücken. In blau ist in der Mitte ein in der hydrophoben Tasche des Enzyms verbliebenes Xenonatom abgebildet, welches in mindestens $10 \%$ aller gebildeten Kristalle vorhanden war. Die Grafik in (B) zeigt die Vergrößerung der C-terminalen Disulfidbrücke. Abbildung aus Lakomek et al. (2009b, S. 224).

Die grundlegende Tertiärstruktur des 66.3-kDa-Proteins besteht aus zwei Schichten mit antiparallel angeordneten $\beta$-Faltblattstrukturen, die von mehreren $\alpha$-Helices unter und über diesen Schichten flankiert werden (vgl. Abb. 4.16). Weitere $\alpha$-Helices umgeben die beiden $\beta$-Faltblattschichten, so dass diese hufeisenförmig eingefasst sind, während eine Seite der $\beta$-Faltblattschichten weiterhin von außen zugänglich bleibt. Drei der fünf für das 66.3-kDa-Protein beschriebenen N-Glykane flankieren diesen Zugang zur potentiellen Substratbindungstasche. Zur besseren räumlichen Orientierung, welche Teile und Strukturen des Proteins von welchem Fragment gebildet werden, siehe Abb. 4.17. 


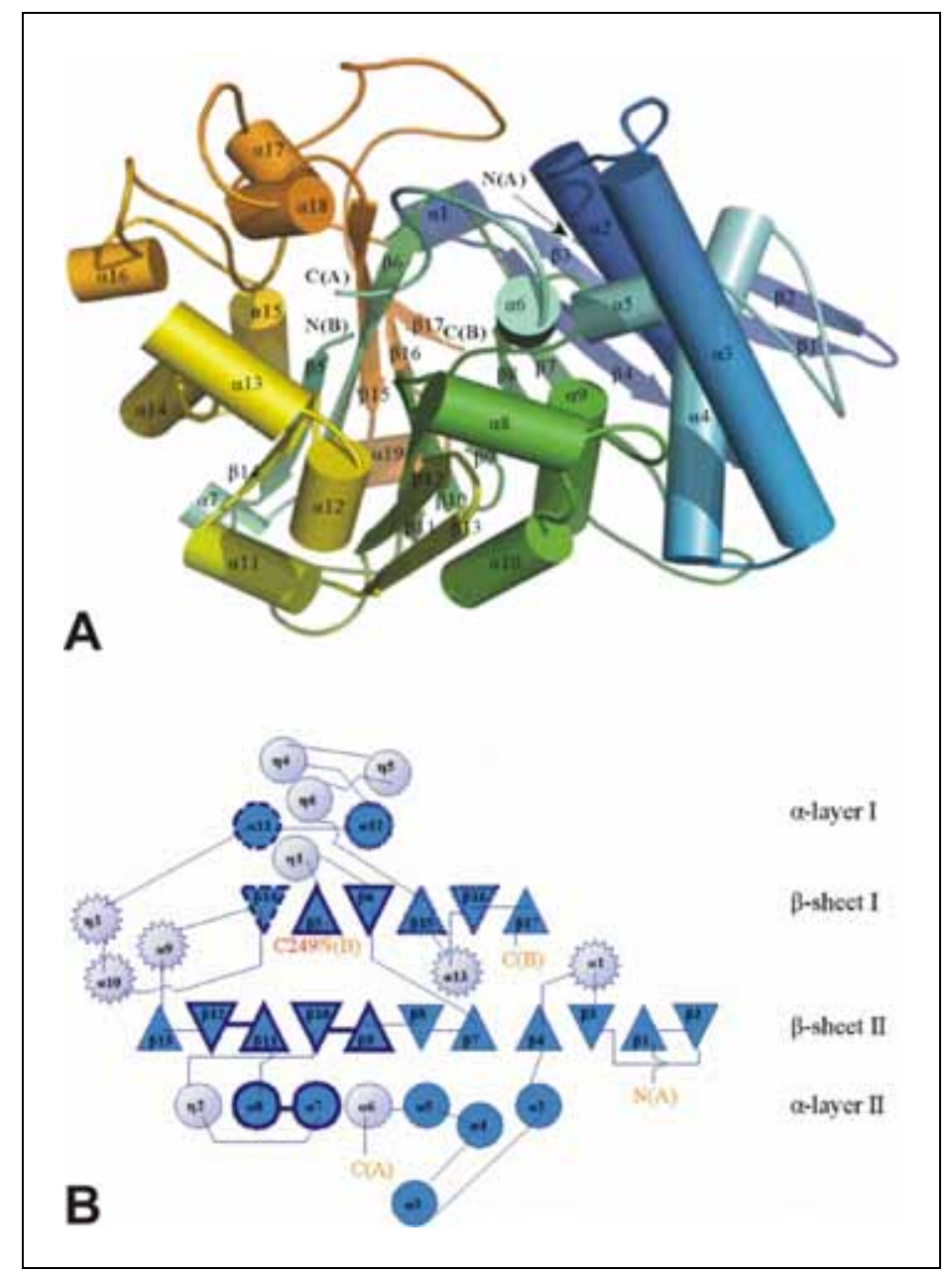

Abb. 4.16: Grundlegende Struktur des 66.3-kDa-Proteins

(A) Die verschiedenen Regionen des Proteins wurden regenbogenfarben je nach ihrer Position in der Polypeptidkette vom N-Terminus (blau) bis zum C-Terminus (orange) gefärbt. (B) In der topologischen Darstellung stehen hellblaue Kreise für Helices unter oder über der anti-parallelen $\beta$-Faltblattebene, blaue Kreise zeigen Helices, die die Ebene flankieren und die hellblauen Sterne zeigen Helices die in Loops über, unter oder zwischen der zusammengedrückten Ebene angeordnet sind. Mit $N(A), C(A)$, $\mathrm{N}(\mathrm{B})$ und $\mathrm{C}(\mathrm{B})$ sind die $\mathrm{N}$ - und $\mathrm{C}-$-Termini des 28- und 40-kDa-Fragments angegeben. Abbildung aus Lakomek et al. (2009a, S. 6). 


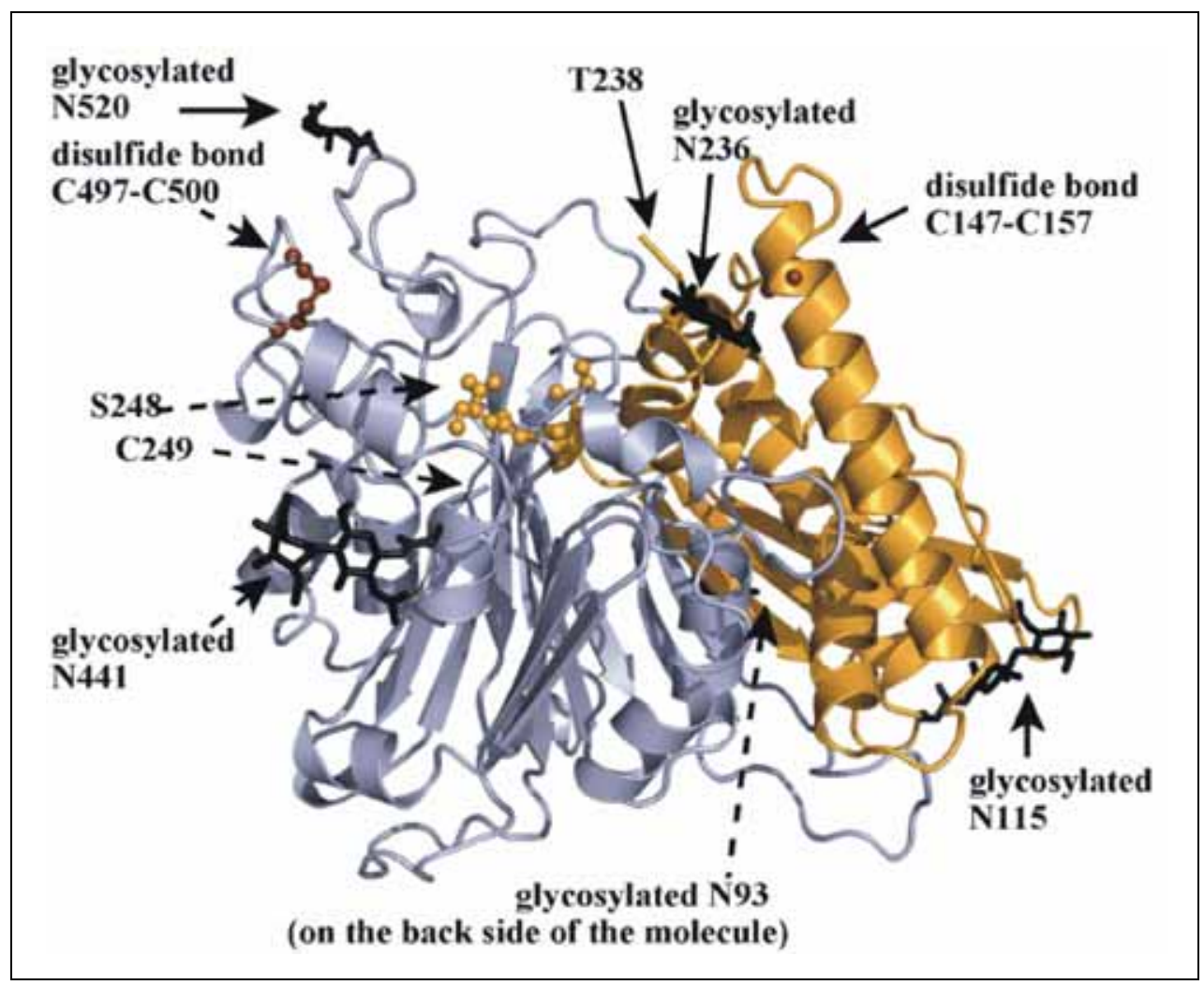

Abb. 4.17: Cartoon-Modell des 66.3-kDa-Proteins (3FGR)

Abb. 4.17 zeigt einen Blick entlang der $\beta$-Faltblätter. Das 28-kDa-Fragment bzw. 40-kDa-Fragment ist in orange bzw. grau gefärbt. Die letzten vier C-terminalen Aminosäuren des 28-kDa-Fragments (G245-S248) sowie die beiden intramolekularen Disulfidbrücken sind im Kugel- und Stäbchenmodus dargestellt und farbig in orange bzw. braun abgebildet. Die fünf $\mathrm{N}$-Glykane und die Asparaginseitengruppen, an denen sie befestigt sind, sind als dicke schwarze Linien gezeigt. Abbildung aus Lakomek et al. (2009a, S. 6).

\subsubsection{Autokatalytische Prozessierung}

Die Kristallisation gab in zwei verschiedenen Formen Hinweise auf den Prozessierungsprozess des 66.3-kDa-Proteins.

Zum einen wurden in der SDS-PAGE-Analyse, des nach der Kristallisation wieder gelösten Kristalls, von dem ursprünglichen Proteingemisch aus der 75-kDa-Proform mit den 40- und 28-kDa-Fragmenten, nach der Inkubation zur Kristallisation nur noch die 40- und 28-kDa-Fragmente nachgewiesen (vgl. Abb. 4.18). Dies legt die Prozessierung des 66.3-kDa-Proteins während der Inkubation zur Kristallisation nahe. $\mathrm{Da}$ in dem aufgereinigten rekombinanten Proteingemisch nur sehr geringe Mengen an Fremdprotein enthalten sind, konnte dies als weiterer Hinweis für die autokatalytische Prozessierung des 66.3-kDa-Proteins angesehen werden. 
Des Weiteren konnten Rückschlüsse auf den genauen Mechanismus dieser autokatalytischen Prozessierung auf Grund der verschiedenen Reifungsstufen in den gesammelten Datensätzen gezogen werden.

Abb. 4.18: SDS-PAGE Analyse
des gelösten Kristalls

Die Abb. 4.18 zeigt die nach ihrer Größe aufgetrennten Proteine nach SDS-PAGE mit anschließender Coomassie BlueFärbung. Links ist ein Größenstandard aufgetragen, in der Mitte ist zum Vergleich die eingesetzte Proteinlösung vor der Kristallisation zu sehen. Auf der rechten Seite ist die Proteinlösung des in Puffer gelösten Kristalls dargestellt. Abbildung modifiziert nach Lakomek et al. (2009b, S. 223).

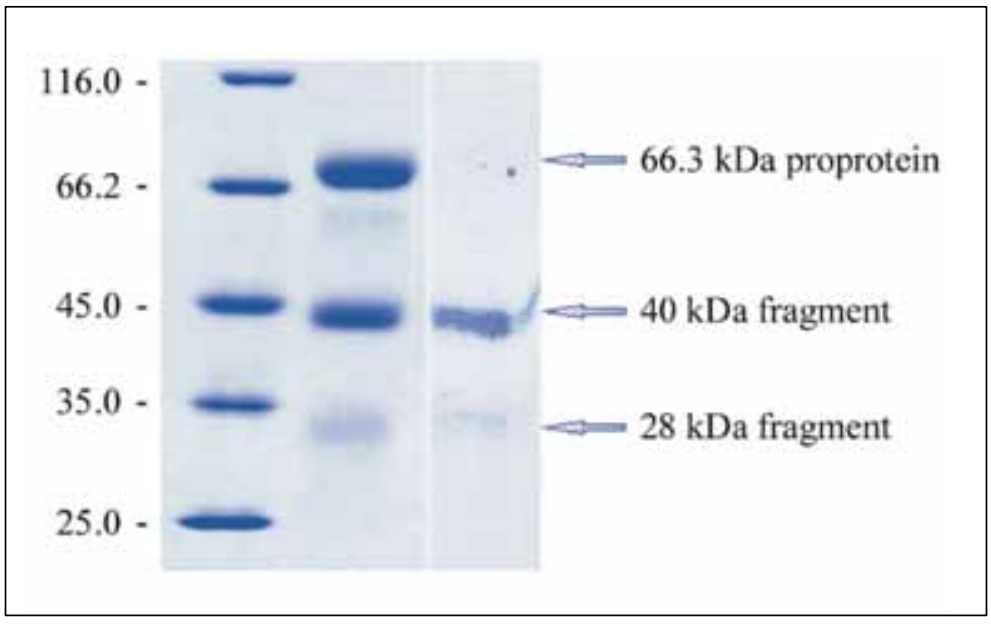

Die schrittweise posttranslationale autokatalytische Reifung stellt sich in den Kristallstrukturen wie folgt dar (siehe auch Lakomek et al. (2009b)): Das Modell 3FGW, als unreife Form des 66.3-kDa-Proteins, besteht lediglich aus einer zusammenhängenden Polypeptidkette, in der die 40- und 28-kDa-Fragmente noch über einen sogenannten Linker, bestehend aus zehn Aminosäuren (AS 239 bis 248), verbunden sind. Im Modell 3FGR ist die Aminosäurekette zwischen S248 und C249 gespalten. Durch diese Spaltung erhält der Linker eine höhere Flexibilität und es resultiert eine bessere Zugänglichkeit des C-Terminus des Linkers für eventuelle weitere Prozessierungsschritte. Im abschließenden Modell 3FGT ist der Linker um zwei Aminosäuren verkürzt, der C-Terminus des 28-kDa-Fragments schließt jetzt mit S246 ab. Durch die Verkürzung des Linkers wird eine große darunterliegende hydrophobe Tasche des Proteins zugänglich (vgl. Abb. 4.19), in der auch das vermutete hydrolytisch aktive Zentrum lokalisiert ist (vgl. Kap. 4.5.6).

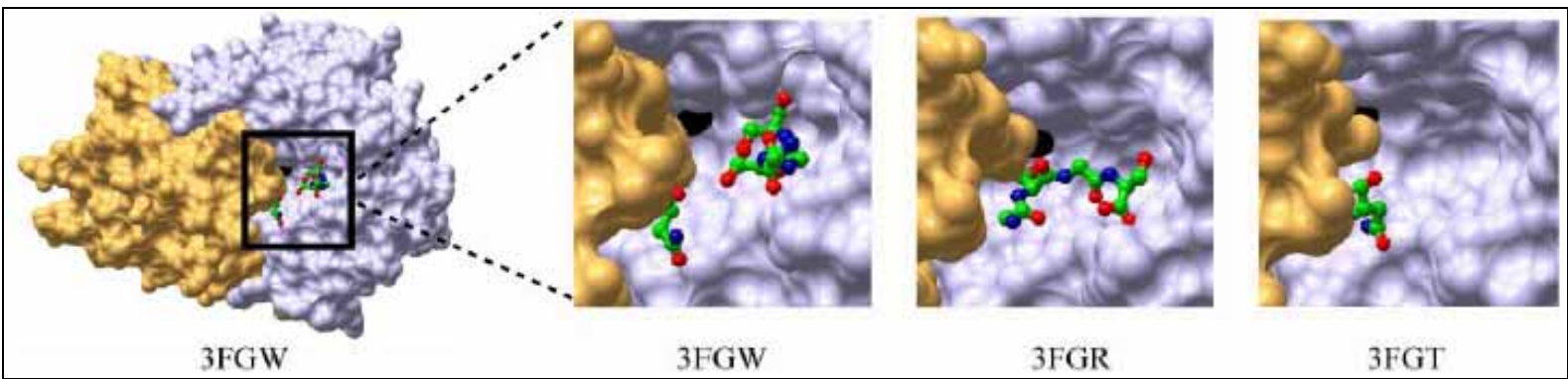

Abb. 4.19: Räumliche Anordnung des Linkers entsprechend den verschiedenen Reifungsstufen 
In Abb. 4.19 wird die räumliche Anordnung des sukzessiv gekürzten Linkers und die dadurch bessere Zugänglichkeit der hydrolytisch aktiven Tasche dargestellt. Dabei sind die Aminosäuren P60-T238 des $\mathrm{N}$-terminalen und die Aminosäuren C249-P592 des C-terminalen Fragments als orange bzw. graue Oberflächen dargestellt. Die Aminosäuren des Linkers (N239-S248) sind dagegen im Stäbchen- und Ballmodell dargestellt. Abbildung aus Lakomek (2009, S. 78).

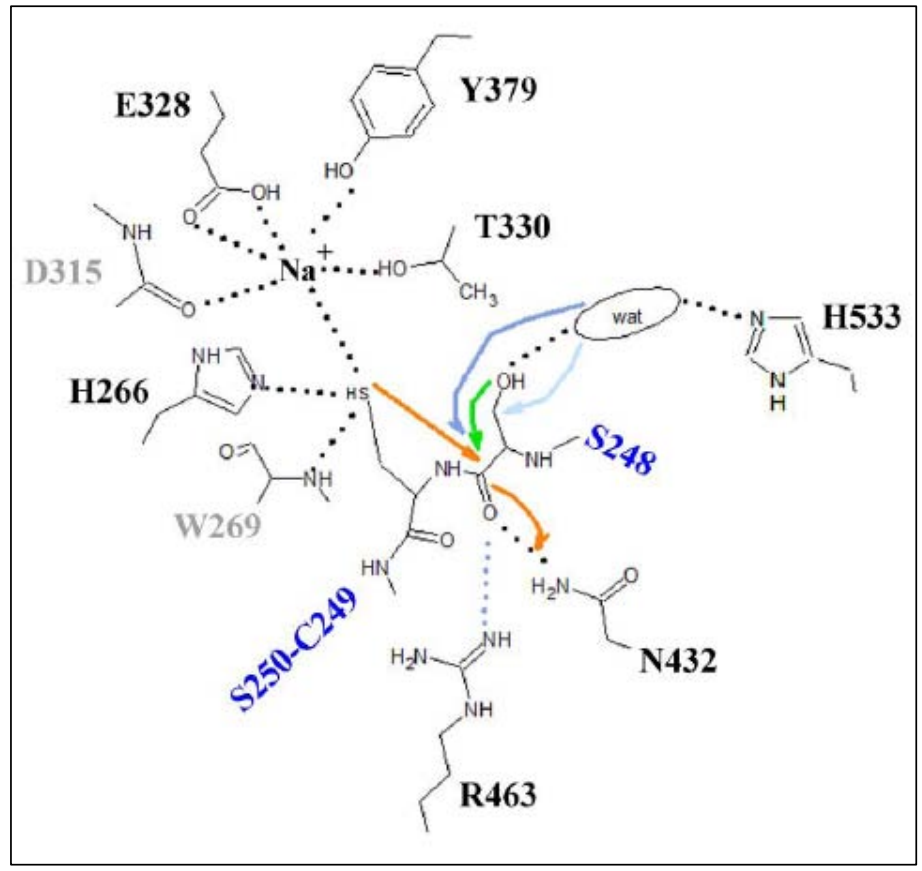

Abb. 4.20: Mechanismus der Autokatalyse

In Abb. 4.20 ist dargestellt wie die potentielle autokatalytische Spaltung des 66.3-kDa-Proteins mechanistisch stattfinden könnte. Dabei sind die Aminosäuren neben der zu spaltenden Peptidbindung in der Peptidkette blau markiert, während die Aminosäuren der an der Spaltung beteiligten Seitengruppen schwarz bzw. grau gekennzeichnet sind. Der nukleophile Angriff auf das Carbonyl-C von S248 durch die Sulfhydryl-Gruppe von C249 und die anschließende Bildung des Oxyanions sind durch orange Pfeile angedeutet. Mögliche Angriffe nach diesem Übergangszustand werden durch grüne und blaue Pfeile angegeben, je nachdem, ob das Sauerstoffatom der Serin-Seitenkette oder das des gebundenen Wassermolekül an der Reaktion teilnimmt. Das oktaedrisch gebundene Natrium (OCS249, E328, T330, Y379, D315) stabilisiert die Konformation des katalytischen Zentrums. Abbildung aus Lakomek (2009, S. 86).

\subsubsection{Potentielle Funktion des 66.3-kDa-Proteins durch Strukturvergleich}

Ein Vergleich der strukturellen Ähnlichkeit vom Modell des 66.3-kDa-Proteins mit anderen Proteinen in der Strukturdatenbank (PDB) mittels des Programms DALI ergab mehrere strukturelle Übereinstimmungen mit unterschiedlicher Qualität, gemessen an den Z-Werten (vgl. Tab. 4.6) (Holm and Sander 1996).

Die Enzyme aus der Liste mit den größten Übereinstimmungen und deshalb höchsten Z-Werten waren bakterielle Hydrolasen. Bei genauerer Betrachtung dieser Hydrolasen stellt man fest, dass die meisten der in der Tab. 4.6 aufgeführten Enzyme in die Superfamilie der N-terminalen nukleophilen Hydrolasen (Ntn-Hydrolasen) gehören. Das 66.3-kDa-Protein weist nur sehr geringe Sequenzhomologien mit den Mitgliedern dieser Superfamilie auf, allerdings ist das Charakteristikum dieser Enzym-Superfamilie viel mehr die Tertiärstruktur und die Anordnung der Seitengruppen im aktiven Zentrum. Dabei ist die Kernstruktur eine aßßа-Konformation mit N-terminaler, nukleophiler Seitenkette im katalytisch aktiven Zentrum der Ntn-Hydrolasen (Brannigan et al. 1995; Oinonen and Rouvinen 2000). 
Diese aufgeführten Merkmale treffen auch im besonderen Maße auf das 66.3-kDaProtein zu (vgl. Abb. 4.21 und Abb. 4.22), so dass eine Zugehörigkeit des 66.3-kDaProteins zu dieser Superfamilie der Ntn-Hydrolasen als wahrscheinlich angenommen werden kann. Ebenfalls interessant in diesem Zusammenhang ist, dass alle Ntn-Hydrolasen autokatalytisch aktiviert werden, wie es auf Grund der oben dargestellten Ergebnisse auch für das 66.3-kDa-Protein angenommen wurde.

\section{Tab. 4.6: Ergebnisliste der Strukturdatenbankabfrage mittels DALI}

Tab. 4.6 zeigt die Proteine, die mittels DALI-Suche (Holm and Sander 1996) als ähnlich zum 66.3kDa-Protein eingestuft wurden. Dargestellt sind jeweils der Name und die Datenbank-ID des Proteins zusammen mit dem Wert für die strukturelle Ähnlichkeit mit dem 66.3-kDa-Protein (Z-Wert), sowie die Auflösung des Proteins (Rmsd) und die Sequenzhomologien zum 66.3-kDa-Protein (\% ID). Tabelle modifiziert nach Lakomek (2009, S.68).

\begin{tabular}{|c|c|c|c|c|}
\hline Protein & PDB-ID & Z-Score & $\operatorname{Rmsd}[\AA]$ & $\%$ ID \\
\hline Cephalosporin acylase (CA) & $10 q z$ & 17.0 & 3.6 & 11 \\
\hline Penicillin-V-acylase (PVA) & $2 p v a$ & 16.2 & 3.0 & 6 \\
\hline $\begin{array}{l}\text { Conjugated bile acid (=choloylglycine) } \\
\text { hydrolase }(\mathrm{CABH})\end{array}$ & $2 \mathrm{bjf}$ & 16.2 & 3.1 & 6 \\
\hline Penicillin $G$ acylase (PGA) & $1 \mathrm{k} 5 \mathrm{~s}$ & 15.4 & 3.4 & 11 \\
\hline IMP cyclohydrolase (IMPC) & $2 n t m$ & 8.4 & 3.2 & 14 \\
\hline $20 \mathrm{~S}$ proteasome & 1ryp & 8.3 & 3.1 & 7 \\
\hline conserved protein & $1 \mathrm{kuu}$ & 8.2 & 3.2 & 14 \\
\hline Proteasome component $\mathrm{Y} 7$ & 1gOu & 8.2 & 3.0 & 8 \\
\hline Proteasome $\alpha$ subunit & $1 j 2 q$ & 7.8 & 3.2 & 11 \\
\hline Proteasome $\alpha$-type subunit 1 & $2 \mathrm{~h} 6 \mathrm{j}$ & 7.3 & 4.1 & 16 \\
\hline HSLV protease & $1 \mathrm{~g} 3 \mathrm{k}$ & 7.2 & 3.0 & 9 \\
\hline Proteasome component C7- $\alpha$ & $1 z 7 q$ & 7.2 & 5.6 & 11 \\
\hline $\begin{array}{l}\text { ATP-dependent HSL protease ATP-binding } \\
\text { subunit }\end{array}$ & 1ofh & 7.2 & 3.1 & 9 \\
\hline $\begin{array}{l}\text { ATP-dependent HSLU protease ATP-binding } \\
\text { subunit }\end{array}$ & $1 g 3 i$ & 7.0 & 3.4 & 9 \\
\hline Protein YPL144W & $2 z 5 c$ & 6.4 & 3.3 & 13 \\
\hline UNP Q5LQD5_SILPO (hypothetical protein) & $2 \mathrm{imh}$ & 6.1 & 4.1 & 17 \\
\hline Glutamine PRPP amidotransferase & 1gph & 2.8 & 4.3 & 10 \\
\hline Horse plasma gelsolin & $1 \mathrm{~d} 0 \mathrm{n}$ & 2.8 & 4.1 & 7 \\
\hline Antithrombin III & 1att & 2.6 & 7.8 & 5 \\
\hline
\end{tabular}




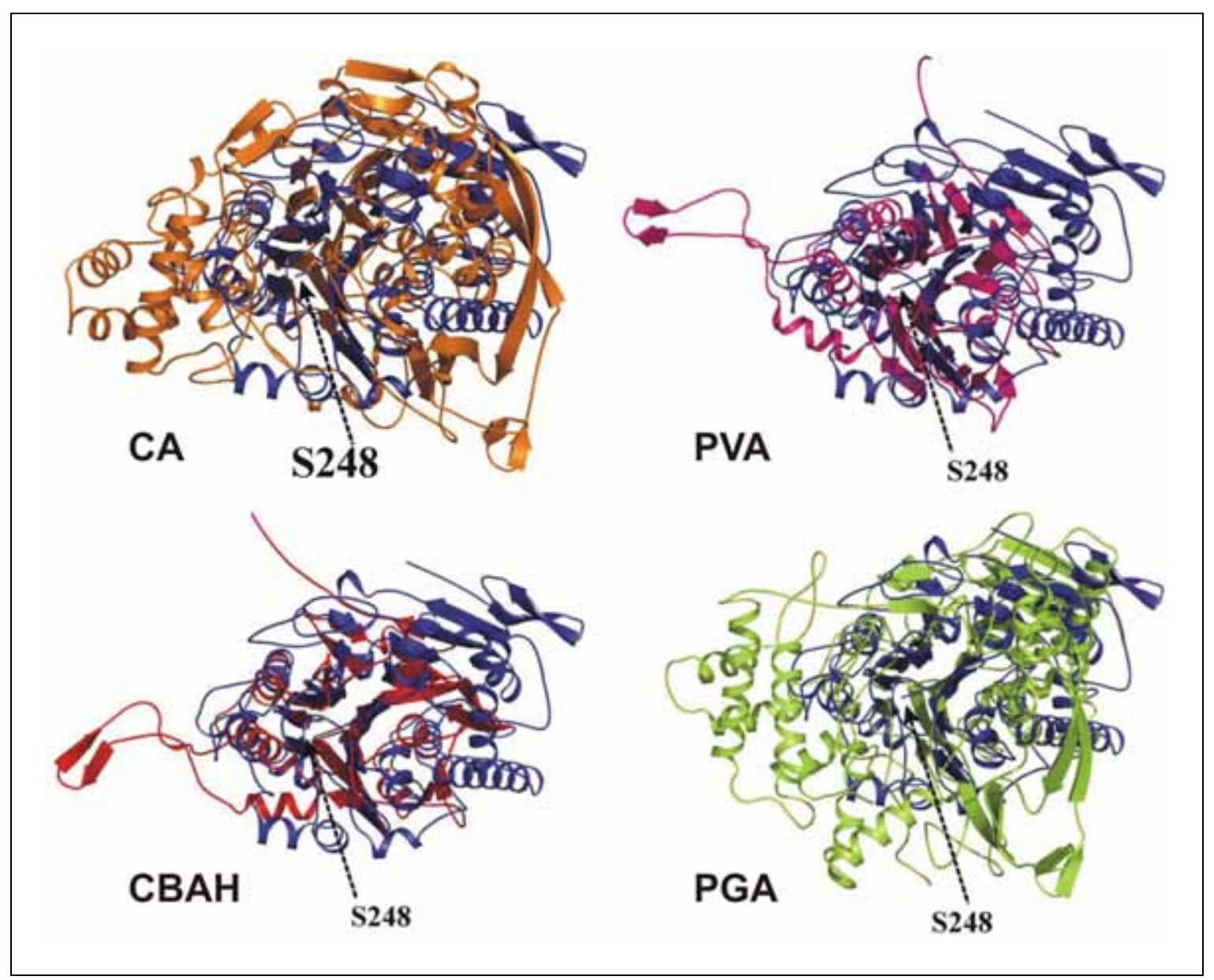

Abb. 4.21: Tertiärstrukturvergleich verschiedener Proteine der Superfamilie der Ntn-Hydrolasen mit dem 66.3-kDa-Protein

Die Abb. 4.21 zeigt den Tertiärstrukturvergleich des 66.3-kDa-Proteins mit vier Mitgliedern der Superfamilie der Ntn-Hydrolasen. Dabei ist das 66.3-kDa-Protein jeweils in blau dargestellt. In orange, lila, rot und grün sind die Enzyme Cephalosporin acylase (CA), Penicillin-V-acylase (PVA), Conjugated bile acid hydrolase (CBAH) und Penicillin G acylase (PGA) dargestellt. Abbildung modifiziert nach Lakomek (2009, S. 80+83).

Ntn-Hydrolasen spalten nicht-peptidische Amidbindungen durch einen nukleophilen „Angriff“ der N-terminal gelegenen Aminosäure auf das Kohlenstoffatom der Amidbindung des Substrats. Die N-terminal gelegene Aminosäure kann dabei ein Cystein, Threonin oder Serin sein. Im 66.3-kDa-Protein dient demzufolge C249 als N-terminales Nukleophil, welches erst nach autokatalytischer Spaltung zwischen S248 und C249 als solches zur Verfügung steht. Weitere für die katalytische Funktion essentielle Aminosäuren im aktiven Zentrum von Ntn-Hydrolasen sind ein Asparagin und ein Arginin (Prabhune and Sivaraman 1990; McVey et al. 2001), welche im potentiell aktiven Zentrum des 66.3-kDa-Proteins mit N432 und R463 vertreten sind. Darüber hinaus findet sich oft ein Arginin im katalytischen Zentrum, welches allerdings in einigen Ntn-Hydrolasen durch ein Histidin ersetzt wird, so auch im 66.3-kDa-Protein durch H266. Auf Grund des niedrigen $\mathrm{pH}-$ Werts im lysosomalen 
Kompartiment kann davon ausgegangen werden, dass das Histidin in protonierter Form vorliegt, so dass es die Funktion des Arginins ersetzen kann. Neben T330 und N432 spielt bei der Bildung des Oxyanions des 66.3-kDa-Proteins noch eine dritte Seitengruppe eine Rolle, nämlich der Stickstoff des W269, welcher eine Wasserstoffbrückenbindung mit C249 ausbildet (vgl. Abb. 4.22 und Abb. 4.20).

Wie oben beschrieben, besitzt das 66.3-kDa-Protein tatsächlich alle im aktiven Zentrum von Ntn-Hydrolasen beschriebenen Seitengruppen in der für die Katalyse notwendigen räumlichen Anordnung (vgl. Abb. 4.22) und wird daher ebenfalls in der Lage sein, nicht-peptidische Amidbindungen zu spalten, wie es für Enzyme der Superfamilie der Ntn-Hydrolasen üblich ist (Lakomek et al. 2009b).

\section{Abb. 4.22: Vergleich des aktiven Zentrums verschie- dener Ntn-Hydrolasen}

Die Abb. 4.22 zeigt eine Überlagerung der konservierten Aminosäuren im aktiven Zentrum von den vier Ntn-Hydrolasen mit dem höchsten Z-Wert und dem 66.3-kDa-Protein. Für das konservierte N-terminale Nukleophil ist die ganze Aminosäure gezeigt, während bei den anderen Aminosäuren nur die relevanten Anteile dargestellt sind. Gefärbt sind jeweils die Atome für Stickstoff, Sauerstoff und Schwefel in blau, rot und orange, während die Zugehörigkeit der Aminosäuren zum jeweiligen Protein daneben wie folgt angegeben ist: 66.3-kDa-Protein in grau (3FGR), Cephalosporin Acylase (1OQZ) in pink, Penicillin-V-Acylase (3PVA) in gelb, konjugierte Gallensäuren-Hydrolase (2BJF) in grün, Penicillin G Acylase (1K5S) in orange. Abbildung aus Lakomek et al. (2009a, S. 8).

\subsubsection{Potentielle Substrate}

Unter den eukaryontischen Vertretern der Enzym-Superfamilie der Ntn-Hydrolasen sind unter anderem auch lysosomale Proteine $\mathrm{zu}$ finden, was den direkten Zusammenhang zum 66.3-kDa-Protein herstellt. Diese lysosomalen Proteine sind in den Abbau von bioaktiven Lipiden involviert, so spaltet die $N$-acylethanolaminehydrolyzing acid amidase (NAAA) beispielsweise $\mathrm{N}$-Acylethanolamide (Tsuboi et al. 
2005), während die Acid Ceramidase (AC) Ceramide in Sphingosine und die dazugehörige freie Fettsäure spaltet (Park and Schuchman 2006).

N-Acylethanolamide (NAEs) sind Gewebshormone (Mediatoren), die im menschlichen Körper in physiologischen Situationen nur in Spuren zu finden sind. Verschiedenste pathophysiologiche Vorgänge korrelieren allerdings mit einem lokal begrenzten, massiven Anstieg der NAE-Konzentration (Hansen HS et al. 2000; Schmid and Berdyshev 2002). In diesem Zusammenhang werden NAEs antiinflammatorische (Mazzari et al. 1996), neuroprotektive (Skaper et al. 1996), immunsuppressive (Berdyshev et al. 1997), sowie analgetische (Cravatt et al. 2001) Wirkungen zugeschrieben. Damit der Anstieg der NAE-Konzentration lokal begrenzt bleibt und nicht systemisch wirksam wird, ist ein schneller und effizienter Abbau der NAEs im betroffenen Gewebe notwendig. Hierbei könnte die potentielle Funktion des 66.3-kDa-Proteins analog zu der oben genannten Hydrolase (NAAA) eine Rolle spielen.

In der Nähe des katalytischen Zentrums befinden sich einige polare Aminosäureseitengruppen (S225, T238, N274 und T378), die für die Bindung eines potentiellen Substrats geeignet wären (Lakomek et al. 2009b).

Da es außer der Strukturanalyse keinen weiteren Hinweis über den Charakter des Substrats des 66.3-kDa-Proteins gibt, wurden für die weitere biochemische Analyse der hydrolytischen Aktivität des 66.3-kDa-Proteins Substrate gewählt, die sich an den Substraten der anderen lysosomalen Enzyme der Superfamilie der Ntn-Hydrolasen orientierten.

Da für die NAAA eine Substratspezifität bei den NAE festgestellt werden konnte, die sich auf die Länge der an das Ethanolamin gekoppelte Fettsäure bezieht (Tsuboi et al. 2005), wäre für das 66.3-kDa-Protein eine Aktivität im Bereich anderer Ethanolamin-gekoppelter Fettsäuren denkbar. Weil die NAAA N-Palmitoylethanolamid ( $\left.\mathrm{C}_{16: 0^{-}} \mathrm{NAE}\right)$ als bevorzugtes Substrat spaltet, kämen $\mathrm{C}_{12: 0^{-}}, \mathrm{C}_{14: 0^{-}}, \mathrm{C}_{18: 0^{-}}$,

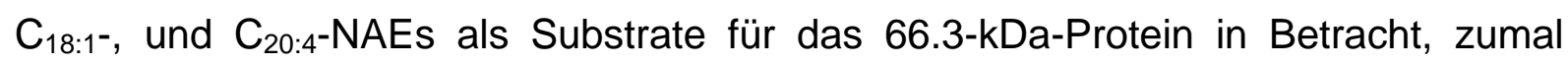
keine weiteren Enzyme beschrieben sind, die an dem Abbau solcher Verbindungen beteiligt wären. 


\subsection{Funktionelle Analyse des 66.3-kDa-Proteins}

\subsubsection{Synthese eines ${ }^{14} \mathrm{C}$-markierten Substrats}

Um die Spaltung einzelner N-Acylethanolamide durch das 66.3-kDa-Protein in vitro überprüfen zu können, wurde eine Reihe von Ethanolaminderivaten als potentielle Substrate für das 66.3-kDa-Protein synthetisiert. Dabei wurden unterschiedliche ${ }^{14} \mathrm{C}$-markierte Fettsäuren, wie z.B. ${ }^{14} \mathrm{C}$-Palmitinsäure, mit Ethanolamin bzw.

${ }^{14} \mathrm{C}$-markiertes Ethanolamin mit freien Fettsäuren amidiert.

Die Synthese der Substrate erfolgte in Kooperation mit der Abteilung von Prof. Ackermann am Institut für Organische und Biomolekulare Chemie der Universität Göttingen. Dipl. Chem. René Sandmann synthetisierte exemplarisch Palmitoylethanolamid $\left(\mathrm{C}_{16: 0}\right)$. Die weiteren Substrate wurden nach dem gleichen Procedere selbst synthetisiert.

Die radioaktiv markierten Substrate waren im Einzelnen:

Tab. 4.7: Liste der ${ }^{14} \mathrm{C}$-markierten Substrate

\begin{tabular}{ll}
\hline $\boldsymbol{A b k}$. & Name \\
\hline $\mathrm{C}_{12: 0}$ & Laurylethanolamid \\
$\mathrm{C}_{14: 0}$ & Myristoylethanolamid \\
$\mathrm{C}_{16: 0}$ & Palmitoylethanolamid \\
$\mathrm{C}_{18: 0}$ & Stearylethanolamid \\
$\mathrm{C}_{18: 1}$ & Oleylethanolamid \\
$\mathrm{C}_{20: 4}$ & Arachidonethanolamid \\
\hline
\end{tabular}

\subsubsection{Klonierung der NAAA-Positivkontrolle}

Um in den nachfolgenden NAE-Aktivitätsbestimmungen eine Positivkontrolle zur Verfügung zu haben, wurde die cDNA der murine $N$-acylethanolamine acid amidase (mNaaa) aus Leber-, Nieren- und Herz-RNA mittels reverser Transkription mit anschließender PCR mit den Primern mNaaa-F1 und mNaaa-R1 gefolgt von einer nested-PCR mit den Primern mNaaa-F2-Nhel und mNaaa-R2-HIS-Notl amplifiziert (vgl. Kap. 8.2.2). Dadurch wurde am C-Terminus analog zum 66.3-kDa-Protein ein His-Tag eingefügt und mittels add-on-Primern wurden die Restriktionsendonukleaseschnittstellen für Nhel am 5'-Ende und für Notl am 3'-Ende eingefügt. Bei der 
Überprüfung der PCR-Produkte in der Gelelektrophorese zeigte sich eine deutliche und spezifische Bande in jedem Ansatz. Für das PCR-Produkt aus Herz und Nieren stimmte auch die erwartete Größe des PCR-Produktes, während sich das PCRProdukt aus Leber-RNA etwa $100 \mathrm{bp}$ kürzer darstellte. Eine anschließend durchgeführte Sequenzierung zeigte eindeutig eine Spleißvariante der mNaaa im Lebergewebe an, der das Exon 2 fehlte. Des Weiteren konnten mehrere SingleNukleotid-Polymorphismen (SNP) (C140T, G425A, G435C, G487A) festgestellt werden, die zum Teil heterozygot, zum Teil homozygot vorlagen und in unterschiedlichem Maße zum Aminosäureaustausch führten (vgl. Kap. 8.2.3). Die His-getaggte mNaaa auf der Basis der Herz-RNA wurde in entsprechender Richtung in den pcDNA3.1-Hygro (+)-Vektor kloniert und abschließend zur Überprüfung des korrekten Leserahmens sequenziert. Die gefundenen Punktmutationen hatten in den Analysen keine Bedeutung für die Spaltungsaktivität der mNaaa.

\subsubsection{NAE-Hydrolyse des 66.3-kDa-Proteins}

Auf Grund der im Kap. 4.5.7 dargestellten Überlegungen zu möglichen Substraten, sollte das 66.3-kDa-Protein auf seine hydrolytische Aktivität gegenüber Acylethanolamiden mit unterschiedlich langen Fettsäuren untersucht werden.

Die Untersuchungen der NAE-Spaltungsaktivität wurden zum Teil in Kooperation mit der Arbeitsgruppe von Herrn Prof. Ueda am Biochemischen Institut der medizinischen Fakultät der Kagawa Universität in Japan durchgeführt. Aus Gründen der Übersichtlichkeit werden im Folgenden nur die Ergebnisse der in Japan durchgeführten Dünnschichtchromatographie dargestellt. Die in der Abteilung Biochemie II durchgeführten Analysen mittels Flüssigkeitsszintillationsmessung wurden nicht dargestellt.

Die hydrolytische Aktivität unterschiedlicher Proben wurde in einer Endpunktanalyse quantitativ untersucht. Dabei dienten transient transfizierte Zellen im Vergleich mit nicht-transfizierten Zellen, sowie das aufgereinigte rekombinante 66.3-kDa-Protein, als potentiell hydrolytisch aktive Proben. Für die Hydrolyse wurde das 66.3-kDaProtein sowie die mNaaa in HT1080- und HEK293T-Zellen transfiziert, die Zellen nach 48 Stunden geerntet und daraus Zellhomogenate erstellt. Die Effizienz der 
Transfektion wurde mit Antikörpern gegen das His-Tag der Fusionsproteine im Western-Blot überprüft.

In einem ersten Versuchsansatz wurde die Aktivität der Proben für das N-Palmitoylethanolamid überprüft. Dazu wurden $20 \mu \mathrm{g}$ Gesamtprotein eines jeden Homogenats im sauren Puffersystem ( $\mathrm{pH} \mathrm{4,5)} \mathrm{mit} \mathrm{radioaktivem} \mathrm{Substrat} \mathrm{inkubiert.}$ Die Reaktion wurde durch die Zugabe eines Diethylether-Methanol-Citrat-Gemischs gestoppt. Um die abgespaltenen Fettsäuren von den an Ethanolamin gekoppelten Fettsäuren zu differenzieren, wurden die Proben dünnschichtchromatographisch aufgetrennt (Tsuboi et al. 2005). Dabei wanderte die freie Fettsäure bei dem Laufmittel aus Chloroform-Methanol-Ammoniumhydroxid kürzer mit der Laufmittelfront, als die an das Ethanolamin gekoppelte Fettsäure. Die Auswertung der Dünnschichtchromatographieplatten erfolgt autoradiographisch mittels eines Phosphoimagers.

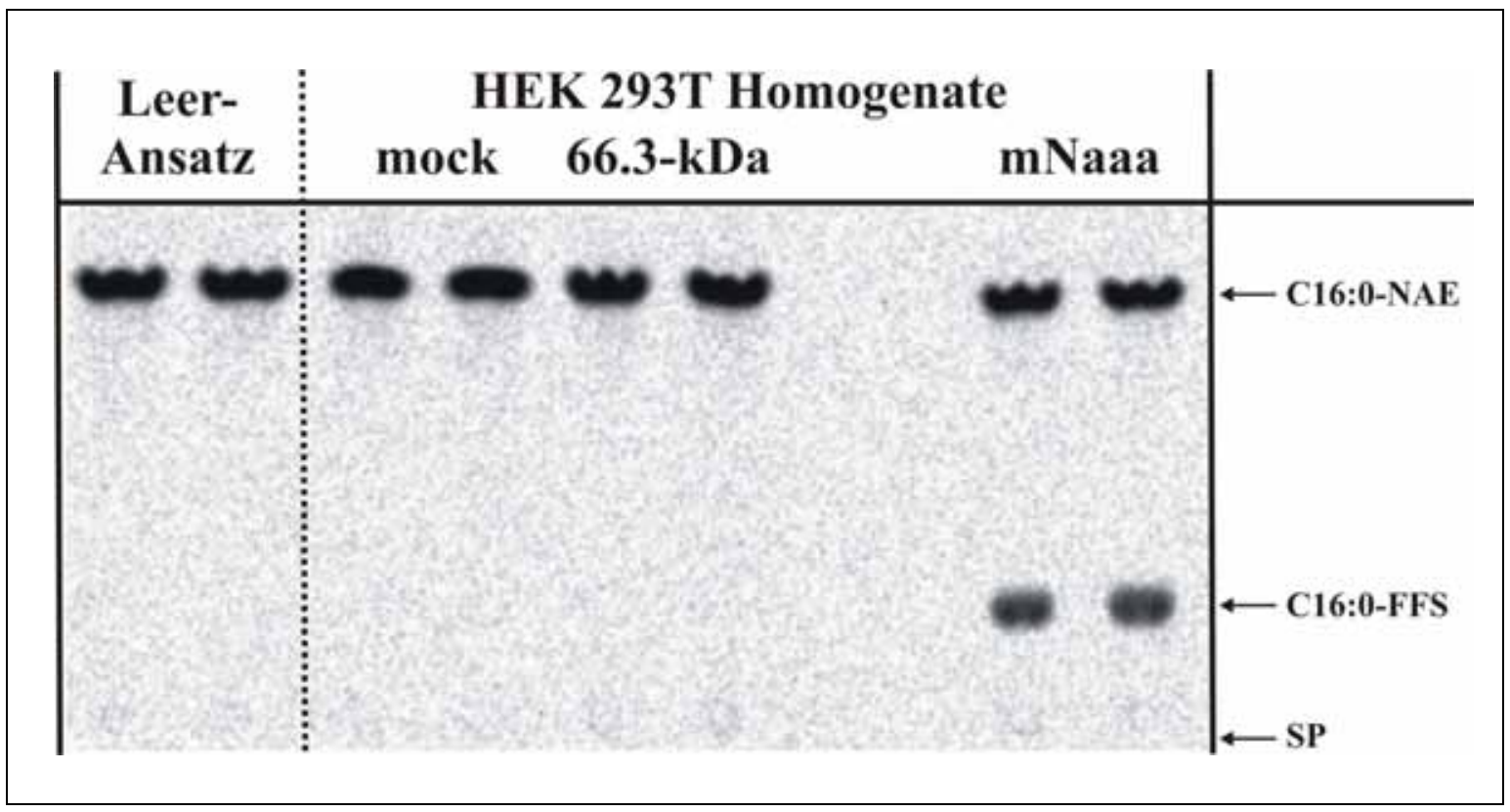

\section{Abb. 4.23: Hydrolytische Aktivität für N-Palmitoylethanolamid in Doppelansätzen}

Das ${ }^{14} \mathrm{C}$-markierte Palmitoylethanolamid wurde mit HEK293T-Zellhomogenaten inkubiert. Links neben der gestrichelten Linie ist der Versuchsansatz völlig ohne Homogenat als Negativkontrolle dargestellt (Leer-Ansatz). Die HEK293T-Zellhomogenate wurden mit leerem pcDNA3.1-Vektor transfiziert (mock), mit 66.3-kDa-Protein transfiziert $(66.3-\mathrm{kDa})$ und als Positivkontrolle mit muriner $\mathrm{N}$-Acylethanolamin acid amidase (mNaaa) transfiziert und analysiert. Rechts wurde mit Pfeilen die Laufweite des NPalmitoylethanolamids (C16:0-NAE), sowie die der freien Palmitinsäure (C16:0-FFS) markiert. Der Startpunkt der Chromatographie wurde ebenfalls mit einem Pfeil markiert (SP). 
Wie in Abb. 4.23 dargestellt zeigten die HEK293T Zellhomogenate mit transfiziertem 66.3-kDa-Protein keine Aktivität gegenüber dem N-Palmitoylethanolamid, wohingegen bei der NAAA-Positivkontrolle eine quantitative Abspaltung (39\%) der Palmitinsäure vom Ethanolamin erfolgte.

Im zweiten Versuchsansatz wurde das 66.3-kDa-Protein in verschiedenen molekularen Formen auf seine hydrolytische Aktivität gegenüber unterschiedlichen Substraten getestet. Dafür wurde einerseits das aufgereinigte rekombinante 66.3kDa-Protein in zwei unterschiedlichen Konzentrationen analysiert, andererseits wurden HT1080- und HEK293T-Zellen mit dem pcDNA3.1-Hygro (+) transfiziert, der das His-getaggte 66.3-kDa-Protein beinhaltete. Als Positivkontrolle dienten HEK293T-Zellen, die mit dem pcDNA3.1-Hygro (+) transfiziert wurden, welcher die $\mathrm{mNaaa}$ beinhaltete (vgl. Abb. 4.24).

Die N-Acylethanolamidspaltende Aktivität der mNaaa als Positivkontrolle war gegenüber dem Palmitoylethanolamid $\left(C_{16: 0}\right)$ und Myristoylethanolamid $\left(C_{14: 0}\right)$ mit 44\% bzw. 42\% umgesetztem Substrat am größten. Auch Laurylethanolamid $\left(\mathrm{C}_{12: 0}\right)$ wurde noch zu 26\% in das Ethanolamin und die freie Fettsäure umgesetzt. Diese Ergebnisse stimmten weitestgehend mit denen von Herrn Prof. Uedas Arbeitsgruppe bereits publizierten Ergebnissen überein (Tsuboi et al. 2007). Gleiches galt auch für die hier nicht dargestellten Ergebnisse der Substrate Stearylethanolamid $\left(C_{18: 0}\right)$, Oleylethanolamid $\left(C_{18: 1}\right)$ und Arachidonethanolamid $\left(C_{20: 4}\right)$. Das 66.3-kDa-Protein seinerseits wies weder in aufgereinigter Form noch nach Überexpression in HT1080oder HEK293T-Zellen hydrolytische Aktivität gegenüber den sechs getesteten Substraten auf. 


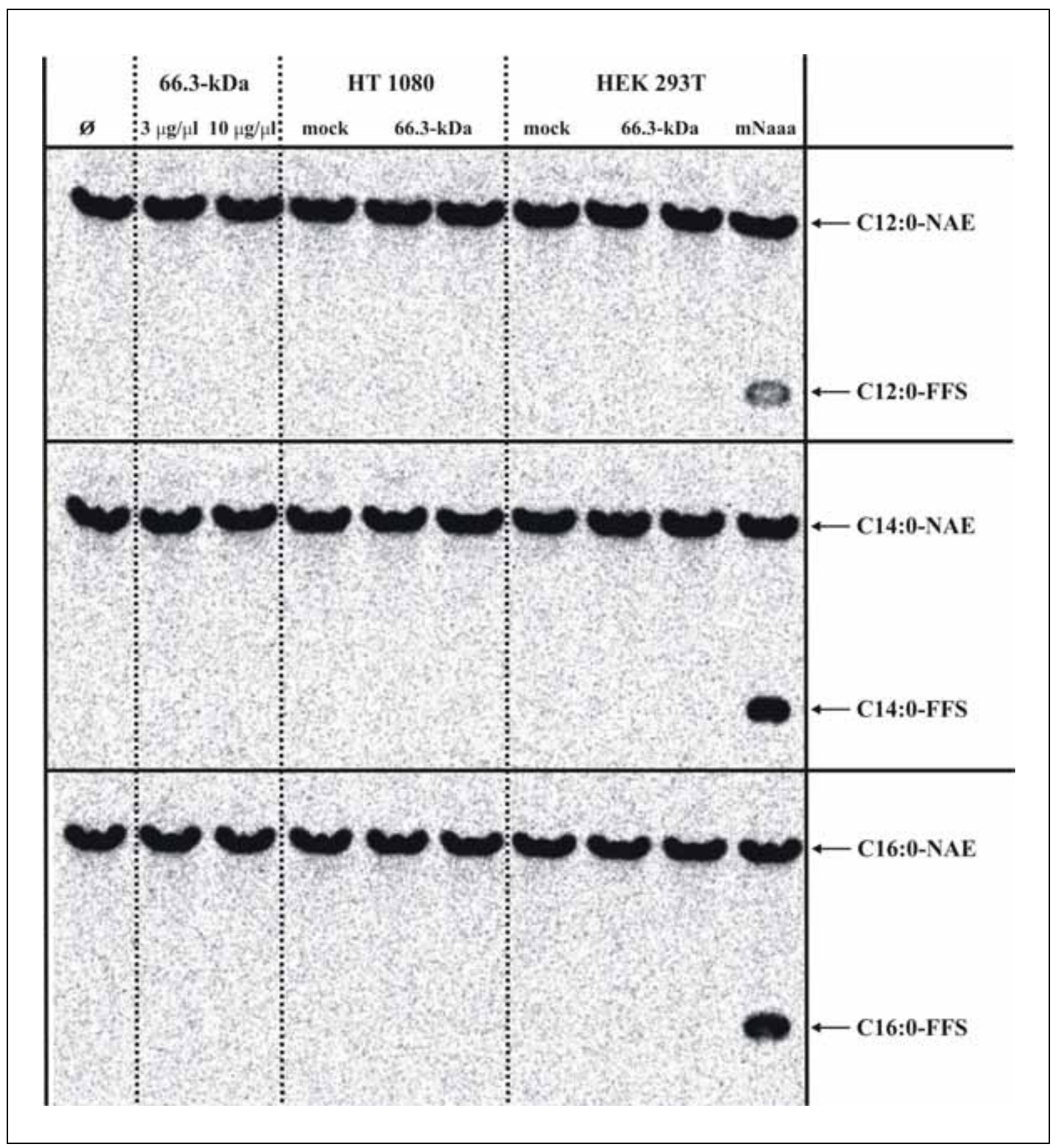

\section{Abb. 4.24: Hydrolytische Aktivität gegenüber verschiedenen N-Acylethanolamiden}

Die Abb. 4.24 zeigt die hydrolytische Aktivität gegenüber drei verschiedenen ${ }^{14} \mathrm{C}$-markierten $\mathrm{N}$ Acylethanolamiden (vgl. Tab. 4.7). Ganz links wurde als Negativkontrolle ein Ansatz ohne Homogenat bzw. Enzym analysiert. Von dem aufgereinigten, rekombinanten 66.3-kDa-Protein wurde jeweils $1 \mu \mathrm{g}$,

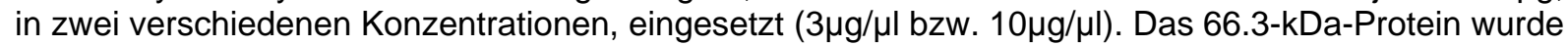
sowohl in HT1080-Zellen als auch in HEK293T-Zellen transfiziert. Mit mock sind nicht-transfizierte Homogenate zum Vergleich mit aufgetragen. Als Positivkontrolle wurde die mNaaa in HEK293TZellen transfiziert (ganz rechts). In jeder Probe wurden $40 \mu \mathrm{g}$ Zellhomogenat eingesetzt, mit Ausnahme der mNaaa, bei der lediglich $10 \mu \mathrm{g}$ eingesetzt wurden. Die Laufweite des $\mathrm{N}$-Acylethanolamids (NAE) und der freien Fettsäure (FFS) ist jeweils rechts mit Pfeilen markiert. 


\subsection{Vergleichende Lipidanalyse}

Nachdem es mittels NAE-Assay nicht gelungen war eine direkte Funktion des 66.3-kDa-Proteins im Abbau der N-Acylethanolamide nachzuweisen, sollte anhand einer vergleichenden Lipidanalyse nach generellen Unterschieden im Lipidmuster von Ethanolamin enthaltenen Lipiden gesucht werden.

Dazu wurden 66.3-kDa-Protein-defiziente MEFs (Mouse Embryonic Fibroblasts) und Kontroll-MEFs ebenso wie stabil überexprimierende HT1080-66.3-kDa-Protein-Zellen und HT1080-Kontrollzellen für 20 Stunden mit ${ }^{14} \mathrm{C}$-markiertem Ethanolamin metabolisch markiert (vgl. Kap. 3.3.5). Anschließend wurden die Zellen geerntet und deren Gesamtlipide mit einem Chloroform-Methanol-Gemisch extrahiert. Die Chloroformphase wurde eingedampft, und die darin enthaltenen Lipide wurden der zweidimensionalen Dünnschicht-chromatographie zugeführt. Dabei wurden die Lipide in der ersten Dimension mit einem Laufmittel aus Chloroform-MethanolAmmoniak-Wasser aufgetrennt. In der zweiten Dimension diente ein Gemisch aus Chloroform-Methanol-Aceton-Essigsäure-Wasser zur weiteren Auftrennung der Lipide auf der Chromatographie-platte (vgl. Kap. 3.5.2) (Bütikofer et al. 1989).

In der zweidimensionalen Dünnschichtchromatographie konnte kein qualitativer oder quantitativer Unterschied im Muster der Ethanolamin-Derivate in den verschiedenen Zellpopulationen festgestellt werden. Die Ergebnisse der MEFs sind vergleichbar mit denen der HT1080-Zellen. Eine Zuordnung der einzelnen Lipid-Spots war nur für bestimmte Lipidbestandteile möglich (vgl. Abb. 4.25). Bei Auffälligkeiten im Verteilungsmuster wäre eine massenspektrometrische Analyse der einzelnen LipidSpots zur Klärung der Identität erfolgt. 
MEFs $\%$

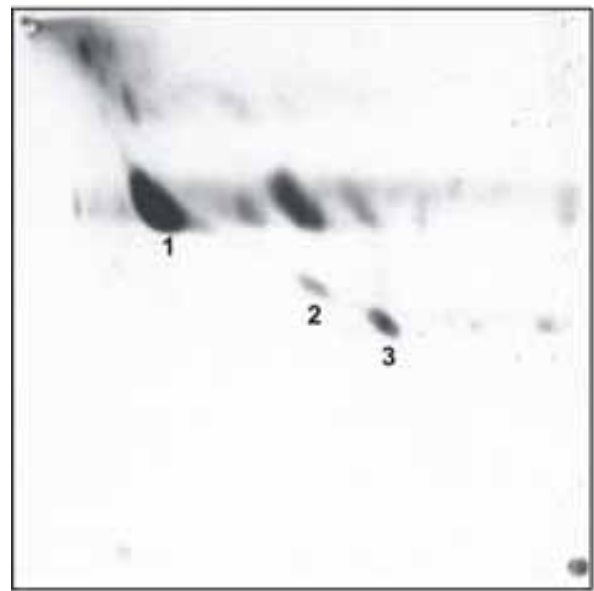

HT1080

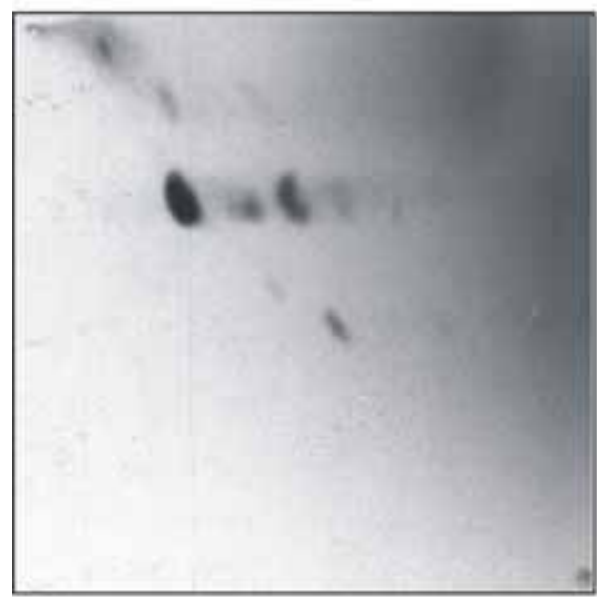

\section{MEFs $+/+$}

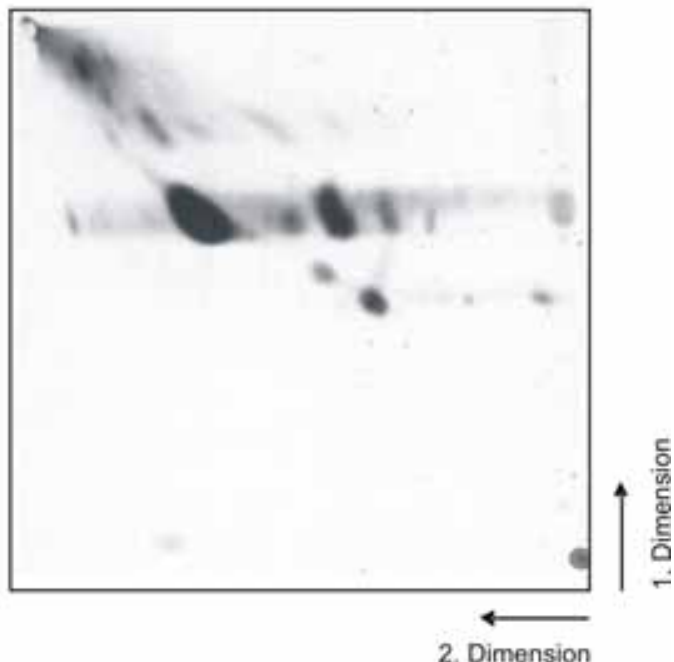

HT1080-66.3-kDa

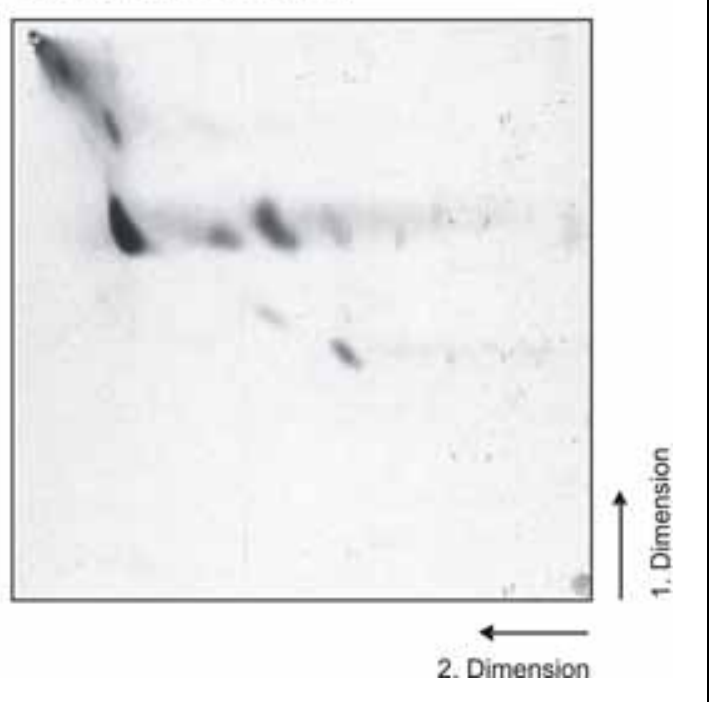

Abb. 4.25: Zweidimensionale Dünnschichtchromatographie der extrahierten Lipide aus ${ }^{14} \mathrm{C}$-Ethanolamin-markierten Zellpopulationen

In Abb. 4.25 ist die Autoradiographie einer vergleichenden zweidimensionalen Dünnschichtchromatographie der extrahierten Lipide aus zuvor mit ${ }^{14} \mathrm{C}$-Ethanolamin-markieten Zellen nach drei Tagen dargestellt. Oben wurden 66.3-kDa-Protein-defiziente MEFs mit Kontroll-MEFs verglichen. Unten wurden 66.3-kDa-Protein-überexprimierende HT1080-Zellen mit nicht überexprimierenden HT1080-Zellen verglichen. Der Startpunkt war jeweils in der rechten unteren Ecke, die erste Dimension verläuft vertikal, die zweite Dimension horizontal. Links oben wurden drei Spots mit Zahlen versehen. $\quad 1=$ Phosphatidylethanolamid, $2=$ methyliertes Phosphatidylethanolamid, 3 = lyso-Phosphatidylethanolamid. Die Schwärzung im linken unteren Bild ist die Folge von eingedrungenem Licht in die Kassette während der dreitägigen Exposition. 


\subsection{Massenspektrometrische Untersuchung der verschiedenen Fragmente des 66.3-kDa-Proteins}

Die in Vorarbeiten durchgeführten Untersuchungen zur Prozessierung des 66.3-kDaProteins in HT1080-Zellen ergaben eine Synthese des 66.3-kDa-Proteins als PräProfrom, aus der durch Abspaltung des Signalpeptids von Aminosäure 1 bis 46 die 75-kDa-Proform entsteht (Deuschl et al. 2006). Diese wird in ein N-terminales 28-kDa-Fragment und ein C-terminales 40-kDa-Fragment gespalten. Die Ergebnisse der Kristallisation konnten diesen Prozessierungsschritt wie oben beschrieben bestätigen. Dabei bildet das 28-kDa-Fragment mit dem 40-kDa-Fragment als Komplex eine funktionelle Einheit. Da das 66.3-kDa-Protein in F2-Fraktionen allerdings hauptsächlich als 28-kDa-Fragment und 15-kDa-Fragment zu detektieren war, während das 40-kDa-Fragment nur noch in geringen Mengen zu finden war, legt dies eine weitere Prozessierung des 40-kDa-Fragments nahe. Das 15-kDa-Fragment war bereits als C-terminales Peptid des 40-kDa-Fragments beschrieben worden. Über den Verbleib des N-terminalen Peptids des 40-kDa-Fragments gab es bisher keine Erkenntnisse. Die Ergebnisse der Kristallisation gaben aber gerade diesem N-terminalen Peptid des 40-kDa-Fragments eine entscheidende Bedeutung für die katalytische Funktion des Gesamtproteins. Daher war davon auszugehen, dass sich auch der N-terminale Anteil als 25-kDa-Fragment in der aktiven Form des 66.3-kDaProteins darstellte (vgl. Abb. 4.27 C). Bei der näheren Betrachtung des aufgereinigten, rekombinanten 66.3-kDa-Proteins im Silbergel, sowie im WesternBlot mit dem 66-Antiserum stellte sich heraus, dass in einigen Präparationen das 15kDa-Fragment gut zu detektieren war, während es in anderen Präparationen völlig fehlte. Dabei schien die Prozessierung des 40-kDa-Fragments in das 15-kDaFragment am besten im HEPES-Puffer stattzufinden. Auffälligerweise ließ sich gerade in dieser HEPES-Präparation im Bereich des 28-kDa-Fragments eine weitere Bande bei $25 \mathrm{kDa}$ detektieren (vgl. Abb. 4.26 A). 


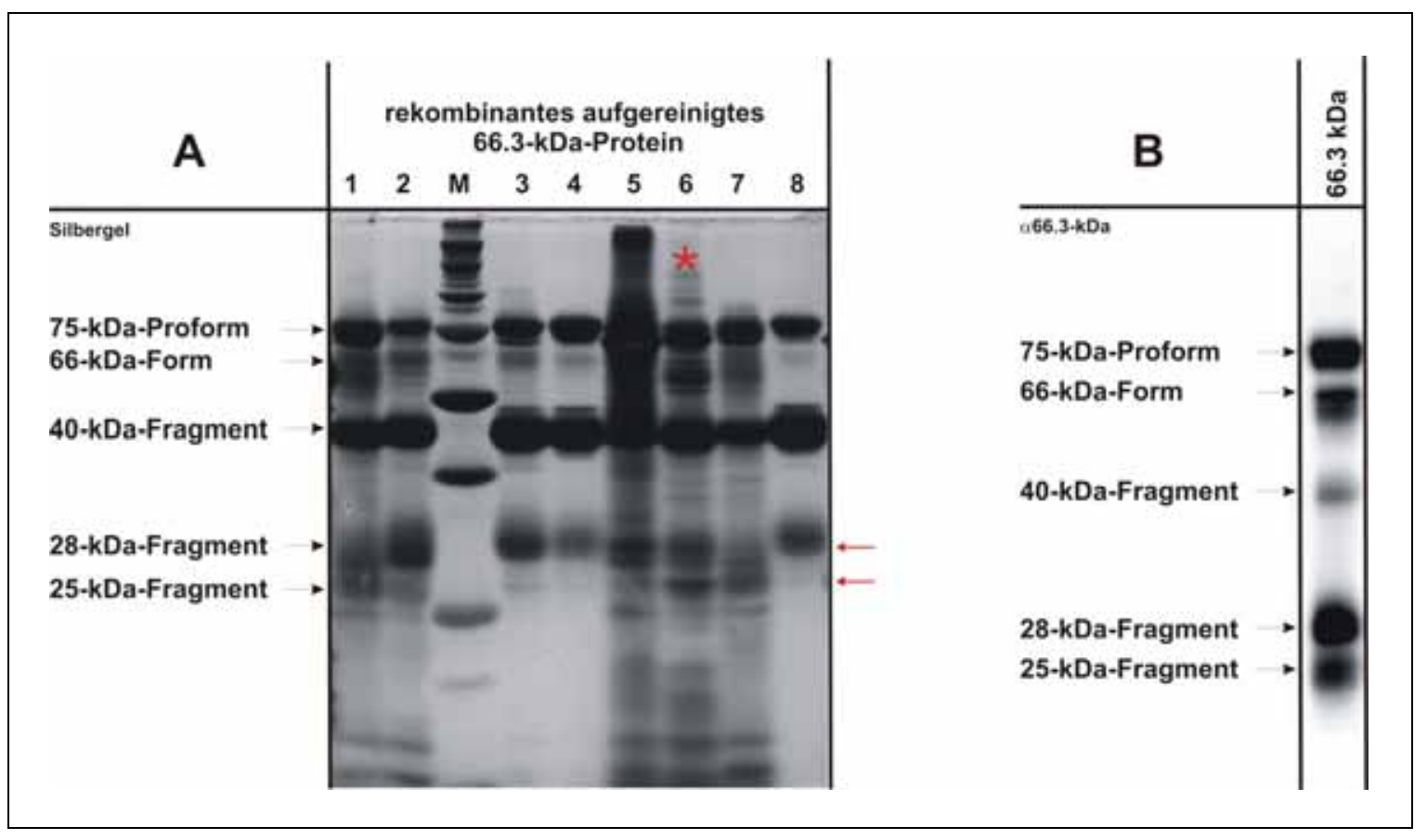

Abb. 4.26: Doppelbande des 66.3-kDa-Proteins im Silbergel und Western-Blot

Die Abb. 4.26 zeigt die Aufreinigung des 66.3-kDa-Proteins im Silbergel (A) und im Western-Blot mit 66-Antiserum (B). Die HEPES-Präparation ist in (A) mit einem roten Stern markiert. Die beiden roten Pfeile markieren im Silbergel die Doppelbande, welche im Western-Blot deutlich zu erkennen ist.

Zur weitergehenden Untersuchung der Doppelbande wurde ein Teil dieser HEPESPräparation des 66.3-kDa-Proteins im Polyacrylamidgel aufgetrennt und die Bestandteile des oberen und unteren Anteils dieser Doppelbande wurden mittels Massenspektrometrie identifiziert. Dazu wurden die Banden aus dem Polyacrylamidgel nach Coomassie Blue-Färbung ausgestanzt, im Gel mit Trypsin verdaut und die Peptide für eine Petid-Mass-Fingerprint-Analyse verwendet (MALDITOF-MS/PMF).

Die massenspektrometrischen Analysen wurden von Bernhard Schmidt und Nicole Eiselt der Abteilung Biochemie II am MALDI-TOF-MS (Reflex I/III, Bruker Daltonik) durchgeführt. 


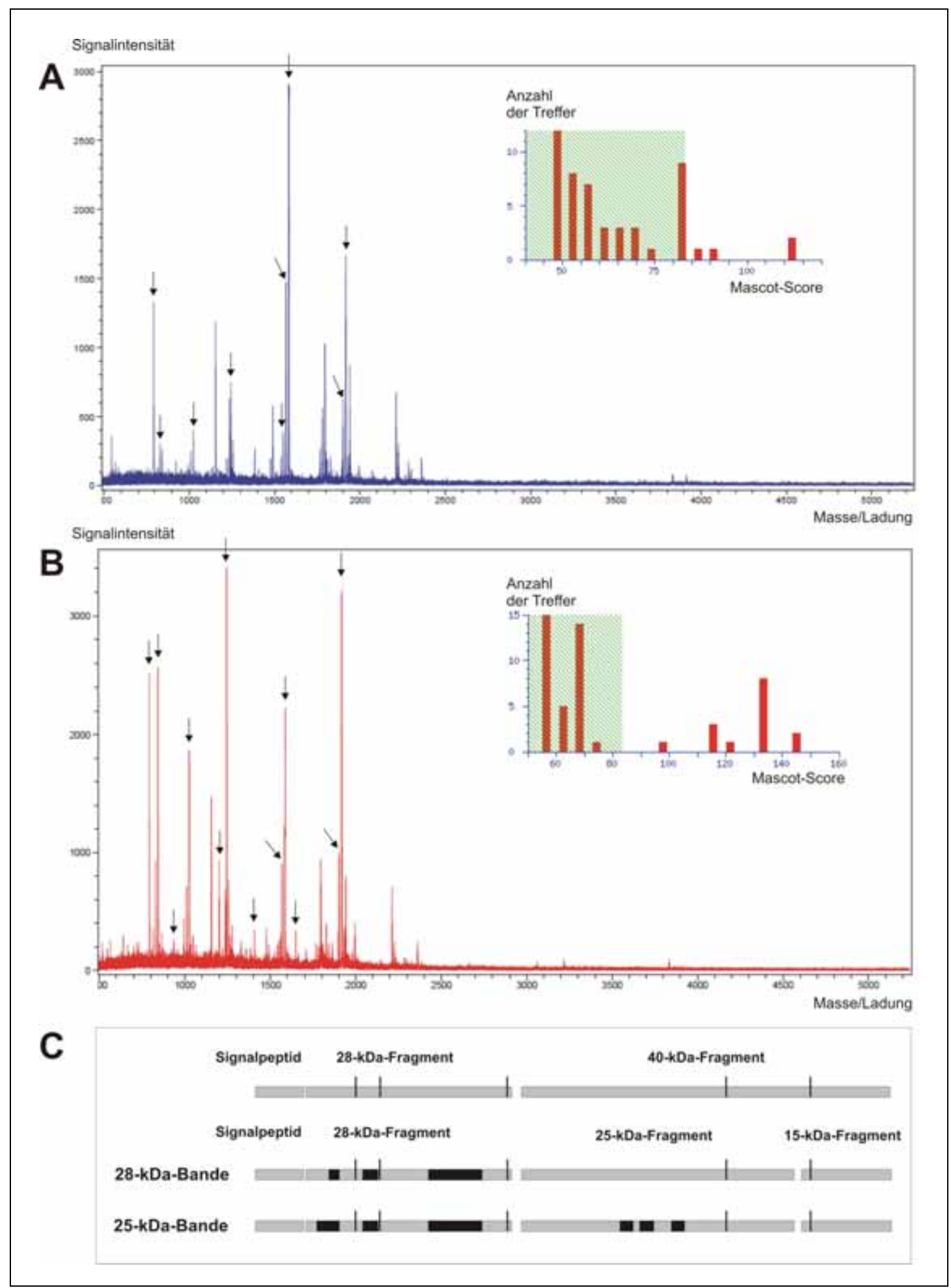

Abb. 4.27: Graphische Darstellung der massenspektrometrisch nachgewiesenen Peptide in der Doppelbande

In (A) und (B) sind die Ergebnisse der Massenspektrometrie des oberen bzw. unteren Anteils der Doppelbande des 66.3-kDa-Proteins dargestellt. Es sind jeweils die Massenspektrometrie-Rohdaten dargestellt, in denen die zum 66.3-kDa-Protein gehörigen Peptide mit einem schwarzen Pfeil markiert sind. Rechts darüber sind die Treffer in der NCBInr-Datenbank mit dem jeweiligen Mascot-Score abgebildet. Der grün schraffierte Bereich kennzeichnet dabei den nicht signifikanten Bereich $(p>0,05)$. In (C) ist die Prozessierung des 66.3-kDa-Proteins vom 40-kDa-Fragment in ein 25-kDa-Fragment und ein 15-kDa-Fragment abgebildet. Die verschieden Fragmente des 66.3-kDa-Proteins sind als graue Balken dargestellt. Die jeweils in der 28- bzw. 25-kDa-Bande massenspektrometrisch nachweisbaren 
Anteile der Fragemente sind in schwarz hervorgehoben. Dabei waren alle Peptide, die sich in der 28$\mathrm{kDa}$-Bande nachweisen ließen, auch in der 25-kDa-Bande zu detektieren. Darüber hinaus konnten in der 25-kDa-Bande auch Peptide des 25-kDa-Fragments gefunden werden. Mit schwarzen Strichen sind die fünf Glykosylierungsstellen des 66.3-kDa-Proteins markiert.

Die ermittelten Massen wurden mit Hilfe des Programms Mascot (Matrix-Science) mit den Einträgen von in silico verdauten Proteinen mit der Proteindatenbank NCBInr (http://www.ncbi.nlm.nih.gov; Stand 02.12.09) verglichen. Für jede Übereinstimmung zwischen experimentell bestimmten Daten und den theoretischen Daten eines Datenbankeintrages wurde ein Mascot-Score ermittelt (vgl. Abb. 4.27).

Die massenspektrometrische Analyse der oberen der beiden Banden (28-kDaBande) ergab mit einem maximalen Mascot-Score von 112 Punkten eindeutig die Zugehörigkeit der gefundenen Fragmente zum 66.3-kDa-Protein (vgl. Abb. 4.27 A). Auch die weiteren Treffer mit signifikantem Mascot-Score stellen verschiedene Datenbankeinträge des 66.3-kDa-Proteins dar. Insgesamt konnten neun tryptische Peptide dem 66.3-kDa-Protein zugeordnet werden. Diese neun Peptide liegen alle im $\mathrm{N}$-terminalen 28-kDa-Fragment des 66.3-kDa-Proteins (vgl. Abb. 4.27 A und C sowie

Tab. 4.8). In der massenspektrometrischen Analyse der unteren Bande (25-kDaBande) konnte mit einem maximalen Mascot-Score von 152 Punkten erwartungsgemäß das 66.3-kDa-Protein identifiziert werden. Auch hier sind alle Treffer mit signifikantem Mascot-Score auf verschiedene Datenbankeinträge des 66.3-kDa-Proteins zurückzuführen. Insgesamt konnten in der unteren Bande zwölf tryptische Peptide gefunden werden, die dem 66.3-kDa-Protein zuzuordnen waren. Neun dieser zwölf Peptide sind dem 28-kDa-Fragment zugehörig, während die verbliebenen drei Peptide dem potentiellen 25-kDa-Fragment als N-terminales Peptid des prozessierten 40-kDa-Fragements zugeordnet werden konnten (vgl. Abb. 4.27 B und C). Somit wurden vom 28-kDa-Fragment insgesamt 38\% der Aminosäuresequenz in der massenspektrometrischen Analyse detektiert. Für das 25-kDaFragment waren es 14\% der Aminosäuresequenz (vgl. Tab. 4.8). Es wurden weder Peptide der Signalsequenz noch des C-terminalen 15-kDa-Fragments detektiert. Einzelne Peptide der 28- und 25-kDa-Fragmente konnten nicht detektiert werden, da sie nicht in dem Bereich der eingestellten Messgrenzen für entstandene Peptide von 0,5 bis $4 \mathrm{kDa}$ lagen, oder durch eine Glykosylierung auf Grund ihrer damit 
verbundenen Massenzunahme nicht in der Peptid-Mass-Fingerprint-Analyse dem eigentlichen Peptid zugeordnet werden konnten.

\section{Tab. 4.8: Massenspektrometrisch erfasste, tryptische Peptide des 66.3-kDa-Proteins}

Die Tab. 4.8 listet alle dem 66.3-kDa-Protein zuzuordnenden, tryptischen Peptide auf, die in der massenspektrometrischen Analyse der Doppelbande aus 28- und 25-kDa-Fragment zu detektieren waren. Dabei sind die Peptide nach ihrer Position im Gesamtprotein von N- zum C-Terminus sortiert aufgelistet. Im oberen Teil der Tabelle sind die Ergebnisse für das 28-kDa-Fragment dargestellt, im unteren Teil der Tabelle die Ergebnisse für das 25-kDa-Fragment. Die fettgedruckten Peptide wurden sowohl in oxidierter, als auch in nicht-oxidierter Form detektiert.

\begin{tabular}{cccl}
\hline Berechnete Masse & Gemessene Masse & Sequenz & Abgedeckte Sequenz 38\% \\
\hline 1242,69 & 1243,67 & $68-79$ & SLLLDAASGQLR \\
1581,74 & 1582,69 & $100-113$ & ETGWAYLDLSTNGR \\
1549,73 & 1550,71 & $162-173$ & NFLEANLEWMQR \\
1899,86 & 1900,89 & $174-188$ & EMELNPDSPYWHQVR \\
827,54 & 828,51 & $189-195$ & LTLLQLK \\
1024,45 & 1025,46 & $196-204$ & GLEDSYEGR \\
790,43 & 791,49 & $205-211$ & LTFPTGR \\
& & & \\
& & & Abgedeckte Sequenz 14\% \\
\hline 1646,82 & 1647,80 & $341-353$ & YVQPQGCVLEWIR \\
1405,72 & 1406,69 & $360-372$ & LALDGATWADVFK \\
1198,61 & 1199,54 & $390-401$ & AFLPNGPSPGSR \\
\hline
\end{tabular}

Die Ergebnisse der massenspektrometrischen Untersuchung bestätigen die anfänglichen Vermutungen, dass die Doppelbande aus dem 28-kDa-Fragment und dem potentiellen 25-kDa-Fragment gebildet werden. Diese Ergebnisse legen eine Prozessierung der 75-kDa-Proform in ein 28- und 40-kDa-Fragment mit sukzessiver Weiterprozessierung des 40-kDa-Fragments in ein C-terminales 15-kDa-Fragment und ein N-terminales 25-kDa-Fragment nahe. Der N-Terminus des 15-kDaFragments ist durch die Edman-Analysen in Vorarbeiten mit Serin 514 beschrieben worden (Deuschl et al. 2006). Ob der C-Terminus des 25-kDa-Fragments allerdings direkt mit der vorherigen Aminosäure (Arginin 513) endet, oder ob im Rahmen der Prozessierung weitere Aminosäuren abgespalten werden, ist unklar.

Welchen Einfluss die unterschiedlichen Pufferbedingungen während der Aufreinigung speziell auf die Geschwindigkeit dieser womöglich autokatalytischen Weiterprozessierung des 66.3-kDa-Proteins hatten, kann hier nicht abschließend geklärt werden. 


\subsection{Transkriptomanalyse des 66.3-kDa-Protein-GeneTrap- Mausmodells}

Parallel zu den bisher beschriebenen Untersuchungen zur Struktur und Funktion des 66.3-kDa-Proteins wurde in der Arbeitsgruppe ein GeneTrap-Mausmodell für das 66.3-kDa-Protein etabliert (vgl. Kap. 1.5.4).

Um mögliche Einflüsse des GeneTraps für das 66.3-kDa-Protein in der Maus (66gt) auf den Gesamtorganismus und speziell auf die Regulierung anderer Proteine oder ganzer Stoffwechselwege im Screeningverfahren beurteilen zu können, wurde eine Transkriptomanalyse des Lebergewebes von 66gt-Mäusen (-/-) mit jenem normaler Mäuse (+/+) verglichen. Die Leber eignet sich auf Grund ihrer vergleichsweise homogenen Zellpopulation aus Hepatozyten, Kupfferzellen und wenigen Endothelund Itozellen besonders gut für eine vergleichende Transkriptomanalyse. Da verschiedene Zelltypen ein unterschiedliches Genexpressionsprofil aufweisen, erleichtert die relative Homogenität die technische Durchführung und Interpretation der Expressionsdaten. Zudem steht die Leber mit vielen Teilen des Organismus stoffwechselbezogen in Beziehung und ist eines der präferentiell betroffenen Organe bei vielen lysosomalen Speichererkrankungen (Futerman and van Meer 2004; Woloszynek et al. 2004).

Zum besseren Verständnis der nachfolgend beschriebenen Ergebnisse soll hier noch einmal der in der Einleitung ausführlich beschriebene GeneTrap des 66.3-kDaProteins in der Maus kurz dargestellt werden (vgl. 1.5.4).

In das Gen, welches für das 66.3-kDa-Protein kodiert, inserierte im Intro 6 der genomischen DNA eine GeneTrap-Kassette. Diese GeneTrap-Kassette besteht aus einer für die Neomycinphosphotransferase kodierenden Sequenz, welche im 5'Bereich von einer Splice-Akzeptor-Sequenz und im 3'-Bereich von einer TerminatorSequenz flankiert wird. Die aus dieser genomischen Sequenz transkribierte mRNA enthält die Sequenzen der Exone 1 bis 6, gefolgt von der GeneTrap-Kassette. Die Exone 7 bis 12 sind nicht Teil der mRNA, da am Ende der GeneTrap-Kassette die Terminator-Sequenz zum vorzeitigen Ende des Transskripts führt. Das aus dieser 
mRNA translatierte Fusionsprotein besteht demnach aus den Aminosäuren 1 bis 324 des 66.3-kDa-Proteins und der Neomycinphosphotransferase (vgl. Abb. 4.28).

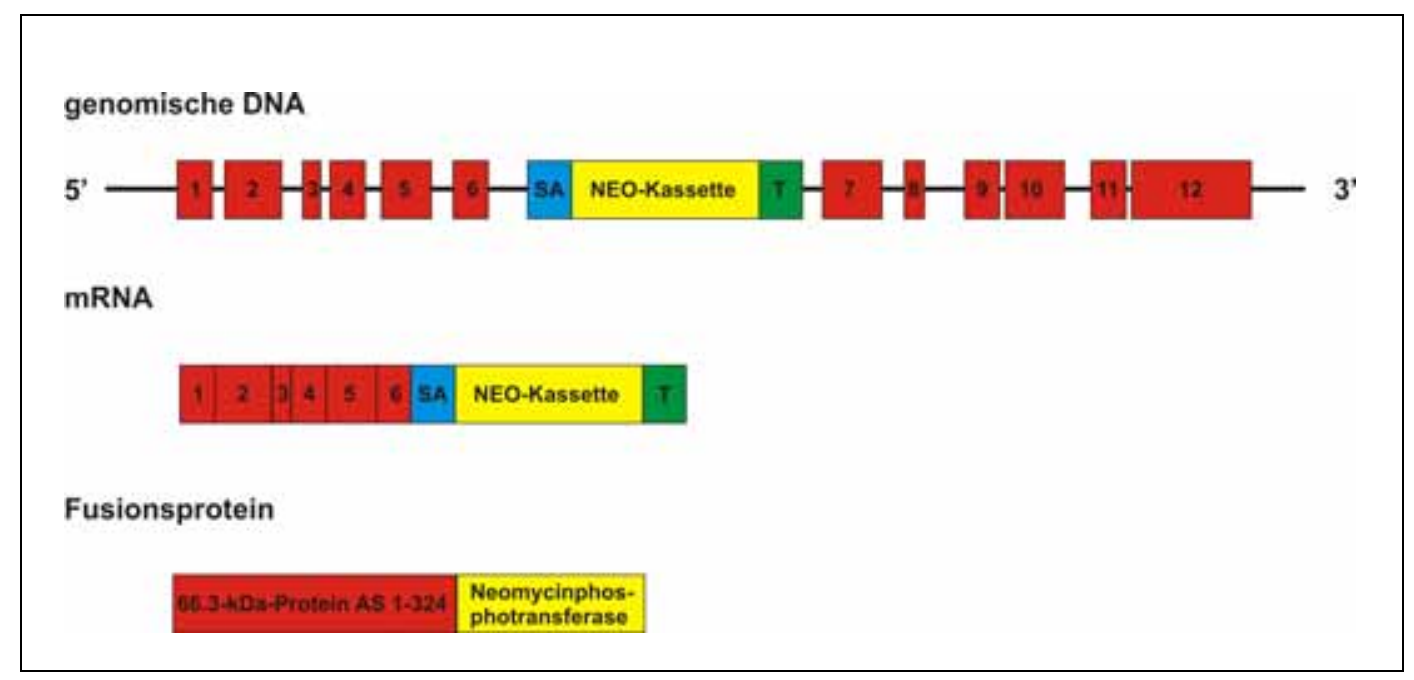

Abb. 4.28: Darstellung des GeneTraps für das 66.3-kDa-Protein in der Maus

Die Abb. 4.28 beschreibt die Schritte des GeneTraps für das 66.3-kDa-Protein in der Maus von der Insertion der GeneTrap-Kassette in die genomische DNA bis hin zum Fusionsprotein. Dabei stehen die Zahlen eins bis zwölf für die jeweiligen Exone des 66.3-kDa-Proteins. SA und T stehen für die Elemente des Splice-Akzeptors (SA) und des Terminators (T), während mit NEO-Kassette die Sequenz gekennzeichnet ist, die für eine Neomycinphosphotransferase kodiert.

\subsubsection{Microarray}

Die Transkriptomanalyse mittels Microarray wurde im Transkriptomanalyselabor (TAL) der Universitätsmedizin Göttingen durchgeführt.

Im Fall des 66gt-Mausmodells wurde die RNA aus jeweils fünf $(+/+)$ Tieren mit fünf (-/-) Tieren verglichen. Dazu wurde RNA aus Leber isoliert und in biotin-markierte cRNA umgeschrieben, die ihrerseits für die Hybridisierung im Microarray verwendet wurde. Als Chip für den Oligonukleotid-Microarray fand der Whole Mouse Genome Microarray G4122F-chip der Firma Agilent Technologies Verwendung.

Die mittels der Software Affymetrix-Data-Suite ausgelesenen FluoreszenzIntensitäten des Microarrays wurden direkt mit auf den Chips befindlichen Kontrollhybridisierungsproben normalisiert. Gene wurden als differentiell exprimiert angesehen, wenn sie mindestens einen 1,5-fachen Expressionsunterschied und bei dem für jedes Gen durchgeführten t-Test (Student's t-Test) einen p-Wert <0,05 aufwiesen. Auf eine Korrektur der p-Werte auf multiples Testen musste auf Grund der geringen Replikate $(n=5)$ verzichtet werden. 


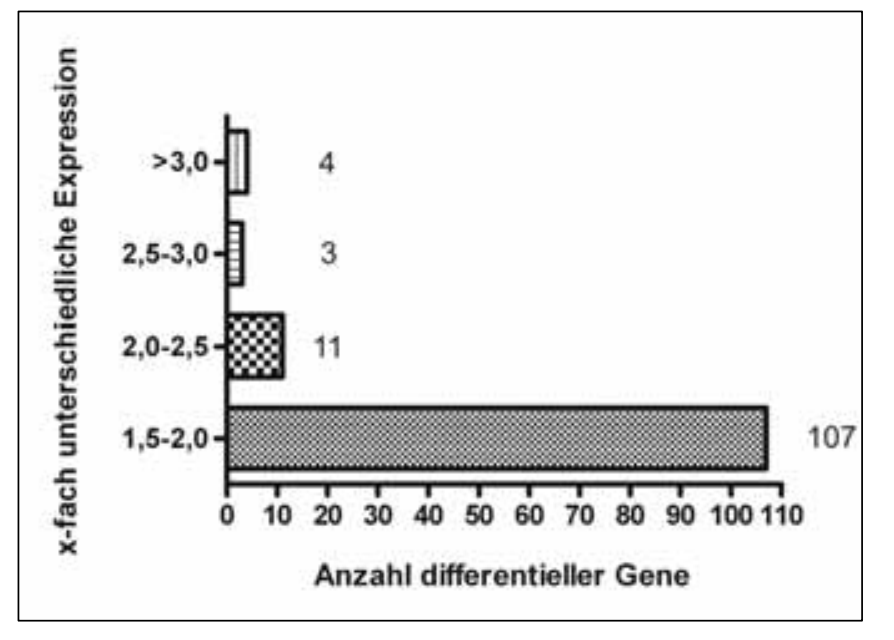

\section{Abb. 4.29: Anzahl der differentiell exprimierten Gene}

Abb. 4.29 zeigt, wie viele Transkripte in welchem Ausmaß differentiell exprimiert wurden.

Wie in Abb. 4.29 dargestellt, wurden die meisten (107 von 125) differentiell exprimierten Gene nur gering durch den GeneTrap des 66.3-kDa-Proteins induziert bzw. reprimiert (1,5 bis 2-fach). Bei 18 Genen unterschied sich die Genexpression mehr als 2-fach zwischen den beiden Vergleichsgruppen. Davon waren lediglich 7 Gene mehr als 2,5-fach induziert bzw. reprimiert worden. Eine Liste aller Gene, die mehr als 2-fach differentiell exprimiert waren, ist in Tab. 4.9 dargestellt. Das am stärksten reprimierte Gen ist erwartungsgemäß das für das 66.3-kDa-Protein kodierende Gen. Diese Reprimierung des 66.3-kDa-Transkripts bezieht sich ausschließlich auf ein im 3'-Bereich gelegenes Oligonukleotid. Ein weiteres auf dem Microarraychip vorhandenes Oligonukleotid, welches im 5'-Bereich des 66.3-kDaTranskripts gelegen ist, war nicht differentiell exprimiert. Insgesamt war für den GeneTrap eine deutlichere Reprimierung des Gens erwartet worden, als sie sich im Microarray anhand des 3'-Oligonukleotids darstellte (7,5-fach reprimiert).

\section{Tab. 4.9: Differentiell exprimierte Gene, Wildtyp vs. 66gt}

Die Tab. 4.9 enthält alle mehr als 2-fach differentiell exprimierten Gene aus dem Microarray, der fünf $(-/-)$ Tiere mit fünf $(+/+)$ Tieren vergleicht. Für jedes Gen sind Name, Beschreibung und die Referenznummer unter der es bei NCBI zu finden ist (Refseq), sowie die Lokalisation auf dem Genom und die differentielle Exprimierung angegeben. Dabei stehen positive Werte für eine Induktion im 66gt, während negative Werte eine Repression kennzeichnen.

\begin{tabular}{lllcr}
\hline Name des Gens & Beschreibung & Refseq & Lokalisation & 66gt vs. WT \\
\hline 1300012G16Rik & $\begin{array}{l}\text { RIKEN cDNA 1300012G16 } \\
\text { gene (66.3-kDa-Gen) }\end{array}$ & NM_023625 & $5 \mathrm{~F}$ & $-7,52$ \\
\hline Cish & $\begin{array}{l}\text { cytokine inducible SH2- } \\
\text { containing protein }\end{array}$ & NM_009895 & 9 F1 & $-3,86$ \\
\hline Aldh2 & - & - & - & $-3,71$ \\
\hline C730043017 & - & - & - & $-3,12$ \\
\hline
\end{tabular}




\begin{tabular}{|c|c|c|c|c|}
\hline Asns & asparagine synthetase & NM_012055 & $6 A 1$ & $-2,85$ \\
\hline Socs2 & $\begin{array}{l}\text { suppressor of cytokine } \\
\text { signaling } 2\end{array}$ & NM_007706 & $10 C 2$ & $-2,83$ \\
\hline Clec2h & $\begin{array}{l}\text { hypothetical protein } \\
\text { LOC100043863 }\end{array}$ & $X M \_001481112$ & $6 F 3$ & $-2,41$ \\
\hline Daglb & diacylglycerol lipase, beta & NM_144915 & $5 G 2$ & $-2,19$ \\
\hline Arrdc3 & arrestin domain containing 3 & NM_001042591 & $13 \mathrm{C3}$ & $-2,17$ \\
\hline Camk2b & $\begin{array}{l}\text { calcium/calmodulin- } \\
\text { dependent protein kinase II, } \\
\text { beta }\end{array}$ & NM_007595 & $11 \mathrm{A1}$ & $-2,13$ \\
\hline Ppp1r14a & $\begin{array}{l}\text { protein phosphatase 1, } \\
\text { regulatory (inhibitor) subunit } \\
14 \mathrm{~A}\end{array}$ & NM_026731 & $7 B 1$ & $-2,11$ \\
\hline Trim56 & $\begin{array}{l}\text { hypothetical protein } \\
\text { LOC100044233 }\end{array}$ & XM_001471909 & - & $-2,08$ \\
\hline Serpina4-ps1 & $\begin{array}{l}\text { serine (or cysteine) } \\
\text { peptidase inhibitor, clade } A \text {, } \\
\text { member } 4, \text { pseudogene } 1\end{array}$ & NR_002861 & $12 E$ & $-2,04$ \\
\hline $\operatorname{Lnx1}$ & ligand of numb-protein $X 1$ & NM_010727 & $5 D$ & 2,16 \\
\hline Ddit4 & $\begin{array}{l}\text { DNA-damage-inducible } \\
\text { transcript } 4\end{array}$ & NM_029083 & $10 B 3$ & 2,17 \\
\hline$B c / 6$ & B-cell leukemia/lymphoma 6 & NM_009744 & 16 B1 & 2,28 \\
\hline A230097K15Rik & $\begin{array}{l}\text { RIKEN cDNA A230097K15 } \\
\text { gene }\end{array}$ & NM_172715 & $5 E 4$ & 2,39 \\
\hline Fbxl10 & $\begin{array}{l}\text { F-box and leucine-rich } \\
\text { repeat protein } 10\end{array}$ & NM_001005866 & $5 F$ & 2,99 \\
\hline
\end{tabular}

Bei der eingehenden Analyse der differentiell exprimierten Gene konnten keine Präferenzen für bestimmte Signal- oder Stoffwechselwege festgestellt werden (pathway-Analyse). Bei genauerer Betrachtung der Lage der differentiell exprimierten Gene im Genom der Maus fiel auf, dass viele der differentiell exprimierten Gene auf dem Chromosom 5 lokalisiert waren (vgl. Abb. 4.30). Auf dem gleichen Chromosom befindet sich auch das 66.3-kDa-Protein-Gen mit der inserierten GeneTrap-Kassette. 


\section{Verteilung der differentiell exprimierten Gene im Karyogramm der Maus}

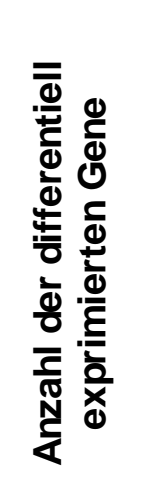

Abb. 4.30: Verteilung der differentiell exprimierten Gene im Karyogramm der Maus

In Abb. 4.30 ist die Verteilung der differentiell exprimierten Gene auf das Genom der Maus dargestellt. Dabei ist die absolute Zahl der mehr als 2-fach differentiell exprimierten Gene als Säule für jedes Chromosom abgebildet.

Chromosom

Die Chromosomen sind von 1 bis 19 der Größe nach nummeriert, so dass man bei einer rein zufälligen Verteilung der Gene über das Genom der Maus die meisten differentiell exprimierten Gene auf Chromosom 1 erwartet hätte. In welchem Zusammenhang die Häufung der differentiell exprimierten Gene auf Chromosom 5 mit dem GeneTrap des 66.3-kDa-Protein steht, konnte nicht weiter geklärt werden.

Zusammenfassend bleibt festzuhalten, dass die lediglich 7,5-fache Reprimierung des 66.3-kDa-Transkripts im 3'-Bereich, der eigentlich durch den GeneTrap ersetzt worden sein sollte, an der Effizienz des GeneTraps zweifeln ließ. Des Weiteren konnten die differentiell exprimierten Gene keinen Anhalt für die Beeinträchtigung eines bestimmten Signal- oder Stoffwechselwegs liefern und es bestand eine auffällige, punktuelle Häufung der differentiell exprimierten Gene in der Nähe des GeneTraps auf Chromosom 5.

\subsubsection{Real-Time-PCR}

Die Real-Time-PCR ist eine Methode, mit der quantitative Aussagen über das Verhältnis von bestimmten Transkriptmengen zu einem Referenztranskript getroffen werden können. Die Vergleichbarkeit verschiedener Proben untereinander wiederum wird durch eine Normalisierung der Ergebnisse auf sogenannte Housekeeper-Gene erreicht, die in ihrer Expression zelltypspezifisch konstant sind und nicht durch die Versuchsbedingungen induziert oder reprimiert werden. Zur genaueren Beschreibung der Methode vergleiche Kap. 3.2.3. 
Inklusive des 66.3-kDa-Proteins wurden acht Gene ausgewählt, für die die semiquantitativen Microarray-Genexpressionsanalyseergebnisse in der Real-Time-PCR validiert werden sollten (vgl. Tab. 4.10). Dabei wurden die Kandidaten nach differenzieller Expression und p-Wert im Microarray, sowie nach Zugehörigkeit zum Lipid-Stoffwechsel als potentiell relevanter Stoffwechselweg für das 66.3-kDa-Protein ausgewählt. Zusätzlich wurden Kandidaten mit einer Funktion am bzw. im lysosomalen Kompartiment in die Analysen ausgenommen. Für die eingehende Analyse des GeneTraps des 66.3-kDa-Proteins wurden verschiedene Bereiche des 66.3-kDa-Transkripts quantifiziert. Dabei wurden zwei Bereiche im 3'-Bereich des Transkripts ausgewählt, der im GeneTrap-Transkript durch die Neomycinkassette ersetzt worden war und zusätzlich einer im 5'-Bereich, der sowohl im Wildtyp als auch im GeneTrap-Transkript vorliegen sollte. Um eine gewisse Vergleichbarkeit zwischen den Real-Time-PCR- und den Microarray-Ergebnissen zu gewährleisten, beinhalteten die ausgewählten Bereiche für die Real-Time-PCR die auf dem Microarray verwendeten Oligonukleotidsequenzen. Zusätzlich wurde ein Bereich auf der Neomycinkassette des GeneTrap-Transkripts für die Analyse ausgewählt.

Andere zu untersuchende Gene wurden anhand eines ca. 100 bp großen Abschnitts durch spezifische Primer amplifiziert (vgl. Kap. 8.3.1). Dieses als Amplikon bezeichnete Fragment sollte wiederum einen Exonübergang einschließen, um gegenüber der typischen Kontamination der Proben mit genomischer DNA eine maximale Spezifität zu erreichen. Für jedes Gen wurden drei technische Replikate von allen fünf 66gt-Tieren mit denen der fünf Kontrolltiere analysiert. Dazu wurden die jeweilige cDNA und das spezifische Primerpaar zusammen mit dem interkalierenden Fluoreszensfarbstoff SYBR-green ${ }^{\circledR}$ in 384-well-Platten pipettiert und die Zunahme der Fluoreszenz wurde in der logarithmischen Phase der PCR am TaqMan®-Gerät analysiert. Anschließend wurden die Daten mit dem SequenceDetection-System der Firma Applied Biosystems ausgewertet.

Gemessen wurde das Überschreiten einer bestimmten Fluoreszenzschwelle (Threshold) in Abhängigkeit des Amplifikationszykluses. Für die so erhaltenen Daten wurden Mittelwerte der technischen Replikate gebildet und auf den Mittelwert des Housekeeper-Gens normalisiert. Als Housekeeper-Gen wurde die Glycerinaldehyd3-phosphat-Dehydrogenase (GAPDH) verwendet. Die so gewonnenen Werte für den 
GeneTrap bzw. die Kontrolltiere wurden wiederum gemittelt und zueinander in Beziehung gesetzt ( $\Delta \Delta$ ct-Werte). Für die jeweils fünf $\Delta \Delta$ ct-Werte wurden anschließend die p-Werte im t-Test ermittelt (vgl. Tab. 4.10).

\section{Tab. 4.10: Ergebnisse der Real-Time-PCR}

Die Tab. 4.10 zeigt die Ergebnisse der Real-Time-PCR (RTqPCR) zusammen mit den entsprechenden Ergebnissen aus dem Microarray (Array). Die differentielle Expression ist als x-Faches der Expression gegenüber dem Wildtyp dargestellt. Negatives Vorzeichen bedeutet reprimierte Expression, während positive Zahlen eine Induktion angeben. Für jedes Experiment wurde ein t-Test der $\Delta \Delta$ ct-Werte berechnet (p-Werte). ${ }^{*}=$ nicht signifikant.

\begin{tabular}{|c|c|c|c|c|c|c|}
\hline Name des Gens & Beschreibung & Lokalisation & Array & $\begin{array}{l}\text { p-Werte } \\
\text { Array }\end{array}$ & RTqPCR & $\begin{array}{l}p \text {-Werte } \\
\text { RTqPCR }\end{array}$ \\
\hline 66.3-kDa-Protein & 66.3-kDa-Protein & $5 \mathrm{~F}$ & $-7,52$ & $<0,0001$ & $-10,09$ & $<0.0001$ \\
\hline Aldh2 & $\begin{array}{l}\text { adult male corpora } \\
\text { quadrigemina } \\
\text { cDNA }\end{array}$ & 5 F-G1 & $-3,71$ & 0,0014 & $-1,20$ & $0,2276^{*}$ \\
\hline Daglb & $\begin{array}{l}\text { diacylglycerol } \\
\text { lipase, beta }\end{array}$ & $5 \mathrm{G} 2$ & $-2,19$ & 0,0026 & $-2,28$ & 0,0065 \\
\hline Rac1 & $\begin{array}{l}\text { RAS-related C3 } \\
\text { botulinum substrate } \\
1\end{array}$ & $5 \mathrm{G} 2$ & $-1,89$ & 0,0007 & $-1,01$ & $0,9726^{*}$ \\
\hline Ctsa & cathepsin A & $2 \mathrm{H} 3$ & $-1,43$ & 0,0026 & $-1,50$ & 0,0394 \\
\hline Scpep1 & $\begin{array}{l}\text { serine } \\
\text { carboxypeptidase } 1\end{array}$ & $11 \mathrm{C}$ & $-1,42$ & 0,0423 & $-1,52$ & 0,0306 \\
\hline Vps33a & $\begin{array}{l}\text { vacuolar protein } \\
\text { sorting } 33 \mathrm{~A}\end{array}$ & $5 \mathrm{~F}$ & 1,65 & 0,0018 & $-1,15$ & $0,2991^{*}$ \\
\hline $\mathrm{Fbxl} 10 / \mathrm{Kdm} 2 \mathrm{~b}$ & $\begin{array}{l}\text { F-box and leucine- } \\
\text { rich repeat protein } \\
10\end{array}$ & $5 \mathrm{~F}$ & 2,99 & $<0,0001$ & 1,48 & $0,1370^{*}$ \\
\hline
\end{tabular}

Die Real-Time-PCR-Ergebnisse wiesen eine geringe Standardabweichung auf und lieferten daher genaue Aussagen zu der Signifikanz ( $p$-Werte) der jeweiligen differentiellen Genexpression. Der Trend der Microarray-Ergebnisse konnte für die meisten untersuchten Transkripte bestätigt werden. Eine Ausnahme stellt hierbei lediglich das Transkript des Vps33a-Gens dar, welches im Microarray als signifikant induziert eingestuft wurde $(+1,65$-fach, $p=0,0018)$, während die Quantifizierung in der Real-Time-PCR eine nicht signifikante Repression ergab $(-1,15$-fach, $p=0,2991)$. Für einige der verbleibenden Transkripte konnte die Quantifizierung mittels Real-TimePCR eine signifikante Repression darlegen (Daglb, Ctsa, Scpep1), während die Ergebnisse für andere Kandidaten keine signifikante $(p>0,05)$, differentielle Expression ergaben (Aldh2, Rac1, Fbxl10). Für das Transkript des 66.3-kDa-Proteins 
konnte im Rahmen der Real-Time-PCR-Untersuchungen eine 10-fache Reprimierung quantifiziert werden (vgl. Abb. 4.31).

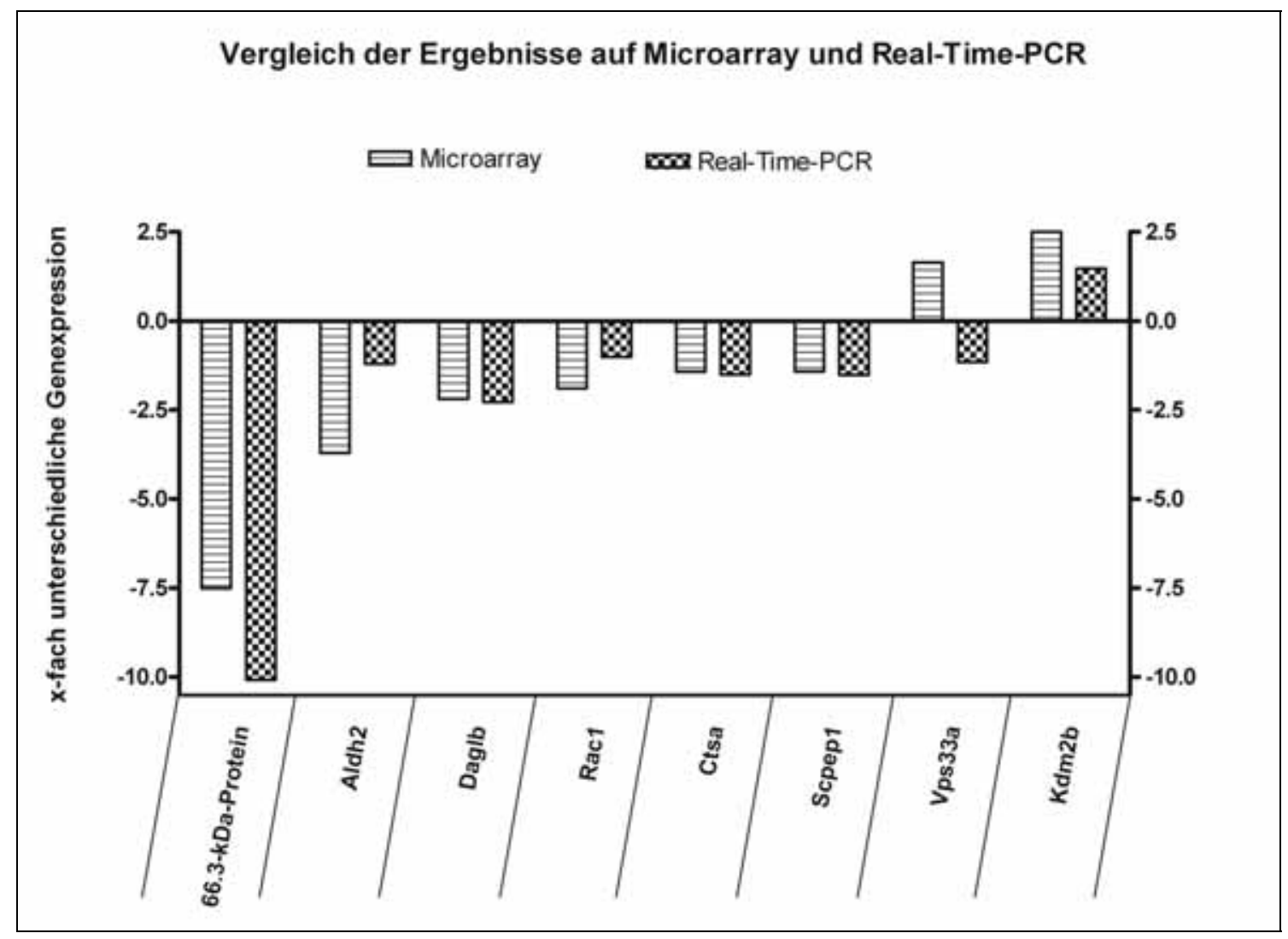

Abb. 4.31: Vergleich von Microarray und Real-Time-PCR

Die Abb. 4.31 vergleicht die Ergebnisse des Microarrays mit denen der Real-Time-PCR für die ausgewählten Transkripte (vgl. Tab. 4.10). Dabei ist die differentielle Expression der Kandidaten als x-fache Induktion bzw. Repression mit positiven bzw. negativen Säulen dargestellt. Die erste Säule eines Kandidaten zeigt das Microarray-Ergebnis, während die zweite Säule das Ergebnis der RealTime-PCR darstellt.

Die Ergebnisse der eingehenden Analyse des 66.3-kDa-Transkripts sind in Tab. 4.11 dargestellt. Dabei zeigte sich eine ca. 10-fache Reprimierung des 3'-Bereichs des 66.3-kDa-Transkripts, wohingegen der 5'-Bereich eine mit 1,12-fach minimale und nicht signifikante Induktion erfährt. Die Ergebnisse für die Analyse der Neomycinkassette zeigten erwartungsgemäß eine sehr starke Induktion (ca. 72-fach) des Transkripts für die in der GeneTrap-Kassette verwendete NeomycinPhosphotransferase an. Ähnlich hohe Werte hätte man für die Reprimierung des 3'Bereich des 66.3-kDa-Transkripts erwartet. 


\section{Tab. 4.11: Analyse des GeneTraps in der Real-Time-PCR}

Die Tab. 4.11 stellt die Ergebnisse der Real-Time-PCR für die einzelnen Bereiche des 66.3-kDaTranskripts dar. Angegeben ist jeweils der $x$-fache Unterschied vom Wildtyp zum 66gt, sowie die hierfür berechneten $\mathrm{p}$-Werte. ${ }^{*}=$ nicht signifikant.

\begin{tabular}{lll}
\hline Genabschnitt des 66.3-kDa-Protein & 66gt vs. WT & p-Werte \\
\hline 3'-Bereich Exon 7-8 & $-10,09$ & $<0.0001$ \\
3'-Bereich Exon 8-10 & $-9,77$ & $<0.0001$ \\
5'-Bereich Exon 1-2 & 1,12 & $0,3570^{\star}$ \\
Neomycinkassette des GeneTraps & 71,74 & 0,0300 \\
\hline
\end{tabular}

\subsection{3 Überprüfung des 66.3-kDa-Transkripts auf Anteile der Neomycinkassette mittels reverser Transkription}

Grundsätzlich ist es trotz der in das 66.3-kDa-Gen inserierten GeneTrap-Kassette möglich, auf zwei Wegen Transkripte zu erhalten, die den 3'-Bereich beinhalten. Zum einen ist es denkbar, dass das Splice-Akzeptor-Element des GeneTrap-Kontrukts nicht effizient genutzt wird und somit reine Wildtyp-Transkripte ohne Anteile der GeneTrap-Kassette entstünden. Auf der anderen Seite wäre auch die ineffiziente Nutzung des Terminators der GeneTrap-Kassette möglich, was dazu führen würde, dass Teile der GeneTrap-Kassette zwischen dem 5'- und 3'- Bereich des 66.3-kDaTranskripts gelegen wären.

Nachdem sich eine relativ schwache Reprimierung des 66.3-kDa-Transkripts im GeneTrap-Mausmodell im 3'-Bereich des 66.3-kDa-Proteins ergeben hatte, sollte nachfolgend überprüft werden, ob es sich bei den detektierten Transkripten im 3'Bereich um Wildtyp-Transkripte handelt, aus denen ein vollständig funktionsfähiges 66.3-kDa-Protein entstehen könnte. Um dies zu klären, wurde mittels RT-PCR, gefolgt von einer Nested- bzw. Semi-Nested-PCR, der Abschnitt, in dem die GeneTrap-Kassette inseriert ist, in 66gt-Mäusen und Kontrolltieren sequenziert.

Dafür wurde in zwei unterschiedlichen Ansätzen mit verschieden Primern ein ca. 420 bzw. 530 bp langes Fragment, welches den potentiellen Übergang vom endogenen 66.3-kDa-Transkript auf die Neomycinkassette enthielt, amplifiziert (vgl. Abb. 4.32). In Ansatz 1 wurde mit den Primern F4 und R5 ein 721 bp langes Fragment amplifiziert, welches als Template für die Semi-Nested-PCR mit den Primern F4 und 
QPR1 diente, welche wiederum ein 529 bp langes Fragment amplifizierte. Analog zu Ansatz 1 wurde im Ansatz 2 zuerst ein 927 bp langes Fragment mit den Primern F3 und QPR1 amplifiziert, welches als Template für die Nested-PCR mit den Primern F4 und QPR2 diente. Das dadurch entstandene 419 bp lange PCR-Produkt wurde, zusammen mit dem des ersten Ansatzes, in der Gelelektrophorese analysiert. Hierbei ließ sich kein Größenunterschied zwischen dem PCR-Fragment des 66gtMausmodells und dem des Wildtyps erkennen. Die anschließende Sequenzierung zeigte keine Sequenzunterschiede zwischen der 66gt- und der aus Wildtyp-RNA gewonnenen cDNA. Daher muss davon ausgegangen werden, dass die im 66gtMausmodell bestimmten $10 \%$ an Transkripten durch die ineffiziente Nutzung des Splice-Akzeptor-Elements als Wildtyp-Transkripte vorliegen und nicht als GeneTrapTranskripte (vgl. dazu auch Diskussion Kap. 5.4).

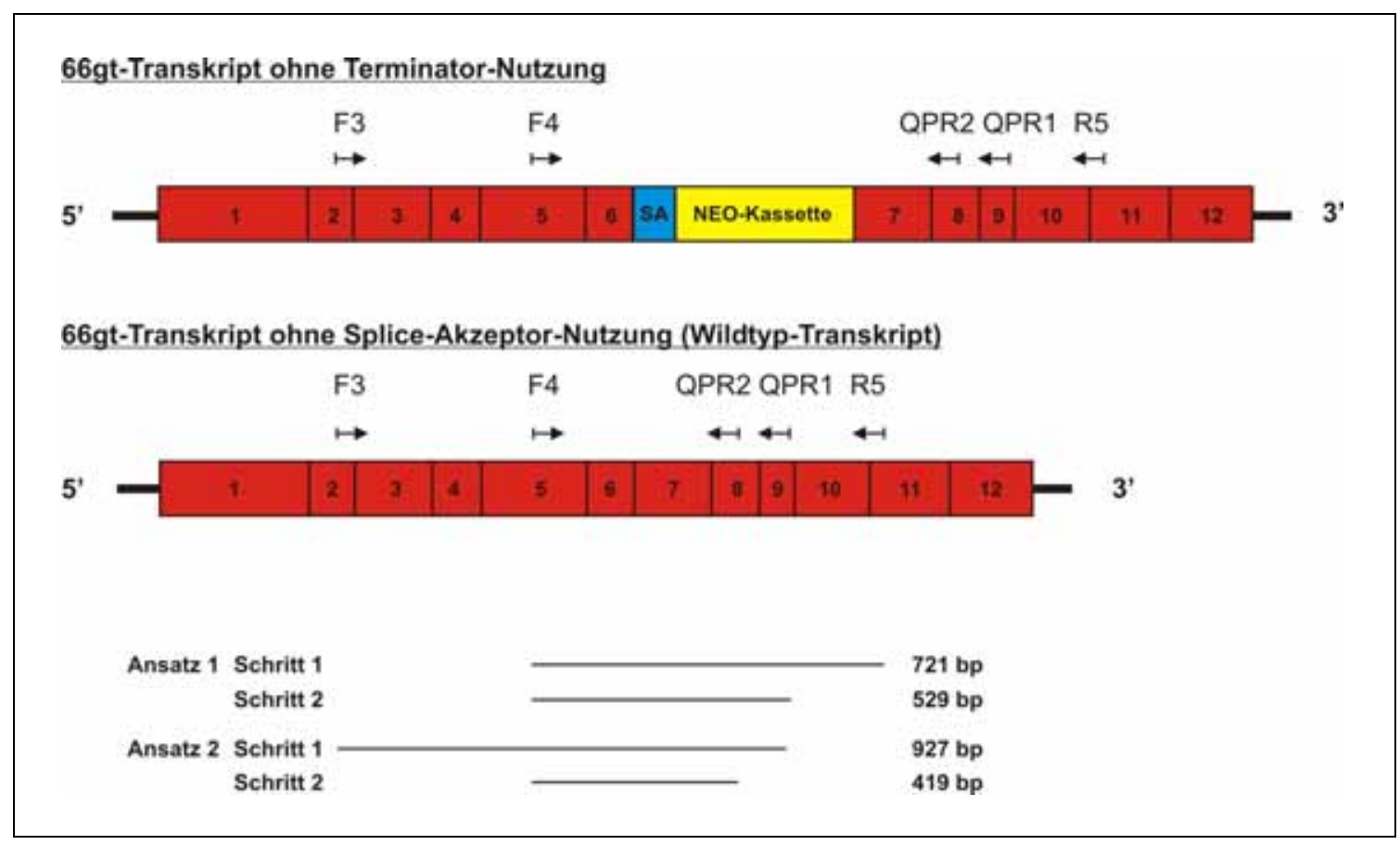

Abb. 4.32: Mögliche Transkripte des 66.3-kDa-Proteins im 66gt-Mausmodell

Die Abb. 4.32 zeigt die beiden möglichen Transkripte die im 66gt-Mausmodell vorliegen könnten. Dabei sind die 12 Exone des 66.3-kDa-Proteins als rote Kästen dargestellt. Mit schwarzen Pfeilen sind die Positionen der für die Nested- bzw. Semi-Nested-PCR verwendeten Primer markiert. Darunter sind die Größen der jeweiligen Fragmente im Wildtyp als Produkte der PCR mit schwarzen Linien angedeutet. Für den Fall, dass Teile der GeneTrap-Kassette im Transskript enthalten sind, wie es darüber dargestellt ist, wären die PCR-Produkte entspechend größer. 


\section{Diskussion}

Seit der Entdeckung des Lysosoms durch de Duve im Jahr 1955 wurden bis heute über 85 lysosomale Matrix- und Membranproteine beschrieben (Lübke et al. 2009). Medizinische Relevanz haben die meisten dieser Proteine insbesondere dadurch, dass ihnen häufig eine humane lysosomale Speichererkrankung zugeordnet werden konnte. Durch die eingehenden Analysen der betroffenen Proteine ist es heute möglich, in einigen Fällen den Verlauf der Krankheit durch spezifische Substitutionstherapien oder die Inhibition der Substratbiosynthese positiv zu beeinflussen (vgl. Kap. 1.3.2). Vor diesem Hintergrund scheint der weiteren Erforschung des lysosomalen Proteoms, sowie der molekularen und funktionellen Charakterisierung der einzelnen lysosomalen Proteine, eine wichtige Rolle zuzukommen.

In der hier vorliegenden Arbeit stand die funktionelle Charakterisierung des 66.3kDa-Proteins im Vordergrund, welches von Kollmann et al. (2005) im Rahmen einer Proteomanalyse MPR-abhängiger Proteine erstmals beschrieben wurde. Auch in weiteren Proteomanalysen des Lysosoms konnte das 66.3-kDa-Protein wiederholt identifiziert werden (Sleat et al. 2005; Sleat et al. 2006; Qian et al. 2008). Das murine 66.3-kDa-Protein (Plbd2) (UniProtKB Q3TCN2) und sein humanes Ortholog, das PLBD2, welches auch als Manose-6-Phosphat-Protein p76 (UniProtKB Q8NHP8) bekannt ist, wurden seither ausführlich molekular charakterisiert (Deuschl et al. 2006; Jensen et al. 2007). Leider blieb die physiologische Funktion der Proteine dabei unklar.

Um die Funktion eines unbekannten Proteins zu erschließen, gibt es eine Reihe verschiedener Möglichkeiten. Dabei ist die bioinformatische Analyse eines Proteins der erste Schritt, um einen Anhaltspunkt für eine mögliche Funktion zu erhalten (Miernyk and Thelen 2008). Eine bioinformatische Analyse ist umso erfolgversprechender, desto mehr Proteine mit ähnlicher Funktion und Aufbau bekannt sind. Deshalb hat die bioinformatische Analyse für lysosomale Proteine bislang noch nicht den Stellenwert, den sie für bestimmte andere Proteinfamilien hat. 
So wurde für das 66.3-kDa-Protein beispielsweise vorhergesagt, es würde sezerniert. Zur Prozessierung wiederum konnten überhaupt keine Angaben gemacht werden. Dass das 66.3-kDa-Protein jedoch nicht sezerniert wird und zumindest in HT1080-Zellen und MEFs primär in der Zelle verbleibt und lysosomal lokalisiert ist, konnte eindeutig gezeigt werden (Deuschl et al. 2006). Auch dass das 66.3-kDaProtein nach einem spezifischen Schema prozessiert wird, konnte zweifelsfrei dargestellt werden (Deuschl et al. 2006; Jensen et al. 2007).

Eine weitere Möglichkeit bei der Suche nach der Funktion eines Proteins stellen sowohl in-vivo- als auch in-vitro-Interaktionsstudien dar, bei denen Interaktionspartner eines Proteins mit verschiedensten Methoden identifizieren werden und somit Rückschlüsse auf die Funktion des betreffenden Proteins geben können. Dabei werden Methoden wie z. B. das Y2H-System, die KoImmunpräzipitation, das Quervernetzen, der Fluoreszenz-Resonanzenergietransfer (FRET) oder Biacore-Analysen angewendet (Kuroda et al. 2006).

Die Kristallisation von Proteinen wiederum ist ein Ansatz, bei dem die strukturellen Informationen eines Proteins genutzt werden können, um eine Einordnung in eine funktionelle Gruppe über den Strukturvergleich mit bekannten Proteinen vornehmen zu können.

Eine Art Rückwärtsanalyse stellen knock-out-Mäuse sowie deren Transkriptomanalyse dar. Hier werden gegebenenfalls Veränderungen im lebenden Gesamtorganismus beobachtet, die durch die funktionelle Ausschaltung eines Gens hervorgerufenen werden, um anschließend Rückschlüsse auf die Funktion des betreffenden Proteins ziehen zu können.

\subsection{Interaktionsstudien mit dem 66.3-kDa-Protein}

Eine der zuvor beschriebenen Möglichkeiten, sich einer unbekannten Funktion eines Proteins experimentell zu nähern, stellen Interaktionsstudien dar. Dabei kann über potentielle Interaktionspartner eventuell eine Einordnung des untersuchten Proteins in bestimmte Stoffwechselprozesse stattfinden oder sogar auf Grund der Zugehörigkeit zu einem größeren Proteinkomplex ein direkter Hinweis auf die katalytische Funktion gegeben werden. So konnte durch Interaktionsstudien 
lysosomaler Proteine beispielsweise die Rolle des PPCA als intrazelluläres Transportprotein für die N-Acetyl-alpha-Neuraminidase dargestellt werden (van der Spoel et al. 1998). In einem weiteren Beispiel konnte das Zusammenspiel von Glucocerebrosidase mit Saponinen und sauren Lipiden durch Interaktionsstudien beschrieben werden (Morimoto et al. 1990). Deshalb sind verschiedene Ansätze von Interaktionsstudien gewählt worden, um mögliche Interaktionspartner zu identifizieren bzw. zu bestätigen.

In Vorarbeiten wurden bereits Interaktionsstudien durchgeführt. Dabei wurde mittels einer Affinitätschromatographie mit dem 66.3-kDa-Protein die lysosomale Aspartylprotease Cathepsin D als potentieller Interaktionspartner identifiziert. Eine bereits in Vorarbeiten begonnene $\mathrm{Y} 2 \mathrm{H}$-Screening-Methode wurde in dieser Arbeit fortgesetzt. Anschließend wurden eine Affinitätschromatographie mit Pepstatin A, eine Ko-Immunpräzipitation sowie das Arbeiten mit Quervernetzern als Interaktionsstudien angeschlossen.

In dieser Arbeit wurde durch die Untersuchung mit in-vivo-Quervernetzern ein weiterer Ansatz zur Ermittlung von verschiedenen Interaktionspartnern für das 66.3kDa-Protein durchgeführt. Es konnten dabei allerdings weder neue potentielle Interaktionspartner gefunden werden, noch die Interaktion des 66.3-kDa-Proteins mit der lysosomalen Aspartylprotease Cathepsin D als potentieller Interaktionspartner bestätigt werden. Da keine weiteren Interaktionspartner identifiziert werden konnten, sollte im Rahmen dieser Arbeit vorrangig die Interaktion von Cathepsin D mit dem 66.3-kDa-Protein eingehender untersucht werden.

\subsubsection{Interaktionstudien von Cathepsin D mit dem 66.3-kDa-Protein}

Im Y2H-System stellte sich heraus, dass die zuvor detektierte Interaktion von Cathepsin D mit dem 15- bzw. 28-kDa-Fragment lediglich auf einer artifiziellen Interaktion mit einem der im $\mathrm{Y} 2 \mathrm{H}$-System verwendeten Transkriptionsfaktoren beruhte (vgl. Kap. 4.1.3).

Die Untersuchungen mittels Pepstatin-A-Affinitätschromatographie konnten eine Ko-Elution des 66.3-kDa-Proteins mit dem Cathepsin D zeigen und somit die affinitätschromatographischen Ergebnisse mit immobilisiertem 66.3-kDa-Protein aus 
Vorarbeiten bestätigten. Auffällig war hierbei, dass präferentiell eher die unreifen Vorläufer-Formen als die reifen Formen mit Cathepsin D koeluierten. Da mit der Scpep1 auch ein weiteres lysosomales Matrixprotein in nahezu identischer Weise wie das 66.3-kDa-Protein mit dem Cathepsin D koeluierte, konnte hier allerdings nicht von einer spezifischen Interaktion des 66.3-kDa-Proteins mit dem Cathepsin D ausgegangen werden.

Auf Grund der bisher nicht ganz eindeutigen Ergebnisse zur Interaktion von Cathepsin D und dem 66.3-kDa-Protein, wurde mit der Ko-Immunpräzipitation ein weiterer experimenteller Ansatz zu Hilfe genommen. Hierbei war es möglich, aus Zellhomogenaten das 66.3-kDa-Protein gekoppelt an das Cathepsin D mittels Ko-Immunpräzipitation zu extrahieren.

Die Interaktion von Cathepsin D mit dem lysosomalen Matrixprotein 66.3-kDa-Protein konnte somit in verschiedenen Versuchansätzen gezeigt werden (Affinitätschromatographie mit Pepstatin A, Affinitätschromatographie mit dem 66.3kDa-Protein, Ko-Immunpräzipitation), während andere Versuchansätze diese Interaktion nicht belegen konnten $(\mathrm{Y} 2 \mathrm{H}$, in-vivo-Quervernetzung). Bei der Interpretation dieser Ergebnisse sind die methodischen Einschränkungen der verschiedenen Methoden zu beachten.

Im $\mathrm{Y} 2 \mathrm{H}$-System findet die Interaktion der untersuchten lysosomalen Proteine im Zellkern der Hefen bei einem neutralen $\mathrm{pH}$-Wert statt. Das für lysosomale Proteine unphysiologische Milieu im Zellkern der Hefen stellt somit keineswegs die optimalen Bedingungen für Interaktionsstudien lysosomaler Proteine dar. Zudem ist bekannt, dass Modifikationen wie N-Glykosylierungen an Proteinen sowohl kotranslational als auch posttranslational stattfinden (Ruiz-Canada et al. 2009). Dabei erfahren Proteine auf dem sekretorischen Weg gerade posttranslational andere Modifikationen als Proteine, die nach ihrer Synthese in den Zellkern transloziert werden. Gerade im Hinblick auf die für lysosomale Proteine essentiellen N-Glykosylierungen und Mannose-6-Phosphorylierungen kann dies ein Problem darstellen. Die Weiterentwicklung der Two-Hybrid-Systeme zum Mammalian-Two-Hybrid-System $(\mathrm{M} 2 \mathrm{H})$ könnte zwar eine verbesserte posttranslationale Modifizierung gewährleisten (Kuroda et al. 2006), löst aber nicht das Problem des neutralen pH-Werts, der auch 
im Zellkern von Säugerzellen vorherrscht. All diese Aspekte sollten zwar bei der Beurteilung der Ergebnisse im $\mathrm{Y} 2 \mathrm{H}$-System Berücksichtigung finden, stellen aber keinen Ausschluss dafür dar, das lysosomale Proteininteraktionen erfolgreich im Y2H-System untersucht werden können. So wurde beispielsweise die Interaktion von Cathepsin B mit dem humanen Homolog des SETA bindenden Protein 1 (Liu et al. 2006) als auch die Interaktion von Prosaposin mit dem Rhox5 (Guo et al. 2007) im $\mathrm{Y} 2 \mathrm{H}$-System identifiziert.

Anders als im $\mathrm{Y} 2 \mathrm{H}$-System sind die Bedingungen für die Interaktion lysosomaler Proteine in der durchgeführten Affinitätschromatographie mit Pepstatin $\mathrm{A}$ vom $\mathrm{pH}$ Wert annähernd physiologisch. Lediglich die Bindung des Pepstatin A im katalytisch aktiven Zentrum von Cathepsin D könnte einen sterischen Einfluss auf die Effektivität der Bindung von Interaktionspartnen haben.

Die in der Pepstatin-A-Affinitätschromatographie dargestellte Ko-Elution von Cathepsin D mit dem 66.3-kDa-Protein wurde zunächst als nicht spezifisch eingestuft, da mit der Scpep1 ein weiteres lysosomales Matrixprotein in den Elutionsfraktionen zu detektieren war. Da sowohl das 66.3-kDa-Protein als auch die Scpep1 ein C-terminales His-Tag tragen, könnte es sich eventuell um ein Artefakt handeln, welches durch das His-Tag hervorgerufen wurde. Dies würde ebenfalls erklären, warum vornehmlich die unprozessierten Formen dieser beiden Proteine in den Elutionsfraktionen zu finden waren und nicht die prozessierten Formen. Zudem wäre es auch möglich, dass es sich bei der dargestellten Ko-Elution des 66.3-kDaProteins und der Scpep1 mit dem Cathepsin D um eine Interaktion der Transportformen (Precursor) handelte.

Anhand der Ko-Immunpräzipitation des 66.3-kDa-Proteins mit dem Cathepsin D konnte die Interaktion mittels einer dritten Methode nachgewiesen werden. Bei der mit Zellhomogenaten durchgeführten Ko-Immunpräzipitation kann die Interaktion der betreffenden Proteine unter in-vivo-ähnlichen Verhältnissen stattfinden. Ko- und posttranslationale Modifikationen der beteiligten Proteine sind hierbei nicht gestört. Der Erfolg einer Ko-Immunpräzipitation hängt im großen Maße von der Affinität des Antikörpers zum Substrat ab. Hier konnte mit dem Cathepsin-D-Antiserum KIIS5 ein bereits in Western-Blots und Immunfluoreszenzen etabliertes Antiserum verwendet 
werden. Die gelegentlich bei Ko-Immunpräzipitationen vorkommenden falsch positiven Ergebnisse durch eine Bindung direkt an die Protein-G-Sepharose oder an die Oberfläche der Reaktionsgefäße konnten durch die Kontrollen mittels Präimmunserum ausgeschlossen werden. So wurde eine Reihe von Interaktionen lysosomaler Proteine mittels Ko-Immunpräzipitation bestätigt. Hier wären die Interaktion von Cathepsin D mit Prosaposin (Zhu $Y$ and Conner 1994), sowie die Interaktion von PPCA mit der Neuraminidase (van der Spoel et al. 1998) und die Interaktion der Glucocerebrosidase mit LIMP-2 (Reczek et al. 2007; Blanz et al. 2010), als Beispiele zu nennen, bei denen die Interaktion mittels KoImmunpräzipitation validiert worden ist.

In Zusammenschau der Ergebnisse ist eine Interaktion des 66.3-kDa-Proteins mit dem Cathepsin $D$ als sehr wahrscheinlich anzusehen. Ob es sich bei dieser Interaktion um eine spezifische Interaktion ausschließlich dieser beiden Proteine untereinander handelt, ist zweifelhaft. Vielmehr wäre eine Interaktion dieser beiden Proteine im Sinne der Bildung von Superkomplexen denkbar, wie sie zuvor beispielsweise für eine Reihe von lysosomalen Matrixproteinen wie betaGlucuronidase, alpha-Mannosidase und Cathepsin D beschrieben wurde (Jadot et al. 1997). Die genaue Zusammensetzung dieser Superkomplexbildung ist noch nicht im einzelnen verstanden. Es konnte gezeigt werden, dass die Superkomplexe dem Transport von lysosomalen Vorläuferproteinen in das lysosomale Kompartiment dienen, wie es für den Vorläufer von Cathepsin D und Saposin beschrieben wurde (Grassel and Hasilik 1992; Zhu Y and Conner 1994). Mit der Komplexbildung aus Sialidase, beta-Galaktosidase und der N-acetylaminogalactose-6-sulfat Sulfatase mit der lysosomalen Carboxypeptidase Cathepsin A wurde ein weiterer lysosomaler Multienzymkomplex beschrieben, bei dem die Komplexbildung der Proteine als Degradationsschutz dient. Sind die Sialidase, die $\beta$-Galaktosidase und die Nacetylaminogalactose-6-sulfat Sulfatase nicht mit dem PPCA (Protective Protein/ Cathepsin A) assoziert, kommt es zu einer sehr raschen Degradation der beteiligten Proteine. So führt beispielweise ein Defekt des PPCA zum klinischen Bild der Galactosialidose (Galjaard et al. 1987). Es wird ebenfalls diskutiert, dass lysosomale Proteine in großen Superkomplexen vorliegen und damit eine Art Matrix lysosomaler Enzyme bilden. So konnte z. B. gezeigt werden, dass lysosomale Proteine auch nach Entfernung der lysosomalen Membran noch ein extrahierbares, gelartiges 
Gemisch mit hoher Dichte bilden (Jadot et al. 1997). Gerade unter der Berücksichtigung, dass lysosomale Proteine auch anteilig sezerniert werden, wäre ein funktioneller Zusammenhalt lysosomaler Proteine im Extrazellularraum ebenso wie in der lysosomalen Matrix selbst, sicherlich von Vorteil. Hier würde der sequentielle Abbau von Makromolekülen wie N-Glykane und Glykosaminoglykane durch lysosomale Glykosidasen im Sinne von Substratketten deutlich beschleunigt. Ob die Interaktion des 66.3-kDa-Proteins mit dem Cathepsin D tatsächlich im Rahmen einer solchen „Matrixbildung“ oder im Rahmen des Vorläufer-Transports stattfindet, könnten eventuell weitergehende Untersuchungen mit Methoden wie der blue-native-Gelelektrophorese zeigen.

\subsection{Prozessierung und Dimerisierung des 66.3-kDa-Proteins}

Durch die Kristallisation und die massenspektrometische Analyse der Fragmente war es möglich, neue Erkenntnisse über den Ablauf der Prozessierung des 66.3-kDaProteins zu erlangen. Bisher war bekannt, dass das 66.3-kDa-Protein als lysosomales Protein am rauen endoplasmatischen Retikulum synthetisiert wird und vom Prä-Proprotein eine 46 Aminosäuren lange Signalsequenz abgespalten wird. Die somit entstandene 75-kDa-Proform wird in HT1080-Zellen in ein N-terminales 28kDa-Fragment und ein C-terminales 40-kDa-Fragment gespalten. Weiterhin konnte mit dem anti-His-Antikörper ein ebenfalls C-terminales 15-kDa-Fragment detektiert werden, welches den C-terminalen Anteil des 40-kDa-Fragments darstellte (vgl. Kap. 1.5.2) (Deuschl et al. 2006). Auch (Jensen et al. 2007) kam, in von unseren Analysen unabhängigen Untersuchungen, zu einem sehr ähnlichen Prozessierungsmuster für das 66.3-kDa-Protein. Abweichend wurde hier für die Prozessierung des 40-kDaFragments zum 15-kDa-Fragment ein 27-kDa-Fragment als Übergangsform beschrieben (Jensen 2007).

Die Ergebnisse der Kristallisation, wie sie in Kap. 4.5 beschrieben wurden, konnten die Prozessierung von der 75-kDa-Proform in ein N-terminales 28-kDa-Fragment und ein C-terminales 40-kDa-Fragment bestätigen und legen für diesen Prozessierungsschritt einen autoproteolytischen Mechanismus nahe. Über den zweiten Prozessierungsschritt vom 40-kDa-Fragment zu einem 25- und 15-kDaFragment konnte die Kristallisation allerdings keine Erkenntnisse liefern (Lakomek et al. 2009b; Lakomek et al. 2009a). 
Ergänzend zu der zuvor beschriebenen Prozessierung des 66.3-kDa-Proteins konnte mittels Massenspektrometrie eindeutig gezeigt werden, dass es sich im Bereich um 25/28 kDa um eine Doppelbande handelt, die zum einen das N-terminale 28-kDaFragment und zum anderen das 25-kDa-Fragment beinhaltet, welches als $\mathrm{N}$-terminaler Abschnitt des 40-kDa-Fragments identifiziert wurde.

Es ist davon auszugehen, dass die Prozessierung der 75-kDa-Proform zum reifen 66.3-kDa-Protein in zwei Schritten erfolgt. Das reife 66.3-kDa-Protein besteht letzten Endes aus drei nicht-kovalent miteinander verbundenen Fragmenten (vgl. Abb. 5.1). Beispiele für eine solche Prozessierung lysosomaler Proteine mit anschließender Komplexbildung sind die Dipeptidyl-Petidase1 (auch als Cathepsin C bekannt), oder auch die Acid ceramidase. Die Dipeptidyl-Petidase1 entsteht durch die nichtkovalente Verknüpfung der durch Prozessierung entstandenen Proteinfragmente zu einem heterotrimeren Komplex mit einem Molekulargewicht von 180 kDa (Cigic et al. 1998). Dabei konnte gezeigt werden, dass die Prozessierung und die Bildung des Oligomers bereits vor Erreichen des reifen Lysosoms stattfindet (Muno et al. 1993). Auch die Acid ceramidase besteht aus zwei nicht-kovalent miteinander verknüpften Untereinheiten ( $\mathrm{He}$ et al. 2003). Häufig bleiben die proteolytisch prozessierten Untereinheiten jedoch kovalent über Disulfidbrücken miteinander verknüpft. Hier sei beispielhaft nur die lysosomale alpha-Mannosidase (M2B1) genannt, die durch Proteolyse des Vorläufers in fünf Fragmente (A-E) entsteht, die über Disulfidbrücken kovalent miteinander verknüpft sind (Hansen $G$ et al. 2004).

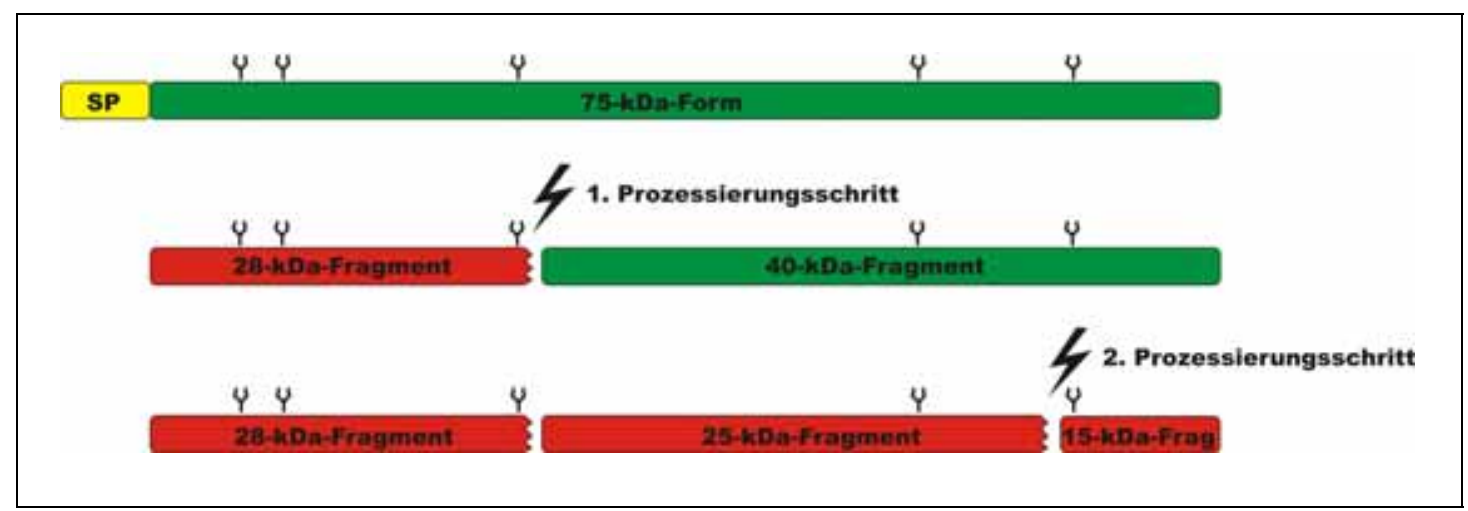

\section{Abb. 5.1: Prozessierung des 66.3-kDa-Proteins}

Die Abb. 5.1 zeigt das aktuelle Prozessierungsschema des 66.3-kDa-Proteins. In gelb ist das Signalpeptid (SP) dargestellt. Alle grün markierten Fragmente sind unreife Übergangsformen, während die rot markierten Fragmente die vermutlich reifen Fragmente des 66.3-kDa-Proteins darstellen. 
Ergänzend zur Prozessierung konnte in dieser Arbeit mit verschiedenen Methoden gezeigt werden, dass das 66.3-kDa-Protein als Homodimer vorliegt. Erste Hinweise darauf lieferten die Ergebnisse der in-vitro-Quervernetzung, bei der sich eine zusätzliche Bande bei etwa 140 kDa bildete, wobei aufgereinigtes rekombinantes 66.3-kDa-Protein mit dem Quervernetzer SPDP behandelt wurde (vgl. Kap. 4.4.2). Auch im Rahmen der Gelfiltration für die Kristallisation konnte dieser 140-kDaKomplex dargestellt werden (vgl. Kap. 4.5.2).

Schließlich ergaben Berechnungen auf Grundlage der durch die Kristallisation erhaltenen dreidimensionalen Struktur (vgl. 4.5.4), dass eine Dimerisierung des 66.3kDa-Proteins am wahrscheinlichsten ist. Die Berechnungen des PISA-Servers (Krissinel and Henrick 2007) favorisieren auf Grund des energetisch sinnvollsten Zustands eine Kopf-an-Kopf Homodimerisierung des 66.3-kDa-Proteins (vgl. Abb. 5.2), wobei ein Kontakt von etwa 4\% der Proteinoberfläche entsteht (Lakomek 2009). Die Homodimerisierung des 66.3-kDa-Proteins könnte dabei einerseits aus der 75kDa-Proform bzw. dem 28- und 40-kDa-Fragment bestehen, andererseits wäre auch die Zusammensetzung eines 66.3-kDa-Proteins aus 15-, 25- und 28-kDa-Fragment grundsätzlich denkbar. Hierbei kann allerdings nicht vorhergesagt werden, ob die dreidimensionale Struktur des 66.3-kDa-Proteins nach dem weiteren Prozessierungsschritt des 40-kDa-Fragments unverändert bleibt. Während die Prozessierung der 75-kDa-Proform in das 28- und 40-kDa-Fragment zwar den Zugang zur Substratbindungstasche im einzelnen Molekül freigibt, hatte dieser Prozessierungsschritt keine Auswirkung auf die Konformation des Homodimers (Lakomek et al. 2009b).

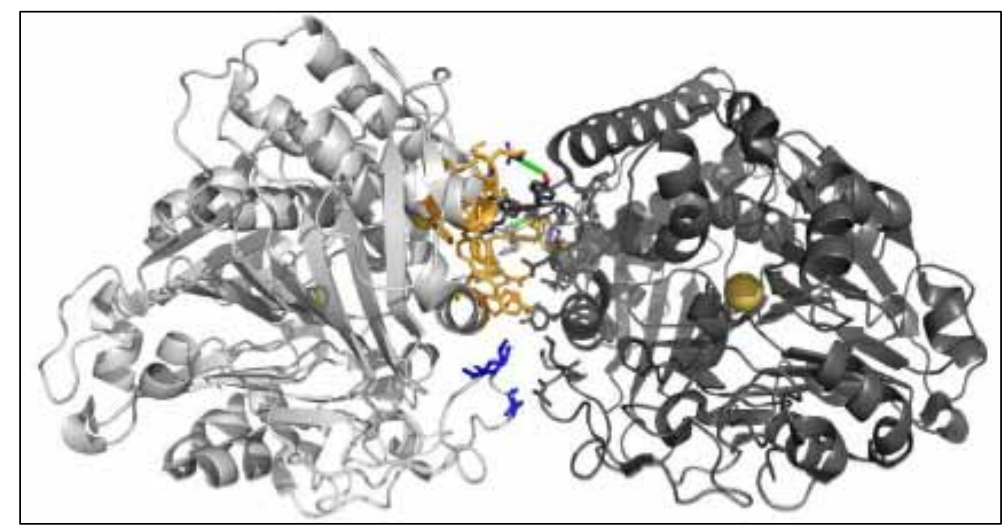

Abb. 5.2: Potentielle Dimerisierung des 66.3-kDaProteins

In der Abb. 5.2 sind die Interaktionsflächen zweier 66.3kDa-Proteine miteinander dargestellt, die sich auf Grund der Berechnung des PISA-Servers ergeben. Die Aminosäuren, die an der Interaktion beteiligt sind, sind in bunt dargestellt, dabei sind die orange eingefärbten Aminosäuren dem 28-kDa-Fragment zugehörig, während die blauen Aminosäuren Teil des 40-kDa-Fragments sind. Wasserstoffbrücken sind in grün angedeutet. Abbildung modifiziert nach Lakomek (2009, S. 87). 


\subsection{Funktionelle Analyse des 66.3-kDa-Proteins}

Für die Funktion des 66.3-kDa-Proteins gab es bislang nur den Hinweis aus Datenbankeinträgen bei Pfam und ExPASy, in denen dem 66.3-kDa-Protein auf Grund der gefundenen Aktivität des homologen Proteins p67 im Schleimpilz (Dictyostelium discoideum) eine Phospholipase B-Aktivität zugeschrieben wurde (Morgan et al. 2004). Somit wäre das 66.3-kDa-Protein laut Pfam-Datenbank in die Enzymgruppe der Carboxylesterhydrolasen einzuordnen (EC 3.1.1.-).

Die Funktion von Phospholipasen besteht in der Hydrolyse von Acylester- und Phosphodiesterbindungen in Glycerophospholipiden, wie Phosphatidylcholin oder Phosphatidylethanolamin (Morgan et al. 2004). Entsprechend der Einteilung der Phospholipasen in A1, A2, B (A1+A2), C oder D, sind Phospholipasen B zur Hydrolyse der Acylreste sowohl in sn-1 als auch in sn-2 Position befähigt (vgl. Abb. 5.3) (Waite 1985; Löffler and Petrides 2003).

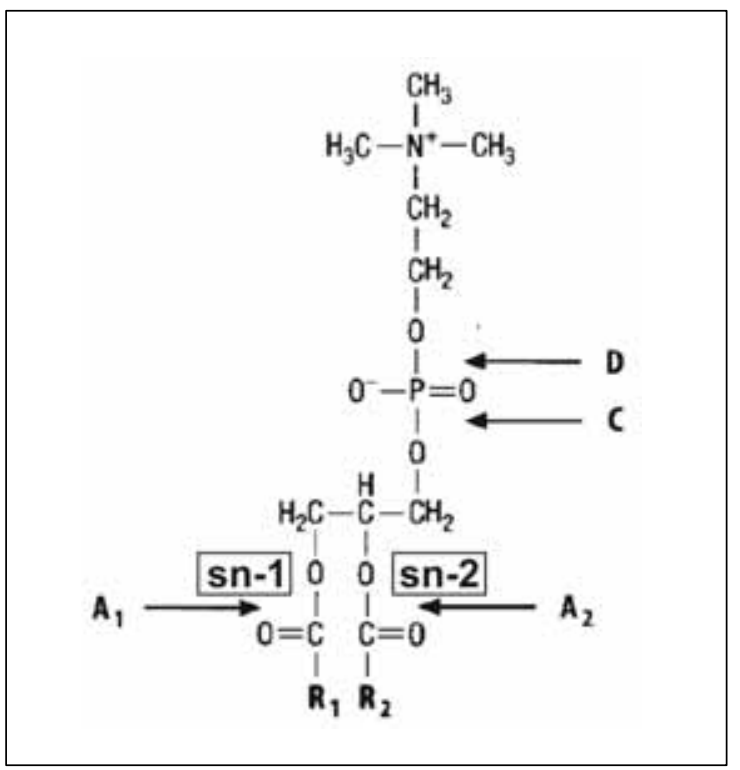

\section{Abb. 5.3: Angriffspunkte der Phospholipasen}

Die Abb. 5.3 zeigt die Angriffspunkte der unterschiedlichen Phospholipasen am Beispiel von Phosphatidylcholin. Dabei wir eine Kombination von Phospholipase A1- und Phospholipase A2-Aktivität als Phospholipase B-Aktivität definiert. Abbildung modifiziert nach (Löffler and Petrides (2003) S. 606).

Auf Grund der naheliegenden Überlegung, dass auch das murine 66.3-kDa-Protein Phospholipase B-Aktivität aufweisen könnte, wurden Untersuchungen mit HT1080Zellen und Lysosomen-angereicherten, subzellulären Fraktionen durchgeführt. Dabei wurde ${ }^{14} \mathrm{C}$-markiertes Lyso-Phosphatidylcholin (LPC) als natürliches Phospholipase B-Substrat mit HT1080-Zellen, die das 66.3-kDa-Protein überexprimieren (gain of function) und lysosomenangereicherten, subzellulären Fraktionen aus Lebergewebe von 66gt-Mäusen (loss of function) mit den jeweiligen Kontrollen inkubiert und anschließend dünnschichtchromatographisch auftrennt. Die 
Dictyostelium-Homogenate dienten hierbei als Positivkontrolle für eine Phospholipase B-Aktivität. Dabei konnte jedoch kein Unterschied der Phospholipase B-Aktivität zwischen Proben und Kontrollen festgestellt werden (Arbeitsgruppen-interne Mitteilung). Des Weiteren konnte auch für das humane Ortholog des 66.3-kDa-Proteins p76, welches von den Prozessierungsschritten dem 66.3-kDa-Protein sehr ähnlich ist, bislang keine Phospholipase B-Aktivität dargestellt werden (Jensen et al. 2007). Das p67 aus D. discoideum war bislang daher der einzige Vertreter dieser homologen Proteingruppe, für den eine Phospholipase BAktivität nachgewiesen werden konnte.

Das humane, lysosomale Matrixprotein FLJ22662 ist zu 32\% identisch mit dem p76, dem humanen Ortholog des 66.3-kDa-Proteins (Lübke et al. 2009). Die Prozessierung des FLJ22662 ist der Prozessierung des p76 und des 66.3-kDaProteins sehr änhlich. Interessanterweise konnte bei dem Protein FLJ22662 eine Phospholipase B-Aktivität nachgewiesen werden (Xu et al. 2009). Entscheidend für den Nachweis der katalytischen Aktivität dieses Proteins war ein finaler Reifungsprozess, der sich erst nach 16-wöchiger Lagerung bei $4{ }^{\circ} \mathrm{C}$ vollzog (Xu et al. 2009). Dieser finale Reifungsprozess konnte allerdings durch die Inkubation mit Extrakten aus isolierten Granula der neutrophilen Granulozyten in vitro beschleunigt werden. Es konnte gezeigt werden, dass dieser finale Reifungsschritt in einer weiteren limitierten Proteolyse der gebildeten Fragmente besteht. Ohne diesen Reifungsschritt konnte keine Aktivität des Proteins nachgewiesen werden (Xu et al. 2009).

Demnach ist ein bislang unbekannter Faktor aus den Granula der neutrophilen Granulozyten für die Reifung des Proteins FLJ22662 zum katalytisch aktiven Protein verantwortlich. Die Granula der neutrophilen Granulozyten stellen zellspezifische primäre Lysosomen dar. Es ist davon auszugehen, dass diese sich von dem Milieu der Lysosomen in HT1080- und HEK293T-Zellen unterscheiden. Geht man von einem dem FLJ22662-Protein ähnlichen Aktivierungsmechanismus für das 66.3-kDaProtein aus, so sind die bisher verwendeten Zellpopulationen für die funktionelle Analyse des 66.3-kDa-Proteins ungeeignet. Daher erscheint es sinnvoll, das 66.3kDa-Protein aus den Granula der neutrophilen Granulozyten aufzureinigen, um 
anschließend eine Phospholipase B-Aktivität nachweisen zu können. Dazu sind Untersuchungen mit einer Makrophagen-Zelllinie aus der Maus (RAW264.7) geplant.

Ungeachtet der vorherigen Überlegungen, die eine Phospholipase B-Aktivität des 66.3-kDa-Proteins präferieren, konnte das 66.3-kDa-Protein durch die Ergebnisse der Kristallisation auf Grund der spezifischen dreidimensionalen Faltung in die Superfamilie der Ntn-Hydrolasen eingeordnet werden (vgl. Kap. 4.5.4). Dementsprechend wäre das 66.3-kDa-Protein nicht in die Enzymklasse 3.1.1 einzuordnen, sondern in die Enzymklasse 3.5.1, der die Ntn-Hydrolasen zugeordnet sind. Die Funktion der Enzyme dieser Enzymklasse besteht in der Hydrolyse nichtpeptidischer Amidbindungen in linearen Amiden.

Verbindungen mit nicht-peptidischer Amidbindung befinden sich neben den $\mathrm{N}$-Acylethanolamiden auch in acetylierten Lysinseitengruppen, Sphingosinen oder hydrophoben Proteinmodifikationen wie die N-Myristoylierung oder Glypiation. Da der Abbauweg dieser genannten Substrate bisher nicht vollständig geklärt ist, wäre eine Beteiligung des 66.3-kDa-Proteins an ihrem Abbau im Lysosom durchaus denkbar.

Die N-terminalen Bereiche von Histonen besitzen viele acetylierte Lysinseitengruppen (Strahl and Allis 2000; Zhang $Y$ and Reinberg 2001; Berger 2002). Die Acetylierung von Histonen bei der räumlichen Organisation der DNAStruktur in eukaryontischen Zellen spielt eine entscheidende Rolle bei der Regulation der Genexpressionen (Jenuwein and Allis 2001). Im Gegensatz zu den bereits charakterisierten regulatorischen Histon-Deacylasen (HDACs) könnte das 66.3-kDaProtein eine Rolle in der Degradation dieser Histone in apoptotischen Vesikeln haben, die von Makrophagen phagozytiert wurden (Odaka and Mizuochi 1999).

Zu den hydrophoben Proteinmodifikationen zählt zum einen die C-terminale Isoprenylierung, bei der über eine Thioesterbindung Farnesyl- oder Geranylreste an einer Cysteinseitengruppe kovalent verknüpft werden. Des Weiteren gibt es die Acylierungen von Proteinen, wobei die S-Acylierung (Palmitoylierung) von der $\mathrm{N}$-Acylierung (Myristoylierung) zu unterscheiden ist. Bei der S-Acylierung wird eine Palmitinsäure an eine Cysteinseitengruppe über eine Thioesterbindung verknüpft (Towler et al. 1988), während bei der N-Acylierung über eine Amidbindung ein 
Myristoyl am N-terminalen Glycin angeheftet wird (vgl. Abb. 5.4 A). Die Thioesterbindungen sind instabiler als die Amidbindungen, weshalb die S-Acylierung einem hohen regulatorischen turn over unterliegt, während die N-Acylierung eine irreversible Proteinmodifikation darstellt (da Silva and Klein 1990). Eine weitere posttranslationale, hydrophobe Modifikation von Proteinen stellt die Glypiation dar, bei der am C-Terminus des Proteins über ein Ethanolamin und somit über eine Amidbindung ein Glykosyl-Phosphatidylinositol-Anker (GPI-Anker) an das betreffende Protein angebracht wird (Ferguson and Williams 1988; Casey 1995) (vgl. Abb. 5.4 B).

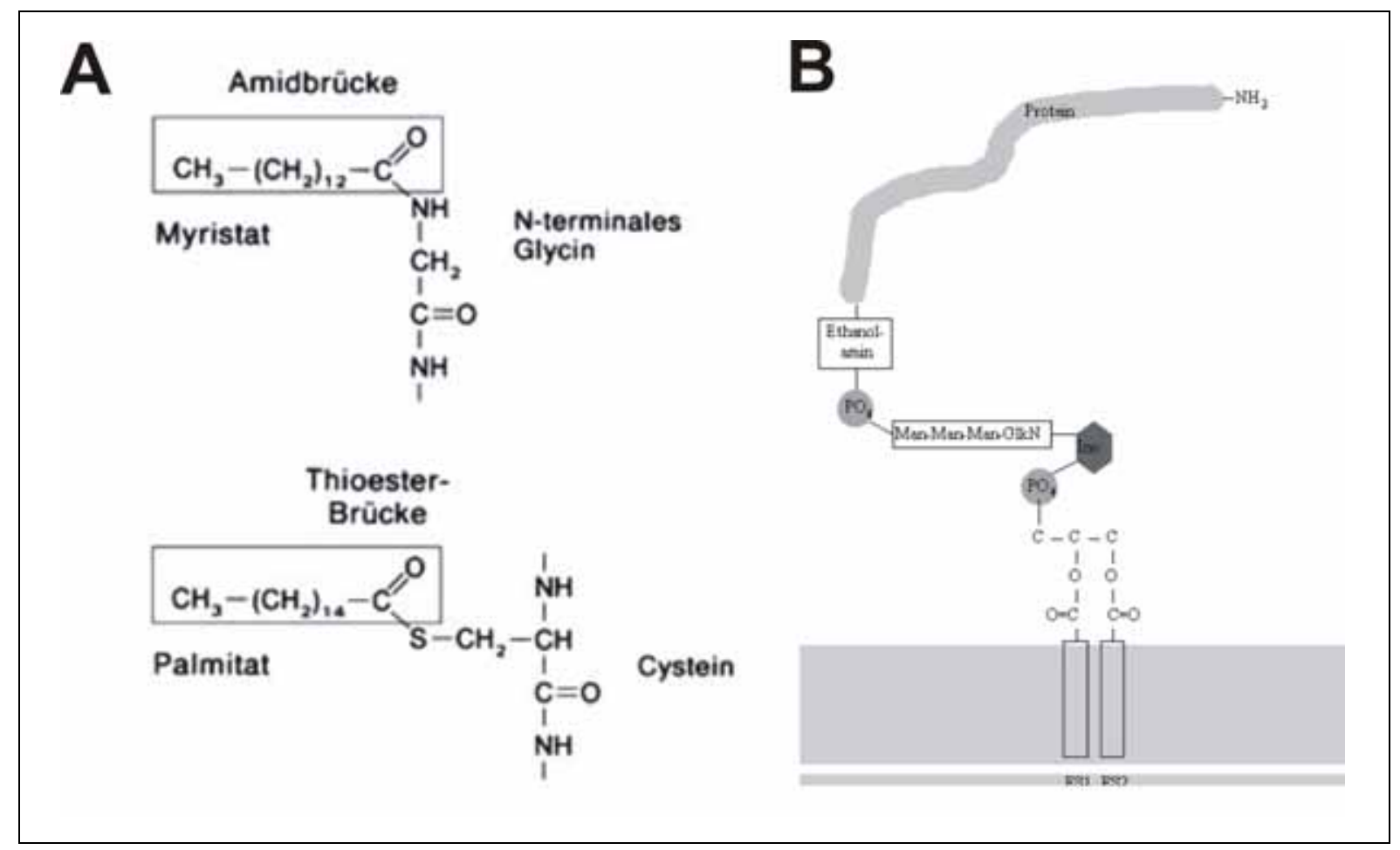

Abb. 5.4: Möglichkeiten der hydrophoben posttranslationalen Proteinmodifikation

In der Abb. 5.4 sind drei verschiedene Möglichkeiten der hydrophoben posttranslationalen Proteinmodifikation dargestellt. In $A$ ist die Myristoylierung über eine Amidbindung, sowie die Palmitoylierung über eine Thioesterbindung dargestellt. In B ist der Aufbau eines GPI-Ankers schematisch dargestellt, modifiziert nach (Schulz (1998), S. 24).

Während die verantwortlichen Enzyme für den Abbau von farnesylierten, geranylierten und palmitoylierten Proteinen bereits identifiziert wurden, bleibt der Abbau von myristoylierten Proteinen bislang unklar (Lu and Hofmann 2006). Für den GPI-Anker ist zwar die Abspaltung von Diacylglycerin (DAG) und Inositol-1,4,5trisphosphat $\left(\mathrm{IP}_{3}\right)$, als sogenannte sekundäre Botenstoffe durch die Phospholipase $\mathrm{C}$ beschrieben, die verantwortlichen Enzyme für die Abspaltung des Ethanolamin vom Protein sind allerdings nicht beschrieben. Ein Abbau von myristoylierten Proteinen 
und dem Ethanolamin von GPI-Ankern über das Lysosom mittels der hydrolytischen Aktivität des 66.3-kDa-Proteins wäre somit denkbar.

Klinische Relevanz bekommen die Abbauvorgänge von Proteinen mit posttranslationalen, hydrophoben Modifikationen nicht zuletzt durch die Beschreibung der schweren neurodegenerativen Störung der Infantilen Neuronalen Ceroid-Lipofuszinose (INCL) durch Defekte der Palmitoyl-Protein-Thioetherase1 (PPT1), die als lysosomale Hydrolase die Depalmitoylierung von Proteinen katalysiert (Michel and Michel 1997; Lu and Hofmann 2006). Durch die fehlende katalytische Aktivität der PPT1 kommt es zur Bildung von Speichervakuolen mit der Kumulation von palmitoylierten Proteinen, wie z. B. das Wachstum-assoziierte Protein 43 (GAP-43) und somit zum klassischen Bild einer lysosomalen Speichererkrankung (Vesa et al. 1995; Hofmann et al. 1997; Zhang Z et al. 2006). Deshalb scheint die Kenntnis weiterer Abbauwege hydrophober Proteinmodifikationen im Hinblick auf die Pathophysiologie unbekannter LSDS klinische Relevanz zu haben.

Mit der Acid ceramidase (AC) und die N-acylethanolamine-hydrolyzing acid amidase (NAAA) sind zwei ebenfalls im lysosomalen Kompartiment vorkommende NtnHydrolasen bekannt. Die AC wie auch die NAAA werden genauso wie das 66.3-kDaProtein durch Prozessierung aus einem Vorläuferprotein gebildet und besitzen mehrere N-Glykosylierungen (Bernardo et al. 1995; He et al. 2003; Tsuboi et al. 2007). Interessanterweise besteht der erste Schritt der Prozessierung sowohl bei der AC als auch bei der NAAA und dem 66.3-kDa-Protein in einer Spaltung vor einem Cystein. In Anlehnung an die NAAA, für die eine Substratspezifität für das N-Palmitoylethanolamid gezeigt werden konnte (Tsuboi et al. 2005), wurde das 66.3kDa-Protein auf die hydrolytische Aktivität gegenüber verschiedenen NAEs untersucht. Die Entscheidung, das 66.3-kDa-Protein zuerst auf die hydrolytische Aktivität gegenüber verschiedenen NAEs zu untersuchen, soll keineswegs bedeuten, dass die oben beschriebenen anderen möglichen Substrate als weniger wahrscheinlich für das 66.3-kDa-Protein angenommen werden.

Bei den im Rahmen dieser Arbeit durchgeführten Untersuchungen konnte keine N-Acylethanolamid-spaltende Aktivität des 66.3-kDa-Proteins nachgewiesen werden 
(vgl. Kap. 4.6.3). Auch die daraufhin durchgeführte Lipidanalyse von Ethanolaminderivaten aus HT1080-Zellen konnte keinen Unterschied zwischen 66.3kDa-Protein-überexprimierenden HT1080-Zellen im Vergleich zu Kontroll-HT1080Zellen zeigen. Da auch diese Ergebnisse mit HT1080-Zellen erhoben wurden, kann auf Grund der zuvor beschriebenen fehlenden Faktoren für die Aktivierung des 66.3kDa-Proteins nicht davon ausgegangen werden, dass das 66.3-kDa-Protein in seiner hydrolytisch aktiven Form vorliegt. Eine hydrolytische Funktion des 66.3-kDaProteins auf diesem Gebiet kann daher auch noch nicht ausgeschlossen werden.

\subsection{Beurteilung des 66.3-kDa-Protein-GeneTrap-Mausmodells}

Die im Rahmen dieser Arbeit durchgeführte Transkriptomanalyse sowie die quantitative Real-Time-PCR für das GeneTrap-Mausmodell des 66.3-kDa-Proteins (66gt-Mausmodell) zeigte eine quantitative Reprimierung des endogenen 66.3-kDaTranskripts im Vergleich zum Wildtyp von etwa 90\%. Demnach konnten noch 10\% der Menge des endogenen Transkripts verglichen mit dem Wildtyp detektiert werden. Diese Ergebnisse wurden durch die anschließende RT-PCR mit nachfolgender Sequenzierung des 66.3-kDa-Transkripts an Gewebehomogenaten des 66gtMausmodells bestätigt. Es ist davon auszugehen, dass mit der durchgeführten RTPCR vornehmlich das Wildtyp-Transkript des 66.3-kDa-Proteins amplifiziert wurde. Warum sowohl das Wildtyp-Transkript als auch das GeneTrap-Transkript des 66.3kDa-Proteins entstehen, bleibt offen. Grundsätzlich ist die Entstehung von WildtypTranskripten im GeneTrap nur dann möglich, wenn das Splice-Akzeptorelement der GeneTrap-Kassette beim Splicen nicht effizient genutzt wird (Schnutgen et al. 2005). In diesem Fall würde die im Intron zwischen Exon sechs und Exon sieben gelegene GeneTrap-Kassette beim Splicen verloren gehen und ein vollständiges WildtypTranskript entstehen. Mit welcher Effektivität ein jeweiliges Splice-Akzeptor-Element genutzt wird hängt zum einen von der Splice-Konsensus-Sequenz und zum anderen von den im 3'-Bereich folgenden Exonen ab. Ebenso haben die Sekundärstrukturen der das Spliceelement umgebenden Region einen Einfluss auf die Effektivität des Splicevorgangs (Brunak et al. 1991; Watakabe et al. 1991).

Differentielle Northern-Blot-Analysen zeigten zudem, dass in einigen Geweben des 66gt-Mausmodells Wildtyp-Transkripte zu detektieren waren. Bei den durchgeführten Untersuchungen ließen sich mit einer Sonde für den 3'-Bereich Transkripte des 66.3- 
kDa-Proteins in der Niere und im Hoden nachweisen. Die daraufhin durchgeführte Real-Time-PCR aus Hodengewebe konnte ebenso wie die hier dargestellten Ergebnisse aus Lebergeweben eine unvollständige Deletion des 3'-Bereiches nachweisen.

Unter der Annahme, dass die detektierten 10\% Wildtyp-Transkripte eine Restsynthese von ebenfalls 10\% funktionell aktivem 66.3-kDa-Protein ergeben, wäre die Ausbildung eines Phänotyps für das 66gt-Mausmodell sehr unwahrscheinlich, da zur Manifestation lysosomaler Speichererkrankungen Restaktivitäten der betreffenden Enzyme von meist unter 1-5\% erst zum Entstehen eines Phänotyps führen (Futerman and van Meer 2004). Jedoch sollte eine 90\%ige Verringerung des 66.3-kDa-Proteins in 66gt-Geweben deutliche Unterschiede in den durchgeführten biochemischen Messungen hervorrufen, so dass die Aussagekraft der mit 66gtGeweben durchgeführten Untersuchungen keineswegs eingeschränkt ist. Die Annahme, dass eine 90\%ige Verringerung der Transkriptmenge auch eine 90\%ige Verringerung der enzymatischen Aktivität des betroffenen Genprodukts bedingt, kann durch Untersuchungen an knock-out-Mäusen eindrucksvoll belegt werden. So besitzen heterozygote Tiere in der Regel eine 50\%ige enzymatische Restaktivität gegenüber den Wildtyp-Tieren (Zhu M et al. 2006).

Die zuvor dargestellten Ergebnisse für das 66.3-kDa-Transkript stehen arbeitsgruppen-internen Ergebnissen auf Proteinebene des 66gt-Mausmodells gegenüber. In Western-Blots mit dem 66-Antiserum konnte gezeigt werden, dass sowohl in Geweben von 66gt-Tieren, als auch in den hergestellten Lysosomenangereicherten, subzellulären Fraktionen aus der Leber, in denen lysosomale Proteine ca. 50-fach angereichert sind, kein Signal für das 66.3-kDa-Protein detektiert werden konnte (vgl. Abb. 5.5). 


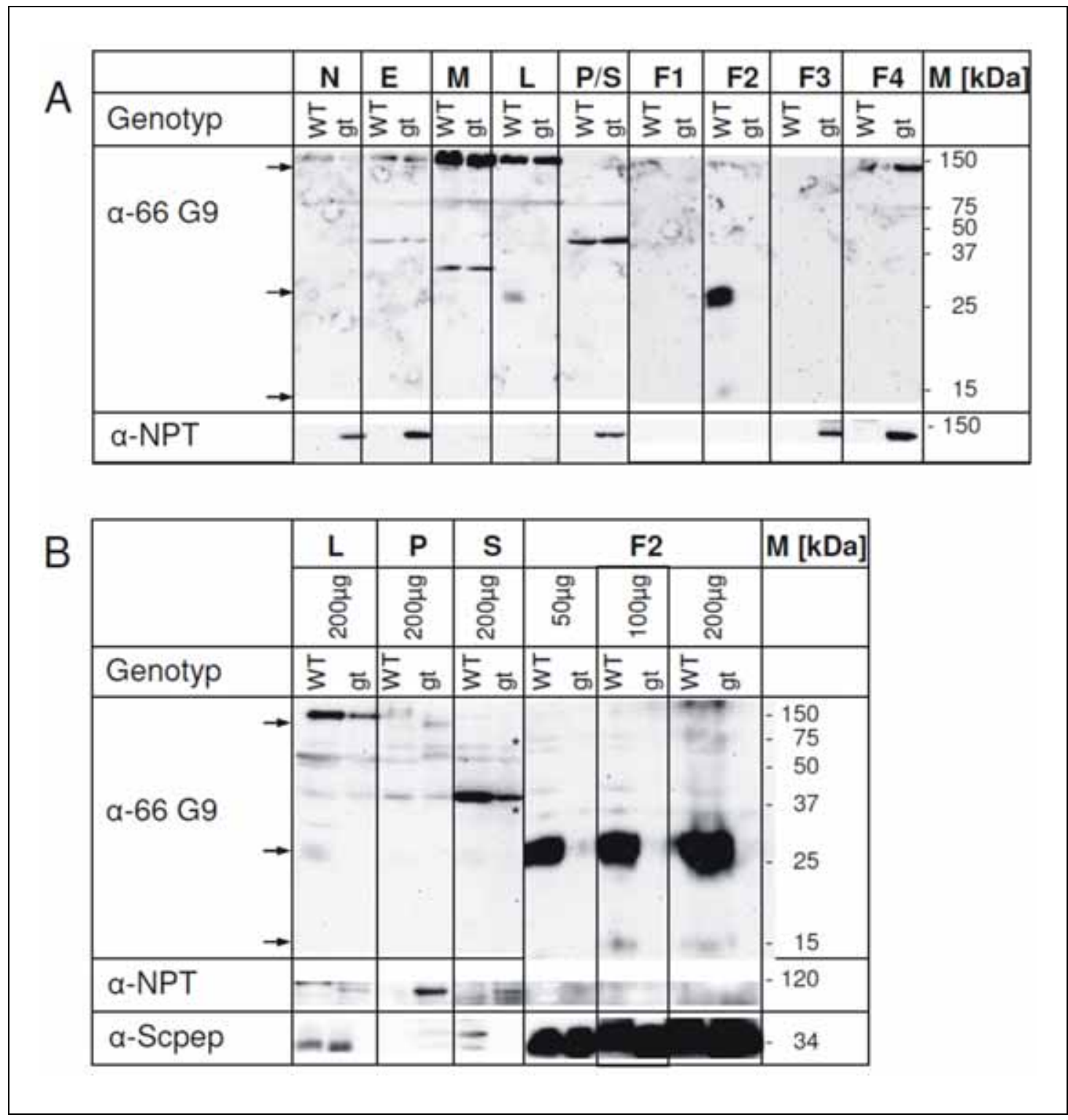

Abb. 5.5: Analyse einer subzellulären Fraktionierung von Mausleberhomogenat nach Tyloxapol-Behandlung

(A) Differentielle Fraktionierung von Leberhomogenaten. Eingesetzt wurden $200 \mu \mathrm{g}$ der Fraktionen $\mathrm{N}$, $\mathrm{E}, \mathrm{M}, \mathrm{L}, \mathrm{P} / \mathrm{S}$ und $50 \mu \mathrm{g}$ der Fraktionen F1 - F4. Detektiert wurden das 66.3-kDa-Protein ( $\alpha-66 \mathrm{G} 9)$ und die Neomycin-Phosphotransferase-Domäne des GeneTrap-Fusionsproteins ( $\alpha$-NPT). (B) Differentielle Fraktionierung von Leberhomogenaten. Eingesetzt wurden $200 \mu \mathrm{g}$ der Fraktionen L, P und S sowie 50 $\mu \mathrm{g}, 100 \mu \mathrm{g}$ und $200 \mu \mathrm{g}$ der Fraktion F2. Detektiert wurden das 66.3-kDa-Protein ( $\alpha-66 \mathrm{G} 9$ ) und die Neomycinphosphotransferase-Domäne des GeneTrap-Fusionsproteins ( $\alpha-\mathrm{NPT})$. Als Ladekontrolle für die Fraktionen $L$ und F2 diente das lysosomale Protein Scpep1 ( $\alpha$-Scpep). Die Pfeile markieren Signale des 66.3-kDa-Proteins bzw. des 66t-Fusionsproteins, Sterne $\left(^{*}\right)$ markieren unspezifisch erkannte Signale.

Die oben diskutierten Ergebnisse aus der Transkriptomanalyse sind demzufolge nur bedingt auf die Proteinebene übertragbar. Warum aus den verbliebenen WildtypTranskripten des 66gt-Mausmodells keine detektierbare Synthese des 66.3-kDaProteins erfolgt oder ob dieses durch die Anwesenheit eines 66.3-kDaFusionsproteins besonders schnell abgebaut wird, ist noch fraglich. Eventuell liegen 
die gebildeten Proteinmengen des 66.3-kDa-Proteins im 66gt-Mausmodell auch unterhalb der Nachweisgrenze des Western-Blots.

Insgesamt wird eine aussagekräftige Beurteilung zur funktionellen Inaktivierung des 66.3-kDa-Proteins im entsprechenden GeneTrap-Mausmodell wohl erst nach Identifizierung der genauen Funktion des 66.3-kDa-Proteins möglich sein, weil erst anhand der funktionellen Untersuchungen an GeneTrap-Mausgeweben eine Beurteilung der funktionellen Inaktivierung des 66.3-kDa-Proteins möglich ist. 


\subsection{Ausblick}

Die Untersuchungen der hier vorliegenden Arbeit erbrachten konkrete Hinweise für die Funktion des 66.3-kDa-Proteins und die potentiellen Substrate. Leider konnte eine enzymatische Aktivität noch nicht nachgewiesen werden. Es sind bereits mehrere verschiedene experimentelle Ansätze in Arbeit, mit denen es gelingen sollte, die enzymatische Aktivität des 66.3-kDa-Proteins nachzuweisen bzw. das potentielle Substrat zu identifizieren.

Zum einen soll das 66.3-kDa-Protein aus den Granula von Makrophagen für eine erneute Aktivitätsbestimmung gegenüber Phospholipiden und N-Acylethanolamiden verwendet werden. Hierzu soll das 66.3-kDa-Protein in RAW264.7-Zellen überexprimiert werden und es sollen Aktivitätsbestimmungen mit Homogenaten dieser Zelllinie erfolgen. Um das eigentliche Substrat des 66.3-kDa-Proteins zu identifizieren, wurden bereits verschiedene, vermutlich inaktive Mutanten des 66.3kDa-Proteins generiert. Dabei wurden die durch die Kristallisation für die hydrolytische Funktion als essentiell eingestuften Aminosäuren gezielt mutiert (C249S; N432Q; R463Q). Durch eine schonende Aufreinigung der mutierten, hydrolytisch inaktiven 66.3-kDa-Proteine soll es gelingen, das in der hydrophoben Tasche des Proteins gebundene Substrat, im Sinne einer sogenannten Substratfalle, mit aufzureinigen und nachfolgend massenspektrometrisch zu analysieren. Um die Interaktion des 66.3-kDa-Proteins mit dem Cathepsin D bezüglich einer eventuellen Superkomplexbildung weiter zu analysieren, wurden bereits verschiedene blue nativGelelektrophoreseuntersuchungen mit Lysosomen-angereicherten Fraktionen begonnen.

Neuere und vielversprechende Methoden um die Interaktion vom 66.3-kDa-Protein und Cathepsin D noch genauer zu untersuchen stellen Methoden wie die Rasterkraftmikroskopie (AFM=Atomic Force Microscopy) dar, dabei können in Einzelmolekül-Analysen die Kräfte zwischen zwei interagierenden Molekülen gemessen werden (Moy et al. 1994), wie es beispielweise für die Interaktion von Saposin C mit der Phopholipidmembran beschrieben ist (You et al. 2003).

Falls es gelingt die Funktion oder das Substrat des 66.3-kDa-Proteins zu identifizieren, sollte das 66gt-Mausmodell spezielleren Untersuchung unterzogen 
werden. Hier könnten dann sogenannte Metabolom-Analysen von Blut-, Urin- oder verschiedenen Geweben durchgeführt werden in denen standardmäßig ca. 200 Metabolite quantitativ bestimmt werden könnten, um eventuelle Pathologien der Maus aufzuzeigen. Diese Metabolom-Analysen könnten sowohl in der AG Zellkulturtechnik von Prof. Dr. Thomas Noll an der Universität Bielefeld, als auch in der AG von Prof. Dr. Karsten Niehaus am Center for Biotechnologies (CeBiTec) der Universität Bielefeld durchgeführt werden. Zeigt das 66gt-Mausmodell keine pathologischen Befunde in den entsprechenden Untersuchungen, sollte auf Grund der durchgeführten Transkriptomanalyse über die Generierung eines klassischen knock-out-Mausmodells anstelle des GeneTraps für das 66.3-kDa-Protein nachgedacht werden. 


\section{Zusammenfassung}

Im Mittelpunkt dieser Arbeit stand das von Kollmann et al. (2005) erstmals beschriebene und von Deuschl et al. (2006) ausführlich molekular charakterisierte murine 66.3-kDa-Protein.

Die in Vorarbeiten bereits vermutete Interaktion des 66.3-kDa-Proteins mit der lysosomalen Aspartylprotease Cathepsin D konnte im Rahmen der vorliegenden Arbeit mit verschiedenen Interaktionsstudien (Ko-Immunpräzipitation, Pepstatin-AChromatographie, Vernetzung mit heterobifunktionalen Quervernetzern) bestätigt werden. Weitere Interaktionspartner konnten für das 66.3-kDa-Protein im Rahmen dieser Untersuchungen jedoch nicht identifiziert werden, wobei der Schwerpunkt der durchgeführten Untersuchungen auch auf der Bestätigung der putativen Interaktion des 66.3-kDa-Proteins mit dem Cathepsin D lag.

Das zuvor beschriebene Prozessierungsmuster für das 66.3-kDa-Protein konnte durch die Identifizierung eines weiteren Fragments des 66.3-kDa-Proteins mittels MALDI-TOF-MS/PMF und Western-Blot-Untersuchungen ergänzt werden. Die Prozessierung des 66.3-kDa-Proteins stellt sich demnach als zweistufiger, wahrscheinlich autokatalytischer Prozess dar. Die drei entstandenen Fragmente bleiben nicht-kovalent miteinander verknüpft und stellen vermutlich die aktive Form des 66.3-kDa-Proteins dar. Zudem konnte mittels Gelfiltration und Quervernetzung gezeigt werden, dass je zwei 66.3-kDa-Proteine als funktionell stabiler Homodimer aus jeweils 2 bzw. 3 Untereinheiten vorliegen.

Nach der Kristallisation des 66.3-kDa-Proteins konnten Röntgenbeugungsmuster generiert werden, mit deren Hilfe die dreidimensionale Struktur des 66.3-kDaProteins ermittelt werden konnte. Der Vergleich der dreidimensionalen Struktur des 66.3-kDa-Proteins mit bereits bekannten Proteinstrukturen konnte auf Grund der

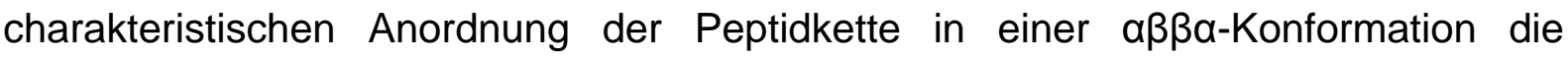
Zugehörigkeit des 66.3-kDa-Proteins in die Superfamilie der Ntn-Hydrolasen 
(Enzymklasse 3.5.1) zeigen und eine hydrolytische Funktion im Lipid-Stoffwechsel bei der Spaltung von linearen, nicht-peptidischen Amidbindungen vorhersagen.

Mögliche Substrate für das 66.3-kDa-Protein wären somit u. a. verschiedene N-Acylethanolamide oder Sphingosine, sowie hydrophobe Proteinmodifikationen mit Amidbindungen wie die N-Myristoylierung, Glypiation oder Lysin-Acetylierung. Der Nachweis einer speziellen hydrolytischen Funktion des 66.3-kDa-Proteins gegenüber einem Substrat konnte im Rahmen dieser Arbeit nicht gezeigt werden.

Unabhängig von den Ergebnissen auf Proteinebene konnte im Rahmen einer durchgeführten Proteomanalyse des 66gt-Mausmodells eine Häufung der differentiell exprimierten Gene um die Insertionsstelle der GeneTrap-Kassette auf Chromosom 5 festgestellt werden. Insgesamt waren 85,6\% der insgesamt 125 differentiell exprimierten Gene nur geringgradig differentiell exprimiert (1,5-2-fach) und es zeigte sich eine maximale, differentielle Expression eines Gens mit einer 3,71-fachen Reprimierung. Die differentiell exprimierten Gene konnten ferner in einer pathwayAnalyse auch keinem bestimmten Stoffwechsel zugeordnet werden. All diese Ergebnisse stehen im Einklang damit, dass das 66gt-Mausmodell keinen auffälligen Phänotyp aufweist. In Geweben des 66gt-Mausmodells ließ sich allerdings kein 66.3kDa-Protein nachweisen, obwohl es nicht zur vollständigen Unterdrückung der 66.3kDa-Wildtyp-Transkripte im GeneTrap kommt. 


\section{$7 \quad$ Literaturverzeichnis}

Austin CP, Battey JF, Bradley A, Bucan M, Capecchi M, Collins FS, Dove WF, Duyk G, Dymecki S, Eppig JT, et al. (2004): The knockout mouse project. Nat Genet 36, 921-924.

Ausubel LJ, Krieger JI, Hafler DA (1997): Changes in cytokine secretion induced by altered peptide ligands of myelin basic protein peptide 85-99. J Immunol 159, 2502-2512.

Ballabio A, Gieselmann V (2009): Lysosomal disorders: From storage to cellular damage. Biochim Biophys Acta 1793, 684-696.

Barton NW, Brady RO, Dambrosia JM, Di Bisceglie AM, Doppelt SH, Hill SC, Mankin HJ, Murray GJ, Parker RI, Argoff CE, et al. (1991): Replacement therapy for inherited enzyme deficiency--macrophage-targeted glucocerebrosidase for Gaucher's disease. N Engl J Med 324, 1464-1470.

Berchem G, Glondu M, Gleizes M, Brouillet JP, Vignon F, Garcia M, LiaudetCoopman E (2002): Cathepsin-D affects multiple tumor progression steps in vivo: proliferation, angiogenesis and apoptosis. Oncogene $\underline{21}, 5951-5955$.

Berdyshev EV, Boichot E, Germain N, Allain N, Anger JP, Lagente V (1997): Influence of fatty acid ethanolamides and delta9-tetrahydrocannabinol on cytokine and arachidonate release by mononuclear cells. Eur J Pharmacol $\underline{330}, 231-240$.

Berger SL (2002): Histone modifications in transcriptional regulation. Curr Opin Genet Dev 12, 142-148.

Bernardo K, Hurwitz R, Zenk T, Desnick RJ, Ferlinz K, Schuchman EH, Sandhoff K (1995): Purification, characterization, and biosynthesis of human acid ceramidase. J Biol Chem 270, 11098-11102.

Blanz J, Groth J, Zachos C, Wehling C, Saftig P, Schwake M (2010): Diseasecausing mutations within the lysosomal integral membrane protein type 2 (LIMP-2) reveal the nature of binding to its ligand beta-glucocerebrosidase. Hum Mol Genet 19, 563-572.

Bond JS, Butler PE (1987): Intracellular proteases. Annu Rev Biochem $\underline{56}$, 333-364.

Brannigan JA, Dodson G, Duggleby HJ, Moody PC, Smith JL, Tomchick DR, Murzin AG (1995): A protein catalytic framework with an $\mathrm{N}$-terminal nucleophile is capable of self-activation. Nature $\underline{378}, 416-419$.

Braulke T, Geuze HJ, Slot JW, Hasilik A, von Figura K (1987): On the effects of weak bases and monensin on sorting and processing of lysosomal enzymes in human cells. Eur J Cell Biol $\underline{43}$, 316-321.

Bresciani R, Von Figura K (1996): Dephosphorylation of the mannose-6-phosphate recognition marker is localized in later compartments of the endocytic route. Identification of purple acid phosphatase (uteroferrin) as the candidate phosphatase. Eur J Biochem 238, 669-674. 
Brunak S, Engelbrecht J, Knudsen S (1991): Prediction of human mRNA donor and acceptor sites from the DNA sequence. J Mol Biol 220, 49-65.

Bütikofer P, Lin ZW, Kuypers FA, Scott MD, Xu CM, Wagner GM, Chiu DT, Lubin B (1989): Chlorpromazine inhibits vesiculation, alters phosphoinositide turnover and changes deformability of ATP-depleted RBCs. Blood $\underline{73}, 1699-1704$.

Byrd JC, MacDonald RG (2000): Mechanisms for high affinity mannose 6-phosphate ligand binding to the insulin-like growth factor $11 /$ mannose 6-phosphate receptor. J Biol Chem $\underline{275}$, 18638-18646.

Canuel M, Korkidakis A, Konnyu K, Morales CR (2008): Sortilin mediates the lysosomal targeting of cathepsins $\mathrm{D}$ and $\mathrm{H}$. Biochem Biophys Res Commun 373, 292-297.

Casey PJ (1995): Protein lipidation in cell signaling. Science $\underline{268}$, 221-225.

Cheng SH, Smith AE (2003): Gene therapy progress and prospects: gene therapy of lysosomal storage disorders. Gene Ther $\underline{10}$, 1275-1281.

Cigic B, Krizaj I, Kralj B, Turk V, Pain RH (1998): Stoichiometry and heterogeneity of the pro-region chain in tetrameric human cathepsin C. Biochim Biophys Acta 1382, 143-150.

Cravatt BF, Demarest K, Patricelli MP, Bracey MH, Giang DK, Martin BR, Lichtman $\mathrm{AH}$ (2001): Supersensitivity to anandamide and enhanced endogenous cannabinoid signaling in mice lacking fatty acid amide hydrolase. Proc Natl Acad Sci U S A $\underline{98}$, 9371-9376.

Cuppoletti J, Aures-Fischer D, Sachs G (1987): The lysosomal H+ pump: 8-azidoATP inhibition and the role of chloride in $\mathrm{H}+$ transport. Biochim Biophys Acta $\underline{899}, 276-284$.

da Silva AM, Klein C (1990): A rapid posttranslational myristylation of a 68-kD protein in D. discoideum. J Cell Biol 111, 401-407.

Dahms NM, Lobel P, Breitmeyer J, Chirgwin JM, Kornfeld S (1987): 46 kd mannose 6-phosphate receptor: cloning, expression, and homology to the $215 \mathrm{kd}$ mannose 6-phosphate receptor. Cell $\underline{50}, 181-192$.

Dahms NM, Lobel P, Kornfeld S (1989): Mannose 6-phosphate receptors and lysosomal enzyme targeting. J Biol Chem 264, 12115-12118.

De-Zolt S, Schnutgen F, Seisenberger C, Hansen J, Hollatz M, Floss T, Ruiz P, Wurst W, von Melchner H (2006): High-throughput trapping of secretory pathway genes in mouse embryonic stem cells. Nucleic Acids Res 34, e25.

de Duve C (1969): The peroxisome: a new cytoplasmic organelle. Proc R Soc Lond B Biol Sci 173, 71-83.

de Duve C, Pressman BC, Gianetto R, Wattiaux R, Appelmans F (1955): Tissue fractionation studies. 6. Intracellular distribution patterns of enzymes in ratliver tissue. Biochem J $\underline{60}, 604-617$.

Deiss LP, Galinka H, Berissi H, Cohen O, Kimchi A (1996): Cathepsin D protease mediates programmed cell death induced by interferon-gamma, Fas/APO-1 and TNF-alpha. EMBO J 15, 3861-3870.

Deuschl F: Molekulare Charakterisierung des murinen 66.3-kDa-Proteins. Med. Diss. Göttingen 2008 
Deuschl F, Kollmann K, von Figura K, Lübke T (2006): Molecular characterization of the hypothetical 66.3-kDa protein in mouse: lysosomal targeting, glycosylation, processing and tissue distribution. FEBS Lett $\underline{580}, 5747-5752$.

Dierks T, Schlotawa L, Frese MA, Radhakrishnan K, von Figura K, Schmidt B (2009): Molecular basis of multiple sulfatase deficiency, mucolipidosis II/III and Niemann-Pick C1 disease - Lysosomal storage disorders caused by defects of non-lysosomal proteins. Biochim Biophys Acta 1793, 710-725.

Eng CM, Guffon N, Wilcox WR, Germain DP, Lee P, Waldek S, Caplan L, Linthorst GE, Desnick RJ, International Collaborative Fabry Disease Study G (2001): Safety and efficacy of recombinant human alpha-galactosidase A-replacement therapy in Fabry's disease. N Engl J Med 345, 9-16.

Ferguson MA, Williams AF (1988): Cell-surface anchoring of proteins via glycosylphosphatidylinositol structures. Annu Rev Biochem 57, 285-320.

Fukuda M (1991): Lysosomal membrane glycoproteins. Structure, biosynthesis, and intracellular trafficking. J Biol Chem 266, 21327-21330.

Futerman AH, van Meer G (2004): The cell biology of lysosomal storage disorders. Nat Rev Mol Cell Biol $\underline{5}, 554-565$.

Gahl WA, Bashan N, Tietze F, Bernardini I, Schulman JD (1982): Cystine transport is defective in isolated leukocyte lysosomes from patients with cystinosis. Science 217, 1263-1265.

Galjaard H, Willemsen R, Hoogeveen AT, Mancini GM, Palmeri S, Verheijen FW, D'Azzo A (1987): Molecular heterogeneity in human beta-galactosidase and neuraminidase deficiency. Enzyme 38, 132-143.

Garcia M, Derocq D, Pujol P, Rochefort H (1990): Overexpression of transfected cathepsin $D$ in transformed cells increases their malignant phenotype and metastatic potency. Oncogene $\underline{5}, 1809-1814$.

Gaxiola R, de Larrinoa IF, Villalba JM, Serrano R (1992): A novel and conserved saltinduced protein is an important determinant of salt tolerance in yeast. EMBO J 11, 3157-3164.

Gieselmann V (1995): Lysosomal storage diseases. Biochim Biophys Acta 1270, 103-136.

Gieselmann V, Pohlmann R, Hasilik A, Von Figura K (1983): Biosynthesis and transport of cathepsin D in cultured human fibroblasts. J Cell Biol $\underline{97}, 1-5$.

Glondu M, Liaudet-Coopman E, Derocq D, Platet N, Rochefort H, Garcia M (2002): Down-regulation of cathepsin-D expression by antisense gene transfer inhibits tumor growth and experimental lung metastasis of human breast cancer cells. Oncogene 21, 5127-5134.

Goldstein JL, Brown MS, Anderson RG, Russell DW, Schneider WJ (1985): Receptor-mediated endocytosis: concepts emerging from the LDL receptor system. Annu Rev Cell Biol 1, 1-39.

Graham FL, Smiley J, Russell WC, Nairn R (1977): Characteristics of a human cell line transformed by DNA from human adenovirus type 5 . J Gen Virol $\underline{36}, 59-$ 74.

Grassel S, Hasilik A (1992): Human cathepsin D precursor is associated with a 60 kDa glycosylated polypeptide. Biochem Biophys Res Commun 182, 276-282. 
Greiner-Tollersrud OK, Berg T: Lysosomal Storage Disorders. In: Lysosomes. hrsg. v. Saftig, P, Landes Bioscience/Eurekah.com Springer Science+Business Media, Inc., New York 2005, 60-74

Grewal SS, Shapiro EG, Krivit W, Charnas L, Lockman LA, Delaney KA, Davies SM, Wenger DA, Rimell FL, Abel S, et al. (2004): Effective treatment of alphamannosidosis by allogeneic hematopoietic stem cell transplantation. J Pediatr 144, 569-573.

Guo F, Huang X, Li S, Sun L, Li Y, Li H, Zhou Y, Chu Y, Zhou T (2007): Identification of prosaposin as a novel interaction partner for Rhox5. J Genet Genomics $\underline{34}$, 392-399.

Hansen G, Berg T, Riise Stensland HM, Heikinheimo P, Klenow H, Evjen G, Nilssen O, Tollersrud OK (2004): Intracellular transport of human lysosomal alphamannosidase and alpha-mannosidosis-related mutants. Biochem J 381, 537546.

Hansen HS, Lauritzen L, Strand AM, Moesgaard B, Frandsen A (1995): Glutamate stimulates the formation of $\mathrm{N}$-acylphosphatidylethanolamine and $\mathrm{N}$ acylethanolamine in cortical neurons in culture. Biochim Biophys Acta $\underline{1258}$, 303-308.

Hansen HS, Moesgaard B, Hansen HH, Petersen G (2000): N-Acylethanolamines and precursor phospholipids - relation to cell injury. Chem Phys Lipids $\underline{108}$, 135-150.

Hasilik A (1992): The early and late processing of lysosomal enzymes: proteolysis and compartmentation. Experientia 48, 130-151.

Hayashi H, Niinobe S, Matsumoto Y, Suga T (1981): Effects of Triton WR-1339 on lipoprotein lipolytic activity and lipid content of rat liver lysosomes. J Biochem 89, 573-579.

Hayashi H, Shitara M, Yamasaki F (1982): The origin of lipid accumulated in liver lysosomes after administration of triton WR-1339. J Biochem 92, 1585-1590.

He X, Okino N, Dhami R, Dagan A, Gatt S, Schulze H, Sandhoff K, Schuchman EH (2003): Purification and characterization of recombinant, human acid ceramidase. Catalytic reactions and interactions with acid sphingomyelinase. $\mathrm{J}$ Biol Chem 278, 32978-32986.

Hemsley KM, Hopwood JJ (2009): Delivery of recombinant proteins via the cerebrospinal fluid as a therapy option for neurodegenerative lysosomal storage diseases. Int J Clin Pharmacol Ther 47 Suppl 1, S118-123.

Hershko A, Ciechanover A (1992): The ubiquitin system for protein degradation. Annu Rev Biochem 61, 761-807.

Heukeshoven J, Dernick R (1988): Improved silver staining procedure for fast staining in PhastSystem Development Unit. I. Staining of sodium dodecyl sulfate gels. Electrophoresis $\underline{9}, 28-32$.

Hille-Rehfeld A (1995): Mannose 6-phosphate receptors in sorting and transport of lysosomal enzymes. Biochim Biophys Acta 1241, 177-194.

Hofmann SL, Lee LA, Lu JY, Verkruyse LA (1997): Palmitoyl-protein thioesterase and the molecular pathogenesis of infantile neuronal ceroid lipofuscinosis. Neuropediatrics $\underline{28}, 27-30$. 
Holm L, Sander C (1996): Alignment of three-dimensional protein structures: network server for database searching. Methods Enzymol 266, 653-662.

Horowitz M, Pasmanik-Chor M, Borochowitz Z, Falik-Zaccai T, Heldmann K, Carmi R, Parvari R, Beit-Or H, Goldman B, Peleg L, et al. (1998): Prevalence of glucocerebrosidase mutations in the Israeli Ashkenazi Jewish population. Hum Mutat $\underline{12}$, 240-244.

Hunziker W, Geuze HJ (1996): Intracellular trafficking of lysosomal membrane proteins. Bioessays $\underline{18}, 379-389$.

Jadot M, Dubois F, Wattiaux-De Coninck S, Wattiaux R (1997): Supramolecular assemblies from lysosomal matrix proteins and complex lipids. Eur $\mathrm{J}$ Biochem $\underline{249}, 862-869$.

Jensen AG: Etude de p76, une nouvelle protéine mannose-6-phosphate: caractérisations biochimiques, localisation lysosomale et approche de la fonction. Biol. Diss. Grenoble 2007

Jensen AG, Chemali M, Chapel A, Kieffer-Jaquinod S, Jadot M, Garin J, Journet A (2007): Biochemical characterization and lysosomal localization of the mannose-6-phosphate protein p76 (hypothetical protein LOC196463). Biochem J 402, 449-458.

Jentsch TJ, Stein V, Weinreich F, Zdebik AA (2002): Molecular structure and physiological function of chloride channels. Physiol Rev $\underline{82}, 503-568$.

Jenuwein T, Allis CD (2001): Translating the histone code. Science 293, 1074-1080.

Jeyakumar M, Butters TD, Cortina-Borja M, Hunnam V, Proia RL, Perry VH, Dwek RA, Platt FM (1999): Delayed symptom onset and increased life expectancy in Sandhoff disease mice treated with N-butyldeoxynojirimycin. Proc Natl Acad Sci U S A $\underline{96}$, 6388-6393.

Kirkegaard T, Roth AG, Petersen NH, Mahalka AK, Olsen OD, Moilanen I, Zylicz A, Knudsen J, Sandhoff K, Arenz C, et al. (2010): Hsp70 stabilizes lysosomes and reverts Niemann-Pick disease-associated lysosomal pathology. Nature $\underline{463}, 549-553$.

Knight CG, Barrett AJ (1976): Interaction of human cathepsin D with the inhibitor pepstatin. Biochem J 155, 117-125.

Koike M, Shibata M, Ohsawa Y, Nakanishi H, Koga T, Kametaka S, Waguri S, Momoi T, Kominami E, Peters C, et al. (2003): Involvement of two different cell death pathways in retinal atrophy of cathepsin D-deficient mice. Mol Cell Neurosci 22, 146-161.

Kollmann K, Mutenda KE, Balleininger M, Eckermann E, von Figura K, Schmidt B, Lübke T (2005): Identification of novel lysosomal matrix proteins by proteome analysis. Proteomics $\underline{5}, 3966-3978$.

Kollmann K, Damme M, Deuschl F, Kahle J, D'Hooge R, Lüllmann-Rauch R, Lübke T (2009): Molecular characterization and gene disruption of mouse lysosomal putative serine carboxypeptidase 1. FEBS J 276, 1356-1369.

Kornfeld R, Kornfeld S (1985): Assembly of asparagine-linked oligosaccharides. Annu Rev Biochem 54, 631-664.

Kornfeld S (1992): Structure and function of the mannose 6-phosphate/insulinlike growth factor II receptors. Annu Rev Biochem 61, 307-330. 
Kornfeld S, Mellman I (1989): The biogenesis of lysosomes. Annu Rev Cell Biol $\underline{5}$, 483-525.

Krissinel E, Henrick K (2007): Inference of macromolecular assemblies from crystalline state. J Mol Biol $\underline{372}, 774-797$.

Kuroda K, Kato M, Mima J, Ueda M (2006): Systems for the detection and analysis of protein-protein interactions. Appl Microbiol Biotechnol 71, 127-136.

Laemmli UK (1970): Cleavage of structural proteins during the assembly of the head of bacteriophage T4. Nature $\underline{227}, 680-685$.

Lakomek K, Dickmanns A, Mueller U, Kollmann K, Deuschl F, Berndt A, Lübke T, Ficner R (2009a): De novo sulfur SAD phasing of the lysosomal $66.3 \mathrm{kDa}$ protein from mouse. Acta Crystallogr D Biol Crystallogr $\underline{65}$, 220-228.

Lakomek K, Dickmanns A, Kettwig M, Urlaub H, Ficner R, Lübke T (2009b): Initial insight into the function of the lysosomal $66.3 \mathrm{kDa}$ protein from mouse by means of X-ray crystallography. BMC Struct Biol $\underline{9}, 56$.

Lakomek K: Structural characterization of the lysosomal $66.3 \mathrm{kDa}$ protein and of the DNA repair enzyme MTH0212 by means of X-ray crystallography. Biol. Diss. Göttingen 2009

Lawrence BP, Brown WJ (1992): Autophagic vacuoles rapidly fuse with pre-existing lysosomes in cultured hepatocytes. J Cell Sci 102 (Pt 3), 515-526.

Leighton F, Poole B, Beaufay H, Baudhuin P, Coffey JW, Fowler S, De Duve C (1968): The large-scale separation of peroxisomes, mitochondria, and lysosomes from the livers of rats injected with triton WR-1339. Improved isolation procedures, automated analysis, biochemical and morphological properties of fractions. J Cell Biol $\underline{37}$, 482-513.

Liou W, Geuze HJ, Geelen MJ, Slot JW (1997): The autophagic and endocytic pathways converge at the nascent autophagic vacuoles. J Cell Biol 136, 6170.

Liu JP, Liu NS, Yuan HY, Guo Q, Lu H, Li YY (2006): Human homologue of SETA binding protein 1 interacts with cathepsin $\mathrm{B}$ and participates in TNF-Induced apoptosis in ovarian cancer cells. Mol Cell Biochem 292, 189-195.

Löffler G, Petrides PE: Biochemie \& Pathobiochemie. 7. Auflage; Springer-Verlag, Heidelberg 2003

Lowry OH, Rosebrough NJ, Farr AL, Randall RJ (1951): Protein measurement with the Folin phenol reagent. J Biol Chem 193, 265-275.

Lu JY, Hofmann SL (2006): Thematic review series: lipid posttranslational modifications. Lysosomal metabolism of lipid-modified proteins. J Lipid Res 47, 1352-1357.

Lübke T, Lobel P, Sleat DE (2009): Proteomics of the lysosome. Biochim Biophys Acta $\underline{1793}, 625-635$.

Luzio JP, Pryor PR, Bright NA (2007): Lysosomes: fusion and function. Nat Rev Mol Cell Biol $\underline{8}, 622-632$.

Masson C, Cisse I, Simon V, Insalaco P, Audran M (2004): Fabry disease: a review. Joint Bone Spine 1ㅡ, 381-383. 
Masters SC (2004): Co-immunoprecipitation from transfected cells. Methods Mol Biol 261, 337-350.

Matsuda J, Suzuki O, Oshima A, Yamamoto Y, Noguchi A, Takimoto K, Itoh M, Matsuzaki Y, Yasuda Y, Ogawa S, et al. (2003): Chemical chaperone therapy for brain pathology in G(M1)-gangliosidosis. Proc Natl Acad Sci U S A $\underline{100}$, 15912-15917.

Mazzari S, Canella R, Petrelli L, Marcolongo G, Leon A (1996): N-(2hydroxyethyl)hexadecanamide is orally active in reducing edema formation and inflammatory hyperalgesia by down-modulating mast cell activation. Eur $\mathrm{J}$ Pharmacol $\underline{300}$, 227-236.

McVey CE, Walsh MA, Dodson GG, Wilson KS, Brannigan JA (2001): Crystal structures of penicillin acylase enzyme-substrate complexes: structural insights into the catalytic mechanism. J Mol Biol 313, 139-150.

Meijer AJ, Codogno P (2004): Regulation and role of autophagy in mammalian cells. Int J Biochem Cell Biol 36, 2445-2462.

Meikle PJ, Hopwood JJ, Clague AE, Carey WF (1999): Prevalence of lysosomal storage disorders. JAMA 281, 249-254.

Michel JB, Michel T (1997): The role of palmitoyl-protein thioesterase in the palmitoylation of endothelial nitric oxide synthase. FEBS Lett $\underline{405}$, 356-362.

Miernyk JA, Thelen JJ (2008): Biochemical approaches for discovering proteinprotein interactions. Plant J $\underline{53}, 597-609$.

Mignani R, Cagnoli L (2004): Enzyme replacement therapy in Fabry's disease: recent advances and clinical applications. J Nephrol 17, 354-363.

Morgan CP, Insall R, Haynes L, Cockcroft S (2004): Identification of phospholipase B from Dictyostelium discoideum reveals a new lipase family present in mammals, flies and nematodes, but not yeast. Biochem J $\underline{382}$, 441-449.

Morimoto S, Kishimoto Y, Tomich J, Weiler S, Ohashi T, Barranger JA, Kretz KA, O'Brien JS (1990): Interaction of saposins, acidic lipids, and glucosylceramidase. J Biol Chem 265, 1933-1937.

Morishima H, Takita T, Aoyagi T, Takeuchi T, Umezawa H (1970): The structure of pepstatin. J Antibiot (Tokyo) $\underline{23}, 263-265$.

Moy VT, Florin EL, Gaub HE (1994): Intermolecular forces and energies between ligands and receptors. Science 266, 257-259.

Muno D, Ishidoh K, Ueno T, Kominami E (1993): Processing and transport of the precursor of cathepsin $\mathrm{C}$ during its transfer into lysosomes. Arch Biochem Biophys 306, 103-110.

Myerowitz R (1997): Tay-Sachs disease-causing mutations and neutral polymorphisms in the Hex A gene. Hum Mutat $\underline{9}$, 195-208.

Neufeld EF, Muenzer J: The Mucopolysaccaridoses. In: The Metabolic and Molecular Bases of Inherited Disease. hrsg. v. Scriver, CR, Beaudet, AL, Sly, WS, Valle, D, Childs, B, Kinzler, KW and Vogelstein, B, $8^{\text {th }}$ Edition, Vol. 3, McGraw-Hill, New York 2001, 3421-3452 
Neuhoff V, Arold N, Taube D, Ehrhardt W (1988): Improved staining of proteins in polyacrylamide gels including isoelectric focusing gels with clear background at nanogram sensitivity using Coomassie Brilliant Blue G-250 and R-250. Electrophoresis $\underline{9}$, 255-262.

Odaka C, Mizuochi T (1999): Role of macrophage lysosomal enzymes in the degradation of nucleosomes of apoptotic cells. J Immunol 163, 5346-5352.

Ohashi T, Watabe K, Uehara K, Sly WS, Vogler C, Eto Y (1997): Adenovirusmediated gene transfer and expression of human beta-glucuronidase gene in the liver, spleen, and central nervous system in mucopolysaccharidosis type VII mice. Proc Natl Acad Sci U S A 94, 1287-1292.

Ohkuma S, Poole B (1978): Fluorescence probe measurement of the intralysosomal $\mathrm{pH}$ in living cells and the perturbation of $\mathrm{pH}$ by various agents. Proc Natl Acad Sci U S A $\underline{75}$, 3327-3331.

Oinonen C, Rouvinen J (2000): Structural comparison of Ntn-hydrolases. Protein Sci $\underline{9}, 2329-2337$.

Park JH, Schuchman EH (2006): Acid ceramidase and human disease. Biochim Biophys Acta 1758, 2133-2138.

Perkins DN, Pappin DJ, Creasy DM, Cottrell JS (1999): Probability-based protein identification by searching sequence databases using mass spectrometry data. Electrophoresis 20, 3551-3567.

Peters C, von Figura K (1994): Biogenesis of lysosomal membranes. FEBS Lett $\underline{346}$, 108-114.

Peterson GL (1979): Review of the Folin phenol protein quantitation method of Lowry, Rosebrough, Farr and Randall. Anal Biochem 100, 201-220.

Pfaffl MW (2001): A new mathematical model for relative quantification in real-time RT-PCR. Nucleic Acids Res $\underline{29}$, e45.

Pohlmann R, Waheed A, Hasilik A, von Figura K (1982): Synthesis of phosphorylated recognition marker in lysosomal enzymes is located in the cis part of Golgi apparatus. J Biol Chem 257, 5323-5325.

Poorthuis BJ, Wevers RA, Kleijer WJ, Groener JE, de Jong JG, van Weely S, Niezen-Koning KE, van Diggelen OP (1999): The frequency of lysosomal storage diseases in The Netherlands. Hum Genet 105, 151-156.

Prabhune AA, Sivaraman H (1990): Evidence for involvement of arginyl residue at the catalytic site of penicillin acylase from Escherichia coli. Biochem Biophys Res Commun 173, 317-322.

Preusser-Kunze A, Mariappan M, Schmidt B, Gande SL, Mutenda K, Wenzel D, von Figura K, Dierks T (2005): Molecular characterization of the human Calphaformylglycine-generating enzyme. J Biol Chem 280, 14900-14910.

Qian M, Sleat DE, Zheng H, Moore D, Lobel P (2008): Proteomics analysis of serum from mutant mice reveals lysosomal proteins selectively transported by each of the two mannose 6-phosphate receptors. Mol Cell Proteomics $\underline{7}$, 58-70.

Rechsteiner M (1991): Natural substrates of the ubiquitin proteolytic pathway. Cell $\underline{66}, 615-618$. 
Reczek D, Schwake M, Schröder J, Hughes H, Blanz J, Jin X, Brondyk W, Van Patten S, Edmunds T, Saftig P (2007): LIMP-2 is a receptor for lysosomal mannose-6-phosphate-independent targeting of beta-glucocerebrosidase. Cell 131, 770-783.

Roeser D, Preusser-Kunze A, Schmidt B, Gasow K, Wittmann JG, Dierks T, von Figura K, Rudolph MG (2006): A general binding mechanism for all human sulfatases by the formylglycine-generating enzyme. Proc Natl Acad Sci U S A $103,81-86$.

Roldan ER, Harrison RA (1989): Polyphosphoinositide breakdown and subsequent exocytosis in the $\mathrm{Ca} 2+/$ ionophore-induced acrosome reaction of mammalian spermatozoa. Biochem J 259, 397-406.

Rome LH, Hill DF (1986): Lysosomal degradation of glycoproteins and glycosaminoglycans. Efflux and recycling of sulphate and Nacetylhexosamines. Biochem J 235, 707-713.

Ruiz-Canada C, Kelleher DJ, Gilmore R (2009): Cotranslational and posttranslational $\mathrm{N}$-glycosylation of polypeptides by distinct mammalian OST isoforms. Cell $\underline{136}, 272-283$.

Saftig P, Hetman M, Schmahl W, Weber K, Heine L, Mossmann H, Koster A, Hess B, Evers M, von Figura K, et al. (1995): Mice deficient for the lysosomal proteinase cathepsin $\mathrm{D}$ exhibit progressive atrophy of the intestinal mucosa and profound destruction of lymphoid cells. EMBO J 14, 3599-3608.

Sambrook J, Maniatis T, Fritsch EF: Molecular cloning: a laboratory manual. Cold Spring Harbor, New York 1989

Schaefer RM, Tylki-Szymanska A, Hilz MJ (2009): Enzyme replacement therapy for Fabry disease: a systematic review of available evidence. Drugs $\underline{69}$, 21792205.

Schiffmann R (2010): Therapeutic approaches for neuronopathic lysosomal storage disorders. J Inherit Metab Dis.

Schmid HH, Berdyshev EV (2002): Cannabinoid receptor-inactive Nacylethanolamines and other fatty acid amides: metabolism and function. Prostaglandins Leukot Essent Fatty Acids $\underline{66}$, 363-376.

Schnutgen F, De-Zolt S, Van Sloun P, Hollatz M, Floss T, Hansen J, Altschmied J, Seisenberger C, Ghyselinck NB, Ruiz P, et al. (2005): Genomewide production of multipurpose alleles for the functional analysis of the mouse genome. Proc Natl Acad Sci U S A 102, 7221-7226.

Schröder B, Hasilik A (2006): A protocol for combined delipidation and subfractionation of membrane proteins using organic solvents. Anal Biochem 357, 144-146.

Schulz JG: Identifikation des Glykosylphosphatidylinositol-verankerten Heparan Sulfat Proteoglykans Glypikan als Toxizitäts-vermittelndem Rezeptor für betaAmyloid der Alzheimer'schen Krankheit in der neuronalen PC12 Zellinie. Med. Diss. Berlin 1998

Shapiro EG, Lockman LA, Balthazor M, Krivit W (1995): Neuropsychological outcomes of several storage diseases with and without bone marrow transplantation. J Inherit Metab Dis $\underline{18}$, 413-429. 
Signorell A, Rauch M, Jelk J, Ferguson MA, Bütikofer $P$ (2008): Phosphatidylethanolamine in Trypanosoma brucei is organized in two separate pools and is synthesized exclusively by the Kennedy pathway. J Biol Chem 283, 23636-23644.

Skaper SD, Facci L, Romanello S, Leon A (1996): Mast cell activation causes delayed neurodegeneration in mixed hippocampal cultures via the nitric oxide pathway. J Neurochem $\underline{66}$, 1157-1166.

Skarnes WC, von Melchner H, Wurst W, Hicks G, Nord AS, Cox T, Young SG, Ruiz $P$, Soriano $P$, Tessier-Lavigne $M$, et al. (2004): A public gene trap resource for mouse functional genomics. Nat Genet $\underline{36}, 543-544$.

Sleat DE, Lackland H, Wang Y, Sohar I, Xiao G, Li H, Lobel P (2005): The human brain mannose 6-phosphate glycoproteome: a complex mixture composed of multiple isoforms of many soluble lysosomal proteins. Proteomics $\underline{5}, 1520-$ 1532.

Sleat DE, Zheng H, Qian M, Lobel P (2006): Identification of sites of mannose 6phosphorylation on lysosomal proteins. Mol Cell Proteomics $\underline{5}, 686-701$.

Stein M, Zijderhand-Bleekemolen JE, Geuze H, Hasilik A, von Figura K (1987): Mr 46,000 mannose 6-phosphate specific receptor: its role in targeting of lysosomal enzymes. EMBO J $\underline{6}, 2677-2681$.

Strahl BD, Allis CD (2000): The language of covalent histone modifications. Nature 403, 41-45.

Stromhaug PE, Seglen PO (1993): Evidence for acidity of prelysosomal autophagic/endocytic vacuoles (amphisomes). Biochem J 291 (Pt 1), 115121.

Suchanek M, Radzikowska A, Thiele C (2005): Photo-leucine and photo-methionine allow identification of protein-protein interactions in living cells. Nat Methods $\underline{2}$, 261-267.

Towler DA, Gordon JI, Adams SP, Glaser L (1988): The biology and enzymology of eukaryotic protein acylation. Annu Rev Biochem 57, 69-99.

Tsuboi K, Sun Y-X, Okamoto Y, Araki N, Tonai T, Ueda N (2005): Molecular characterization of $\mathrm{N}$-acylethanolamine-hydrolyzing acid amidase, a novel member of the choloylglycine hydrolase family with structural and functional similarity to acid ceramidase. The Journal of biological chemistry $\underline{280}, 11082-$ 11092.

Tsuboi K, Takezaki N, Ueda N (2007): The N-acylethanolamine-hydrolyzing acid amidase (NAAA). Chem Biodivers 4, 1914-1925.

Ueda N, Yamamoto K, Yamamoto S, Tokunaga T, Shirakawa E, Shinkai H, Ogawa M, Sato T, Kudo I, Inoue K, et al. (1995): Lipoxygenase-catalyzed oxygenation of arachidonylethanolamide, a cannabinoid receptor agonist. Biochim Biophys Acta $\underline{1254}$, 127-134.

van der Spoel A, Bonten E, d'Azzo A (1998): Transport of human lysosomal neuraminidase to mature lysosomes requires protective protein/cathepsin $A$. EMBO J 17, 1588-1597.

Vellodi A (2005): Lysosomal storage disorders. $\mathrm{Br} \mathrm{J}$ Haematol $\underline{128}$, 413-431. 
Vesa J, Hellsten E, Verkruyse LA, Camp LA, Rapola J, Santavuori P, Hofmann SL, Peltonen L (1995): Mutations in the palmitoyl protein thioesterase gene causing infantile neuronal ceroid lipofuscinosis. Nature $\underline{376}, 584-587$.

von Figura K, Hasilik A (1986): Lysosomal enzymes and their receptors. Annu Rev Biochem 55, 167-193.

Waite M (1985): Approaches to the study of mammalian cellular phospholipases. J Lipid Res 26, 1379-1388.

Wall DA, Grange DK, Goulding P, Daines M, Luisiri A, Kotagal S (1998): Bone marrow transplantation for the treatment of alpha-mannosidosis. J Pediatr $\underline{133}, 282-285$.

Watakabe A, Sakamoto H, Shimura $Y$ (1991): Repositioning of an alternative exon sequence of mouse IgM pre-mRNA activates splicing of the preceding intron. Gene Expr 1, 175-184.

Wattiaux R, Wibo M, Baudhuin P (1963): [Effect of the injection of Triton WR 1339 on the hepatic lysosomes of the rat.]. Arch Int Physiol Biochim $\underline{71}, 140-142$.

Weinreb NJ (2008): Imiglucerase and its use for the treatment of Gaucher's disease. Expert Opin Pharmacother $\underline{9}, 1987-2000$.

Woloszynek JC, Roberts M, Coleman T, Vogler C, Sly W, Semenkovich CF, Sands MS (2004): Numerous transcriptional alterations in liver persist after short-term enzyme-replacement therapy in a murine model of mucopolysaccharidosis type VII. Biochem J $\underline{379}$, 461-469.

Xu S, Zhao L, Larsson A, Venge P (2009): The identification of a phospholipase B precursor in human neutrophils. FEBS J 276, 175-186.

You HX, Qi X, Grabowski GA, Yu L (2003): Phospholipid membrane interactions of saposin C: in situ atomic force microscopic study. Biophys J $\underline{84}, 2043-2057$.

Zhang T, Xu Q, Chen FR, Han QD, Zhang YY (2004): Yeast two-hybrid screening for proteins that interact with alpha1-adrenergic receptors. Acta Pharmacol Sin $\underline{25}, 1471-1478$.

Zhang Y, Reinberg D (2001): Transcription regulation by histone methylation: interplay between different covalent modifications of the core histone tails. Genes Dev 15, 2343-2360.

Zhang Z, Lee YC, Kim SJ, Choi MS, Tsai PC, Xu Y, Xiao YJ, Zhang P, Heffer A, Mukherjee AB (2006): Palmitoyl-protein thioesterase-1 deficiency mediates the activation of the unfolded protein response and neuronal apoptosis in INCL. Hum Mol Genet 15, 337-346.

Zhu M, Lovell KL, Patterson JS, Saunders TL, Hughes ED, Friderici KH (2006): Betamannosidosis mice: a model for the human lysosomal storage disease. Hum Mol Genet 15, 493-500.

Zhu Y, Conner GE (1994): Intermolecular association of lysosomal protein precursors during biosynthesis. J Biol Chem 269, 3846-3851. 


\section{$8 \quad$ Anhang}

\subsection{Klonierungen im Y2H-System}

\subsubsection{Vektorkarten}

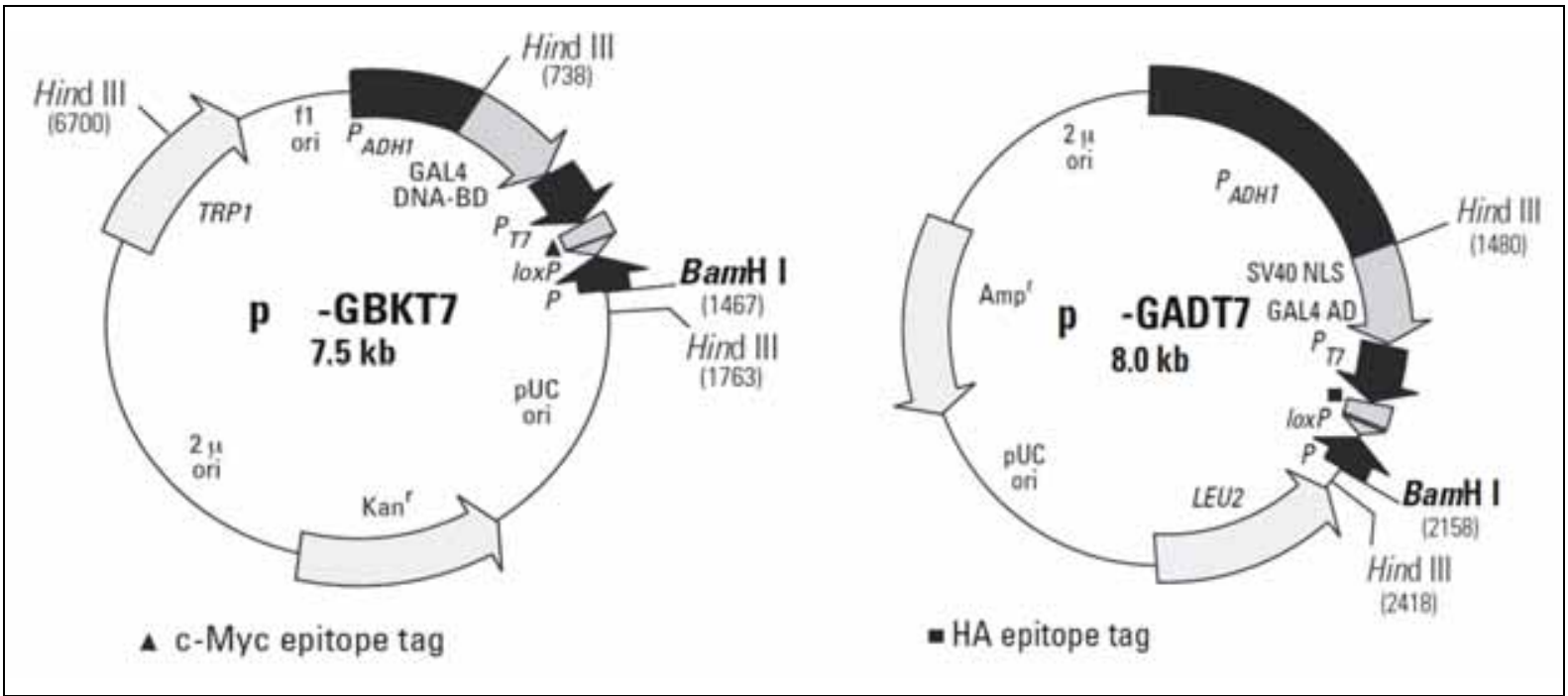

Abb. 8.1: Vektorkarten der verwendeten Vektoren im Matchmarker Two-Hybrid-System

Die Abb. 8.1 zeigt die beiden Vektoren pGBKT7 (prey-Vektor) und pGADT7 (bait-Vektor) die im Matchmarker Two-Hybrid-System verwendet wurden.

\subsubsection{Primer}

Tab. 8.1: Primerliste für Y2H-Klonierungen

\begin{tabular}{l|l}
\hline Primer Name & Sequenz \\
\hline A: 66-EcoR1-Met1-F & GAATTC ATGATGGCGGCCCCCGTGGATGG \\
B: 66-EcoR1-Leu47-F & GAATTC CTCCCTACCCTGGGGCCCGGC \\
C: 66-EcoR1-Cys249-F & GAATTC TGCTCTGCCCTCATCAAGCTGC \\
D: 66-EcoR1-Ser514-F & GAATTC TCTGACCTCAACCCCGCCAATG \\
E: 66-BamH1-Asp594-R & GGATCC TCAGTCCCATGGCACCCTGATG \\
F: 66-BamH1-Arg513-R & GGATCC TCA GCGGGCAGAGATGGCATTCTC \\
G: 66-BamH1-Ser248-R & GGATCC TCA TGAACCGGAGCCCAGGGAAG \\
H: mCatD-Nde1-Met1-F & CATATG ATGAAGACTCCCGGCGTCTTG \\
J: mCatD-SAL1-STOP-R & GTCGAC TTAGAGTACGACAGCATTGGC \\
\hline
\end{tabular}




\subsection{Klonierungen der mNAA}

\subsubsection{Informationen zum pcDNA3.1 Hygro (+)-Vektor}

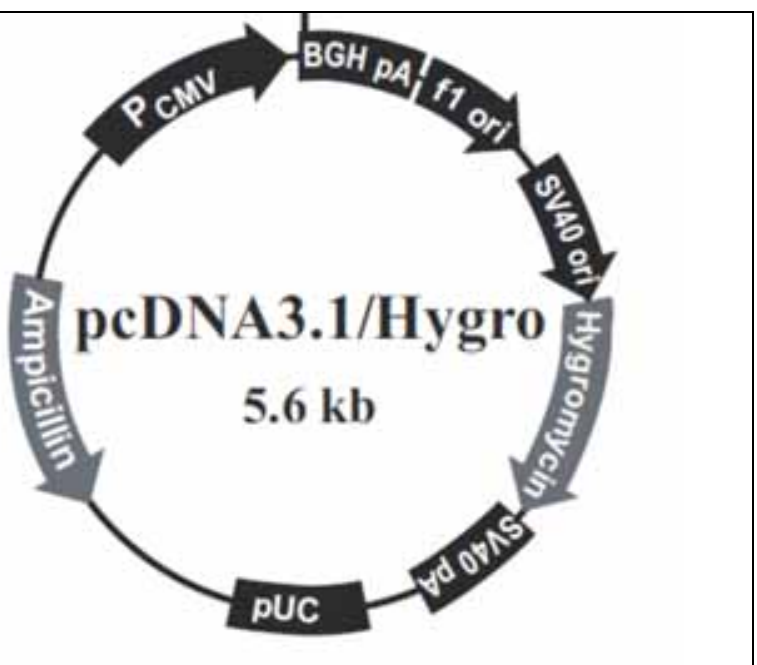

Abb. 8.2: Vektorkarte des pcDNA3.1 Hygro (+)

enhancer region ( $3^{\prime}$ end)

689 CATTGACGTC AATGGGAGTT TGTTTTGGCA CCAAAATCAA CGGGACTTTC CAAAATGTCG

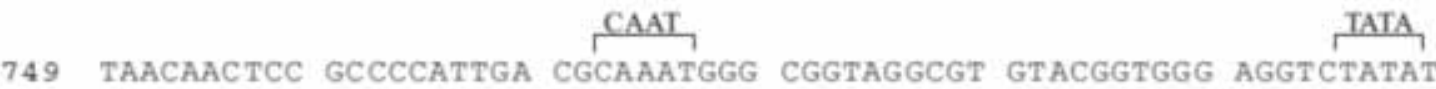

809 AAGCAGAGCT CPCTGGCTAA CTAGAGAACC CACTGCTTAC TGGCTTATCG AAATTAATAC

17 promoteriprimer binding site Pme I Afll Hind III Asp718I Kpn I

869 GACTCACTAT AGGGAGACCC AAGCTGGCTA GCGTTTAAAC' TTAAGCTTGG TACCGAGCTC
BamH I
$B s t \times 1^{*}$
EcoR V
$B r t I^{*} \operatorname{Not} 1$ Tho I

929 GंGATCCACTA GTCCAGTGTG GTGGAATTCT GCAGATATCC AGCACAGTGG CGGCCGCTCG

$\begin{array}{ccc}\text { Ahal } & \text { Apal Pmel } & \text { BGH reverse priming site } \\ 989 \text { AGTCTAGAGG GCCCGTTTAA ACCCGCTGAT CAGCCTCGAC TGTGCCTTCT AGTTGCCAGC }\end{array}$

1049 CATCTGTTGT TTGCCCCTCC CCCGTGCCTT CCTTGACCCT GGAAGGTGCC ACTCCCACTG

BGH poly (A) site

1109 TCCTTTCCTA ATAAAATGAG GAAATTGCAT

Abb. 8.3: Multicloningsite (MCS) des pcDNA3.1 Hygro (+)-Vektors

Die für die Klonierung der mNAAA in den pcDNA3.1 Hygro (+)-Vektor verwendeten Restriktionschnittstellen sind rot umrandet. 


\subsubsection{Primer}

Tab. 8.2: Primerliste für die Klonierung der mNAAA

In den Sequenzen ist die Restriktionsschnittstelle unterstrichen, die Anteile der NAAA sind Fettgedruckt und das His-Tag ist kursiv dargestellt.

\begin{tabular}{ll}
\hline Primer Name & Sequenz \\
\hline mNaaa-F1 & 5'- CAT TGG TCC GGT GGT GGC CTC AG -3' \\
mNaaa-F2-Nhel & 5'- CGC GCT AGC ATG GGG ACC CTA GAC ACC AGG G -3' \\
mNaaa-R1 & 5'- GTC TTA GAC TTC TAA ATG CAG C-3' \\
mNaaa-R2-His6-Notl & 5'- CGC GCG GCC GCT TAT CCG TGA TGG TGA TGG TGA TGC \\
& GAT CCT CTT CCG CTC GGG TTT CTG ATC ATG GTC AG -3' \\
\hline
\end{tabular}

Tab. 8.3: Primerliste für Sequenzierungen der mNAAA im pcDNA3.1 Hygro (+)-Vektor

\begin{tabular}{ll}
\hline Primer Name & Sequenz \\
\hline T7_Fwd & 5'- AAT ACG ACT CAC TAT AGG -3' \\
BGH_Rev & 5'- TAG AAG GCA CAG TCG AGG -3' \\
mNaaa-R3-Seq. & 5'- CTG AGG TTG AGC GAG TCA CAG -3' \\
\hline
\end{tabular}

\subsubsection{SNPs der mNAAA}

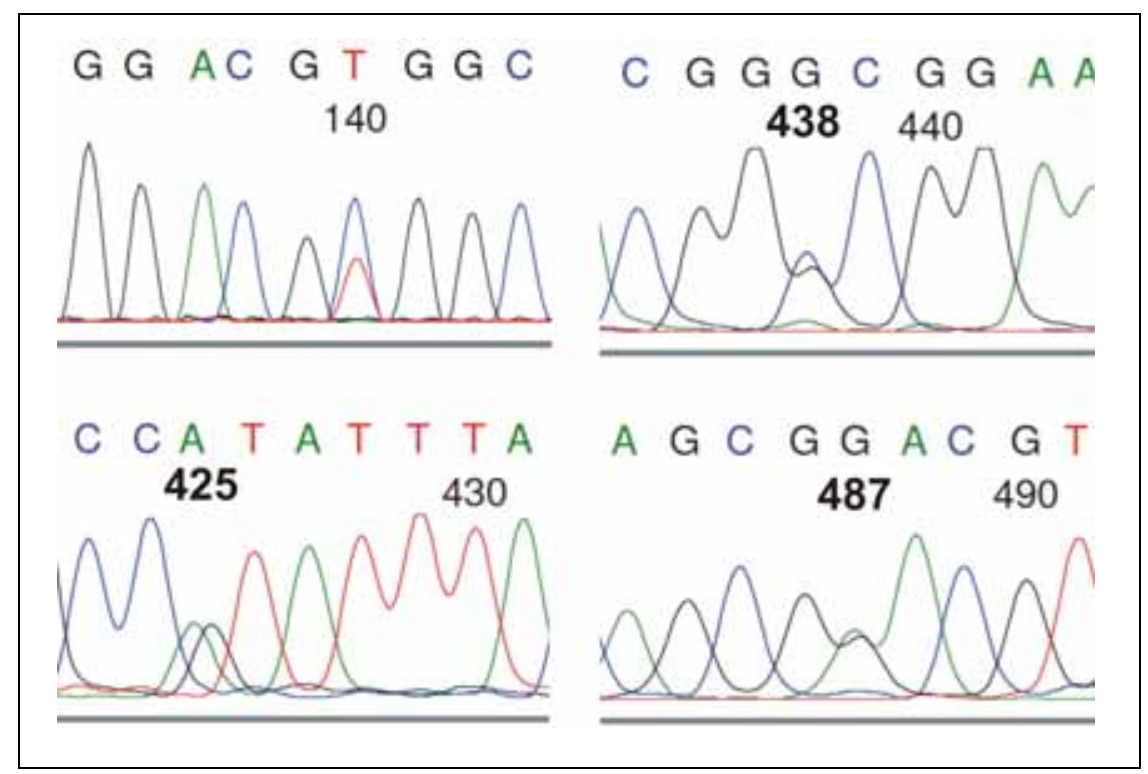

Abb. 8.4: Ausschnitte der Sequenzierung der mNAAA

Die Abb. Abb. 8.4 zeigt Ausschnitte aus der Sequenzierung der mNAAA. Die vier gefundenen SNPs lagen bei dem hier sequenzierten Tier heterozygot vor (C140T, G425A, G435C, G487A). 


\subsection{Real-Time-PCR und RT-PCR}

\subsubsection{Primer-Sequenzen der Real-Time-PCR}

Tab. 8.4: Primerliste der verwendeteten Primer für die Real-Time-PCR

Alle Primer sind von 5' nach 3' angegeben, F: Forward, R: Reverse.

\begin{tabular}{ll}
\hline Primer Name & Sequenz \\
\hline GAPDH & F: GAG TCA ACG GAT TTG GTC GT \\
& R: GAC AAG CTT CCC GTT CTC AG \\
66 kDa - 3' [ex7-8] & F: GCT GTG TGC TGG AGT GGA TA \\
& R: TGG GGA GGA ATG CCT TGT A \\
66 kDa - 3' [ex8-10] & F: AAG GCA TTC CTC CCC AAC \\
& R: GCT AGC CCA GTA GGT CGT TTT \\
66 kDa - 5' & F: TGG GCC AAC CTC ACC AAC \\
& R: ACC ACA CCA GCT GCA TAG G \\
Aldh2 [Ex6-7] & F: AAC GTG GTG GTG ATG AAG GT \\
& R: GAA TCC GGG AAC GAT ATT GA \\
Daglb [Ex4-5] & F: GGG CAG GAT GAT AAC ACC A \\
& R: TTG TCT TGT TGC TGG TGG AG \\
Ctsa [Ex7-8] & F: CAC CTT GGC TGT ACT GGT CA \\
& R: CCC AGA AGG CCA TGG TAG TA \\
Scpep1 [Ex10-11] & F: CCC CAT CAA AAA GAA GCT CA \\
& R: CTG CCA GCA ACT TAT CCA CA \\
Vps33a [Ex7-8] & F: CAA GAA CTT CAA CGC TGT GG \\
& R: ACG CAA ACT GCT TGA TCT CC \\
Kdm2b [Ex12-15] & F: CCC TGA GGG AAT CGA GGA C \\
& R: CCG GTT CTT TGC AGT TTT CT \\
\hline
\end{tabular}

8.3.2 Primer für die Überprüfung des 66.3-kDa-Transkripts auf GeneTrapKassetten-Anteile

Tab. 8.5: Primerliste RT-PCR des 66gt-Mausmodells

\begin{tabular}{ll}
\hline Primer Name & Sequenz \\
\hline F4 & 5'- GCT GCT GCC TGG CGG GCA TG -3' \\
R5 & 5'- CAG AGG GTC ATG GAG GAA ATC -3' \\
QPR1: qPCR 3' Ex8-10 Rev & 5'- GCT AGC CCA GTA GGT CGT TTT -3' \\
F3 & 5'- GCA GCT GGT GTG GTG GAG G -3' \\
QPR2: qPCR 3' Ex7-8 Rev & 5'- TGG GGA GGA ATG CCT TGT A -3' \\
\hline
\end{tabular}


Veröffentlichungen aus dieser Arbeit:

Lakomek K, Dickmanns A, Kettwig M, Urlaub H, Ficner R, Lübke T (2009):

Initial insight into the function of the lysosomal $66.3 \mathrm{kDa}$ protein from mouse by means of X-ray crystallography. BMC Struct Biol $\underline{9}, 56$. 


\section{Danksagung}

Zuallererst möchte ich mich bei dem neuen Abteilungsleiter der Biochemie II, Prof. Dr. Peter Rehling, für die Möglichkeit bedanken, meine Dissertation in seiner Abteilung anzufertigen und möchte der gesamten Abteilung Biochemie II für eine hervorragende inspirierende und freundliche Arbeitsatmosphäre während meiner Zeit im Labor danken.

Besonderer Dank gebührt allen ehemaligen Mitarbeitern der Abteilung Biochemie II, die mich in meiner Einarbeitungszeit so tatkräftig unterstützt und mir das Erlernen der Arbeitstechniken im Labor enorm erleichtert haben. Dank an Kathrin, Markus, Florian, Tanja, Jenny, Ellen, Martina, Jutta, Karthik, Olaf und Peter.

Auf gar keinen Fall möchte ich an dieser Stelle vergessen, den Damen der Abteilung zu danken, ohne die ein organisierter Tagesablauf im Labor fast undenkbar gewesen wäre. Vielen Dank Frau Engelmann, Frau Aeplinius, Frau Diederich und allen anderen bisher nicht erwähnten Mitarbeitern der Biochemie II.

Der größte Dank von allen gebührt meinem Doktorvater Prof. Dr. T. Lübke für die Bereitstellung des sehr interessanten Themas und die unglaublich gute Betreuung, sowohl während der experimentellen Phase im Labor, als auch für das herausragende Engagement während der Abfassung dieser Dissertationsarbeit.

Ein ganz spezieller Dank gebührt allen Partnern und Kollegen, die auch über die Abteilungsgrenzen hinaus zum Gelingen dieser Arbeit beigetragen haben:

Kristina Lakomek, Achim Dickmanns, Henning Urlaub und Prof. Ralf Ficner für die Zusammenarbeit bei der Kristallisation; Prof. Peter Bütikofer für die Unterstützung bei der Lipidanalyse; Rene Sandmann für die Unterstützung bei der Synthese der Substrate für den NAE-Assay; Prof. Tsuboi und Prof. Ueda für eine vorbildliche Kooperation im Rahmen der NAE-Analysen, PD Dr. med. Michael Simons für die Nutzung der Räumlichkeiten und Inkubatoren am MPI; Dr. Olaf Jahn für das ZurVerfügung-Stellen der UV-Lampe, der Filterscheiben und der Räumlichkeiten am MPI; Prof. Wolfgang Engel und Dr. Arne Zibat für die Möglichkeit zur Nutzung des Taq-Man-Analysegeräts im Rahmen der Real-Time-PCRs; Nicole Eiselt, Klaus 
Neifert und Bernhard Schmidt für die Hilfe bei den massenspektrometrischen Analysen.

Zu guter Letzt möchte ich meiner Freundin Svenja, sowie Martina und Sarah für die akribische Arbeit beim Korrekturlesen dieser Dissertation danken. 


\section{Lebenslauf}

Am 15. Juli 1983 wurde ich als erstes Kind meiner Eltern Gabriele Kettwig geb. Baumann und Alfons Kettwig in Höxter, Nordrhein-Westfalen geboren. Berufsbedingt zogen wir 1986 von Fürstenberg nach Lauenförde. Kurze Zeit nach dem Umzug wurde mein Bruder Markus geboren. In Lauenförde besuchte ich vier Jahre lang einen Kindergarten, bis ich im September 1990 in der Grundschule Lauenförde eingeschult wurde. Ab August 1994 besuchte ich das Städtische Gymnasium in Beverungen, an welchem ich im Juni 2003 meine Schulausbildung mit der Allgemeinen Hochschulreife abschloss. Während meiner Schulzeit konnte ich in den Jahren 1999, 2001, 2002 und 2003 mit großem Erfolg am Wettbewerb „Jugend Forscht" teilnehmen. Hinzu kam die Teilnahme am Bundes-Umwelt-Wettbewerb 1999, sowie das Elsbeeren-Projekt im Rahmen der Lokalagenda 21. Seit dem Jahre 2000 bin ich als ehrenamtlicher Helfer beim Deutschen Roten Kreuz tätig. 2004 konnte ich hier erfolgreich die staatliche Prüfung zum Rettungshelfer ablegen. Nach dem Abitur leistete ich ab Juli 2003 meinen Zivildienst auf einer neurologischen Station der Asklepios-Weserbergland-Klinik. Nach Ende des Zivildienstes und vor Beginn des Studiums im Oktober 2004 absolvierte ich ein Praktikum auf der Lehrrettungswache in Beverungen. Zum Wintersemester 2004/05 begann ich das Studium der Humanmedizin an der Georg-August Universität zu Göttingen, das ich voraussichtlich im Frühjahr 2011 mit der 2. Ärztlichen Prüfung abschließen werde. Im Frühjahr 2008 begann ich die experimentellen Arbeiten meiner vorliegenden Dissertation mit dem Thema „Funktionelle Analyse des murinen 66.3-kDa-Proteins“ in der Arbeitsgruppe von Herrn Prof. Dr. Torben Lübke. 